ซิ 





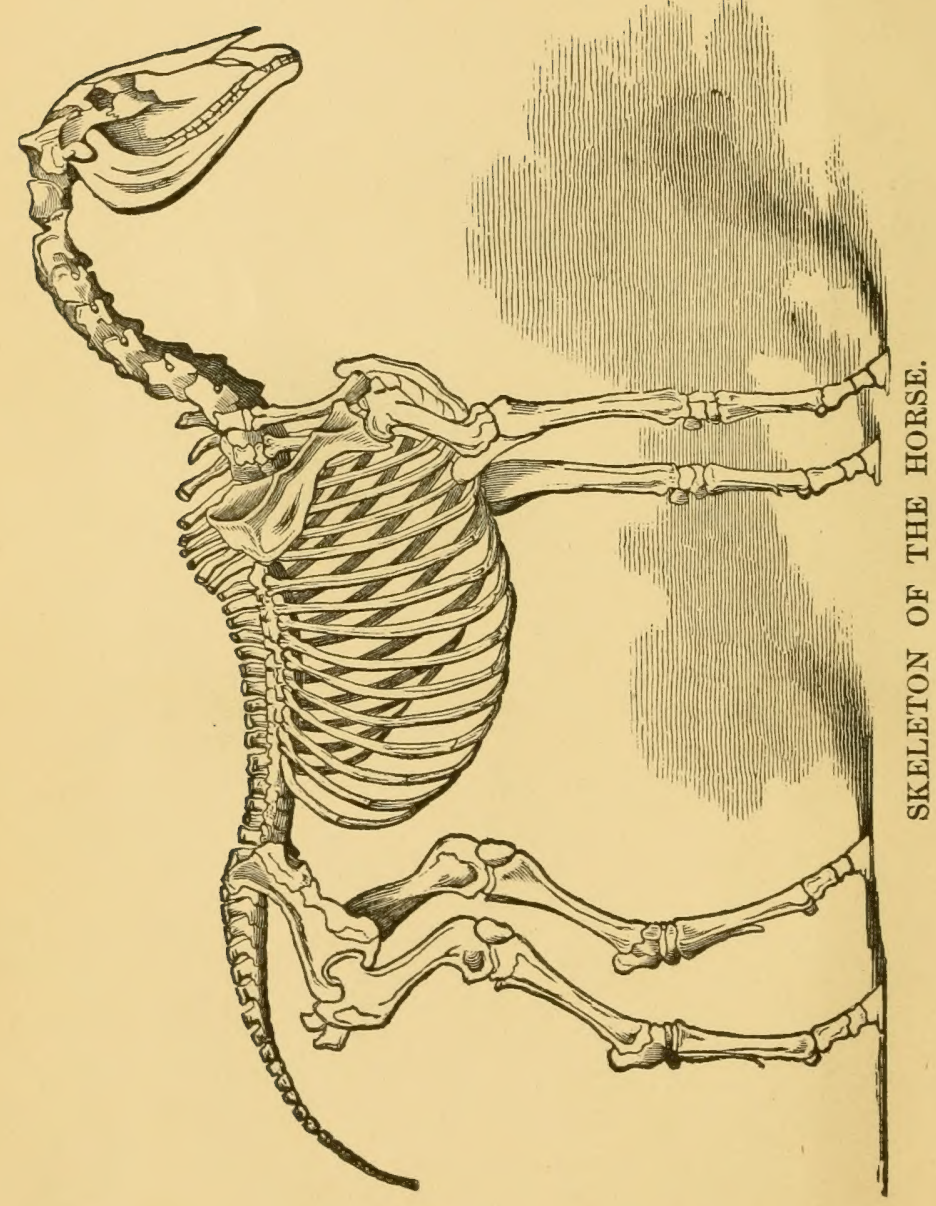





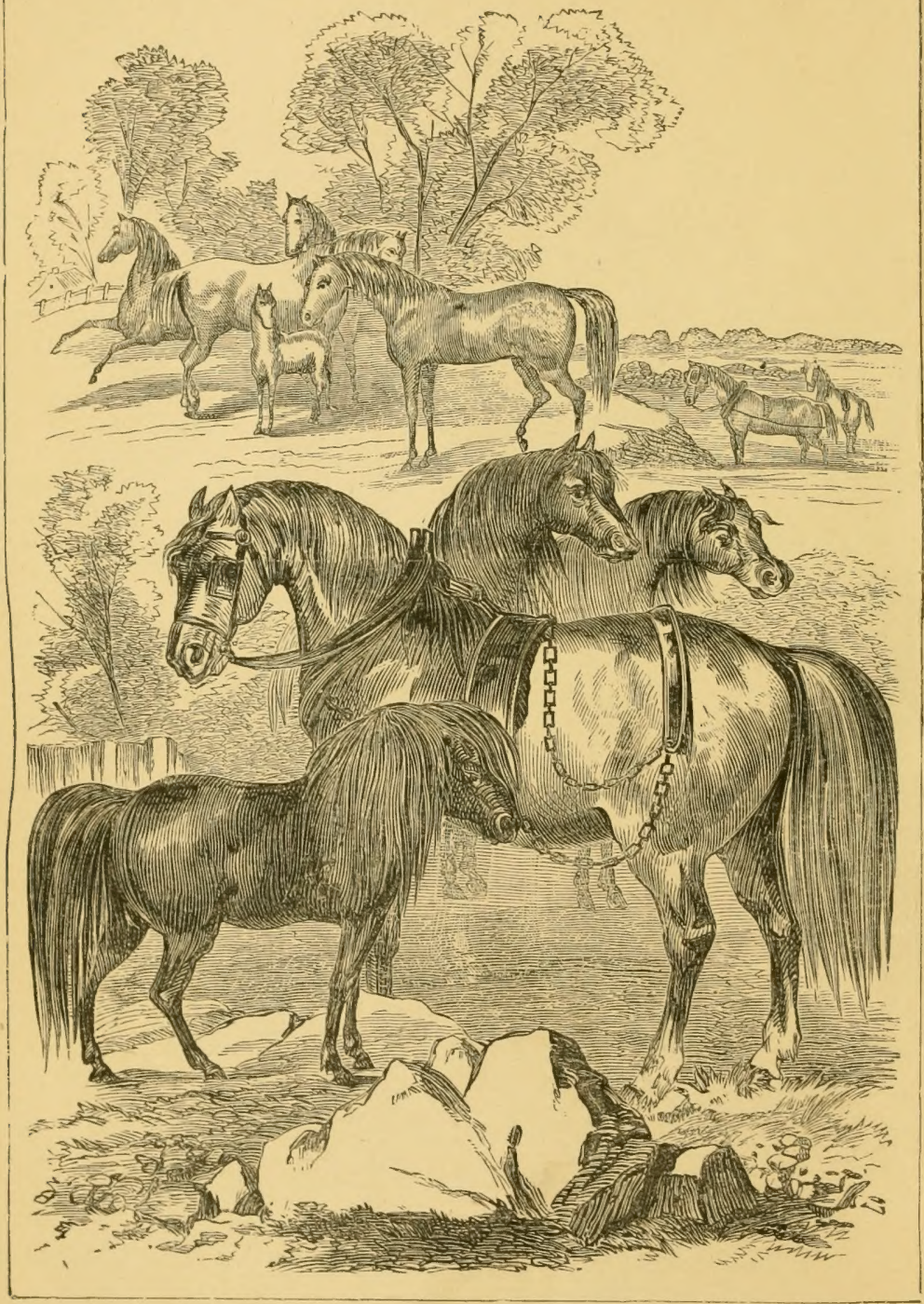




\title{
TH E
}

\section{MODERN HORSE DOCTOR.}

\author{
TREATING ON
}

\section{DISEASE AND LAMENESS IN HORSES.}

\author{
BY \\ GEO. H. DADD, M.D., \\ TETERTNARY BURGEON.
}

\section{NEW EDITION.}

WITH AN INTRODUCTION BY DR. GEORGE THURBER.

ILUUSTRATED.
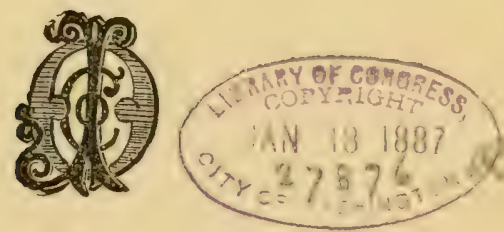

NEW YORK :

O. JUDD CO., DAVID W. JUDD, PrEs'T.

751 B R O A D W A .

$188 \%$. 
Entered, according to Act of Congress, in the year 1886, by the o. JUDD CO.

In the Office of the Librarian of Congress, at Washington. 


\section{PUBLISHERS A N NOU NCEMENT.}

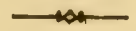

That a new edition of Dadd's Modern Horse Doctor is called for so soon after the last, is striking testimony to its value. Though works upon the Treatment of the Horse of greater pretensions have appeared since his, they have not superseded it. The hold that this volume has upon the people is due, in the first place, to the soundness of the authors teachings, as well as to the common-sense manner in which they are presented. As an author, he assumes no superior airs, and admits the reader at once into his confidence, adapting his teachings to the comprehension of all. The title of the book is an illustration of his popular style. He called it a "Horse Doctor," which every one can understand, whereas had he entitled it a "Veterinary Vade Mecum" the average horse owner might have been repelled at the outset. The continued popularity not only indicates that the manner of the work meets the popular taste, but that its teachings are founded upon a knowledge of his subject.

New York, January, $188 \%$. 



\section{P R E F A T 0 R Y.}

THE author of this work has endeavored to give the reader correct ideas of the nature and treatment of diseases occurring in that faithful servant and noble animal, the horse. It is intended to supply the wants of that class of agriculturists and horsemen - and their name is legion-who are in favor of a more sanative and rational system of medication than that recommended in many works on farriery. Such individuals, in consequence of the scarcity of competent veterinary surgeons, are compelled to treat their own horses; and this work is intended to be to them, in the hour of need, one that will enable them to restore the sick and cure the lame.

The author has aimed to be brief, yet practical, and has selected, eclectically, from the materia medica, those agents which his own experience, during a professional career of nine years in the vicinity of Boston, has proved to be the most efficacious in curing disease and lameness-so far as medicine is capable of accomplishing those objects; for it is a well-known fact that medicine, unaided by nature in the silent operation of the life forces, is, in most cases, positively useless. Some knowledge of the law of physiology, as it applies to brute bodies, is indispensable for the successful treatment of disease; and all who practice the veterinary art should study that law, not only in view of practising understandingly, but for the more important purpose of preventing many thousands of unnecessary cases of disease 
and premature deaths that are annually occurring among all classes of live stock; for many diseases and premature deaths follow encroachments on the sanative laws of life. The more a man knows of physiology, the less faith has he in medicine. He resorts to our great catholicon, Nature. Animals, if left to themselves, invariably do the same thing; they seek rest and some simple agent which their own instinct points out as the Balm of Gilead, and they almost invariably recover, except when about runving their last race. The province of the physician is to know when to withhold medicine; for many diseases are self-limited, and would, if the patient were placed in favorable circumstances, run through their various grades up to a healthy termination without the use of some of the trash styled medicine.

Those who wish to practice according to the principles laid down in this work must learn to exercise patience, and practice a rational expectancy. Nature performs all her operations in a series of slow and gradual changes, and any attempts to hurry her can only be accomplished at the expense of the vital principle.

\section{G. H. DADD.}




\section{CONTENTS.}

\section{PRELIMINARY.}

Or the Qualifi:ations necessary for the Practice of Veterinary Medicine,................................. 15

Great Benefits derived from studying Comparative Anatomy

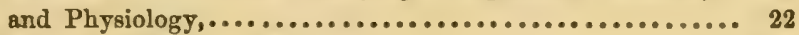

Brief Histary of Veterinary Science, $. \ldots \ldots \ldots \ldots \ldots \ldots \ldots \ldots \ldots . .28$

\section{DISEASES OF THE BRAIN AND ITS MEMBRANES.}

Stomach Staggers, ................................ 35

Sleepy Staggers, ................................... 40

Inflammation of the Brain,......................... 42

Apoplexy,............................................ 43

Vertigo, .............................................. 46

Concussion of the Brain,............................. 49

Lethargy, ..................................... 51

Inflammation of the Arachnoid Membrane of the Brain,........ 51

Remarks on and Explanation of Vapor Bath,.............. 52

\section{DISEASES OF THE RESPIRATORY ORGANS AND AIR PASSAGES}

Pink Eye and Horse Ail, .............................. \&4

Bpasm of the Larynx,................................ 58

Laryngitis, ................................... 61

Iflammation of the Lungs, .......................... 63

psy of the Chest, .............................. 72

euro-pneumonia, ................................ 75

Pleurisy, ........................................ 76

Consumption,................................... 81

Strangles, $\ldots \ldots \ldots \ldots \ldots \ldots \ldots \ldots \ldots \ldots \ldots \ldots \ldots \ldots \ldots . \ldots \ldots$ 
Bronchitis,.................................... 94

Catarrh, ...................................... 97

Nasal Gleet, .................................... 106

Roaring, ........................................... 101

Common Cough, .................................. 103

Tracheotomy, ....................................... 105

Bleeding from the Nose,........................... 10...

Heaves or Broken Wind,........................... 106

\section{DISEASES OF THE URINARY ORGANS.}

Inflammation of the Kidneys, ...................... 108

Bloody Urine, ...................................... 113

Albuminous Urine,.................................... 114

Profuse Staling, .................................... 118

Inflammation of the Bladder,....................... 119

Suppression of Urine,.............................. 122

\section{DISEASES OF THE DIGESTIVE CAVITY AND ITS SURFACES.}

Bots,......................................... 125

Description of the Horse's Stomach,..................... 130

Inflammation of the Bowels,........................ 133

Inflammation of the Stomach and Bowels, ................ 139

Twisting of the 1ntestines,........................... 147

Colic,........................................... 150

Inflammation of the Peritoneum, .................... 154

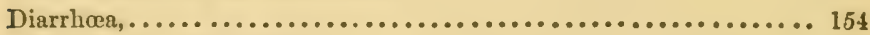

Falling of the Fundament, ........................... 156

Scours and Constipation in young Colts, .................... 161

Indigestion, ........................................ 166

\section{DISEASES OF THE LIVER.}

Jaundice, ......................................... 168

Inflammation of the Liver, ......................... 172

\section{DISEASES OF THE EYE AND ITS MEMBRANES.}

Inflammation of the Eye,......................... 174

Cataract,........................................178

Amaurosis or Gutta Serena, ........................... 179

Specife or Periodic Ophthalmis....................... 181 


\section{DISEASES OF THE NERVOUS SYSTEM.}

Palsy,.............................................. 184

Locked -jaw, ........ ................................. 187

Springhalt, ....................................... 200

Hysteria, .......................................... 203

Hysteritis, ......................................... 207

\section{FEVER IN HORSES.}

Remarks on Fever, .................................... 207

Simple Scarlet Fever, ................................ 213

Malignant Scarlet Fever,............................. 216

Typhus Fever,...................................... 219

Putrid Fever, ....................................... 220

\section{DISEASES OF THE MOUTH.}

Blavering, .......................................... 224

Inflammation of the Tongue, ......................... 227

Wounds of the Tongue, ............................... 228

Lampas, ........................................... 228

Aphthæ, or Thrush, .................................. 231

Dentition, .......................................... 231

Sharp and Projecting Teeth,........................... 231

Bishoping, ...................................... 232

\section{LAMENESS FROM STRAIN AND OTHER CAUSES.}

Observations on Lameness, ............................ 232

Hip Joint Lameness, ................................ 236

Lameness of the Stifle Joint,.......................... 237

" "Hock,............................ 238

" "Shoulder,.............................. 239

"4 Elbow Joint, ........................... 240

Curb, ............................................243

Navicularthritis,................................... 244

Operation for Neurotomy,............................ 247

Pleurodynia,...................................... 254

Acute Rheumatism, or Founder, ...................... 256

Chronic Rheumatism,................................. 261

Bpasm of the Muscles, ................................ Z62

Splent, ............................................ 263

Bparin, ...... .................................. 26* 
Bng and Blood Spavins,............................ 278

Windgalls, ......................................27t

Ringbone, ........................................ 276

Remarks on Strain, ............................... 262

Strain of the Fetlock, .............................. 283

" " Knee, .................................... 283

" " Coffin Joint, ............................ 283

" "Back,.................................... 283

" "Shoulder,............................. 284

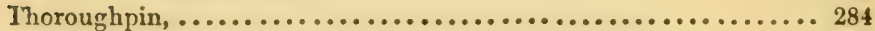

Open Joint,..................................... 286

Lemarks on Dislocation, ............................... 289

Dislocation of the Neck, ........................... 289

" "Shoulder,........................... 290

" " $\quad$ "Hip,.............................. 290

4 "Stifle,............................ 291

" " Fetlock, ..........................291

\section{DISEASES OF TIE SKIN AND SUB-CELLULAR TISSUES.}

Grense or Scratches, .............................. 292

Hardening of the Skin, ............................. 298

Mhalanders and Sulanders,............................ 299

Poultry Lousiness,.................................. 300

Rats Tail,..................................... 305

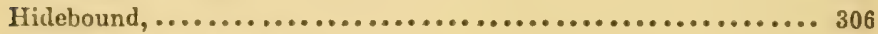

Falling off of the Hair, ....................................... 308

Ringworm, ..................................... 309

Swelling of the Legs, .............................. 311

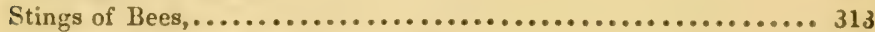

Cutaneous Eruption and Itching,...................... 316

Mange, ........................................ 316

Cracked Heels,................................ 317

Acute Irritation of the Skin,......................... 318

Sweating, ........................................ 321

IVarts, ........................................ 324

Considerations and Experiments relating to Contagious $\Gamma$ ise asee, 325

Melanosis,...................................... 329

\section{DISEASES OF THE HOOF AND LAMINAE.}

Observations on the Horse's Hoof,...................... 331

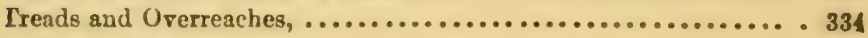

Quarter Crack,................................. 338

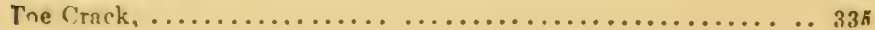


Quittor

Pumice F jot,

Foot Rot......................................... 345

Corns,............................................ 34 ?

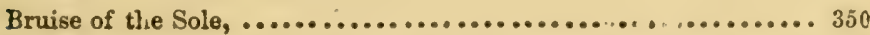

Thrush, .......................................... 350

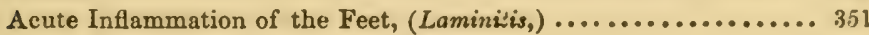

Contrastion of the Hoof, (Hoof bound, $) \ldots . . . \ldots \ldots \ldots . . . . . . . .354$

Canker of the Foot,.................................. 36 s.

Cutting, (Interfering, $\ldots \ldots \ldots \ldots \ldots \ldots \ldots \ldots \ldots \ldots \ldots \ldots \ldots . . \ldots \ldots$

\section{GENERALITIES}

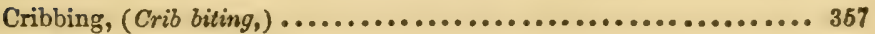

Poll Evil,........................................ 361

Fistula of the Withers,............................... 363

Docking, ........................................... 36.

Wounds, ......................................... 365

Incised Wounds, ................................ 365

Contused " $\quad$. ................................... 366

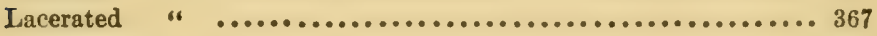

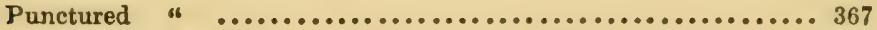

Penetrating " ..................................... 368

Penetrating Wound of Intestine,....................... 368

. " of the Chest, ........................ 370

Worms,......................................... 37n

Nicking,........................................ 378

Metcorization, .................................... 374

Protrusion of the Penis,............................ 376

Urethral Gleet, .................................... 377

Glanders,........................................ 378

Farey,....................................... 387

Wet Packing, .................................... 394

Disinfection of Stables,.............................. 396

On the Use of the Cautery, ........................... 398

Operation of Lithotomy, ............................. 399

Scalded Shorts,.................................. 399

Method of administering Medicines to Horses,............... 400

Soundness, as opposed to Lameness,.................... 401

Lymphatitis, ..................................... 412

On the Gadfly,.................................... 414

Medicinal Preparations used in Veterinary Practice, ...........4 418

Posological Table, ................................. 428

Abstract of Setenth Census,........................... \$31

Table of Bones,.................................. 432 


\section{L LUSTRATIONS.}

ras

Breziton,......................................

Stomach axd Bowbls,............................. 34

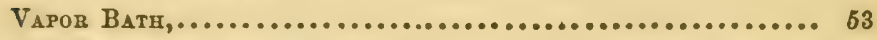

Male Organs of Greneration, ........................ 109

Female Organs of Gengration, ...................... 120

Sтомасн, .................................... 126

Bотs,..................................... 126

Fortos, ....................................... 204

Method of Slinalwa a Honge,.......................... 233

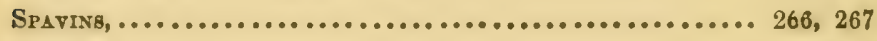

RLNabore, ................................... 267

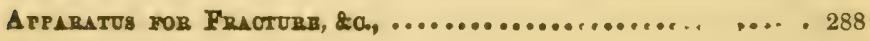




\section{THE MODERN HORSE DOCTOR.}

\section{ON THE QUALIFICATIONS NECESSARY FOR THE PRACTICE OF VETERINARY MEDICINE.}

THE subject to which the author is about directing the reader's attention is one of great importance to Americans, both as regards their individual and national interests; for while it contributes to the honor and greatness of the one, it advances the interests of the other; and no man, class of men, nor a nation, can feel satisfied that they have done their duty to their flocks and herds, the cattle on a thousand hills, the noble war-horse, - the right arm of a nation's power on hard-contested battle fields, - unless there are means provided for their restoration when sick, a remedy against deterioration, and a preventive against empiricism and barbarity. The means, remedy, and preventive are comprehended in the veterinary science.

This science is to the brute just what human medicine is to his master; and if we estimate the value of the former in exact ratio to that of those noble animals which we are so often permitted to behold, it must be apparent, to every thinking mind, that a ccience which contemplates so much that is really useful and beneficial to the lower orders of creation may be worthy the support of the American people.

In allusion to the veterinary science, the author has no reference to the haphazard method which is now practised by mans, who, without any medical training, or even attending medical lectures on the sister art, when there are such favorable opportunities, vainly attempt to prescribe for the sick and dying, sup. posing that they have inherited medical skill from their ancestors. This is not legitimate science. Our art is not aequired in 
this way; it is the property of the industrious and devoted stu. dent, and from all others it is withheld. Facts in medicine are, like the hidden treasures of the earth, only to be discovered by patience and industry.

In order to obtain the necessary knowledge for successful prao tice, some often hare devoted a lifetime to it, yet, after all, acknowledged themselves but feeble children, in regard to the magnitude of their professional responsibilities.

It follows, then, that there is no hereditary road to medical truth; that the necessary knowledge which our art requires as an element for its correct practice, can only be attained by unremitting and methodical observation, by years of careful study and practice.

But we refer to a rational system of medication hunded upon the physiological laws of life; a correct system of therapeutics, pathology, and chemistry, without a knowledge of which no man can ever practise this science with any degree of credit or success

Reader, let us reason together. Every qualified human practitioner enters upon the duties of his profession with an understanding of anatomy, physiology, pathology, and chemistry, and has other scientific qualifications, all of which, combined, enable their possessor, under the direction of a trained intellect, to understand the laws of nature; to comprehend her ways and means of sustaining the vital forces, promoting their larmony, and preventing discord.

Such an individual possesses a knowledge of what is already known, or believed to be so, of the theory and practice of medicine in all its details; his own daily experience confirms the facts or points out errors. He treasures up the one and rejects the other, and in the investigation of a medical case, the human surgeon finds a useful guide to correct diagnosis in conference with his patient. The responses of the latter throw considerable light on the nature, locality, and intensity of the malady. These advantages hare no parallel in veterinary medicine; we cannot question our patients, and can only judge of the state of their health by physical examination - by the signs revealed. Hence the greater need of preliminary education and tact on the part of whose who undertake to prescribe for brutes. 
It may be urged, that much of the information requirer? for the practice of our art is acquired by the senses. Then we answer that they require cultivation; the mind must be educated, so as to be abls to digest the phenomena which constantly occur, in every variety of feature and form, throughout the whole range of medical diversitr.

Surely, if the qualifications here so briefly alluded to, and others not entmerated, are requisite for the successful practice of buman surgery, how can they be dispensed with in tle veterinary department? Surely, they cannot; for they are an essential element not to be dispensed with.

The intelligent and thinking husbandman, who, as a matter of necessity, has been compelled to prescribe for the ailments of his flocks and herds, without the privileges of medical tuition, has probably often felt that every new gleam of light which flits across his path, only serves to bewilder, and make him better acquainted with his own want of knowledge and the comparative darkness that now exists, where all should be bright and radiant.

Such, as well as those engaged exclusively in the management of horses, prescribe to the best of their ability; but death has the advantage of them, for they know not his mode of warfare, nor the means necessary for a suceessful combat. There are a few veterinary surgeons, located in this country, endeavoring to light up the dark spots referred to, and serve the cause of humanity; get, however diligent, when we compare their labors with the magnitude of the cause, they bear the same relation to it that a grain of mustard seed does to a mountain.

In every city, town, and village, throughout this great republic, there is need of veterinary practitioners. We must have them; there are great interests at stake. Some of the interested hare beard, read of, or their animals have experienced the benefits of, a correct system of practice, and now they desire to see such sys. tem extend, so that all may receive benefit therefrom.

The masses, howiver, have not had an opportunity of judging of the merits of this science, in consequence of a llearth of the right kind of information, and the scarcity of its disviples. Books of authority are as scarce as the latter: of American parentage, they are few as far between; and this is mortifying to our 
national pride, especially when we contemplate the universal $\mathbf{m}$ telligence that pervates all classes of community. There are intellectual stars in this country, the brilliancy of whose productions has astonished the world of literature in every department except the one here alluded to, and that is a barren waste - neglected, unexplored. Works of authority are those recognized as such by the faculty, written by men whose impartiality, love of truth, practical industry, and method have gained for themselves that popularity and respect which the author seriously recommends to American rivalry.

It is true we have works on farriery, but they are not of the right kind; they lack merit; they may be rich in theory, but their pages are barren of the practical and useful ; the few golded truths that they contain are so mixed up with the sands of errors that, in order to distinguish and select one from the other, greater amount of vetermary talent and discrimination is needed than usually falls to the lot of those who read.

Without, however, casting any reflections on the authors of such works, who have given to our people the very best proofs of their noble natures and philanthropic motives, we observe that these productions, although the very best they were enabled to write, are not what the age requires, or our interests demand.

If the community wish to peruse a work of authority on lame. ness, glanders, or furcy, they must, at great expense, procure foreign authors; they must consult a Percivall, or some such writer. A horse literature is sadly needed, for we have diseases in this country, peculiar to climate and location, that differ somewhat from those familiar to the nations of the old world.

The extreme diversities in the climate of the United State are a frightful cause of disease - a subject worthy the investigation of all men; especially does the subject demand attention from those who would boast of the sanitary condition of their flocks and herds, for it is only by comparing the diseases of locations most dissimilar in their character and temperature, that the most useful illustrations of morbid influences are to be obtained.

We ask, Where are our statistical tables of diseases peculis n this country? And echo answers Where? 
What do we know practically of the cause and nature of the various forms of influenza, commonly called pink eye, horse wil. \&c.? The same may be said of milk sickness, pleuro-pneumonia, and many other diseases that we might name. We know nothing - absolutely nothing.

Milk sickness is a disease that at times prevails in the Western States, to such an alarming extent, attended with such a frightful mortality, that it has served as a cause to disband a wbole community. A reward of several thousand dollars has been offered by legislative authority, to be given to that individual who shall first discover and make known the cause of the diseaee.

But the reward has never, to the author's knowledge, been claimed. Diseases of the lungs are so rife in the United States, that, if we except old age, two thirds, or perhaps one half, of the losses experienced by owners of stock in the death of horses and cattle, result from diseased lungs.

Pheumonia is a common form of disease among horses, and great skill and discretion are needed in order to bring it to a favorable termination, for it often laughs to scorn the puny efforts of man however well directed. It requires the very best skill for its treatment, because the organ involved is one whose function gives life and action to all the other organs. It performs the very last act of digestion, which is the decarbonization of the blood; and modern physiologists inform us that the lungs play a more important part in the circulation of the blood through the arterial ramifications than the heart itself; which has heretofore been considered the only source of circulation. Be this as it may, no organ, when deranged, requires so much skill in its early stage as this - early, because the delay of a few hours may prove fatal. A mistake in the diagnosis, or a wrong mellicine administered, may place the patient beyond the aid of man.

You may call on the veterinary surgeon in the latter stages of the disease, and, as often happens, after the patient has been pretty well dosed; but it is too late; the animal has passed the Rubicon, and has entered within the boundaries of the valley of death.

It is necessary, therefore, to be able to detect this disease in its primary form, before it has completely invaded the citsule. 
of life. But how many are there in these Inited States tha san diagnose a disease of this character? Not one hereditary doctor in a hundred can do so witl any degree of certainty; yet, to such a state of perfection are auscultation and percussion now arrived, that the qualified can detect a lesion of the lungs with ustonishing precision. Almost every change that takes place within those organs can now be detected by the surgeon with remarkable exactness. And a regularly educated veterinas surgeon would dishonor his profession, and likewise impart a withering influence to his future operations, if he were found wantiug in this particular. So that the qualifications needed, not only for the management of this, but every other disease, should be of the first order; for it is a fact that the losses from acute diseases are far greater than they ought to be, and these losses are felt by the hard-working farmer, and by those who depend on the earnings of horses for a living; and they certainly must hail as a great blessing any attempts to introduce an improved medical literature, and a rational system of practice that shall remedy the great evils which now exist.

The author now proposes to give the reader some idea, by a single illustration, of the absurd and positively injurious tenden: $y$ which many of our present works on horses have. In a work on the horse, lately published in the city of Boston, we read, that a disease of very frequent occurrence, named ringbone, is an enlargement fed by a bladder; and no doubt the author thought so, or he would not have written it; for he was a highminded man, much opposed to violence and unnecessary medication in the management or treatment of horses. Well, this error in reference to the nature of the disease was not of such great account; but it led to the infliction of a useless and painful operation. The extraction of this bladder is there recommended An operation is to be performed in a portion of the structure highly organized, and, of course, susceptible to great pair, to $\mathrm{ex}$ tract the bladiler, which has about as much to do with the real malady as the reader has with the rising and setting of to-molrow's sun. But whom have we to extract this bladder? The author undertakes to answer for the profession. No educated aurgeon can te found willing to disgrace the art, and belie his 
conscience in the practice of so absurd and cruel an operation. No; the nature of the disease, and the changes which the parts ur dergo, from exostosis to anchylosis, (see article Ringbone,) are so clearly demonstrated in works of authority, and so well illustrated on dissection, that no doubt exists in the minds of the faculty regarding the disease.

There are many other kindred errors existing in like works, bu. our limits prevant their exposure; we have chosen to allude to this particular case, because we have within a few days seen an article in one of our must respectable journals, recommending inlso the extraction of " the bludder, by which the ringbone is fed," for its cure, and that every three out of four cases opercted on were cured.

What they mean by cure possibly amounts to the same thing as when speaking of the cure of spavin, that the lameness after a time disappears. (See Spavin.) The freedom from lameness in some cases of ringbone result from the superior and inferior pastern bones becoming united, (anchylosed,) thus the action of the joint is forever destroyed. This, forsooth, is the cure! When anchylosis can be cured, we shall be able to boast of reversing nature's laws.

Some of our rearlers may think that there is no practical benefit derived from allusions to the unscientific customs of past days. But when we come to consider that the veterinary art has, in this country, progressed in a circle ; that our domestic animals are still the subjects of misuruided notions peculiar to the dark ages; that cruelties which have had their day of reproach are now being enacted over again, even under our own eyes; this is our apology for alluding to the past, so that we may improve in the future.

We live in an age when the little we know of the veterinary art is a mere item of what we should know; for such knowledge can be made an instrument in the hands of philanthropic men for the benefit of all classes of creation.

The imporant discoveries made of late in Europe, in the several departments of veterinary medicine, are indicative of the ago in which we live. Americans nust not be behind the age; their interest, pride, and patriotism slıould arouse t $\mathrm{em}$ to a sense of heir indifference, and culsequent dependence on other ustions 
for veterinary knowledge. In conclusion, we observe, that the veterinary science has to be built and reared on facts, recorded facts, the result of practical experience, for the understanding is incapable of acting on innumerable facts from the memory alone hence our need of the written experience of scientific men. Such writiogs furnish the practitioner with the power, aided by his own observation, in discriminating between maladies which are (fter confunded, to the great injury of the seience.

It is useless, therefore, to suppose that the veterinary art can $x$ acquired at the forge, plough, or in the stable, without preliminary education; and then but very tew could spare the time to study the art and produce records of their experience. 'The length of time necessary for it, the intellectual labor, and the weariness of such pursuit, are obstacles not easily surmounted. Every one to his trade, then. In order to understand how the veterinary science is to be studied, so that men can comprehend its legitimate object, - the why and wherefore of disease, and the modus operandi of medicine, - we must have the same facilities here that now exist in Europe within her veterinary universities.

There are hundreds and thousands of young men in these United States undecided what to do for a living. We say unto such, Come over and help us, for "the harvest is ripe, but the laborers are few." Now is the time to come to the rescue, and carry out the intentions of the veterinary art, and thus change the current of public opinion in its faror.

\section{GREAT BENEFITS DERIVED FROM STUDYING JOYPARATITB}

\section{ANATOMY AND PHYSIOLOGY.}

- If medical men have been guilty of gross errors, it is because they have neg lected to dissect brutes." - Galen.

Witn a view of showing how much human medicine is in debted to comparative investigations on the bodies of animals, let us briefly consu.t the records of the past. 
History informs us that most of the ancient and modern pracritioners who have distinguished themselves in their profession and gained the confidence of mankind, have always paid more of less attention to the dissection of brutes. Thus, in the langruage of Mr. Vines, "they have transplanted to the medical profession the honor of discoveries that were made in trenching on the terri. cory of the veterinary science." "And," continues the same author, " it is sot to the study, the treatment, and cure of animal disease alone, that this science is strictly confined. Second only to human melicine in artual importance, it possesses considerable advantage over it, and offers opportunities for the cultivation of general pathological and physiolocrical knowledge, and more particularly for that important branch termed comparative anatomy, that are far superior to any thing that medical practitioners can boast of."

In the early period of the history of medicine, it has been recorded that dissections of the human body were held in strict abhorrence; and when we contemplate what we observe in our own enlightened day and generation - how medical teachers have often been compelled to resort to illegal means in order to procure the necessary material for demonstrating to their pupils the science of life, and that the authority of the law, and the more formidable one, public opinion, has been arrayed against the gen. eral practice of dissecting the bodies of men - then we are pre. pared to realize how much odium the ancients must have attached to the practice.

From the quotation above, the reader will perceive that Galen attached great importance to the dissection of brutes, and his followers, up to the present day, have, to some extent, carried out his suggestions.

Reading on through the pages of the history of the past, we .eas it that those small lacteals, termed absorbents, which are so numervusly distributed over the internal surface of the alimentary crnal, by the aid of which the blood is furnished with the neces. sary material for supplyiag the waste, developing and preserving the animal organization, were first discovered in kids. Those wonderful pieces of divine mechanism placed within the heart and known to anatomists as its valves, were first discovered in animals by Erasistratus, who alse discovered the cesophagus 
The fallopian tubes, a portion of the female organs of genera tion, were also discovered in a ewe. Galen demonstrated in Rome, on living animals, the organs of sound and respiration. He also showed on them the effect produced by ligature on the nerves.

Vesalius proved, by experiments on animals, that it was possible to restore suspended animation by artificial inflation of . the lungs. This discovery is one of the most important, and has resuited in as gieal good to the human famly as any like discovery made before or since. See the fond and anxious mother bending over the cold and apparently lifeless form of her darling boy, who has just been recovered from the watery element! Witness her agony as sne contemplates what appears to her as a bereavement; and now, hope - the anchor of her soul - is troused, as she watches, with a mother's anxiety and love, the efforts made by the medical attendant, who is now repeating the experiments of Vesalius. His labors are rewarded. Nature resumes her erupire; and anon signs of returning animation aro perceived, and the mother shouts with frantic joy, "He breathes! He lives!"

Are there not thousands of fond parents and anxious friends that have been benefited in a similar manner?

Those urgans termed the salivary glands, which secrete a portion of the fluids necessary for the digestion of fond, were first discovered in an ox, by Eustachius, who subsequently discovered in a horse the thoracic duct.

Dr. Wren made several experiments on living animals, to be assured of the effect of different substances on the blood and sclid parts. This truly valuable discovery has been one of great im. portance to the whole world, for it was then made known that, through the medium of the lacteals, (absorbents,) lacteal veins, and thoracic duet, inorganic materials reached the blood, and finally became deposited in the cellular and solid structures. This discovery has enabled us to explain in what manner the elements of nutrimental matter reach their ultimate destination. It further enables us to explain the why and wherefore of the alteration ir. the color of the cow's milk when fed on beets or saffron, and also the cause of that offensive taste in pork wlien 
fed on the rotten recrements of cities. In short, lacteal absorp. tion gives us the modus operandi of many medicines on the systems of man and animals.

()hservations on taste and feeling were first made on brutes. and afterwards verified on man. The lachrymal dusts wero first discoverel in the eye of a sheep, and the excretory duct of the pancreas was discovered in a turkey.

I3: rnard and Spallanzani discovered the antiseptic properties of the gastric fluid in the following manuer: they obtained some of that fluid from a stomach, mixed it with an equal quantity of putrid blood, and then allowed them to stand together for eighteen hours; the mixture was then injected into the jugular vein of a dog. The mixture produced no inconvenience; and being aware, before making the experiment, that any putrid matter, on being injected into the blood of a living animal, was sure and certain death, the conclusion they arrived at was, that the gastric fluid was endowed with the power of neutralizing the deleterious action (if the putrid ferment, thus depriving the morbid matter of its poison. ous properties; and this conclusion has been frequently verified. This discovery was also of great value in more ways than one; but it enabled us to explain why animal matters in a state of putrefaction, when introduced into the stomach, do not always prove destructive. The reader, probably, knows that the dog, wolf, and many other carnivorous animals are fond of putrid flesh, and that some men, even, have a craving for game in a partial state of decomposition, and they all seem to digest such filth with very little inconvenience.

Another equally important experiment was made by Magendie on a dog. He injected fifteen grains of blood into the jugruas vein of the animal. The effect was, great disturbance of the functions of the brain and circulation, and the animal died in twelve hours.

Another experiment was performed. The same physician introduced two drachms of putrid water, in which fish hat heen $k \in p t$, just underneath the skin, and the animal died almost im. mediately. Such experiments speak to us in a warning roice, they teach us to be careful how we trifle with putrid matter. We may introduce it into the stomach, provided that organ be in 
a healthy state; but the moment it comes in contact with the vital current by other means, that very moment life is endangered.

It was from experiments on animals, made by Drs. Wren Rnd Boyd, that led to the transfusion of blood; for shortly after those experiments, a Frenchman transfused the blood of a human subject into the veins of another, and it is recorded that several lires have in this way been saved.

In the course of transfusing the blood of one animal into that of another, it was discovered that what are termed the glotules of the blood were uniform in all animals of the same species, and yet resented different forms in animals of different tribes. In man, the particles of blood presented flat disks, resembling pieces of money, having a slight depression. In birds, reptiley, and fishes the disks were oval, instead of being round, and instead of being depressed in the centre, they were elevated on each side. From this experiment it was argued that the fitness of the blood cf one animal to the uses of another of a different species depended on the formation of its globules. Experiments have frequently been made to test the truth of this theory, and it has been found to be correct. An eminent physiologist has remarked that, " in order to arrive at an explanation of what is obscure in man, we must look to the lowest and simplest forms of creation. For though in man is combined, in a wonderful and unequalled manner, all the functions which separately exhibit themselves in various other animals, he is not the most fivorable subject for observing their action; hence we are obliged to refer to a num. ber of other tribes for the assistance we gain in the study of their comparative structures. There is not a single species of animal that does not present us with a set of facts which we should never learn but by observing them in such species, and many of the facts ascertained by the observation of the simplest and most common animals."

Yet in view of all these discoveries, and the consequent increase of knowledge, there is yet much to learn. Instead of being at tho summit of the temple of science, we have orly just surmounted some of the obstacles that surround its base, and ero long, phenomena of the most surprising nature yet remain to bis liarsored, and fresh laurels are to be won by the industrioue 
find devoted physiologist. At the moment of writing this article, intellıgence has reached us, that inoculation for the mitigation of pleuru-pneumonia is being practised in France, Holland, and Prussia, and the respective governments of these countries have appointed commissions of scientific men to inquire into the success and value of the practice. The inoculations are made uader the conviction that pleuro-pneumonia is highly contagious, and spreads itself from this ceuse, as well as from the special carses of the extension of epizoötic diseases. What takes place ir the gystem of cattle after inoculation is identical with that observed in man when invculated with virus. The operation in each case engenders a peculiar state of the system, which, without impart. ing the disease itself to the subject, gives immunity against the several causes that produce it. If the experiments shall ultimately prove successful, we may safely say that no discovery of equal improntance to the husbandman has ever dawned upon the veterinary science. In the United States, however, this fearful disease is not so prevalent as in various other countries. This arises in consequence of our cattle and horses being scattered over a much larger territory, and our cities being comparatively exempt from the causes which are said to produce it; yet enough losses occur here to arouse us to a sense of the danger.

It may be proper, however, to inform the reader, that the reports of the commission to the sereral governments are somewhat contradictory, and the novel enterprise has met with some opposition; but this is the history of many improvements of the past; therefore, we must not be hasty in forming our con. clusions.

The advocates of inoculation declare that it is of equal im. portance to vaceination in the human subject. Who knows but in a short time that dreadful scourge in this country, know as milk sickness, or trembles, may be disarmed of its terrors by the same process? Not only milk sickness, but mainy other con tagions diseases, may, perluaps, be made to assume a mild and innoxious form.

As the subject is a new one to the husbandmen of this country, the author may be pardoned for introducing an illustration of the benefits derived from inoculation. "The wown of Hasselt, in 
"hich are kiph two thousand cows and oxen, is a town full of dis tilleries, amd these animals are fed on slops and grains. From the situation, want of dranage, and accumulation of filth, adde ${ }^{3}$ to the inperfect system of ventilation, management, \&c., the location may be considered as the very centre and focus of a disease like pleuro-pneumonia." since the year 1836 the town has never been free from the malady, and many hundreds of animals, luring the past sixteen years, have fallen victims to it, and the lown is now said to be tree from the pest!

Finally, the fiew distinguished men here named, and others, too numerous to mention, animated with a desire for knowledge, have arailed themselves of the opportunities afforded for realing the book of life as it is written by the hand of Omnipotence in the series of animated creation, and the benefits which all have derived are incalculable.

\section{BRIEF HISTORY OF VETERINARY SCIENCE.}

TuE reterinary science, like that practised on man, was first called into exisrence by necessity ; the many diseases to which domestic animals were subject, and to which thej, too frequently foll victims for want of proper professional knowledge, and tle great loss which agriculturists experienced in conseguence, led $\mathrm{tl} \ni \mathrm{m}$ to seek for a remedy.

In the year 1761 , the first veterinary school was established at Lyons, under the patronage of government, whose fostering care the infunt school for a time received. At the commencement of this embryotic enterprise, the populace looked on with inlitier. ence; but many of the liberal and scientific men of that day saw in the enterprise a boundless field for rescarch, a broul road to usefulness and distinetion, and many eagerly embarked in it with anflinching perseverance, overcoming every obstacle, with a view of making known those laws regulating the vitai forces of domes. ic animals.

The fruits of their labors are bequeathed as a legacy to the 
profession, and the names of the first cultivators of veterinary science are inscribed on the tablets of their country's listory as public benefactors.

Four years after the endowment of this, the first school in France, a similar one was established at Alfort. A regular sv8. tem of veterinary medicine was there taught, under which studento w rquired an acquaintance with the various forms of disease, and the modus operandi of therapeutic agents on domestic animals. The novel enterprise was regarded by other nations of Europe with a watchful eye, and they were not slow in coming to the rescue; schools rapidly sprang up in Holland, Berlin, Copenhagen, Stutgard, and in various other places, which proved equally successful and beneficial as the French schools.

We shall now pass over a period of twenty-seven years, during which time the science had gradually enlisted in its ranks men of influence, talent, and research. And now an individual of French descent, named St. Bel, lands on the shores of Fingland, having letters of introduction from the first men in France to Sir Joseph Banks and other influential individuals, to whom he made known his mission; which was, that of establishing the veterinary science, then unknown, and of course unappreciated, in the British dominions.

He was encouraged, with very flattering assurances of success, to commence operations, and shortly after his arrival in London he published proposals for establishing a veterinary school; there seemed, however, to be a sort of indifference manifested among the masses, and consequently very little, beyond making known his object, was effected during the first year. In the following, be published proposals to read lectures on the science, and thus give the English nation an opportunity to judge of the value of the new project; but, alas! he was doomed to dissppointment; his second proposal met with no better success than at first. The apparent failure of his primary labors has been attributed, by an eminent writer, to various causes, and it may be well for us tc pntice them, for the very same causes have been, and are now, in nctuve operation, diverting American skill and intelligence frow embarking in a cause so worthy the attention and support of a free and enlightened nation It was in consequence of the 
charmeter of those who presumed, without the necessary qualifcations, to practise the art, that the English husbandmen refused to put their shoulders to the wheel, and receive the offered boon That country had been visited by diseases of a pestilential type, which had male sad havoc among the stock, and had swept then. from the green hills and verdant valleys, as by the blast of a tor. nado. 'Their horses, too, did not escape the arm of the destroyer; they were constantly suffering and dying from insidious forms of disease, the history and characters of which were almost uniknown. This state of things, together with the unfortunate accurrence that there were no legitimate practitioners, had opened a wide field for adventurers and quacks, whose barbarous system of medication, probably, was the cause of many deaths. These practitioners in lieu of better, were taken as standards, and the people had, to a great extent, formed an estimate of the value of this art in exact ratio to the talents of the village farrier, and in proportion to the success that attended his labors. This is precistly the state of affairs in America.

St. Bel gives us another reason for his failure, but it amounts to nearly the same thing. He says, "The opulence of England offered a wide field for impostors of foreign origin, by whom the nation was daily imposed on, and repeated experience of such impositions naturally excited distrust towards forcigners in general; and because honesty of views was not written on his face, patience and perseverance became his only resources."

At this stage of affairs St. Bel was fortunate enough to make the acquaintance of a gentleman who had a decided taste for the art, and who eagerly responded to the views of the professor, and bade him not despair of ultimate success; assuring him that by sutting the matter in its right light before the people he would soon obtain all he desired. This assurance inspired st. Pel with new hopes, and he immediately issued a pamphlet of some twentyeight pages, entitled, Plan for establishing an Institution to cultivate and teach the Veterinary Art. This pamphlet was well received, and several agricultural societies paid the writer bandsome compliments, and conferred on him honorary distinction.

During the year 1790, several meetings took place between the uxembers of agricultural societies and gentlemen favorable to the 
ause; till, at length, active measures were adopted for promoting the object. A resolution to this purport was now passed, whicb read as follows: "That the parties had observed the good effects produced on the public mind by the exertions of the friends to the art, for its improvement, and approved of St. Bel's plan for establishing a public institution for that purpose." The result was, that an institution was soon endowed, which was named "The Veterinary College of London," to which St. Bel was appointed professor. But unfortunately, that distinguished indi. ridual had scarcely occupied the chair one year, when a surden and brief illness terminated his mortal career, and he was consigned to the silent tomb ere the laurels had scarcely encircled his brow.

Being thus cut off at such an early period, yet in the midst of his usefulness, the prospects of the infant institution became greatly affected - only for a short season, however. The college was considered to be in a flourishing condition; the Duke of Northumberland had already contributed a sum equal in our currency to twenty-five hundred dollars, and the enterprise numbered among its stanch supporters such men as the Earl of Grosvenor, Mr. Penn, Earl Morton, Drs. John Hunter and Crawford, and subsequently that great surgeon and medical hero, Sir Astley Cooper.

Medical men hailed the new enterprise as one not only calculated to ameliorate the condition of suffering domestic animals, but, what was of still greater importance to them and mankind, they perceived in it a fruitful field for the cultivation of comparative anatomy and physiology. With this object in view, Dr. J Hunter assisted the friends of the new school both by his professional influence and from his private purse.

Although the college had been in existence but a brief period, its pupils had gained sufficient knowledge of theory and practice to distinguish themselves; thus fully realizing the antivipations of its founders. Among the first pupils who sought to qualify themselves as efficient veterinary practitioners, we find recorded the names of Laurence, Blain, and Clark. Each of these philanthropists has since left to the world a record of their labors, whicb. even in this enlightened age, serve as useful guides to the young us cirant for veterinary famo. 
The professorship made vacant by the death of the father of this science, St. Bel, was conferred on Mr. Coleman, who had previously devoted himself to physiological research; he, too soon distinguished himself, and the college again assumed its former flourishing condition. A medical committee was now uppointed, consising. of some of the most eminent practitioners that the country could boast of, by whom the pupils were exam. ined, and when found to have aequired sufficient knowledge of the art, certificates were granted accordingly. We are informed that this medical examining committee were lecturers of human medicine, and with a liberality that reflected great credit on them, permitted the veterinary pupils to attend their lectures on human anatomy free of charge. Thus did a band of really great and good men unite their efforts and interests, for the study of the science of life in all its diversity and forms. By this wise association of the sister sciences, its advocates aimed a death blow at the ignorance, quackery, and superstition of the times, and they were successful to some extent; for a new order of practitioners tuok the field; they soon demolished the old landmarks set up by the ignorant farriers, and erected in their stead beacons of light: thus spread the illuminating rays of science broadcast, and the public, as well as their domestic animals, were benefited thereby.

Professor Coleman had now succeeded in securing the patron. age of government - the strings of the public purse were loos. ened, and the parliament vored a sum of money, to be paia annually, tor the support of the college. It is related also, that the reigning monarch, George the Third, granted the rank of commissioned otficers to such veterinary graduates as wart intended as surgeons to the cavalry regiments.

The Honorable East India Company, observing the good ofints produced by such appointments, was likewise induced to follow the example of their monarch in appointing veterinary surgeons to serve in their armies in India. Other nations have thus followed the eximple set them by France and England, so that regular reterinary surgeons may be found in all the four fuarters of the globe.

In England, at the present day, veterinary students rapidly increase; never were they so numerous; recruits arrive from 
pvery quarter, to enlist in the army of scientific veterinary nedj. cine, and ere long human practitioners must look to the laurels, or they will be snatched from their brows.

The advantages under which the veterinary art can now be studied in England, France, and Germany are not inferior to those of the most favored university; and such astonishing dis. coveries, through the aid of chemistry and the microscope, are in such rapid succession surprising the medical world, and so splen did are the achievements in the departments of veterinary surgery, that the noble sons of Esculapius - our brethren of the human school - are watching the labors of their kindred spirits with no ordinary interest.

Such is the brief history of our art; much interesting matter might be adued, with a view of enlisting the sympathies of American philanthropists; but the author feels assured that the time is soon to arrive when the people of this country will unite with their brethren of the old world in a hearty coöperation for tho amelioration of live stock.

\section{EXPLANATION OF CUT.}

1, 1, 1. The three coats of the stomach; generally described as four.

2. Esophagus or gullet.

3. Region of the cardiac orifice of the stomach.

4. Muscular coat of the stomach.

5. Cellular and mucous coat.

6. External coat, or peritoneal tunic, reflected over.

7. Region of the pyloric orifice.

8. Great conrex border.

9. Concave border.

10. Fundus, or great cul-de-sac.

11. Small cul-de-sac.

12. Representing the nerves of the stomach. They carnot, however, be shown to much idvantage in this vier; ; as the cerebro-spir.al and sympathetio torm rarious plexuses mithin the chest, and interchange fibres ere they reach the diaphragm, where they form two branches, termed inferior and superior; one goes to the fundus, and the other to the pyloric end of the stomach.

13. Duodenum, or second stomiach, as it is sone tirues called.

14. Bilary and pincreatic ducts.

15. Small intestine, knowr as duodenum jejunum, and ileum.

16. Terminating portion $u^{t}$ : he ileum, at the junstion of the cxcum and oolon

17. Cæcum, or blind gut.

18. Colon.

19. Rectum.

20. Anus.

21. Sphincter muscle of the anus. 


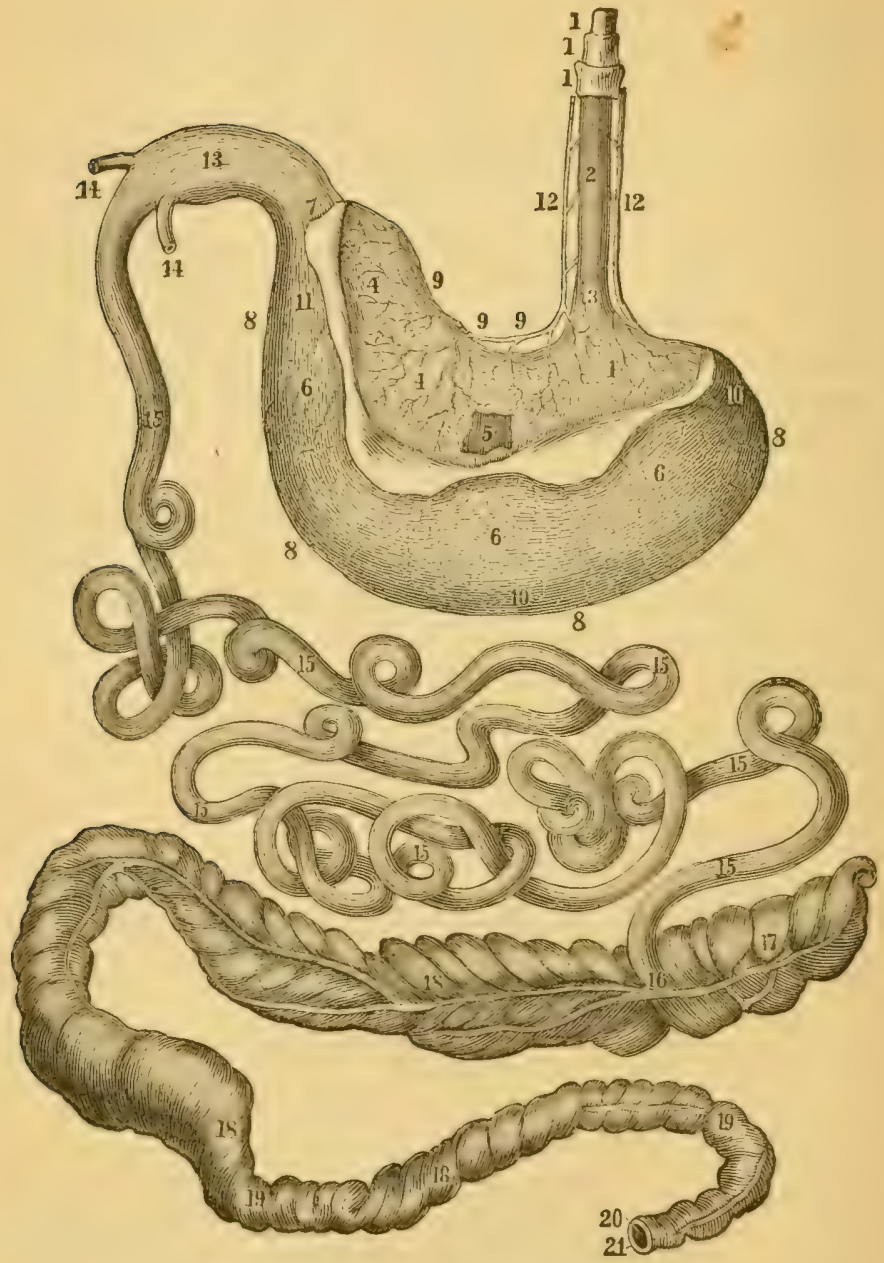

STOMACH AND BOWELS. 


\section{DISEASES OF THE BRAIN AND ITS' MEMBRANES.}

\section{STOMACH STAGGERS.*}

'This is a disease very prevalent in this section of the United States, and probably originates in derangement of the stomach I'Le latter organ is united to the brain in the ties of sympathetic rlationship, through the medium of the great sympathetic nerve; and whenever the stomach becomes overburdened, and thereo fore incapable of performing its normal function, it communicates the intelligence to head quarters, - the brain, - and soon sympa. thetic relations are established, and the brain, as it were, becomes secundarily affected.

Disease of this character seldom, if ever, attacks horses when due care is exercised in regard to dietary management. A very celebrated author has said that this disease never occurs except by the fault of those who have the management of the horse. It sometimes arises from giving a horse too much provender, after he has been kept too long without food, and in the interim worked hard, or driven fast. At other times, a horse may get loose during the night, and so gorge himself that the stomach is incapable of contracting upon its contents, or in any way performing its function; in such cases, the walls of that organ are often ruptured.

- A stomach surcharged with food, without any accompanying tympanitic dis. pentinn, does not appear to occasion any local pain, but operates with that kind of unfluence upon the brain which gives rise to symptoms, not stomachic, but rerebral; hence the analogy between this disease and staggers, and the aupel ation for it of ' stomach staggers." The unnaturally filled stomach prnduces for the first time, a sense of satiety; the horse grows heavy and drowsy, re poses his head upon the manger, falls asleep, and makes a stertorous roise All at once he rouses from his lethargy, and riolently thrusts his head againct :he rack or wall of the stable, or any thing, in fact, that happens to oppose lim, and in this posture paws with his fore feet, or performs the same arion with them as he would were he trotting, evidently all the whilp unconscious of what he is about. His eye, which at first was full of drowsiness, has now acquired a wild, unmeaning stare, or has already become dilated and insensible to light. The respiration is tardv and oppressed; the pulse slow and sluggish the excretions commonlv "nunished - Hippopathologu. 
Not lung ago, a firm in this city (Boston) lost three valuablu lorses, in the course of six weeks, from stomach staggers, brought on by the hazarlous experiment of making the virtims subsist on two meals a day, one at five o'clock in the morning, and the other aftel' work at night. 'The experiment was not from pacuniary motives, hut because the stable was so far ditant from the owners' place of business that it was inconvenient to drive the horses there.

On the death of the first horse, some one possessing a knowl cdge of the fats in the case, and understanding that sudden changes of this character in liet were sure to terminate in stag. sers, represented the matter to one of the partners in business, r'to, however, treated the affair lightly, and remarked that nany of his acquaintance kept their horses on two meals a day, making up for the loss of the noon meal by giving them double allowance at nightit. On the death of the second, which was a rery valuable animal, from a disease that had never before presailed in their stable, the proprietor's themselves began to doubt the expediency of dispensing with the noon neal, and therefore ordered the horses to be driven home at noon; but ere the order was executed, a thirl horse had gone the way of all horseflesh. Some eighteen months have since elapsed, and the survivors, who hav enjoyed their three meals a day, are in good health. The disease was thus timely arrested.

'Those of our species, who, after protracted abstinence, indulge too frecly in the luxuries of the season, can call to mind the.ir sleepy, unplrasant sensations, headaches, fec, can, probably, realize whal a horse suffers from an empty, overloaled, or disordered stomach. From these and other facts which night be adduced, we may safely conclude that the disease is cí stomachic origrin.

The diseate, having once manifested itself, is very apt to return. and for the siniple reason that precautions are not takm to Euard against a relapse. 'So som as the animal appears better, and craves food, be is bountifully supplied, and returns almosi immediately to work : even before the stomach has had time to recover its equilibrium. The animal soon becomes a confiraod dyspef $\mathrm{is}$, and is eaddled with an incurable disease. 
A horse, therefore, having once harl an attack of staggers, should be fed with great care and regularity; care must be ex ercised in regard to the quality as well as the quantity of the food; for, unfortunately, the course pursued by pratitioners - although those of the present day have improved somewhat - leads to prostration and debility; and in order to place the animal in a coudition to sustain the living principle and ward off future attajs, we must furnish him nutritious food, from which allu. nicn inay be extracted with as little expenditure as possible of the chemico-vital forces of digestion.

A horse fed on hay and grain that is deficient in nutriment of inferior quality - is liable also to be the subject of staggers; so that the disease does not always arise from the same exciting cause. It is well known that much of the pasture land in this country abounds in rank weeds and poisonous herbs, which, if partaken of by a horse already enfeebled by disease, are sure to operate unfavorably on some portion of the digestive apparatus. Therefore it need not seem strange if some horses, even at grass, should have an attack of staggers.

Symptoms. - The dull, sleepy appearance and staggering gait of the aninal are symptoms not to be mistaken, and as almost every horseman prides himself on his ability to detect a case of this character, we shall now, therefore, come to the treatment.

Treatment of Stomach Stagyers. - If the patient is known, or even supposed, to labor under distention of the stomach, the most rational course to pursue, instead of bleeding and purging, Is to excite the digestive organs - to secrete the fluid destined for the solution of its contents. Yet, in cases where the stomach if gorged - packed full - and distended beyond its healthy capaci. $\mathrm{ty}$, and there is reason to suppose that, in consequence of the over-listention, some of its muscular fibres are lacerated, or a loss of continuity has taken place, the treatment then will be of no avail. We excite the stomach, therefore, in simple distention, to pour out its gastric fluids for the solution of the alvumi. nous and gelatinous constituents of its contents, so that by the withdrawal of these we afford more room for the reduction to a state of fine division that portion of the food which remains.

We want room in the stomach for the reason that the solven 
nction of the gastric fluid is aided by the least movement of the walls of the stomach, and without successive contractions and relaxations of the muscular fibres of that organ we cannot insure prompt digestion.

If we can only effect the reduction of a small portion of the wlimentary mass, something has been done likely to benefit our patient; for, although, in consequence of obstruction to the pyIcric orifice, that portion of food which is now reduced to $\mathbf{a}$ homogeneous mass cannot move onward through the alimentary route, yet nature finds a way to get rid of it through another channel. It is known to physiologists, that a portion of the nutritious matter, dissolved by the gastric fluid, is at once absorbed into the blood vessels of the stomach, and never passes into the intestinal tube, nor into the special lacteal system.

With the above object in view, we administer remedies of a stimulating and antiseptic character.

\section{Take pure pulverized capsicum,}

'To half an ounce of the former add four ounces of the latter; rub them together in a mortar, and drench the horse with one fourth, in a small quantity of water, at intervals of ten or twenty minutes, until relief be obtained.

A solution of pepsin (which is obtained from the washed stomach of a cow, calf, or pig) might possibly act on the contents of a distended stomach in much less time than any other agent; for, at the ordinary temperature of the body, it is a powerful solvent.

It seems strange, when we take into considerution that the action of the gastric fluid, both in and out of the stomach, is purcly of a chemical nature, that prastitioners du not avail themQ Ires of chemical aids, (either the hydrochloric, acetic, or lacti: a.ids,) which are the real solvents detected in the gastric fluid. rather than to resort to bloodletting; for however well calculated such evil doing may be to deprive the vital machinery of blood, it cannot relieve the stomach of a load of semi-digested fond. It is the doctrine of the schools that any thing having a tenclency to overflow the brain with blood may be considered as 7 cause for s+lggrars, and the idea of the brain, in such cases 
being surcharged, probably first led to the use of the fleam. If the brain be in a state of congestion, there is a cause for it - a distended stomach; relieve that of its burden, remove the cause, and the congestion will disappear.

After the animal has swallowed several doses of the capsicum aus salt, and seems to improve, we may then venture on a dose of cathartic medicine, with a view of carrying off the superabun. Innt carbon; whereas, had the cathartic medicine been given: before the stomach had resumed its digestive function, - whick is now presumed to have taken place, - it would have done more harm than good. The author admits that he was formerly in favor of early purging, that is, so soon as the disease manifested itself; yet a few years of practical experience has weaned him from the hobby; and what contributed most to produce this change in practice was, that by making several post mortem examinations of subjects which had died from staggers of this description, and who had been pretty ersentially dosed by advice of the neighbors, he often found in the cardiac portion of the stomach a mixture of salts, aloes, castor oil, \&c., which had not reached the sensitive tissues of this organ in consequence of its distended state, and the pressure kept up from within by the enormous bulk it contained. In some cases, on removing the food, a portion of the living membrane of the stomach would peel off. So great pressure had the food been submitted to in some cases, that it was about as firm as a Dutch cheese, and the stomach enveloped it with drum-like tightness. There might have been ro help in such cases; but, as we have said, the post mortems have changed our views as to the treatment of the malady now under consideration.

Rarely, if ever, any bad consequence followe the exhibition of cathartic medicine when the vessels of the brain are surcharged provided it be given as here recommended, for it matters not which of these articles - aloes, croton farina, salts, or custor oil -are given: they all act on alimentary surfaces as mechanical srritants, exhaust the fluids of the parts, and tend to draw blood from the brain, and thus favor the nore equal distribution of that fluid.

Catharsis once established, the bowels should be kept soluible 
with green feed or scalded shorts. Superpurgation may be in mediately (hecked by a few doses of charcoal, cr a small quanti ty of bayberry bark and ginger ; but if our subjeet be plethoric no fears need be entertained of over purging from an ordinary dose of medicine. See Cathartic Medicine, or Physic Mass.

Should stomach staggers attack an over-driven or over-ridden horse, he never having manifested any cerebral or digestive derang'ment, nothing more is needed than rest, kind nursing, and * light diet. If' be recover at all, he will be more likely to do so under the judicious promptings of a humane man than by any othar course.

On the other hand, a debilitated, broken-doson subject must be put on a course of tonic medicine, alterative also in its character. The following serves as an example:-

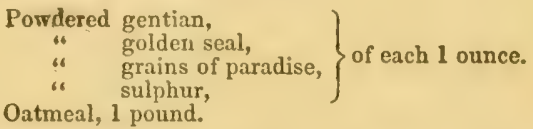

Mix. Divide the mass in twelve parts, and mix one with the fodder, night and morning.

The next form of this kind of disease has received the appellation of

\section{SLEEPY STAGGERS.}

This disease is named sleepy from the fact that its most characteristic symptom is that of coma or somnoleney. Tre subject may be surrounded by all the noise and confusion of a city stabls, yet, in the midst of this, and at any time, day or night, will fall fast asleep with his mouth full of folder. On arousing lim, he evinces some alarm; yet almost immediately, and while standing by his side, he is off into what appears to be a sound nap.

There are other features in the case that enable the observer to make out a diagnosis, such as stertorous breathing; slowness of respiration; slow, soft pulse; amaurotic eyes, (generally closed;) the head either drooping or pressed forward into tho crib. In most cases the excranent is hard and knobby; thr mine scanty. 
The disease probably originates in derangement of the stom ach and its associate digestive organs. It is very apt to termi nate fatally, either from effusion or extravasation.

Freatment. - Here we are at fault, not having beer. very suc. cessful in bringing such cases to a favorable termination. W€ remenber one case, however, that was considered hopeless and by way of experiment we administered the unwarrantable lose of half a pound of lobelia, expecting at the same time that it would cause his death; but, contrary to our expectations, he recovered. The remedy was followed up by stimulating injections and cold water bandages around the head.

The lobelia seemed to have no other effect than to produce profuse perspiration, and this suggested the idea of placing suct patients in a vapor bath - an idea that we have not yet been able? to carry out. 'There is no doubt, however, that nauseating medicines, in conjunction with the warm bath, will do as much to relieve congestion in the horse as they have accomplished in human medicine.

If we had nothing but simple congestion to contend with in the treatment of this malady, our suecess would be more certain; but cases now and then occur when some morbid change takes place in the structure of the brain, so that our treatment avails nothing. The treatment most likely to succeed in a curable case consists in the administration of nauseating medicines. One drachm of lobelia, with half the quantity of bloodroot, may be given in warm water every lour. A dose of cathartic medicine should be administered in the early stage of the disease, followed by injections of salt and water. Counter irritation maj also bo of service when applied to the extremities.

Cathartics and nauseants must be our sheet anchor, and should be repeated until a free evacuation has taken place; for they have a tendency to lessen the force of the circulation, and conse quently relieve the brain. The author is well aware of the difficulty encountered in administering medicine to horses laborng under disease of the brain and its investing m(mbranes; the danger too, both as regards the person of the physician and the life of the $\mathrm{r}$ atient, must be taken into consideration; for there are ines when the patient is unable to swallow, and if we should 
then insist on foreing down a drench, a portion of it might euter the air passages and choke him. The attendant is at times ir, dariger of personal injury from the animal's suddenly falling but these sugrestions apply inore to those forms of diseaso known as

\section{INFLAMMATION OF 'THE BRAIN. - (Phrenitis.)}

This form of disease corresponds to that recognized by human iractitioners as brain fever. In the horse, the disease, frequently, in its last stages, assumes so violent a form that veterinary practitioners have denominated it mad stuggers. The animal is not rabid, however, but frantic; now rearing on his hind legs, the fore ones are plunged into the crib; he extends the head as high as possible towards the ceiling, and then, as quick as thought, furiously dashes himself against the stall, or on the floor, where he lies panting for breath, in a perfect state of delirium. At other times, convulsions will follow each other in quick succession; the animal pants, perspires, and foams at the mouth, as if he were about to breathe his last breath; and a happy release from his sufferings would it be, if at this stage the vital spark were to vacate its tenement; but, unfortunately, he is often doomed to suffer for hours, and sometimes days, ere death takes place.

Treatment. - The treatment of mad staggers must be conducted on the same principles as in the preceding disease. We must embrace the most favorable opportunity; and perhaps while the animal is down will be the best time to administer the fullowing drench :-

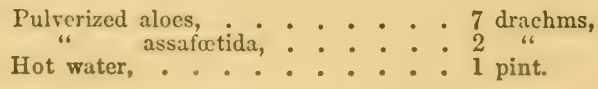

This medicine should be followed up, at intervals, with doges of ealt and water; two ounces of salt to one pint of water, grad. anlly diminishing the quantity of salt until purgation sets in, when it should be discontinued. Injections should be thrown into the rectum every four hours, composed of

Powdered lobelia, ? of each 1 ounce,
Hot water. two or three quarts. 
A counter irritant, consisting of mustard, cayenne, and vinegar may be applied to the chest. The head must be kept cool with water.

If the bowels lo not respond to the aloetic drench, after waiting a reasonable time, it will be advisable to give three or four drachms more. There need be no fears of superpurgation; and if that should be the result, it could not do much harm. "Pur. gation in mad staggers has ever stood in such high repute among furriers, that a common saying among them is 'Purge a horse with stagrers, and you cure him;' and this, like many other old veterinary adages, appears to have been founded in sound observation. In fact. it is a practice pursued by every surgeon in cephalitic cases, with the twofold view of removing any source of irritation or cause for the head affection that may exist within the bowels, and of indirectly abstracting blood by derivation and discharge." - Hippopathology, p. 20.

\section{APOPLEXY.}

The immediate causes of apoplexy are, compression of the brain from congestion of its blood vessels; or by an effusion of blood, or serum, (water, into some portion of the cranial cavity ; or from tumors, which compress some portion of the medullary substance of the brain. Congestion, and subsequently effusion, nay be brought on in subjects predisposed to the disease, by any thing that determines the affiux of blood to the head; or, in other words, by any thing that disturbs the equilibrium of the circulation, and prevents the free return of blood from the brain.

There are various exciting causes which tend to produce san guineous apoplexy; for although the immediate cause seems to be an excess of blood in the ressels of the bruin, this nay be brought about by an overloaded state of the primæ viæ.* In buch cases the symptoms somewhat resemble those of stomach staçgers; the animal appears drowsy, feeble, and is constantly l.anging or resting his head in the crib.

When apoplexy proceeds from fluid within the ventricles of the

- The stomach and intestinal tube are so called 
brain, besides other symptoms, there is a disposition to 1 ear up or fall backwards, when any one attempts to handle the head.

Should apoplexy proceed from tumor within the cranium, it seldom, if ever, admits of perfect recovery.

Symptoms of Sangrineous Apoplexy. - The horse generally falls down suddenly, and remains in a state of insensibility; the breathing is laborious, the eyes are fixed, glassy, and amaurotic the inembranes of the eyes, nose, and mouth are highly injected, uftrimes of a purple color; the veins of the neck are distended, the pulse is strong, full, and slow; the whole muscular system is occasionally affected spasmodically, and the limbs are icy cold.

Treatment. - Our first husiness is to endeavor to arouse the patient out of his lethargy Some strong spirits of hartshorn should be held to the nostrils, while one or two persons are engaged in rubbing the external surface with stimulants; mustard and vinegar must be used pretty freely to the limbs, followed with hard rubbing and stimulating injections. If through these means we should be successful in bringing the patient to a state of consciousness, the next object should be to evacuate the bowels : our usual drench in such cases is,

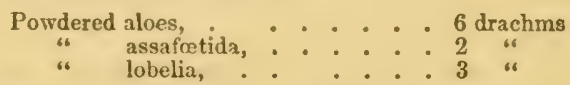

'ro be mixed in warm water, sufficient.

Before this drench is administered, the practitioner must satisfy himself that the patient has so far recovered as to be able to swallow, or the medizine may prove a death warrant. If the apoplectic fit be only the effect of plethora from high feeding ar.d want of proper exercise, this treatment will generally succeed We have had oscasion, however, in a few cases, to follow up the drenth with salts, dissolved in a bucket of water, which our patients generally drank. The after treatment consists in feed. ing the animal with great care; and the best means to prevent a rfcurrence is tc let the animai run to pasture.

Dr. White refers to a case of apoplexy "that was considered hopeless, and not worth any further attention; yet as it was supposed that blood had been effused on the brain, the horse was trepanned, (a portion of the skull removed,) and an opening 
mude in the dura mater, ur outer membrane of the brain, which was immediately followed by a considerable effusion of blood In about ten minutes after the operation, the horse got up, and being led to his stall, began to f'eed immediately. He continued ̊pparently well for several days, but died a fortnight after the operation." *

Tracheotomy, which consists in making an incision into the trachaa, and then introducing a hollow tube for the animal to breathe through, has received the advocacy of some. ?n $\mathrm{p}$. 26, Hippopathology, the following paragraph occurs: "Tracho otomy. On no animal is this operation practised with more facility than on the horse; neither are the consequences of it such - though it may, now and then, leave the animal a roarer as to deter us from practising it in any case in which important benefit is likely to accrue from it. Dr. Physic, of Philadelphia, first suggested its performance in hydrophobia ; and Dr. Marshall Hall has recently advised a trial of it in cases of apoplexy. His words are, 'In apoplexy from congestion, I am persuaded that the fatal event might be averted by the timely adoption of this measure; the patient dies of asphyxia, - (cessation of thie pulse,) - and of an asphyxia which tracheotomy would, I believe, jrevent.",

The author has no faith in the trephine for the cure of congestion, although it might give temporary relief, as in the above case. The instrument has been called into requisition in cases of compression of the brain, from fracture of the skull, and with decided benefit to the patient; but in apoplexy the case is far different; the blood is loaded witl carbon, the respiratory organg are unable to imbibe a sufficiency of oxygen to decarbonize it. and therefore if we were to remove the whole of the skull L.g trephine, we should be just as fir off as ever in unloading the rital current of its defiling burden. There is no way, that the author knows of, by which the blood can be vitalized, other than that which takes place in the lungs throurh the admission of oxygen; therefore tracheotomy, which provides for a due supply to the lungs of pure air, holds out more certain advantager than the former speration. 


\section{VERTIGO. - (Meyrms.)}

Horses are, now and then, attacked with a sort of gildineso, which is apt to come on while going fast; the animal all at once commences shaking his head, stagrers, reels, and stops short; if permitted to rest a while, he recovers, and travels on as if nothing had happened.

The vertiginous symptoms are very apt to return; therefore a burse having once had an attack must be managed with caution; he is certanly unsate for either saddle or chaise; but with duo care in regard to stable management and work, he might be used with some degree of safety in a four-wheeled vehicle, for, if then he should fall, the occupants might escape without injury, otherwise they would not. The disease is generally supposed to be connected with some patholegieal state of the brain or nervous system, and must therefore be considered incurable so long as that organ or system remains in a pathological condition.

The treatment of vertigo, or megrims, as it is sometimes called, does not reflect much credit on us, neither is it all times satisfactory to our employers ; for so soon as the horse returns to work, the same calses which produced a previous attack are again in operation, and soon produce a subsequent one. Our first object is, to act on the digestive surface by means of a full dose of physic. Some mustard, moistened with vinegar, should be rubbed along the neck, on each side, near the head. Some practitioners recommend setons through the temples, or along the nape of the neck; others blister the head. Bloulletting is generally resorted to for most diseases of the brain; with what success the reader may learn by consulting the text books. The practice, however, lacke the sanction of the new school and our own humble advocacy. We hare seen some benefit derived from the daily use of an antaspassnodic draught, composed of

lowdered gum assafotida, . . . . 1 drachm,

Swert spirits of nitre, . . . . . 2 drachms,

Tbin gruel, . . . . . . 1 pint.

To be given so soon as the bowels have responded to the purge, and to be continued until the patient appears better.

This treatment we have found eflicient to prevent a reattack for a longer or shorter sime, depending. however, on the mun- 
ner in which the horse is kept and used. Good grooming, light diet, clean stables well ventilated, and light work, are among the best means for warding off an attack of this, which is genetally considered an incurable disease.

"By vertigo is meant a chronic disease of the horse, chiefly indicated by a disturbance of the sensitive faculties, occasioning derangement in the ordinary functions of life. Much that is in correct has besn written regarding the seat, properly so called. of the evil: at present, most veterinary surgeons are agreed in seeking the proximate cause, not as formerly, in the brain, but in the abdominal organs, and in considering the cerebral affection as purely secondary. The vertigo often succeeds acute encephalitis, the intensity of which has diminished to a certain degree; but very frequently also it comes on without having been preceded by inflammation of the brain. It reconnizes the same causes as the latter, isolation, confinement in hot and badly aired stables, cold, extreme fatigue, blows and injuries on the head, indigestion, unwholesome or too much food in proportion to the exercise taken. The fear of punishment, especially of the whip, occasionally gives rise to it in sensitive and irritable animals. Some horses have an hereditary predisposition to it, and mares are considered more subject to it than stallions. Further, it is scarcely ever observed except in hot weather, and as it is generally at the beginning of summer that it commences to appear, it goes away always in autumn, at least with respect to its chief symptoms. These are the following: the horse, a littlo before lively and active, begins all of a sudden to appear heavy and indolent; he is dejected, and prefers to keep himself in the darkest corner of the stable, eyes dull, look fixed and stupid syelids half shut, inattention to every thing, forgetting even lum self, and, as it were, asleep, and head hanging to the ground, and resting on the manger, or on the rack. His gait is heavy, slow, and unsteady; he raises the fect very high, and puts the antirt sole to the ground, raising and letting down the limbs in a manner purely mechanical, and, as it were, unconsciously. He exhibits much awkwardness in turning, and cannot be pulled back except by depressing the head very much, and pushing it laterally. Generally, also. he Jeans on une side in walkino. To mainiain 
his equilibrium the better, he places the fore legs beneath the belly, and moves his ears in a peculiar manner, and backwards According as the disease progresses, he becomes less and less sensible to external impressions; mastication is performed slowly he takes fiom time to time a mouthful of food, masticates it, swallows a portion of it, but keeps the remainder in his mouth. He prefers taking his food off the ground rather than in any other way, and when drinking he plunges his head into the water, even above his nostrils. During and after some rather violent movements, his symptoms become much aggravated, and the signs of complete insensibility become more and more marked. The animal runs on quite blind till some obstacle stops him, or turus round, or remains tranquil, when, with his head depressed, and the legs crowded beneath the body, without being able to chango this unusual attitude unless assisted to do so. There is never any fever: the pulse is often from ten to twelve pulsations slower than in the normal state.

"In the same way, also, the respiration is constantly slow, deep, and frequently of a sighing character. In almost all cases the tongue is foul, and the mouth dry and clammy. With respect to seatment, the remedies which have succeeded best with me are, camomile (some doses), then sulphur, and nux romica. In a particular case where, indepentently of the symptoms peculiar to vertigo, the conjunctiva, tongue and mouth were more yellow, the horse freogurntly flexed his fore !egs, seldom lay down, freces hard, and passed but little urine. I obtained benefit from the use of nux romica, with sulphur as consecutive treatment. Others user pulsatilla in general: however, they also obtained good efrects from veratrum album in many cases; nux romica was employed with the horse inclined to the left, and arnica when he leaned to the right. Several horses have been cured by means of belladomna; and one, which was consilered as lost, was saved by giving him belladonna. hyoscyamus and nux vomica. The utility of digitalis and opium has been verified in slight cases of ventigo, in which cases benefit has been derived from arnica On one occasion reratrum album was prescribed during four dajs, twice a day, and then stramonium, employed in the same numner: on the fifth day the animal was cured. It is alwavs 
advisable 10 have recourse to sulphur as consecutive treatment." - Veterina'y Homoopathy, p. 127.

\section{CONCUSSION OF THE BRAIN.}

The bony structure - which encloses the cerebral orga.s is so wisely adapted for their protection, that injuries of this claracter are somewhat rare: a very few cases have come to our knowledge during nine years' residence in Massachusetts; but we have never treated but one, and that may be termed a mild case. 'Tlie subject was a bay gelding, nine years old, blind in the off eye from cataract; he had been left opposite the "Revere House," harnessed to a furniture wagon, when some person threw a lighted cigar on him; he then ran across the street, and was suddenly brought up by striking his head against an iron railing; he fell on the pavement, and lay there for some time in an insensible condition, almost pulseless, and the respiration scarcely discernible. He was unharnessed, and the bystanders attempted to risu: him up; but he had lost all control over the muscles of voluntary motion, and drooped his head as though he were dying. The horse having received a wound just abore the left orbit, from which the blood was trickling down, it was supposed that the skull was fractured, and the owner was just thinking about despatching him, when, all at once, he rose on the fore leg: and squatted on his haunches like a dog. After remaining in this position a short time, and making fruitless efforts to get up, he at last, under assistance, rose, and after a good deal of truuble, reached the proprietor's stable.

Our attention having now been called to the patient, we found him scaucely able to stand; pulse about 50, full and jerking, respiration hurried and somewhat laborious; the body bedewed with a cold sweat; the pupil of the sound eye was dilared; the head drooping, and inclined to the nigh side. On exploring the wound, neither fracture nor injury to the bones could be perceived; it was therefore brought together by stitches, and dressed with "Turlington's Balsam."

So soon as the horse had been rubbed dry, a preparaticn, conasting of equal parts of tincture of lobelia and capsicum, was 
applied alorg the back and to the chest; the legs wert haxnd rubbed until reaction took place, and they became warm, thes bandaged. A cold water bandage was applied to the head, and the body covered with a buffalo-skin.

It will be seen by this preliminary treatment that the object was to equalize the circulation, so as to prevent congestiou of the brain; and in furtherance of this object, a stimulating clyster was suministered, all of which seemed to have a good effect.

Not thinking it prudent to risk an antispasmodic draught, the patient was placed in a well-bedded "wide stall," and suituble directions given for his management during the night.

On visiting the patient next morning, the symptoms had slightly improved, and he drank half' a bucket of water containing twenty drops of the tincture of arnica; four hours afterwards were arl. ministered

Powdered aloes, ${ }_{\text {" }}$ assafœida, : : : 6 drachms,
Thin gruel, : * : : 1 pint.

He took, during the day, a small quantity of scalded shorts, forty drops of tincture of arnica, and four gallons of water.

On the evening of the next day, made a visit to the patient, found him with the head still drooping; the parts in the region of the wound were somewhat tumitied and hot; the pulse was soft and less frequent; the bowels had slightly responded to the medicine; in short, the general appearances were indicative of improvement. Directions were given to sponge the lieed, more particu. larly the wound, with a weak mixture of arnica, (one ounce of the tincture to a quart of water.) The diet to consist of thin gruel. In view of remote counter irritation, a paste, made of mustard and vinegar, was rubbed on each side of the chest.

The above includes about all the treatment; the mustard was washed off the next dlay, and for a few succeeding ones the lict was sparing; the head in the mean time was kept bathed when. ever it became hot. The patient returned to work about a fortnight afterwards.

We learned from the owner that the animal had been in his possession about five years, during which time he was never known to lie down. nor did he do so during this sickness. 
It may be of some service to the reader to be informed tha counter irritants should not be resorted to in the early inflamma. tory type of cerebral disorder, for they are always painful to the horse, whose skin is so highly sensitive, and the stimulation or irritations are always reverberated to the affected organs, and also necasion more or less excitement to the whole system. Therefore they should not be resorted to until some general treat. ment has been adopted; they will then be of much use in divert ing the internal local irritations to the surface, by which means the internal tissues are relieved.

\section{LETHARGY.}

This is a mild form of apoplexy, and arises either from a congosted brain, or may be occasioned by an overloaded stomach.

Gibson says, "When a horse falls into a lethargy, he generally rests his head with his mouth in the manger, and his poll often inclined to one side; he will shew an inclination to eat, but for the most part falls asleep with the food in his mouth, and seldom chews, but swallows it down; unless he is roused, he presently falls asleep again. If a horse continues any time in this state, he falls into an atrophy or general decay." The best remedy for this pathological condition is a long run at grass. Lethargy is probably only another name for sleepy staggers, (which see.)

\section{INFLAMMATION OF THE ARACHNOID MEMBRANE OF THE BRAIN. - (Arachnoiditis.)}

'This membrane is situated between the dura and pia mater; the former is situated within and next the cranium, and the latter is in immediate contact with the brain; so that the arachnoid membrane lies between the two, and extends to the termination of the spinal marrow. It is a very difficult affair to diagnose correstly a disease occurring in a membrane so obscure and slightly organized as this is known to be, and it requires corsiderable stretch of the imagination to conceive how this membrane can be the special seat of inflammatory action withont involving its assoiate tissues, and even the brain itself; and even should the cis. 
ease be unaccompanied with inflammation of the brain, which in rarely the case, we know of no special means of treating it other than those recommended for inflammation of the brain. A French writer, however, informs us that acute arachnoiditis is occasioned by loss of continuity, or lesion of that membrane, from which result staggers and water on the brain.

\section{REMARKS ON AND EXPLANATION OF VAPOR BATH.}

The following cut, representing a horse in a vapor bath, will appear somewhat novel to Americans, as we are not aware that any thing of the kind has ever been got up in this country Indeed, Mr. Percivall, from whose work the illustration and explanations have been transcribed, expresses his surprise at the introduction of this apparatus, even at so early a day as the present, in a country too where improvements are continually progressing. We hope that ere long this useful article may be extensively used in this country, for every practitioner must have occasionally felt the need of it.

\section{EXPLANATION.}

$a$ represents a boiler originally erected for the pirpose of supplying the m!lirmary with het water ; $c$ is the main pipe issuing from the top of the boiler, IEuciving the steam, and conducting it, when not required for other purposes, Into sither a flue or the open air at $b$; $e$ and $f$ are branch pipes from. the main vt.e (r), $f$ being that which conducts the steam into a worm $(h)$, winding Inrough a conciensing trough $(\eta)$; e the branch pipe which conulucts the steam (prevented by stop-cock from going in the other direction) into the bath. the place of admission $(n)$ being on nne side, close to the flonr, at a point intermediate between the horse's fore and hind feet while standing in the bath, with his head ontside; $m$ is the bath, being a horse box, such as is used for embark. ing horses on board of shin, with the addition of a lining of Hannel, a roofing of horps and tilting, and burtains over the doors, front and back, to prevent the escape of steam. The box, being placed upon whecls, serres, besides being used as a bith, for the transport of sick or lame horses; and, having doors at both ends, and a mowable plitform for the horse to walk in upon, is in general entered without any great deal of unwillingness.? 
TRE MOUERN HOIZSE DOCTOR.

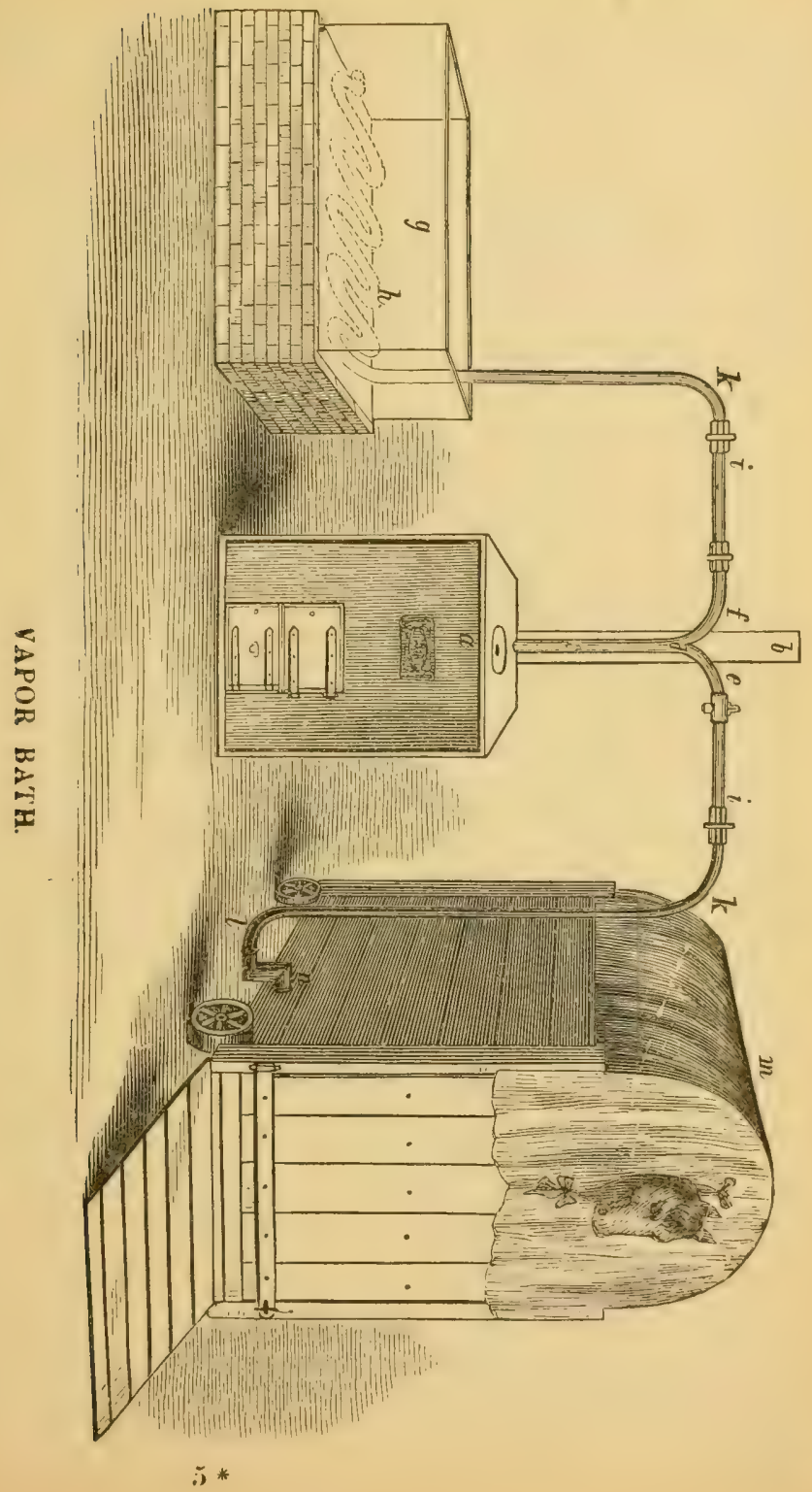




\section{DISLASES OF TIIE RESPIRITORY ORGANS AND AIR PASSAGES}

\section{PINK ETE AND HORSE AIL.*-(Influenza)}

IT will be seen that very little idea can be gained of the nature of the disease under which the subject suffers from the above lerns ; they have their meaning, however, among horse dealers Any uffection of the respiratory organs, from laryngitis to influ. enza, strangles included, are all considered under the above head by some. The disease we propose to enlighten the realer on in this article is infuenza; that reritable disease which usually attacks green horses, as they are called, shortly after their first introduction to city life, although it may occur in the country as well as the eity. The time of its appearance is generally in the spring, when horse dealers crowd the city stables with sale horses. 'This is the most trying period of a horse's life, and generally tests his metal. The sudden change from a pure atmosphere to one contaminated with ammoniacal gases, and other injurious va pors, also the change of food, water, and habits, are calculated to impair the health of even an old stuger, whatever might be their effect on a young horse. If he can withstand these incursions on the sanitary laws of his existence, and at the same time pass saftly through an attack of "pinli-cye," - influenzil, — and come out right side up, his owner can contidently recommend him to any purchaser as one having been through the mill.

We do not wish the reader to confouml influenza with catarrb or strangles, (uhlich see;) although influenza may finally as. sume the form of strangles, or end in a bad discharge from t: nose, chronic cough, Ec., and in inveterate cases, may termir atr in glander's.

The principal features of influenza are, that it apears it cer-

- Tlese terms are used by Lorsemen in New Fngland to denote a kind of Estarrh or influenza, that often breaks out among young horses at particular eeasons of the year, and seems to rage more in some stables than others. It is the gentral oppinion that all horses must have an attack of this sort once in their lives. Therefore a horse that has once had it is considered aeclimated, and bis owner linds a more ready sale for him than for one that has not had this affection. 
tain seasons of the year, in stables, at remote points, prevaling more in some than in others. When once it breaks out in a stable, it is sure to effect all the susceptible subjects; sometimes it creeps from stall to stall in a slow and gratual manner; at others, three or four horses will be attucked all at once, and in the course of a few days all the new comer's are on the sick list. Yet if the stable be well ventilated, and the horses properly manazed, both as regards diet and exercise, the evil day may be put off in some, and others may have so light an attack ats not to occasion any alarm. Many thus managed are known to run clear for years, and then, on coming in contact with the infection, become its victims.

Symptoms. - There is no disease that assumes so greal a variety of symptoms at its commencing as this; still there are some fentures always present that convince us of the nature of the disease we have to treat. The first symptom the stabler notices is, that the horse is dumpish, as he colls it, which signifies debility. This is a remarkable feature, and one that seldom, if ever, presents itself in any other form of disease so early. To a casual observer the horse looks as if he had been sick for months. If you urge him to move, he does so after the fushion of an overgrown elephant. The eye is indicative also of the disease; its vessels are turgid, have an arterial red appearance, (this has perhaps led to the term pink eye, the lids become swollen, and the animal shrinks from the light as if its rays caused pain; the sears trickle over, and now and then a particle of purulent or lymplhy matter can be seen in the angles of the eye. The animal serms 'inable to support the weight of his head; it either remains in a drooping position, or he rests it in the crib. First one hird iimb and then the other swell, become infiltrated with fluid, which constitutes anasarca; or they may both commence to swell at mu; in fact, other parts of the body become dropsical, so that the patient sometimes more resembles an elephant than a horse. This swelling of the legs, let it be mare or less, is considered, in connection with the other features, the diagnostic symptoms. It is very different from that tumefaction which we observe in the limbs of many horses, occasioned by want of exercise, \&c. It comes on suddenly, affects the whole limb, groin, and shenth; 
the latter to such an extent as to cause the penis to protrudo The hair from the first bas an unlealthy aspect and rough feel the ears, nose, and limbs are cold or not, accorling to the stage of the disease. The appetite is poor from the first, and any attempt to swallow tells us that the throat is excessively sure; inspect the fauces, and they will be found inflamed; the tongue it foul, thickly coated, and saliva runs freely, although not asways, for in many cases the mouth is dry and feverish ; the excrements are voided in small quantities; the excretory as well as the secretory functions are as torpid as the animal himself. In the course of a few days a nasal discharge sets up, and this is considered a farorable crisis. In some subjects, however, the disease terminates in submaxillary abscess; the animal sometimes has a troublesome cough.

These are the main features of this form of influenza. They vary in different subjects, both in the mode of attack, intensity, and termination; and in the progress of the disease, although self-limited, it depends murh on treatment, and still more on the management of the horse during his sickness.

Treatment. - Our first business is to ilace the patient in a situation where he may have the benefit of a pure atmosphere, (this is the best medicine for the lungs;) for the blood, being loaded with carbon, owing to its languid circulation, requires pure air to decarbonize it. The body is to be clothed according to the temperature of the stable. If the limbs are cold, they should be well rubbed, and if any difficulty is experienced in in. creasing their temperature, some stimulating liniment should be rubbed on, and Hannel bandages applied if necessary. These: bowever, must be omitted when the limbs become anasarcous; for they only keep the parts hot and feverish. The same apply to body clothing; the natural clothing of the body is all the animal needs in the febrile stage, provided the atmosphere be comfortable.

The following dose should be given early, as it heips to cleas out the digestive cavity of all morbid mate ial :-

Sulphur,

Cream of tartar,

Salt, . . . : : .

Mix, with flaxseed tea, for a drench.
5 drachms,

2 "

1 ounce. 
We find from experience that salt has a good effece on this disease, and therefore generally allow the patient all he will eat.

The best drink for the patient is flaxseed tea, acidulated with cream of tartur, and thickened with powdered licorice. Yet if he eat much salt, which is often the case, a corresponling thirst may be expected: in this event, we see no good reason in withloolding water, provided it be given a quart or two at a time, wills the chill off, although warm water generally excites disgust on the part of our patient, and he will often go thirsty rather than driuk the nauseous stuff, which would at almost any time sicken a dog. As regards the diet: a plethoric horse should be half starved, both in view of reducing his fat and lessening the fever, which, as a matter of course, will accompany the malady. In fact, sloppy drinks and scalded shorts are all that are needed in any case, until the disease turns for the better.

Should the throat be sore, let it be rubbed occasionally with warm vinegar and salt. The discharge from the nostrils must be encouraged by steaming. The rectum may be emptiod necasionally with warm soapsuds. In view of grarding against sub sequent cough and debility, we give the following:-

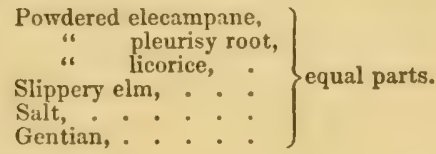

\section{Dose, 1 ounce daily.}

The swollen limbs are to be rubbed frequently, and the patient nuust have walking exercise as soon as the state of his health permits.

It is a notorious fact that there is no disease to which hor'ses in this country are subject that has opened so wide a ficld fir empiricism as this. Every man has his farorite remedy, and otten applies it to his own loss, because he thinks it beneath his dignity to employ a physician to treat what horse dealers consider a simple disease, which, however, frequently becomes com plicated from want of knowing when to do nothing, or applying suitable means at the proper time. 


\section{SPASM OF THE LARYNX.}

The larynx is an irregular cartilaginous tube forning the upper extremity of the windpipe, and is the orcan which produces thas peculiar sound called neighing; it affords free passuge, in its normal state, for respiration, and also attachment for numeroug muscles. Its internal cavity is protected by the common mem. brane termed mucous, which, at times, becomes the seat of a dis. ease known as laryngitis.

Our own opinion is, that the spasm may arise from other cause s than those acting directly on the laryngeal apparatus. From the symptoms detailed by Surgeon Haycock, which we shall here introduce, it seems to bear some analogy to Laryngismus stridulus, ("croup" of the human family,) and that which is here termed spasm may result from a nervous affection induced by indigestion ; in that case spasm of the larynx is a symptom of another disease. What some might term spasm of the larynx may result from some morbid productions within the larynx, an cedematous swelling occurring in the submucous membrane of the larynx, as in cases of violent laryngitis, may give rise to many symptoms noticed by the individual just named; yet a morbid production of this character could not with propriety be called spasm.

The history of laryngismus stridulus - croup - is as follows : the attack comes on during sleep; the child starts suddenly; strugggles for breath; face flushed, and swollen, and purple; and after repeated efforts, we have long inspiration, accompanied with a whooping or crowing noise, arising from obstruction, not spasm. It makts very little difference, however, whether the difficulty of regpiration occur from spasm or obstruction, since the treatraent of either does not materially differ, that is, as regards present silief. The three principal means of cure are-nauseants, counter irritations, and lastly, tracheotomy.

Joet it he understood that this treatment applies to those cases which occur from internal obstruction; the treatment, of course, must vary accorling to the nature of the case. For our prin eipal object is not so much to treat spasm of the larynx, as it should be to discover its cause - that removed, spasm will cease. That 
it is not always a primary disease we have ample testmony from Mr. Haycock's own pen: see Leterinary Homoeopathy, p. 167 "The causes are numerons," $\mathbb{N e . ~ " I t ~ m a y ~ a r i s e ~ f r o m ~ l u r y n g i t i s , " ~}$ \&ce. If it does arise from laryngitis and other affections, it is cnly a secondary disease, or, as Mr. Percivall says, "symptomatic of some distinct and acknowledged genus or species of disease."

Symptoms of Spasm of the Larynx. — "The symptoms of spasm If the larynx are of so evident a nature as to warrant me in say-ng $\mathrm{tl}$ at they declare themselves, and that too in the most decisive nanner. Sometimes the disease manifests itself in a moment, as it were, with a most terrible severity; the animal begins to gasp for breath; the eyeballs protrude, and present a wild, haggard appearance; the nostrils are dilated to their utmost extent; the nose is protruded, and the neck is carried in a line with the back; the flanks heave with most excessive violence, and every time the poor beast inspires air, a sound is emitted, which will vary in its character and intensity according to the vigor of the spasm. Sometimes it will be loud and shrill, sometimes a kind of scream, at other times like the loud twang from a trumpet - or it may be rasping, snoring, or like that elicited when sawing wood. As the disease proceeds, the general symptoms become more violent - the mucous membrane of the mouth assumes a purple color, the animal becomes partially unconscious; he rushes williy from place to place, as though seeking in vain for aid; the body becomes suffused with a streamirig perspiration; at last, the spasm is either surdenly relieved, which is very rarely the case, or he falls heavily to the ground, struggling for a few moments, and then dies completely asphyxiated. If the disease supervene upon an inflammatory attack of the organ, the symptoms in such sases, fur a short period at least, will most probitbly be of a mildes chararter. A partial spasm of the muscles will manilest itself, whish ma: exhibit just such a degree of violence as to excite alarm, and nuthing more, when the whole will gradually scibside, and leave the patient in a very tranquil state; in a shurt time, however, may be in two or three hours, or more or less according to circumstances, it again commences, and continues for a longer period, or it goes on increasing in violence until either relief is afforded surgically or the patient dies." 
We must not therefore, as already observed, consider sfasmi of the larynx in all cases a primary affection, for we know ihat in the human family croup is often associated with impaired nutrition, and well-marked derangements of the digestive organs, and all attempts to cure by local means fail, unless aided with pure air and a well-regulated system of hygiene. So that if impaired nutrition leads to spasmodic diseases, and, reasoning from analogy, we may safely conclude that it does, our object in the treatment should be to restore the digestive organs to their normal state. We have lately read a paper written by Dr. Ferguson, of Dublin, which goes to show that spasm of the larynx can be produced at will: he states, he administered some hydro cyanic acid to several frogs; after death he eximined them, and found the larynx of each one spasmodically closed. A dose was also given to a rabbit, and after death the blood vessels of the larynx and trachea were intensely congested. A similar state of things might be brought about in the horse, by the use of similar poisonous agents; but as medical treatment would, in cases of this kind, fail, it is unnecessary to write any thing nore on that subject.

Treatment. - It has been hinted, at the commencement of this article, that nauseants, counter irritants, and tracheotomy are the principal agents in view of immediate relief; unfortunately, however, the former are of little avail unless administered early before alarming symptoms set in, as in partial spasm. When the patient is attacked suddenly, and shows all the worst features of the disease, he can only be relieved by a surgical operation called tracheotomy. The operation is not considered a dangerous one. yet the services of a qualified person are indispensable; as also in cases which result from the presence of morbid growths in the vicinity of the larynx, surgical skill must be sought.

It is proper, in all cases of either spasm or obstruction existing is or about the larynx, to let the patient inhale the vapor of hot watcr, or else that arising from medicated water. A small por. tion of nitrous ether, dropped on a large sponge previously saturated with hot water, and held up to the patient's nostrils, may give relief; we have tried this article, as well as chloric ether, in rases of obstructed respiration, and think benefit has been derived (Inly a small quantity of ti.ese articles, however, can be userl, for 
in excess they are apt, instead of relixing, to produce rigid spasms of what are known as the vocal cords. In administering chloroform to animals this rule bolds good, for we have invariably found that if etherization is carried beyond a certain point, a tetanic Epasm of the muscular tissues is the result - which is only remedied by removing the breathing apparatus for a short time, when the muscles soon relax and become pliable.

Lubelia is considered, also, a very good relaxant; it is extclled very highly by some physicians for the cure of asthmatical com * plaints, and for relaxing rigid parts ; we have used it in this view for a number of years on all classes of domestic animals, and con sider it a valuable antispasmodic. A strong infusion of lobelia can be brought in contact with the horse's nostrils by means of a sponge, and perhaps prove as beneficial as ether. All sorts of means have been suggested for steaming the nostrils; we prefer the sponge to any other contrivance, for hot steam (that arising from boiling water directly applied) will tend rather to inflame than relax a part alrealy in an irritable state. The sponge, being porous, permits cool air, in the act of respiration, to pass through, mingle with the hot fluid and vapor, and thus moderate its temperature. Counter irritants, applied externally in the region of the throat and chest, are generally recommended; the common hartshorn liniment, essence of mustard, or a mixture composed of equal parts of olive oil, tincture of capsicum, and lobelia, are among the most efficient remedies for this purpose. The rectum must be kept empty by stimulating clysters; all food to be withbeld until the worst symptoms are past, when some thin gruel, sweetened with honey, may be allowed.

\section{LARYNGITIS. - (I flammation of the lining me mbrane of the larynz.)}

The membrane which lines the larynx is one of great senslLility, and prone to take on disease of an acute character, from a trifling cause, and if not properly attended to is very apt to result in chronic cough. The same membrane in the interior of the larynx is part and parcel of that peculiar to the trachea and other air passages; yet it appears to be more sensitive therc, as well as $\boldsymbol{x}$ the bronchial divisions. Mr. White, in alluding to the sensi- 
bility of the membrane of the larynx, and the cumparatuve insen sibility of that portion within the windpipe, says, "This I havu ascertained by opening the trachea, introducing my finger, and scratching the membrane. I did the same with a bit of straw, which the horse did not appear to feel; but on passing it upwards, the moment it touch d the larynx, the most violent irritation and coughing was proluced. I have tried this experiment several times with the same result. In a roarer, where 1 found an ulcer in the larynx, the most distressing irritation and wherziug were prodnced whenever the horse was made to exert himself, and this rendered him so useless that he was killed. In another horse that was glandered, I found (after death) the whole of the internal membrane of the trachea ulcerated; but this horse was not observed to have a cough, nor was he a roarer, the glanders being the only seeming disorder he labored under."

Symptoms. - The animal generally projects the head, indicating a stiffened neck; he endeavors to bring objects, by rotating the eyes, within the range of vision, rather than by moving his head. The respirations are short and painful, and emit a labored sound; the throat and sub-glands are tumefied, but not so much in the early as in the latter stages of its inflammatory type. The act of swallowing is performed with difficulty ; sometimes on attempting to swallow food, or even water, the animal will be seized with a fit of spasmodic coughing, really distressing to witness. The slightest pressure in the region of the throat will excite spasmodic coughing. At first a slight cough is only perceptible; but as the disease progresses, the cough increases, until it becomes hoarse and feeble. These symptoms, without noticing those which may owcur during the progress of the affection, are sufficient in themgelves to indicate the nature and seat of the disease, so that there need be no mistake about it:

Treatment.- In all cases of this character a pure atmospliere is indispensable; the dict must be of a sloppy character, easy of digestion, and containing but a small amount of nutriment. The bowels should be kept soluble with cooling saline aperients; if, however, they can be so kejt hy bran mashes, seasoned with salt, the former may be dispensed with. Some apply poultices, em. brocations and fomentations to the shroat, neither of which shculd be continued any length of time unless they give immediute relief: 
for let it be remembered that the animal may sudlenly expire from suffocation, in his efforts to breathe. In cases of an alarm. ing character, such, for example, as when the mucous membrane. are infiltrated, or tumefied, or the laryngeal cavity oceupied by morbid secretion, recourse must be had to bronchotomy, or trarhe. otomy, either of which terms serres to designate the nature of the operation. It consists in making an opening into the wirdpipe. and introdusing through it a tube, so that the lungs are inflated, without the air having to pass through the laryngeal channel. The operation is both safe and practicable, for it is seldom, if ever, attended with bad results.

This operation, however, should only be resorted to when the danger of suffocation is imminent; and then the breathing tube ought to be remoyed, the wound closed, and the integuments hrought together by stitches, just so soon as the horse shows signs that the danger is past.

We have found water, cold or warm, as the season permitted, very good for relieving acute laryngitis, applied by means of sponges to the throat.

In chronic cases, when the glandular organs around the throat are swollen, a stimulating liniment will be indicated, which should be rubbed in night and morning, the animal to have a nutritious diet, and to be drenched as follows :-

Balsam of fir, . . . . 1 ounce,

Sweet spirits of nitre, . . 2 ounces.

Sirup of garlic, . . . 4 ounces.

Mix. Dose. - One sixth part to be given every night in a pins of thin gruel.

\section{INFIAMMATION OF THE LUNGS.}

\section{PNEUMONIA.}

Mr. Percivall uses the word "pneumony," instead of pneu monia, "to express either a state of congestion or of inflammation in the lungs." The disease may be in the congestive or inflam. matory stages, simple or complicated, involving the bronchia or pleural nembranes, either the one or the other; acute and sub. 
acule are also terms applied to this disease, but these terms have merèly reference to the stage or intensity.

Symptoms of Congestive Pneumonia. - "In the worst cases of this kind, the animal is all over in a tremor; a cold sweat bedews his body; there is no pulse to be felt; his extreme parts botray the coldness of death; his eye is frightfully wild; and, together with the boring of head and stupidity evinced by him, clearly denote the poor sufferer to be labor' cies of delirium. Should this state of congestion come on in the. stable, gradually, and some time after the cause is applied, the horse will show it by appearing dull, listless, heary headed, and off his appetite; his respiration will gradually becone more disturbed and oppressed, indicating much more of labor than of pain. The pulse will be full and quick, but probably so feeble as hardly to be pereeptible. The ear, applied to the chest, de. tects no sound; the usual respiratory murmur is lost. The extremities - the legs and ears - have a cold, death-like feel; and in extreme cases, the mouth is cold also, and the pupils more or less dilated. Cold sweats supervene; no pulse is to be felt ; the animal gradually sinks, and in convulsions and delirium dies."

Symptoms of Inftemmatory Pneumony. _ "The symptoms will be such as are observed at the beginning of common fever and other inflammatory diseases, such as staring, or erection of the Lair, and cold extremities, followed, perhaps, by actual rigor; the horse 'hangs his head' either in or under the manger, and has not eaten his last meal; has had for some days a short, dry cough, which comes on when he is exercised, or after drinking; and is dull and dejected in countenance, and moves with g:eat disinclination. 'To this succerd tever, quickness of pulse, and Leat of mouth, and injection of the membranes of the noss and eyes; and now, in the second stage, the breathing becomes disturbed, and the ease quickly develops itself. The nostrils will be seen opening and shutting their wings; the flanks laboriously working up and down; for the disturbed breathing will be of a kind to indicate embarrassment or oppression, rather than sickness or pain; whereas in subacute cases, the flanks can hardly be seen to move at all; then it is that the nostrils become an important guide to us. The pulse, at the beginning, is ac 
telerated, and commonly distinct; but, as the d.sorder procoeds, it is very apt to grow indistinct from fulness and oppression from which, however, it recovers by loss of blood, and then again becomes perceptible, and often, compared to what it was before. possessed of strength; the ears and legs are colder than ever; the membrane of the nose is moist and reddened, and there is often to be perceived a sparing yellow, slimy issue from one or both nostrils. The horse stands constantly in the same place and posture, often with his fore legs stretched out, and prefers having his head directed either to the door, or to any open window there may be. He never offers to lie down; but from time to time casts a look backwards at his heaving flank, of a peculiar desponding character, which the experienced practitioner does not fail to recognize. The third and last stage is characterized by the respiration becoming quicher and more oppressed; the pulse also quicker, but less distinct; the collness of the extremities continuing unrelieved; the membrane of the nose changing from red to a leaden hue; convulsive twitchings of the muscles of the surface; extreme uneasiness; lying down and rising again ; reeling in his gait; haggard countenance; delirium ; convulsions ; leath." - Hippopathology, vol. ii. p. 79-81.

The causes of this derangement are various: any thing which suppresses the natural evacuations of the system will produce it. Among the chief causes are want of pure air, insuflicient exer eise, exposure to cold, plethora, and uncleanliness. The derangement may, however, be excited by causes varying in their general character. A horse may be driven a long distance after having stood for several days in the stable without proper exer. cise. The lungs are suddenly brought into active operation --a part they are not well calculated to perform after long rest. They, like the muscular or nervous systems, require con tart, yet judicious exercise, in order that they shall maintain their physinlogical relations; and this explains the reason why su many horses are attacked shortly after a smart drive.

Mr. Percivall says, "He that has clean and cool stables will hare a healthy stud, and the converse of this will never fail to engender disease. Above all other considerations, then, in taking the colt from his natural state, it behooves us to guard him fron 
the ricissitudes of cold and heat, and to keep him in an armosphere as pure as that of which we have just deprived him. . Horses of any age, but above all young horses, should never be exposed to a heated air; they may be warmly clothed, and even with advantage be kept in moderately warm stables, but they ought never to respire a hot and stimulating atmosphere.

"The next circumstance to be attended to, in order to preserve the health of a horse recently domesticated, is exercise. Com. pelling the animal at once to perform such exercise as comes under the denomination of work, is merely subjecting him to the invasion of disease, and of disease most proluably of the organs of respiration; hence the old observation, 'A young horse ought never to be sweated in his exercise.' Numberless horses, not only young ones, but of all ages, are, from want of consideration on the part of their owners, killed in this way in the course of a year. A person purchases a young horse of a dealer, who, most likely, has had him for some weeks, during which time the animal has been getting fresh, as the dealers call it; i. e., he has been pampered with all possible care, fed as if he were put up to be fattened for the butcher, and little or not at all exercised: suddenly, the horse, by way of trial, is made to perform by his new master what he calls, and to another would have been, but morlerate work, but what in this case is excessive exertion; and the consequence is, that the animal is attacked with pneumonia, and dies in the course of forty-eight hours. It is of the utmost consequence, therefore, to attend to this circumstance; if the horse be young, we cannot be too gentle with him in regard to his exerase, for at this period he is totally unfit for work.

« . . . Though a horse newly purchased of a dealer is sue whose age indicates that he is able to work, still, in consequence of his having, probably, been kept in a state of inactivity, a proper regimen will be required to put him even in actial condition for hard work. Hunting a horse with others, under such circumstances, is like matehing a man nursed in the lap of indolence, to contend with a pugilist in hard and continual training."

Inflammation of the lungs is generally ushered in with a shiv vring lit, succeedsd by superficial heat of the body and cold ex 
rremities. These symptoms are accompanied by a quick pulse; respiration short, quick, and laborious. The movement at tho flanks, termed abdominal respiration, is marked, generally, by a degree of regularity indicative of the oppressive state of the nrgans of respiration. As the disease progresses, the ears, nose, and legs have an icy coldness; the animal assumes a position that will expand the thorax; the head and neck are extended; nostrils dilated; the fore legs are stiffened and stretched out, and the disease frequently terminates in engorgement of the lungs, and, more frequently in this country than in any ofler, effusion into the thorax.

Mr. Percirall (Lect. xxxviii. p. 323) makes some very inter. esting remarks in connection with pneumonia, which, although intended for the meridian of London, are applicable to this country. He says, "Pulmonary disease runs its course now and then with surprising rapidity. I have known a horse to be attacked with acute pneumonia, and to die from it in the space of seventeen hours ; and it is by no means uncommon for it to prove fatal on the second or third day from its onset. Ignorance of this fact has led to the institution of many lawsuits, and to some गppressive judicial arbitrations for horse dealers; e. g., a gentleman purchases a young horse, warranted sound, and the next day, or the day after, rides or drives the animal, unprepared for fatigue, and consequently unable to bear it, by way of trial; the day following this trial, or rather ordeal, the horse refuses his food, blows a little, and soon after manifests a severe attack of pneumonia, of which, within a few days or weeks from his pur chase, he dies. An action is immediately brought against the dealer. Some blundering, ignorant farrier, on the part of the plaintiff, swears that the animal, when opened, was found 'as rntts: as a pear,' and that he must ccusequently have been dis. eased long before he was bought. The result is, that the dealer is cast, and the gentleman recovers his money. Now, in the generality of these cases, the very reverse of this is the absolute truth; the animal was perfectly sound at the time of purchase, and was made otherwise solely by the exertion his purchaser put him to; and so far from the rottenness of the lungs, or agglutination of them to the sides of the chest. being proots of the contra 
ry, I have seen the one produced in seventeen hours, and know from extensive observation, that the other, viz., blackness and en. gorgement of them with blood, or something like an apprach to mortification, (for rottenness is an expression that has here no definite meaning whatever, may take place in the course of four and twenty hours. Indeed, when pneumonia proves fatal, it most commonly does so in the course of the first three, or four, or Ire days; if it continue beyond this, or there be any remission, it is always a favorable indication. In these cases, the lungs themselves, as I have just stated, are found nearly black, of tho color of the darkest venous blood, with which they are pro. digiously glutted; the pleura also displays a surface highly vascular, and adhesions are occasionally discovered upon it."

'The hot, moist atmosphere, which is to be found in the majority of unventilated stables, prevents the insensible perspiration from being evaporated with that rapidity so necessary for the puritication of the system. The atmosphere may be said to be saturated with moisture, so that the excrementitious materials thrown out from the external surface, instead of finding a ready outlet in space, where they would be soon decomposed and again made fit for respiratory uses, are condensed on the surface, and reabsorbed in their defiling state. It has been discovered by a number of experiments, that when warm-blooded animals are placed in a hot atmosphere, saturated with moisture, the temperature of their bodies is gradually raised $12^{\circ}$ or $13^{\circ}$ above the natural standard, and that the consequence is then inevitably fatal. Let it be understood, then, that no evaporation from the skin can take place when the stable atmosphere is saturated with vapor, and also that if this be the case, the heat of the body increases, rather than decreases a condition which places our patient beyond the reach of the veter irary art. A peculiar feature in the treatment of inflammatory pneumony is, to withdraw heat from the body by evaporation. It is well known that a profuse exhakation from the surface :ulfils all the indicatons that are contemplated in the use of the fleam, and the practice is more rational and less prostrating. A large quantity of solid animal matter, besides other secretions, is carried out of the system by the skin, and the patient is thus relieved. " That which is called the hydropathic system proceeds upon the plan of increasing the cutaneous exhalation to a very large 
smount; and there seems much evidence that certain deleterious matters, the presence of which in the hlood gives rise to varinus diseases, are drawn off from it more speedily and certainly in this way than in any other."

It has been a universal custom to resort to the lancet, in the cure of this disease. From time immmorial, the most talented of the profession have invariably resorted to the fleam, as their in set anchor, in the treatment of this, one of the most destructive ir. the catalugue of veterinary discases. We object to the doples'ry system, for we bave no idea of bleeding a horse to death with a view of saving life. If, as it frequently happens, in this disease the lungs are congested, and the abstraction of blood will promote the free and full circulation of that which remains, then there might be some excuse for bloodletting. It will be urged that horses do get well after being bled; but this is no proof of its utility. On the contrary, it goes to show, as in the case where a horse receives a violent blow on the head, by which the skull is fractured, and he recovers, that his health is restored in spite of the riolence done. Blood is the fuel that keeps the lamp of life hurning; it is the sum of the powers that resist disease. "Without blood there is no heat, no motion in the body ; " its abstraction leaves the various organs less capable of self-defence. But there are other reasons why we olject to the use of the lancet; and the first is, the disease can, if curable, be cured without abstracting blood.

Secondly. In every disease wherein bleeding has been resorted to, complete recovery has been protrated, and the animal manifests the debility by swollen lecos, and other unmistakable evidences of derangement of the normal condition.

Thirdly. Because the letting of blood impoverishes that *hich remains in the system, and leads to other equally danger. ous diseases as the one it was intended to cure.

We are aware that our uncompromising opposition to the use of the lancet, in the treatment of preumonia, will subject us to the sneers of its advocates, who, by the by, are, generally speak ing, a hundred year's behind the age; their dogmas are to them what the laws were to the Merles and Persians. But some consolation is afforded us in the fact that there never was a nen science but was upposed ly some. The scojence that Harvey 
lahored to discover was bitterly opposed, even by profestional men. Galileo, Newton, Franklin, and Fulton -- indeed, a h.sst of men of kindred genius - have been assailed and pronounced th: humbugs of their day. But what care we for censure when ergaged in this glorious work of reform? If we can only arrest the stream of blood that is now, in consequence of an evil system of medication, flowing from the veins of our domestic animals, we thall have dlone a good work; and persecution, from whatever source, only stimulates us to greater exertion. We have but to thank God that we are in enlightened America - among a nati in of scholars, where men delight to honor even a Spurzheim, one whom the nations of the old world denominated a fool. The American people have testified their approbation of his worth by erecting in Mount Auburn Cemetery a monument to his memory. Hence our lot is cast "in pleasant places," and our work is a comparatively light one, to what it would have been in any other country.

Treatment of Inflummation of the Lungs. - Before commencing the treatment of this malady, the horse slould be placed by himself in a shed or barn, where he can breatle an uncontaminated atmosphere; for the author considers it a matter of impossibility to carry a case of inflammatory pneumony to a successful termination in an atmosphere such as we find pervading some of our city stables. In this disease the venous blood is of a black, pitchy character, loaled with carbon, a defiling mass, which requires pure oxygen for its decarbonization, and any thing short of purity is not admissible. No dependence can be placed in remedial agents, or the most consummate skill, unless seer ndel by an amosplere that will decarbonize the blood. Having t?an secured a pure atmosphere, in a situation where the fratient shal fve free from annoynce of every kind, we thus commence $\mathrm{I}_{\mathrm{e}} \mathrm{e}$ reatment: Suppose the bowels to be constipated, oxtremitios cold, respiration laborious, $\& c_{\text {., take }}$

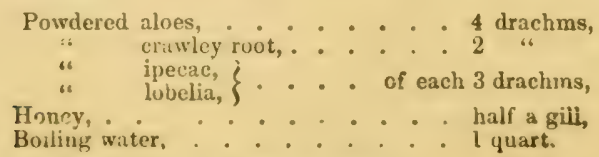

When cool. administer from a bottle. 
Small doses of ipecac and lobelia may be given ver asionally ir. thin gruel, in view of relaxation of the tissues. Injections must also be given.

Many practitioners object to giving fluid in a case of lung fever, for fear it will excite the animal. ILuman practitioners might, with the same propriety, prohibit their fever patients (in. fants) having medicine forced down their throats, for the samo reason; and if they were treated in the same rough mamner $\mathbf{8 3}$ the liorse is, the prohibition would be judicious. To give a horse a ball, under the circumstances, is perfectly absurd; we might just as well substitute a canister shot; for, before the for ner can be digested, the horse is about to kick the bucket.

Having administered the above draught, we next resort to counter irritants. These must be applied particularly to the legrs, with constant hand rubbing, until they are quite warm; then a Hamnel baudage is to be applied to each leg, and the process of rubbing to be again repeated, should they again become cold. Every drop of blood thus invited and retained in the extreme vessels is so much gained towards relieving the congested state of the lungs. Our usual counter irritant is, -

Dissolve the above oils in a wine-glass of alcohol; then add . 2 "

Oil of cedar, . . . . . . . . . . . 4 drachms

'Tr. capsicum, (or hot drops, ) . . . . . . 1 pint.

With a view of promoting the insensible perspiration, the animal should be covered with suitable clothing, not enveloped in a mountain of blankets, or bufialo skins, as we frequently see them; but a single blanket, with flannel leggings, will probably i a all that is needed, even in cold weather. In the hot seasun a liuen covering will be the most suitable. Our only object in clothitry the animal at all, is, to retain the insensible perspiration in the inmediate vicinity of the surface; we then have the mistarials (varmth and moisture) which are generally needed to kse) 》) the relaxation of the capillary and excrementitious vessels of the external surface.

If the discast: is seen and treated according to the above rules. very little else is needed; for, the blood by this means being ecualized, there can be no congestions any where. We haven then only to maintain the equilibrium of the circulation, and the 
cun generally be accomplished by an occasional drink of lobelia and hyssop tea; one ounce of each to a quart of boiling water We use lobelia in the same view that reterinary surgeons use white hellebore, viz., for producing nausea and relaxation. $\mathbf{M r}$ Percivall, when referring (in his Lectures) to the latter article, says, "To describe the operation of hellebore, perhaps I cannot do better than advert for a moment to the use of ipecacuanha, under similar circumstances, in the human subject. That substance is a nauseant, a vomit, and a sudorific, and is highly serviceable in pneumonic affections, from the effects it manifests in lowering vascular action and promoting diaphoresis and expectoration. Much in the same way white hellebore aplears to operate." And so in like manner does lobelia operate. If given to a healthy cow or horse, it nauseates, and induces a profuse flow of saliva, with general relaxation and prostration. In the human r.tject it is superior to all other emetics. It is an excitant of all the secretions, and its efficacy in pulmonary diseases is beyond dispute.

The mild, subacute, inflammatory, and chronic pneumonia may be treated on the general principles here laid down; yot chronic, which may be a continuation of that which was at first inflammatory and dangerous, sometimes requires nothing more in the way of medicine than to lubricate the respiratory passages, which are often left in an irritable state. In such cases we recommend

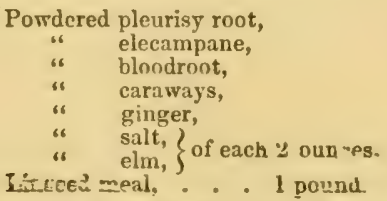

Mix. Divide the mass into sixteen powders, and give one in the food night and morning.

\section{DROPSY OF THE CHEST. - (Hydrothorax.)}

This form of the disease is almost always fatal.

Case of Pnenmonia, terminating in Hydrothorax and Death

- The subjest, a gray mare, six years old, had, just previous to 
the utiuck, fallen into the hands, by purchase, of Mr. B. of this sity. Nothing particular was noticed in her, until the appearanco of febrile symproms. She had gone well - to the satisfaction of her new master. She was in fine spirits, and had a good appetite. On the 17 th of May, she was suddenly taken with a fit of : hir sring. The owner ordered her to be warmly cluthed, and lat a stimulating drench administered. By the aid of blanket, hand :ubbing, and medicine, some improvement apparently tock fllare which, however, was only of short duration. The horsa Was evidently sick, and required professional skill. On the $181 \mathrm{~h}$, at the request of $\mathrm{Mr}$. B., we proceeded to Malden to visit the patient, and found her standing in the stall, looking rather dull. The pulse was over sixty - respiration quick and laborious; the sclerotica, conjunetiva, and nasal membranes were highly injected. The ears, nose, and legs were icy cold, yet the surface generally was hot, and the fore legs, as is usual in such cases, were stiffened out. Tise animal was rather indifferent about food, and had not Iain down for two nights. A strong application, composed of vinegar, mustard, and black pepper, soon had the effect of restor ing heat to the extremities, which were then bandaged. A portion of the mixture was also applied to the chest, in view of cour. ter irritation, and an aperient drench was given. A diet of cut grass and scalded shorts, and warm drinks, was ordered. The disease was treated in the usual manner, and on the tenth day after our first visit, she lay down, and appeared so much improved, that we had hopes of her speedy recovery. She was now permitted to run in an adjoining pasture for two or three hars during the day. In the course of three days, she appeared so much better, that we directed her to be left in the pasture most of the day.

On the 6th of June, Mr. B. called on us, and stated that the mare was not so well. We visited her, and found it to be tho cuse. On leading her out, she was quite unsteady in her gait, und walked with her legs wide apart. There was slight œulema (dropsical swellings) of the breast and belly. The pulse was sixty, although only three days ago it was but forty. The respiration was somewhat distrtissing, apparently performed by the udoominal and intercostal muscles. The respiratory nurmur ov 
the left side was audible; but on the right, there was an absence of all sound. The ribs seemed to be elevated at each inspiration. The animal had a distressing look. The appetite was impaired, and the bowels were constipated; the freces hard and slimy. Effusion had now evidently taken place. We treated the animal in the most judicious manner; at least, to the best of our ability. Counter irritants were applied externally, and aperients, diuretics and alteratives internally. The horse was kept free from excite. mant in the stall, where water and food were brought to her, bu all to no purpose. The symptoms rapidly grew worse. From the 6 th to the $9 \mathrm{th}$ of June, the patient had lost considerable Hom. The bowels had, through the aid of green food and acidulated driuk, been kept in a lax state - a condition very favorable under the eircumstaness. We now determined to try what virtue ther was in tapping the chest: for this purpose we pucked up a foid of the skin covering the intercostal space buhind, and on a level with the point of the ellow. A slight puncture was now made through the skin - then the trocar and canula were pushed through the intercostal muscles and pleura. Through this aperture we caught four and a half gallons of water. A bandages, drawn moderately tight, was wound round the chest, and over this a blanket. After the operation, the respiration appeared mor: trancquil, yet the opreration was of no arail; the mare died ahout thirty-six hours afterwards.

We have had considerable experience in the treatment of hydrothorax, and must confess that it is the most fatal of all chest diseases. Medicines which, under ordinary circumstances, in other diseases of the chest, afford some relief, seem in this diverse to be worse than useless; and if ever we feel disposed to "thr' wi itysic: to the dogs," it is when treating a case of hydrothorsc: $y_{1}$ in duty to our employer, patient, and lastly, for the sake of uur own reputation, we are constrained to use all the mean within our power for the patient's recovery. The majority of botl. human and veterinary practitioners, whose opinions are worth ny thing. all agree that the prognosis of hydrothorax is "gen. erally unfaromable;" that it has seldom been cured, and in many arses will harlly admit even of alleviation. The author of Hip yopathology term the treatment of the disease now under en 
nideration "an affair of desperation," and confesses that bis own practice has proved unsuccessful. "I have frequenfly performed tapping, and as frequently failed in any good result. From an old horse I drew off ten gallons of water- seven quarts from the left side, and thirty-three from the right side. IIe died on th: founth day succeeding the operation, without having been in the luast relieved by the evacuation. After death, six gallons more were found within the chest, and one quart within the pori ianlium."

INFLAMMATION OF THE IUUNGS AND IINING MEMBRANB OF THE CHEST. - (Pleuro-Pneumonia. $)$

The above terms signify a disease of a compound character pleurisy and prieumonia combined. The treatment does not differ from that recommended for pleitrisy and pneumonia, (which see). The disease, however, runs into a state termed typhoid: this is nothing more nor less than an advanced stage of the same disease; the diagnostic symptoms of which are, the nasal membranes have a blue tinge, appearing as if they were glazed over with a coating of lead-colored paint; the breath is very offensive; the throat is somewhat sore, and the glandular structures around are swollen; the patient is in a sinking condition, with no appetite; fuick yet feeble pulse; the urine high-colored and tietid, and the exirement is scanty, voided in round lumps. The borly is trem ulous, and the coat looks as if the horse had been dead for a week or more. In cases of this character, our remedies must be of a kind calculated to stipport the living powers and to arrest desomposition, for which we have never found any thing to equal thes following :-

$$
\begin{aligned}
& \text { Pale brandy, . . . . . . } \frac{1}{2} \text { a pint, } \\
& \text { Tincture of capsicum, . . . . } 1 \text { ounce, } \\
& \text { Table silt. . . . . . . . } 2 \text { ounces, } \\
& \text { Pyroligneous acid, . . . . . ' ounce. }
\end{aligned}
$$

Wlake the mixture until the salt is dissolved; then give a wine glass every hour, as a drench, in a small portion of vatmeal gruel, Salt is a very excellent antimeptic ; portion should now and then be laid on the tongue, or the subject may have an xcasional Irench of ealt and water. 


\section{PLEURIS1. - (Pleuritis.)}

The internal cavity of the cliest and the outer surface of the lung are lined and covered with a highly-organized membrane termed the pleura: here the disease locates itself. In the early stage, the disease is termed acute, and in the latter, chronic. The discase sometimes terminates in suppuration; so that, on examir ing a case after death, shreds and thakes of matter will be found adhering to the pleural membranes. Now and then, the disease terminates in mortification.

"In 1830, a four-year-old horse was discovered at 7 o'cloch in the morning, in his stall, sweating profusely; heaving hard and quick at the flanks, and puffing at an equal rate at the nostrils; pulse but very indistinctly to be felt; mouth hot and climmy; legs intensely cold; head hung down, and countenance betraying serious malady; eyes and nose redlened, and the latter moist with yellowish-bloody matter; breath fetid as well as mouth. When pressed upon the side, he flinched and turned his head, and evinced much soreness. As soon as he was got dry and warm from the cold sweat he was in, he was bled; scarcely, however had two quarts of dark thick blood thowed before he began to reel. The treatment afterwards was such as is ordinarily pursued; but to no purpose. The pain he manifested was extreme. He would rub his nose against the rail across the doorway of the box, thrusting his lips violently against it; his eyes sinking with suf. fering. He was twice seen to lie down, but immediately rose again. Towards the conclusion, a bloody issue appeared at the nose. Before death, he became delirious, and expired in dreadful agony. Water within both sides of the chest - from six to eight quarts; pleura intensely inflamed; costal portion every where most minutely and thickly injected; pulmonary portion, covering the lungs, likewise injected, but it had also become gangrenous it exhibited a green lue; lungs partly tuberculated; otherwise and particularly in the interim, they were sound." - Hippo. pathology.

From the tuberculated state of the lungs, there was, probably mone previous indisposition, which accounts for the rapid course 
of the disease. The author has made several post mortem examinations of pleuritic cases, and has always found the substance of the lungs more or less involved, and a question has arisen in hiq mind whether or not the pleuritic affection was antecedent to the pulmonary Some physicians, and among them Mr. Percivall, doubt if " in flammation is ever fully developed in the pleura withsut extending to the lung, or vice versa. It is not a question I shall trouble myself to solve: all that is necessary for us to know, in my opinion, is the fact, that, when inflammation is invading there parts, it is sufficiently predominant in one to induce us to regard that as the chief or principal seat of disease, and to treat the ase in accordance with such riews; and that it is, comparatively, rarely so equal in its atrack of the two parts as to lead us to believe that one is quite as much the object of our care as the other. There are cases enough of pleuro-pneumonia, perhaps more than of any other description; still I contend, that in almost all of them we shall find either the lungs or the pleura to be the part primarily and principally affected, and as such, as I before observed, to be the especial object of treatment."

Symptoms of Pleurisy. - Like most forms of acute and febrile diseases, pleurisy commences with uneasiness, puffing and blowing, and pain. One feature about this disease, which distinguishes it from all others, is, that the patient is very unwilling to turn in a cir. cular direction; he will turn his head and gaze anxiously at the sides, expressive of pain in that region; but if you attempt to move his body round, he utters something like a grunt, or suppressed groan, indicative of the pain excited by the movement. The surface of the body has a hot, dry feel, showing beyond a doubt that the insensible perspiration is suppressed. Still, how. ever, we must bear in mind that the insensible perspiration may be quit profuse without becoming sensible; for if the atmosphere be warm and dry, and thus able to carry off, in the form of vapor, the fluid which is poured out on the skin, it cannot be perceived, and we may be deceived in our diagnosis.* Every one knowt

- Although no evaporation from the skin can take place when the surround. Ing atmosphere is loaded with vapor, the secretion of the perspiratory glands continu :s; and does so even vhen the skin is immersed in fluid, provided the luid be of high temperature. Hence we see that the conditions uniar which if 
that the drying of a cloth is much more rapidly effected in 8 warm, dry atmosphere, than in a coll. moist one; more quickly; too, in a draught of air, than in a situation where there fs no currtut, and where the air is consequently son charged with moisture. As an illustration, we were once treating a case of pleurisy in an unventilated, darnp stable, and observed that our patient sweated profusely; it was a clear day, the wind westerly, our patient was placed under a shed in the open air: soon, the surface becamo dry and hot; after remaining there for the space of five hours the hair and skin had an unpleasant, feverish feel, although the general feature, aside from this, remained the same. After being led to his old yuarters, the surface soon became moist again. Therefore atmospheric inflnences must always be censidered. The membranes of the eye are generally injected with arterial hlood; the pulse is quick and wiry; mouth hot and dry; a slight lacking cough is sometimes observed, and pressure between the ribs always elicits pain. 'The disease, if not arrested, generally terminates in effusion - dropsy of the chest.

T'reatment. - As in all other inflammatory diseases, the prineipal object will be to equalize the cireulation, thus lessening the determination of blood to the pleura; to effect which, it will be necessary to keep the horse under the exhibition of natuseants lobelia or iprecice. English surgeons use hellebore in this view, but we prefer a compound in the following form:-

is poured forth are peculiar to the living body alone, and entirely different from those under which simple evaporation takes place. The purpose of this watery exhalation, and of its increase under a high temperature, is evidently to kefp the heat of the body as near as possible to a uniform standard. By the erapo ration of thuid from the surfice of the skin, a considerable quantity of heat ia withdrawn from it, becuming latent in the change from fluid to rapor; : $f$ this we make use in applying cooling lotions to inflamed parts. The more rapid the evuporation, the greater is the amount of heat withdrawn in a given time. Hence, if we pour on separate parts a small quantity of ether, alcohol, and water, we shall find that the spot from which the ether is evaporating feels the enldest, and that which is covered by the alcohol less so, whilst the part moistened with water is eomparatively but little chilled. The greater the umount of heat, then, applied to the body, the more fluid is poured out by the perspiratory glands; and as the air can carry it off more readily in proportion to its own heat, the evapuration becomes more rapid, and its cooling ettect цore powerful - Carpenter's Physiology. 


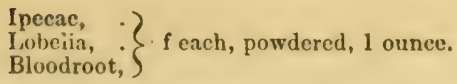

Mix. Divide in six parts, and give one in warm water twice a day

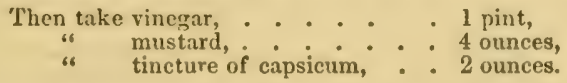

Rub this briskly over the region of the chest, and over all apply flannels wrung out in warm vinegar. Keep the flannel in close contact with the parts by passing a cotton roller several times round the body, which, together with the application, may be discontinued so soon as sufficient counter irritation or soreness is insured. We have found it necessary in some cases to apply the same counter irritant to the fetlocks; it may create great uneasiness, but it is beneficial at times, for we know that every muscular effort of the animal tends to favor the passage of the blood through its capillary floodgates, and tends to the more equal distribution of that fluid. At the same time, we must remember that the foot of a horse, in consequence of its highly-organized arterial and venous structures, is apt to take on a specitic form of inflammation, termed laminitis, on the application of an exciting irritant. And the pleural difficulty, in some cases, may gravitate, by a process termed metastasis, - which implies the shifting of a disease from one part to another, - to the feet, and thus produce a disease almost as difficult to treat as the one now un. der consideration. Therefore due caution must be observed in Irical applications of this character.

To allay pain and calm the nervous irritation, we use

$$
\begin{aligned}
& \left.\begin{array}{c}
\text { Powdered assafetida, } \\
\text { pleurisy root, }
\end{array}\right\} \text { of each } 1 \text { drachm. } \\
& \text { Sirup of garlic, . . . . . } 2 \text { ounces. } \\
& \text { Ihin gruel, . . . . . . } 1 \text { pint. }
\end{aligned}
$$

' 'wo or three doses of this given at intervals of twelve hours will probably suffice.

L. cases where the lungs are involved in the disease - which may be known by the presence of a troublesome cough -- the bllowing drench has been found of great value :-

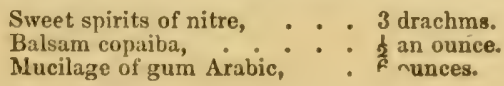

lo be ropeated at discretion 
The state of the bowels must be attended to ; and, although it might not be proper to excite peristaltic action by drastic cathar. tics, yet if the case needs it, we may venture on a mild aperient. such, for example, as the following:-

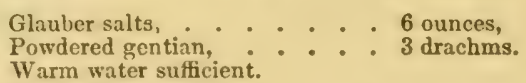

Provided the bowels do not respond at the end of twelve or sixteen hours, the dose may be repeated. In the mean tirz 3 , however, it will be proper to administer injections of sal and water. During the whole stage of the disease, the food must be light, composed of slops, gruel, scalded shorts, or linseed tea.

During a practice of nine years in the city of Boston, we have had but few cases of pure pleurisy; there are cases enough, no doubt, but still other diseases of the respiratory apparatus are more common among the horses of New England. The infrequency of such cases may be accounted for from the fact, we believe, that it often presents itself in a chronic form, and as the subject is not actually incapacitated for work, he goes on, from day to day, until the owner becomes convinced that all is not right, and nct until then does he seck advice; the case has then assumed a complicated form. The following is a case in point. In the month of May, 1853, a dark roan gelding, the property of a gentleman residing at Cambridgeport, was put up at a stable in Roxbury, for sale; the horse remained there about a week; nothing was observed about him that looked like disease, exrept that he breathed "a little short at the flanks." On the $2 d$ day of June, the horse was loaned to a gentleman to drive, with sn understan ling that if the animal suited, the party world purchaje him. IIe was driven but a short distance when it wis discorred that something ailed the horse; the driver noticed that his charge panted hard at the flanks, and required urging to get bim beyond a walk. Ile was put up at the nearest stable, and the next day our attention was called to him. We found the patient with a quick, wiry pulse; skin hot; breath fetid; the flanks heaving; slight cough ; and a discharge of thick, yellow matter, streaked with a dark-colored fluid. He evinced great 
pain when pressure was made on the intercostal spraces. We had him backed out of the stall, but found he moved with great difficulty, and showed evident signs of pain. He grew rapidly worse, and at the end of four days died. The medical treatment was little else than palliative, but it had no sort of eff et on him; effusion had already taken place; two days before he died, the breath became so offensive that it was impossible to en dare it.

We find, on reference to Percivall's Hippopathology, the following passage referring to the forms of pleurisy: "The kinds or forms of pleurisy are two-acute and chronic: one may follow the other; or the chronic kind, as well as the acute, may exist by itself. Although consisting, as far as we know, both in inflammation, they appear quite opposite diseases ; one is full of activity and expression of pain and irritation ; the other comparatively painless, tardy in its progress, and apt to continue many weeks before it will come to any issue."

\section{CONSUMPTION. - (Phthisis.)}

Horses and the human subject are alike liable to this awful malady; in fact, it may be said to spare neither age, sex, profession, nor species; yet there are certain periods in the life of both man and animals when the disease is more likely to make it: appearance. A colt may be the offspring of a mare classed as one of the consumptive diathesis ; the germs of tubercles may ex. ist in the system of the former at birth, yet may not develop such a disease as phthisis, nor unfit the animal for the ordinary busisess of a working horse for many years. Such an animal, if ased at work in the country, where he has the advantage of purn uir, and simple, yet nutritious diet, anci being the property of an individual who practises a judicious system of management, may live to the average age of such description of property. Thero are locations, however, that may be said to be favorable for tho development of consumption, such as low, wet lands, where the humid atmosphere ${ }^{*}$ prevents a full and free evaporation of the

- "It haf been ascertained by experiment that when a warm atroosphere. 
insensible perspiration; such an atmosphere is no less injurious than that of a crowded, unventilated stable. A horse may bo attacked with pueumonia, which may run through its various Btages, and finally end in tubereles, or pulmonary consumption. Perverted nutrition, in a constitution predisposed to the develcpment of this malady, may be equally prolitic with the former; for if the fibrine of the blood be imperferty elatorated, it is lest it to undergo organization ; and, conserfuently, instead of bing sonvertad into living tissue, part of it is deposited as an unorganized mass, resulting in tubercle. In the predisposed, such deposits take place more frequently in the lungs than any other part, and besides imperding the circulation and respination, they produce irritation and inflammation, in the same mamer that other foreign bodies would when imbedled in any of the tissues; to that the issue, although often postponed for several years, is most grenerally fital. Most medical writers agree in the opinion that, when tuberculous matter is once deposited in the lumgrs, there ia no getting rid of it. Mieroscopic: examinations of tubereular matter show that it comsists of half-formed cells, fibres, deen, together with a irranular substince, which seems to be little else than coagulated albumen.

As regarls the existence of tubercles at birth, Mr. Percivall

luaded with dampness, is breathed, there is rather an absorption than an exhalation of anueous vapor; and the same may, probably, take place, in a less de gree, in an ordinary atmosphere, when the body has beren drained of its fluid In this maner, perhaps, we are partly to aceount for the extraordinary ic. :rease in weight which the body undergoes by absurption from the atmosphere, uuder peculiar circumstances.

"That absorption may take place through the lungs is exident also, from be effe s upun the system of certain gises, which act as virulent persons, wen when respired in small proportion. Thus a liral is speedily killed hy breathing atr which contains no more than l-150)th part of sulphuretted hydrugen; and a dog will not live long in an atmosphere eontaining 1-80)(th part of this gas.

"The eflects of carburetted hydrogen are similar; but a larerer proportion is required to destroy lile. Both these gise's are given otf by decomposing ani. mal and veretalie matter, the neirhborhood of which is very injurious to bealth. It is chictly by prerenting the accumulation of such substances tha un efficient draimure lecomes so important a means of preserving health and uromoting life." - Dr Curyenter on sciretion. 
beenis to have some doubts; for, says that writer, "we seen to lack proof of this being the case; whereas we have hasl demon stration enough of horses 'breeding the disease' in their con 3titutions."

The history of pulmonary consumption in the hunnan family a.d):tantiates this opinion ; for men of broad chest and iron constifution have been known to fall vietims to pulmonary discase of this laraster, when we know that the man predisposed, ats it is fermed if the one of narrow elest, spare muscles, tall frame, and slender Lunks. On the same principles we characterize the colt with car row chest, flat sides, long legs, and spare muscles, to be the one most subject to plithisis.

Uur own opinion is, that the evils of domestication have as much, if not more, to do with the development of this form ot pulmonary disease than predisposition. We will introduce to the reader's notice a single illustration of the evils of domestication :-

"When I came to the farm which I now hold by purchase, I found the stables built under large trees, and near a spring of water, with a northern aspect. My horses were soon in poor condition, with long and rough coats, and almost always lax in their bowels, nor could I get them up by extra food or lighter work; but my cows suffered most, for they were always sick. Their milk feil off, and their butter was poor, and of a bad color and taste, and four of them slipped their calves before their time. When the spring came, they lefi their winter quarters in a wore state than I had ever seen them, and two of them died from the scours on going to pasture. (In inquiry, I found that the tenant who had left had always been what the neighbors termed unfor. tunate in his horses and eattle; and from that cause, more than wny other, he had not been able to make both ends meet. Thr truth flathed upon me in an instant, and in a very little timr longer than it has taken me to tell you my story, I had com. menced pulling rown the stable, the unhealthiness of which had heen, I was convinced, the cause of all the evil and all the loss: and it was not more than two days before there was not left on. tone upon another of the whole fabric. I nrw set to wrork and 
erectcd another on higher ground, removed from water, and cleas from the shade of trees, with a south-east aspect, and dry, capa. cious yaud; and from that day I have had neither sickness nos sorrow in my out-door household." - Boston Cultivator.

This is only one among the many evils of domesticated life, and he who would prevent sickness, and thus save himself fron loss and vexation, must know something of the laws of life, and be able to understand how, and by what means, disease and death stride through his flocks and herds.

\section{SYMPTOMS OF PHTHISIS.}

In the early stage of the disease, the hide appears tight about the ribs, and cannot be so easily raised from its subcellular attachments - horsemen often express their idea of this feature in the case by the appellation hidebound. The owner of such an animal may have observed that he sweats under the least exertion, and sometimes coughs, though the cough may be so slight as not to attract notice. This may also apply to his condition, which has in so insidious a manner been falling off that the owner, who may have had the patient continually under his inspection, yet does not actually realize that there has been a gradual wasting of the solids and fluids of the body, which to the man of experience would be very apparent.

As the disease progresses, the respiration becomes somewhat disturbed, and a glance at the flanks shows what is generally termed slight abdominal respiration. The cough, which is generally a short, dry one, has increased. Pressing on the intercostal spaces - between the ribs - gives the animal pain. The pulse is quick and small, and the spirits are occasionally depressed. Sometimes the appetite is good, and the patient eats with considerable relish; at others he seems indifferent to food, but will generally partake of grass if offered to him.

In the latter stages, all the symptoms are aggravated, followed by fetid breath and discharge of bad-looking matter from the nostrils. Dropsical swellings, diarrhcea, and great emaciation terminate the scene. 
We have given the reader merely an outline of the symptoms of this scourge of animated creation; much might be written in detail concerning it, very interesting and instructive to the student of veterinary medicine, yet unprofitable to the practical man, - the man of toil and care, - whose occupation does not admit of so thorough a course of training as that required by the former. It will be noticed, however, in addition to the foregoing eymptoms, that the horse scarcely, if ever, during the latter and indeed it may happen so during the early stage - never lise down; and that the nostrils are always distended, and appesar 'hin around their margins.

Treatment of Consumption. - The main feature in the treatment of the malady contemplates the invigoration of the system, by good, nutritious diet, - including, if possible, green food, gentle exercise, pure air, and if the weather be cold, warm clothing: by the due employment of these means in the early stage, perhaps, many valuable horses might be saved.

As the tubercles seem to be formed at the expense of albumen, such articles should be given as are known to be rich in that material : milk, for example, should be allowed to the amount of a quart per day. It is a well-known and exceedingly interesting fact, that milk affords us the only instance in which nature has provided a single article of food for the support of the animal body; and as it cuntains so large a proportion of albumen, besides oil and sugar, it must be a valuable agent in the treatment of consumption. We know of no better way of strengthening the faith of our readers in this simple, yet sanative agent, than to remark, that all the tissues, organized, and if - there are any unorganized, are formed from the albumen and fibrine of the blood; gelatine may be detected in them, however, yet that nlsc is formed from albumen and fibrine. Gelatine taken ir the form: of jelly, soup or broth, althnugh very useful in the treatment of prostraing diseases, cannot be applied to the nutrition of the albuminous tissues.

"Some experiments have recently been made in Paris on this subject, with a view of determining how far the soup made from crushed bones, which constituted a principal article of iiet in tho bospitals of Paris, was adequate for the support of the patiento 
The result of these has been quite confirmatoly of premivis conclusions, namely, that gelatine may be advantageously mixed with albumen, fibrine, gluten, \&ce, and those other ingiedients which exist in meat, soup, and bread, but that when taken nlone, it has little more power of sustaining life than sugar or atarch possesses."

We know that an animal may be effectually starved to death on sugar or starch; and many articles of diet hitherto con. gillered highly nutritious have failed to support life. - See Lie. lig's Chemistry.

From these and other considerations, which we might urge, milk is superior to every other agent in the treatment of pulmonary consumption. The principal drawback in cases of great prostration, however, is, that the digestive apparatus may be involved in the deterioration of the system, and be unable to digest the fatty constituent, (butter;) hence, in the exhibition of a daily allowance of milk, attention must be paid to the nutritive function, or such a simple article as milk may prove a barrier to our efforts at cure. In a recent case of pulmonary consumption ir. a horse that came under the author's care, one pint of milk, mixed with two ounces of lime water, was given twice a day, with decided benefit; on omitting it for a few days, the horse rapidly grew worse, but seemed to rally in a most surprising manner on resuming the milk treatment. The case was not seen by us until it had become confirmed, or it might, perhaps, have terminated favorably. This, however, may be considered as assuming too much; but we have great confidence in the milk and lime water treatment, aided by whatever medicinal agents the nature of the case seems to require, and therefore recommend our readers to give it a fair trial.

We use lime water in conjunction with milk with the samo view that human physicians have in prescribing phosphate of lime for a "breaking up of the constitution," and lime water is considered very useful for irritable stomach and other maladies of the digestive apparatus.

Proceeding on the dietary principle, with a view of supplying materials to repair the waste of the body, we recommend green regetables, rith the addition of oat-neal, pea-meal, linseed-meal. 
and wheaten flour. A liberal quantity of salt * must be mixed with this description of food, for it not only aidis digestion, but abstrarts fluids from the body, and thus creates a desire for other Ruids. Now, the abstraction of the morbid fluids of the body, and the substitution of water to supply the loss, must be beneficial: for, literally speaking, it cleanses the body by infiltration, the whole body being considered cellular. Aqueous drinks, which include water and hay tea. are rapilly absorbed without undergoing digestion, and are therefore indicated in all cases of diseased lungs, whether salt be used or not.

For the medicinal treatment of this discase we recommend

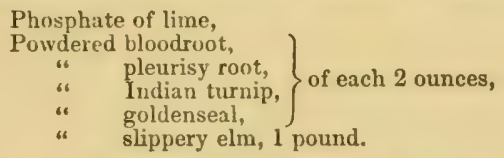

Mix; and divide the mass into twenty-four powders; one to ba given in the food every night.

This compound is best adapted to the disease after it has made some progress; but in the incipient or early stage, and provided the patient be not the subject of debility, the following will be best adapted to the case:-

$\left.\begin{array}{c}\text { Powdered bloodroot, } \\ \text { ". } \\ \text { lobecacuanha, }\end{array}\right\}$ of each 1 ounce.

Mix : divide the mass into twelve parts, and sprinkle one in the food night and morning. These powders may be continued as long as the horse shows signs of strength and spirits; they are calculated to nauseate and debilitate, and no fear need be entertained from the horse showing but slight symptoms of debility or Elıortness of breath, which may follow their use.

During the various stages of the disease, the horse should be necasionally drenched with an infusion of one of the following ı:rticles: liverwort, skunk cabbage, hoarhound, Solomon's seal, or tansy.

Warmth and moisture, in the form of a steam bath, and the

Salt consists of muriatic acid and soda; the former is the essentian ingredient in the gastric juico whilit the latter performs a rery important past in the production of vile. 
eponging of the borly with warm saleratus water, if the weather is not too cold; in either case, dry frictions afterwards will exert a favorable action on the cutaneous exhalants.

Injections of soap and water are to be given should the excre ment be voided with difficulty, or appear knotty.

\section{STRANGLES.}

Strangles may set in from the same causes that induce other cnrarrhal diseases. It is most prevalent in young horses: frum "colthood"* up to the eighth year; after which the disease is somewhat rare. We have seen several well-marked cases occur. ring in Pennsylvania, and in Vermont breeds shortly after their arrival in this city; their ages varying from five to eight years As far as our own experience goes, we have nothing to say as to the extent of its prevalence in colthood, for we do not remember ever having been called to treat such a case; yet there may be a greal number of colts attacked in the course of a year, and get over it; of this we have no means of knowing. We hear, now and then, that such a colt has just recovered from the "horse ail;" but the ambiguousness of the term throws a pall over the nature of the disease, which may, perhaps, be strangles. The disease is, without doubt, one of the evils of domestication, and results from errors in diet, and in the general management, which, if we except a few isolated cases, will bear improvement. If it be a dicense resembling "small-pox, measles, or an eruptive fever occurring but once in the animal's lifetime," - as some writers contend, -then the sooner every horse has it the better, and wi need not trouble ourselves about its causes, for those who have attempted to penetrate the hidden secrets of nature, and bring to light the mystrorious cause of a definite disease, have failed, and thus bud their labor for their pains. But Mr. Percivall sets the matter at rest, for in answer to the question, Do strangles, in any form, secur in all horses? he answers, "No! Many, in my opinion, oseape it." Hence, if many escape, it is very natural for those

- Mr. Percivall, in his Hippopathology, records a case of strangles occurnng m a colt six months old, and also states that Mr. Coward had cbserved the dis case at three months after birth. 
who know the value of pure air, natural food, and exer ise, to conclude that the colt while enjoying these great luxuries by the side of its mother, guided by her superior mind, (instinct, if you please, ) is not liable to be attacked with a disease which, as alrea $l y$ stated, we believe to result from depriving animals of those blessings which nature has in store for them in their unrestrained state. But it often happens that young colts, after running a season with their mother, partaking of the invigorating sountry air, grow up to be strong and robust; and then the period arrives for weaning them. How changed the scene! Instead of being permitted to gambol in their native element, they are confined to a small space, not large enough to swing a cat round, and perhaps as dark as the grave; and the animal, after fretting for a season, and making unsuccessful efforts to escape from its prison house, tamely submits to the discipline, not, lowever, until he has cut, and bruised, and otherwise injured himself. We were called, a short time ago, to visit a young colt that had lacerated his bead, breast, and fore legs in a most shocking manner, in making an attempt to escape through a window from the horrors of confinement. His companions were about a dozen cows, more calculated to alarm and render his position a perilous one than otherwise; and the impure atmosphere, rendered so by the emanations from the excrements, and from the lungs of his companions, was a source of great mischief. Then who can blame such a one for attempting to escape and regain liberty? If strangles should appear in such a subject, it would not be surprising.

Then, again, take a colt from its mother, whose milk contain. all the elements for sustaining life and developing the organizatio: of the young subject, and place it upon a diet of hay or like innu tritious trash, a whole truss of which would not afford one halt the quantity of nutriment contained in a quart of its mother's milk. Inwever profitable and well adapted hay may be for stck of nature growth and powerful digestive organs, it is a sad mistake to suppose that it will do for the young. A case of this kind me under our observation lası ytar. The subject, aged twc 'und a half vears, died in a state of marasmus.* Post mortem 
examination failed to detect any disease other than genernl ematciation. On making inquiries concerning the food, the owner replied, "The colt has been fed on gnod sweet hay and cornstalks ever since it was weaned." This was eapital food for the poor thing, provided, however, its stomach had a grist mill within it ; otherw ise, it was hard fare, and must derange the digestive function, aud ere the colt has attained maturity, dyspepsia, in either a mild or aggravated form, has secured a victim.

The reader will perceive that there is a great difference between a young animal enjoying the privileges of a natural life, partaking of nutrisnental agents adapted to its condition and welfare, and another that shall be shut up in a dark, filthy prison house, perhaps, howerer, he may be permitted the range of the barn fard. which is as bad, if not a worse place, than the barn itself. - and while living in this artificial condition, partaking of food ill adapted to its constitution.

Knowing, then, as we do, that in the difference between a natural and artificial life exist the chief causes of disease, in its diversified forms, then we certainly have just grounds to believe that many young colts reared and fed at a distance have many diseates which the residents of large cities know nothing of, neith as regards the dinease nor the means used to get rid of it. They may have had strangles, yet the owner assures his friends it was only "horse ail" - something which horse dealers suppose every animal is attacked with at sume period of life. Under the :bove abuses, colts are as liable to strangles as a full-grow horse.

The disease is set down by authorities ns non-contagious - not "catching." We have no desire to discuss this question, but leave it for those who, from more extensive experience, are better inalified to judge of the matter. We always take the precaution to separate the patient from healthy animals, and would recom. mend this as a general rule in all catarlat affections. We now come to the symptoms and treatment of strangles, which the fol. lowing case will illustrate: -

The sulject was a gray gelding, aged seven years, the property of Mr. B3., of Buston, which was suffering with an attack of (so alled) lorse ail. The animal had bren off its feed for two or 
three days previous, and appeared dull and unwilling to work: conseguently the owner ordered him to be laid up), and procured unother to do the work. At this stacre our attention was called to lim On applying the finger to the submaxillary artery, (at the angle of the jaw, found the pulse fifty per minute, and strong in character. The respirations were not attended with any peculiarity, being about seventeen; yet we noticed slight abdominal respiration, - commonly denominated heaving-flanks - heaves. The coat looked rough; skin tight; and a hollowness of the flanks, just sufficient to denote debility.

On exploring the throat, a knotty tumor, oceupying the space between the jaws, was found, which appeared hot and tender; the throat also was sore; for the animal was very unwilling to have it handied. The parotid glands - beneath the ear-ap. peared tumefied. The membrane - Schneiderian - of the nose was red-injected; mouth hot; tongue coated with a white fur. and somewhat dry, indicating fever and thirst. On inquiring. was told that the animal coughed occusionully.

T'reatment.--Ordered the animal to be clothed warmly, to bc fed on thin gruel, and the drink to have the chill taken off. Dir? not prescribe any medicine, other than a little sup. tart. pot.cream of tartar, to be given in the drink.*

On visiting the patient next day, March 1, 1851, the tumor under the jaw and surrounding parts had enlarged considerably ; the whole pathological symptoms of the previous day were aug. mented; with the auditional tumefaction of the cheeks and lips, cold extremities, sand constipated bowels.

Treatment. - Ordered the legs to be rubbed and bandaged, the diet to consist of thin gruel acidulated with cream of tartar; and the following mixture to be applied around the jaws and throut : -

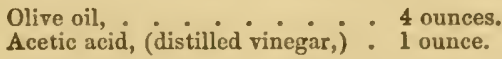

- Horses laboring under febrile symptoms, and having a roated tongue, have not that acute 6ense of taste which we find in healthy ones; hence they will nften drink with avidity what at other times they would refuse to swallow; and tbis is a fort inate circumstance for both doctor and patient ; for tho inrmer ia spared nome truuble, and the latter sume pain and excitement. 
The rectum was relieved of its contents by the following enema

$$
\begin{aligned}
& \text { Powdered aloes, : . : : : } 4 \text { drachms, } \\
& \text { Hot water, } \\
& \text { Common salt, . : : : : : } 1 \text { quarts, } 1 \text { drachm. }
\end{aligned}
$$

March 2. The tumefaction has fearfully increased and spread get is very hard; the animal makes a distressing noise in efforts to breathe; stands in a fixed posture, with the head elevated. a: able to move it.

Treatment. - Prepared a poultice of slippery elm, linseed, lobelia, and poplar bark, which was moistened with water and vinegar, eqqual parts. This was quilted between two pieces of doth, with a view of distributing it over a large surface, and then applied and confined around the throat. The head was also steamed with a mixture consisting of four ounces of tincture of lobelia, and one pint of vinegar, poured upon a red-liot brick held beneath the nose. This appeared to give some relief.

March 3. This morning, the slaver flows out of the swollen mouth, and there is a slight discharge of matter from the nostrils; the animal appears in great agony, and is almost suffocating. On removing the poultice, the tumor appeared very tense, yet soft at a point near the thyroid cartilage: on striking a spring lancet into it, a volume of purulent matter, streaked with blood, issued. ar? . continued to run in a perfect stream; the orifice was afterwards enlarged with a button-pointed bistoury. The quantity of matter discharged was beyond any thing we had ever seen before, amounting to several pints, and, to judge from the collapse of the surrounding parts, must have occupied a large space in the rellular tissue. Relief was immediate, and the poor horse seemer to manifest gratitude by looks and actions not to be mistaken. On offering him a little thin gruel, he drank it greedily, and looked round for more; and no wonder, for during the past thirty-six hours he had not tasted any. thing.

Treutment. - The discharge of the pus was accelerat zd by ap plying a broad bandage drawn moderately tight around the parts The diet to consist of scalded bran and oatmeal.

Visited the patient again in the evenir.g, when the bandage was removed, the parts clesnsed, and afterwards sponged with a cold infusion of bayberry bark - astringent. Gave the following iraught :- 


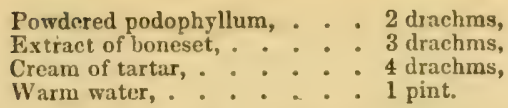

Did not get more thim half of it down, owing to the stiffners of the neck and the unwillingness of the patient to swallow.

March 4. Found the patient greatly improved; appetite fretly good; excretions, dung and urine, seanty, yet natural; lootharge from the throat less copious. The parotid glinds at arge as a man's wrist, also the submaxillary and thyroid glands stili enlarged. Prescribed the following embrocation :-

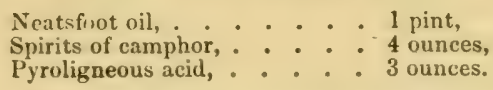

To be applied to the glands night and morning, and one of the following powders to be given in the food at the same time:-

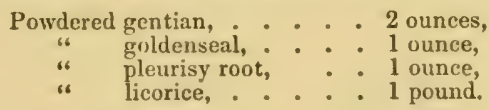

Divided into six parts.

March 7. On leading the patient out of the stall, he appearid somewhat stiff in the limbs. The swelling has all subided, with the exception of the parotid glands, which are quite large. The discharge has almost abated, and the animal appears in good spirits, and has a natural appetite.

From this date the animal was daily exercised, and returned to his usual diet, and in the course of a fortnight was put to work. The parotid glands, however, were enlarged for some weeks after but gradually decreased under the daily application of a stimulating liniment.

\section{Contagiousness of Strangles.}

We learn from the Veteriuarian that M. Reynal, clinical professor at the Alfort School, submits a number of observations corroborative of the contagious character of strangles. He states that "Y'oung horses having strangles, and put into stables with horses of adult age, doing their duty, have communicated the disease to those of the latter who have stood in adjoining stalls, though some few have only exhibited the disease in a catarrabl 
form. Even the foal has been known to suck the disease from its dam.

"Moreover, experiment has been had recourse to, to inoculato for strangles.

"M. Damalix smeared with a sponge impregnated with mat. ter taken from the abscess of strangles, twice daily, both sides of the pituitary membrane and the internal surfaces of the linings of the eyelids, in a sound horse, ahout to be cast for sparin. This was continued for seven days. On the eighth, he remarked, the borse had lost his appetite, had commenced running from ooth nestrils, coughed softly and loosely, had swelling under the jaw, which ended in resolution; all the symptoms terminating eight days from their commencement.

"It has been remarked that strangles is more surely communicated at an early than a late stage, and in a certain form moro readily than in others. Strangles will assume the herpetic character, will simulate farcy and glanders, will settle in the mesenteric glands, or may follow castration. In regard to contagion may be mentioned, as most readily communicable, this form of strangles, which assumes the character of eruptions on the lips, nose, and pituitary membrane."

\section{BRONCHITIS.}

Veterinarians recognize this disease under three aspects, viz.

1. Acute, as when the horse is suddenly attacked with an irritable cough and sore throat, with the usual febrile symptoms, such as yuick, wiry pulse; membranes of the nose and mouth redder than usual; accelesated respiration; great anxiety of countenance, \&c., \&c.

2. C'hronic broncinitis, which sets in after the acute has subeided; this stage is marked by a discharge of watery and some times mucous fluid from the nose; the act of respiration is performed with a sort of wheezing no:se, which is caused by obstruction within the bronchial vessels, either from contraction, by which their calibre is lessened, or else from a thickening of the jning membrane, or, lastly, from the accumulatios of sero nu cons f'nid within their cavities, of which they are somewl.. i ro lieved in the act of coughing. 
3. The third varirty has been named epidemic bronchitis, besuuse lize other epizoötics, it retains its character in every flart of the globe, and appears to maintain its influence in certain lo cations, to the exclusion of other forms of disease. There may, however, be some difference in the severity of the disease at the rommer :ement, height, or decline of the morbid period.

"The epidemic variety," says Percivall, "is remarkable fur tho tmission of copious discharges or fluxes from the nose, at une lime turning yellow, at another green, and then again white. I this form the disorder is exceedingly apt to assume the chronis. type, and, after continuing for a length of time, to leave the animal reduced in Hesh, and much debilitated." There is no doubt in the mind of the author, that many of those cases of abdominal respiration noticed among horses in the New England States, and commonly termed "heares," is the result of bronchitis, which leaves the upper air passages in a contracted state, or else thickens their lining membrane.

Treatment. - Bloorlletting has ever been extolled as one of the main dependences in the cure of bronchitis; but as we bave no faith in the curability of such diseases by the fleam, of course we canno: reconmend the practice to the reader. To equalize the blood so that there shall be no excess in the membranes of the air passages, seems more rational than to abstract it. In view of producing so desirable a result, we use drachm doses of powdered lobelia seeds twice a day. Most veterinarians, however, recommend powdered hellebore, in half drachm doses, twice a day, preceded by free abstractions of bluod. The lobelia is to be continued, together with warmth and moisture to the external surface, until, from the softness of the pulse and moisture on the surface, we are certain that the remedy has taken effect. This is not all that is to be done; for the mucous membranes must be sheathed by lubricants, so as to protect them from the effects of the morbid sccretion continually flowing over their surfaces; and no better or cheaper article than slippery elm can be found. A small portinn of the powdered bark is to be stirred into a given quantity of boiling water, until it forms a mucilage just thick enough for a drink; to a pint of which add two ounces of sirup of garlic to be given twice daily. Counter irritants applied in the vicinity 
of the throat, trachea, and chest, do much good; blisters and setons are highly extulled, but they only torment the patient, and increass the irritability of, not only the parts to which they are applied, but the animal also; and then we cannot regulate their atction so well as we can that of other agents of a more sanative character: for the pain and irritation will sometimes remain a loug time attre their removal. A good effect is generally proJuced from the occasional application of essence of white mustard seed, tinciure of capsicum, and we have witnessed favorable results aftend the use of essence of cedar. When a relaxing effect is desirable - and we do not know but such is always so in bronchitis - the following can be used:-

Vinegar,
Powdered iobelia, : : : 1 pint,

Let the above simmer over a slow fire for a short time, and apply it to the throat two or three times a day. The throat should be encircled with a piece of soft flannel.

The bowels are to be kept loose; not by purgatives, for their action on the digestive surfaces is sure to make matters worse: the patien: must be kept on a sloppy kind of diet, well seasoned with common salt. Fine feed, scalded, and placed before the animal while warm, answers two purposes, viz., that of relaxing the engorged surfaces of the nose and throat firom inhaling the warm vapor, and also has a relaxing effect on the bowels, which are apt to become torpid sometimes, from no other cause than want of exercise. If the patient be carried through the various stages of bronchial difliculty, with an eye single to his comfort and convenience, and proper attention is paid to the wants of nature. the skin kept moist, the bowels loose, the patient having the arlrantages of a pure atmosphere, then the case, if it is a curable one, is sure to te'minate favorably. So long as the patient mani. fests febrile symptoms, the drink should consist of water, acidulated with cream of tartar, and an occasional enema must be administered. In the treatment of bronchitis, whether it be acute, chronic, or epidemic, the patient must be remored from the noxlous eflluvia arising from the bodies and exirements of other snimals, for they are highly deleterious when reintroduced into the living body of an animal which, in consequence of disease, is 
unable to resist their influences. Mr. R. D. Granger has lately written some interesting rmarks on the influence of noxious efluvia in the origin and propagation of epidemic diseases, an extract from which we here introduce. "That the effete matter eliminated from the system is small in amount is no objection to the intensity of its action; for to the physiologist it is well known that a minute quantity of a powerful agent - the putrid matter in. troduced on the point of a needle, in the dissection of the dead -or a single drop of prussic acid placed in the mouth of an animal $\rightarrow$. is sufficient to destroy life. It is in the over-crowded bed rooms, in unrentilated schools, workhouse dormitories, \&c., that this efiete matter taints the air, and, entering the blood, prisons the system."

\section{CATARRH.}

Definition. - A sero-mucous defluxion from, commonly, both nostrils, increased redness of the Schmeiderian membrane, lining the nostrils; oozing of tears from the corners of the eyes; swellings underneath the jaws; snorting; cough, with or without fe. brile disorder. - Percivall.

It is well known that many of the most formidable diseases to which mankind and animals are subject originate in a common cold; hence such a common affection should always receivi our earliest attention, for its treatment is then a very simple atfair : perhaps, if proper attention were paid to the general management of catarrhal subjects, the disease would subside spontaneously ; provided, however, the subject be free from latent disease. But it often happens that catarrh is symptomatic of several other disenses, and then will require a special course of treatment. As regards its spontaneous cure, we may remark, that in our crowded stables such termination may be very rare, for various causes sace in operation to retard rather than favor it. If a horse be in grod flesh, (which generally means a state of plethora,) and kept in a hot stable, catarrh will generally be attended with a cough und quickness of breathing. Now, if the weather is favorable, he may be turned out in the daytime, and partake of green food; when taken up for the night, a bran mash should be given. This shange of air and diet will contribute much towards the cure. 
People generally suppose that cold and exposurc are the sule causes of catarrh; yet it is a well-known fact, that many horses take cold even though they have not, within several days, somo time 3 weeks, been in a situation where cold could be taken after this fashion; in short, have not left their warm, comfortable stables. But we must remember that a high temperature is just as likely to bring on a cold as any other cause, especially wher th ? subject has been liberally fed; and, indeed, veterinary w riter: of the present day teach that catarrh, in general, oftener arisea from heat than cold. But after all, an insalubrious atmosphere may be set down as the chief cause of common colds.

Treatment of common Catarrh. - If the weather be cold, let the animal have comfortable quarters, and a good bed of clean straw. A blanket may be thrown over the body, and the legs should first be well rubbed with a wisp of straw, and then bandaged with Hannel. It has often been remarked, that if a man's feet are cold, his whole system is chilled, and the same may be said of the horse; for, so long as the feet of the latter are cold, we camnot expect to equalize the circulation, or restore the exhalant function. The diet slrould consist of sealded shorts, and these should be given warm, for the steam arising from them aids the nasal discharge, and relaxes local strictures. We have frequently given, with good effect, a quart of linseed tea, sweetened with honey, night and morning. If the throat is sore, a little prowdered bloodroot may be added. The soreness of the throat may be relieved by the following:-

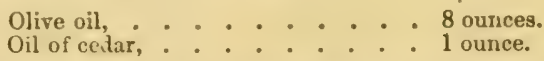

In be rubbed around the parts night and morning. Yet, in alight cases, a simple flannel bandage fastened around the neck might answer the purpose just as well. We frequently employ the following, with a view of regulating the secretions, and lubri cating the mucous surfaces:-

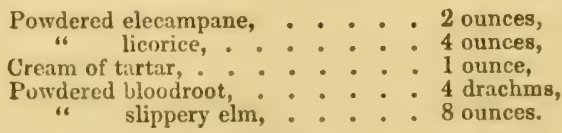

Mix; divi le into eight parts, and give one night and morning. 
Treatment of severe Catarrh.- The same directions as re gards clothing, diet, \&c., just enumerated, apply also to this form of disease - gruel made of Indian meal, to which a few kernels of garlic may be added, and boiled with the same until they are quite soft. A very liberal allowance of this beverage must be got into the horse; if he is not inclined to drink, pour it down his thrat from a bottle, remembering, however, that the parts around the throat are sore, and require you to proceed in the most gentle manner. Be kind to your patient; let him know, by the manner in which you handle him, that your intentions are friendly; but, above all, do not elevate his head higher than necessary, nor pour down the liquor faster than he is able to swallow it. The principal object in the treatment of this form of catarrh is, to restore the function of the skin, which is one of exhalation; and for this purpose we resort to nauseants. The following is the best we know of:-

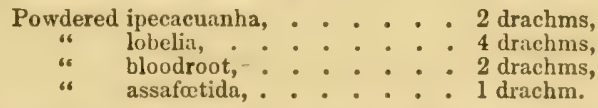

Mix ; divide into four parts, and give one every four hours, in mash or gruel : if administered in gruel, add two ounces of honey, and continue the same until the whole external surface feels warm, which generally happens after the administration of from four to six powders. It is not advisable to continue them too long when the patient is in poor condition, for the medicine is rather prostrating than otherwise. Keep the rectum empty with injections of warm water, into which a small quantity of soft soap mø.y be stirred.

If the discharge from the nostrils is thick and tenacious, steam the head, as recommended in article Strangles. A very trouble. sorne cough may be relieved by adding to the gruel one drachm of fir balsam, or balsam copaiba. If the patient is unwilling to have \& draught administered, and refuses to swallow it, even though he is handled in the most gentle manner, and the cough is sc troublesome that something must be done, then give

Balm of Gilead buds, (chopped fine,j . . . 1 ounce, Powdered skunk cabbage, (ictodes faetid.,) - 3 drachms,

" slippery elm,.. . . . . 3 ounces,

4 lobelia, : : . : : 2 drachms. 
Mix : divide into three powders, and give one in the food, three times, daily. The nasal passages may be kept partially free from accumulations, by blowing into them, from a quill, a portion of the following catarrh snuff:-

$\left.\begin{array}{c}\text { Powdered baylerry bark, } \\ \text { " bloodroot, } \\ \text { lobelia, }\end{array}\right\}$ equal parts.

Catarrh, occurring in any description of live stuck, may l:8 treated on the general principles here alluded to. As regards the proper doses of medicine to be given to animals differing in age, sex, or kind, very little need be said; for the agents are sanative, and a small quantity in addition, or less than the doses here prescribed, as the case may be, is of no material consequence. Aid the vital powers; use agents favorable to physiological action; administer such in small doses, and often; practise good nursing; and disease will, in most cases, terminate favorably.

\section{NASAL GLEET.}

Nasal gleet is considered a chronic affection of the Schneiderian surfaces. The discharge consists of a thick, yellow mucus, and if the animal be at grass, it assumes a green color. At times it becomes purulent, tinged with blood, and if not arrested at this stage, it may finally end in ulceration of the cartilages of the nose: we then have a case of glanders. In the early stage of this complaint, we often have enlargement of the superficial glands under the jaw, and this has led rnany who do not understand the nature of the case to pronounce the subjcct glandered. The discharge is neither persistent nor uniform; for in fine weather it sometimes subsides for several days at a time, and returns after a wet day, if the animal is exposed to the rain or sold; also increasing and decreasing with the fluctuations of the weather.

In ases where the discharge confines itself to the left nostril, becomes tenacious, elastic, and accumulates around the edges of the nasal cavities, and is accompanied by enlargement of the lymphatic submaxillary gland on this side, with a drooping of the ear, we may be prepared for the worst; for ten chances tc one if it does not terminate in glanders. 
Treutment.-- Inject the nasal passages by means of a mid. dling-sizerl syringe, daily, with an infusion of bayberry bark; one ounce of bark to a pint of boiling water; to be set aside until cool, and then strained through fine linen. The constitutional remedies consist of

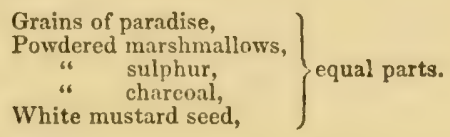

Dose, 1 ounce, daily.

Half an ounce of balsam copaiba, and two drachuns of sweet spirits of nitre, should be given occasionally in thin gruel.

In a case of this kind, good nutritious diet is indicated. The limhs and body must be kept warm, and all exposure avoided.

\section{ROARING.}

Roaring is considered as a symptom of some mechanical ubstruction, or abnormal condition, in or about the upper respiratory passages. "The various collected reports that have been made from time to time on the state of the air passages of roarers, have shown that all of them have produced the etfect in one of three ways, viz., either by contraction of the passage or its orifice; by distortion or deformity of it; or by obstruction within; and this difference of causation, together with the part or place in which it exists, will serve still further to account for the various kinds of, or rather sounds emitted in, roaring."

Roaring is frequently occasioned by a thickening of the mem brane lining the respiratory passages, by which their calibre is diminished. It often follows laryngitis, catarrh, influenza, bronchitis, \&c. It is apt to follow putrid sore throat; at such times we may expect $t$, find ulcerations of the membrane of the larynx, or they may happen to be ulcerated; and if so, there will be a discharge of glairy fluid from one or both nostrils. The thyroid cartilages occasionally become ossified, from the absurd practice of confining a horse's head in an unnatural position, and from pressure by the throat latch, which absurd practice is also apt to 
produce distortion of the larynx or windpipe; the result is ther the same.

Roaring may also be occasioned by pressure on the throat from tumors, \&c., from tonic spasm, and from atrophy of the parts We have always supposed that the seat of roaring was zonfined to the upper respiratory passages; but the following case, related by Mr. Percivall, goes to show that the lungs may be come its seat. "A horse was treated for violent roaring. Tho neck was repeatedly blistered; it was even fired; but still no relief. So painful was it to hear the animal roar, when he was even gently led out of the stable, that bronchotomy was had re. course to, but without avail. At length, seeing the aninal suffered so much pain and distress in breathing, and that the case appeared altogrether insusceptible of being relieved, it was determined to destroy him. On examination, no thickening of the laryngeal or tracheal membrane appeared, nor, in fact, any other disease of those parts; but the lungs were hepatized throughout their substance, and the smaller divisions of the bronchial tubes in many places so compressed that they were hardly pervious."

To prove the nervous origin of roaring, Mr. Field made the following experiment: "IIaving ascertained that the organs of respiration of a horse used for farming purposes were sound, I cast him, and laid bare the recurrent nerve of the off side, and passed a ligature loosely around it; he was then allowed to get up, and, ufter a few minutes, galloped severely without evincing the slightest defect in his breathing. The nerve was then drawn out by the ligature, and one inch and a half of it exrised; and immudiately on only trotting the horse a short distance, such a degree of roaring was oceasioned, that, had the exertion beun usntinued, he would soon have fillen.

"I kept this horse four years, and though his breathing becance auch better, he continued a sad roarer; at the end of that time I destroyed him, for the purpose of procuring the larynx, which exhibited the usual condition of wasted muscles (atrophia) on the side deprived of the influence of the recurrent nerve."

Treatment of Roaring. - The intelligent reader will here per seive, that in the majority of cases very little hopes can be entertained of a cure, and in fict, the defect camnot be cured unless we 
can remove the exciting cause; and that, in cases of distortion, hepatization, \&c., is beyond our art. If the difficulty be at all removable, we know of no better way to accomplish it than by improving the general health of the subject, in the use of proper diet, expectorants, and relaxants; by steaming the nasal pasiages, \&c. If it arise from atropliy of the muscles, let them be stimulated daily with hartshorn liniment, or some such application, und trequent hand rubbing. If from tumors, let them be removed. If the thyroid glands are enlarged, they should be rubbed daily Fith stimulating liniment, or ointment of iodine. The horse el.ould at all times have the free use of his head and neck, or the best treatment might fail. Should the cause of roaring evidently exist (below the fiuces) either in the bronchii, trachea, or lungs, the operation of tracheotomy may be preferred, which consists in making an opening into the trachea, and through it inserting a tube, which may be worn for any length of time, loy taking the precaution to cleanse it occasionally. See Trachentomy.

\section{COMMON COUGH.}

Cough is defined as a sonorous concussion of the thorax, produced by the sudden expulsion of air through the vocal organs. It is present, and often causes some annoyance to the patient, when suffering from catarrh, laryngitis. bronchitis, strangles, horse ail, \&c. Cough is present also in cases of deranged digestive organs, and when a quantity of worms are present in the digestive cavity. We examined a horse once which was the subject of chronic cough from diseased liver. During life the mucous sur. faces were always more or less tinged with bile; le was subject to constipation also. The post mortem revealed a tuberculcus liver. A common cough, therefore, may attend various forms of disease. In many cases of a catarhal character, when a quantity of mucus accumulates in the respiratory passages, the act of coughing ejcuts it, and thus relieves the animal; therefore, a cough of this kind may be salutary rather than otherwise, and in that event needs no treatment.

A sympathetic cough can only be cured by directing our reme. dies to the seat of the malady; that cured, the congh ceases. 
It does not interfere with the treatment of any disease, how ever, to use simple remedies to mitigate a cough which seems sc intense as to cause the patient some annoyance; in this view we resort to

$$
\left.\begin{array}{r}
\text { Powdered slippery elm, } \\
\text { "“ } \\
\text { Indian turnip, } \\
\text { "lecampane, } \\
\text { skunk cabbage, } \\
\text { caraway seeds, }
\end{array}\right\} \text { of each } 4 \text { unces. }
$$

Dose, half an ounce twice a day, in gruel.

A cough may sometimes continue after the disappearance of pulmonary disease, catarh, influenza, \&c. : for this we prescribe

$$
\begin{aligned}
& \text { Balsam of fir, } \\
& \text { Swcet spirits of nitre, : : : } 12 \text { ounce, } \\
& \text { Sirup of garlic, : : : } 4 \text { ounces. }
\end{aligned}
$$

Dissolve the bulsam in the nitre, then add the garlic. Dose, one ounce, night and morning; to be given in mucilage or thin gruel.

For an old chronic cough that seems likely to wear the animal out, and also the patience of its owner, depending perhaps on some organic change, or irritable state of the respiratory surfaces use counter irritation, and give a dose of the following, night and morning :-

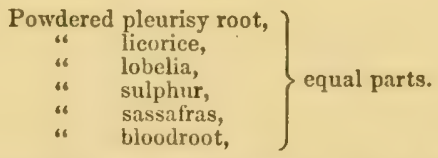

Dose, one ounce, night and morning, for the first two days; then omit the morning dose. To be mixed with the food.

A cough occasioned by derangements of the digestire organs, or from worms, \&c., may be always relieved by the following:-

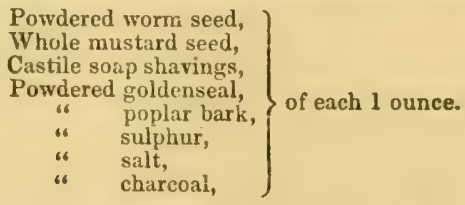

Mix ; and divide the mass into eight parts, and give one every night in the food.

In the treatment of any kind of cough, the horse should be de. prived of his usual amount of water, and be compelled to drink 
some flaxseed or slippery elm tea. If the throat prove sore, bathe it every night with tincture of capsicum.

\section{TRACHEOTOMY.}

This operation consists in making an opening into the windpipe to admit air to the lungs, when the natural passage is obstructed by foreign bodies, or when its calibre is lessened by tumefaction occasioned by disense. In severe cases of laryngiti, strangies, and their kindred diseases, when the patient seems almost suffircated, tracheotomy should be immediately performed. In performing the operation, we select a spot about six inches below the throat, in front of the neck, and over the region of the windpipe; an incision is to be made with a common penknife, (in lieu of a better instrument,) to the extent of two or three inches, in a downward direction, so as to lay bare the trachea; having exposed space sufficient, a circular piece between two rings, corresponding to the size of the tube, is to be cut out, and a short tube inserted, which can be confined in position by means of tape passed around the neck. When the obstruction is removed, or the fauces restored to their natural state, remove the tube, bring the edges of the integuments together, and sew them up.

\section{BLEEDING FROM THE NOSE.-(Epistaxis.)}

Common hemorrhage from the nose is not of itself dangerous, for we never knew, nor do we ever remem.ber hearing, of its being fatal; it merely indicates a congestive state of the nasal, and sometimes the cerebral membranes, or blood ressels; as a symptom, therefore, which it really is, of local congestion, it informs us that there is an unequal distribution of the circulating fluid, or else the patient is plethoric. In either case the trentment is simple: we merely cool the head, warm the limbs, give a dose or two of laxative medicine, exercise the patient, and regulate the diet according to circumstances. When the blood appears frothy and of a dirty color, issuing from one nostril only, the breath being fetid, the respirations somewhat hurried, attended by cough, the owner had better consult a veterinary surgeon for the horse is proatly, or will be, the sulject of glanders 


\section{HEAVES, OR BROKEN WIND.}

Chronic heaves is that condition of a horse which veteritarians designate as broken wind. In cases of this character, the act of inspiration is followed by a violent heaving motion of the ribs and danks; this is the source, probably from whence the term heaven is terived.

The disease bears some resemblance to asthma in the hunan sabject, for in each there is nearly the same difficulty in respiration, attended with dyspepsia and emaciation; there is this difference, howrver - in man there are remissions; while in the horse with confirmed heares (broken wind) there is scarcely any cessation. It is quite common, in Massachusetts, to hear horsemen define every case of abdominal respiration as heaves: such are not to be considered, however, as so many cases of broken wind In order to make out a pure case of the latter, we must have a kind of jerking double flank movement in the jrocess of expiration. Distention of the lungs, or ins piration, must also be followed by a corresponding expransion of the chest and tamks. A slight cough is generally present, which has a wheezing sound, sometimes resembling a sort of grunt, and the subject is a confirmed dyspeptic having a voracious appetite, sturing coat, large belly (tympanic), spare muscles, dull miserable look, drooping head, unwilling to travel fist, and when urged to do so, becomes soon exhausted and "used up ;" the excretions also indicate derangement of the digestive organs. These are the principal symptoms of broken wind, and we have generally found these present iu what is called "heaves."

Regarding the nature of broken wind - which, howerer, is a very funny name for a pathological condition of this character-It originates in disease occurring either in the organs of digestion or of respiration; the former affecting the latter, through the sympathy that is known to exist between them, or else from innutrition - the digestive organs failing to furnish the proper amount of nutrimental matter to supply the respiratory apparatus with its required fuel. The lungs, or rather its air cells, are then dilate 1 , while the respiratory passages and lining membranes ar 
contracted or lesseued in calibre, either from contraction of their tubes or thickening of their lining membranes; and this state of the parts is all that we require to explain the peculiar phenomena of abdominal respiration.

Yet there are various states and conditions of the respiratory apparatus which may give rise to broken wind; in fact, any organic change that permits dilatation of the air cells and bronShial tubes, without a correspouding enlargement of the upper air passages, they retaining their original size, may result in broken wind. In some cases the lungs are emphysematosetheir substance inflated with the gases of the body, without perceptible rupture of parenchyma; a state resembling that known as pneumatosis, a collection of air under the cellular tissue of the skin; they are then specifically lighter, and larger, than their natural state. In such cases we often find the diaphragm in a state of atrophy, pale and atteunated, from over-distention and extra work. The direct causes of heaves or broken wind are over-exertion and indigestion.

Treatment. - The object is to improve the patient's health; and if we can do this successfully, an improvement in a curable case generally follows. We must restore digestion in order to cure indigestion, and in this view we give aromatic tonies; the following we have used with considerable success:-

Tincture of aromatic sulphuric acid.

Writteu for, by physicians, thus :-

R Tr. acid sulph. aro.

Dose, une drachm in a pint of water, night and morning. Most animals, however, will drink it from a bucket. In the mean time we put the animal on a course of the following alterative mediciue: Powdered ginger, gentian, sulphur, salt, cream of tartar, charcoal, licorice, elecampane, caraway seeds, and balm of (iilead buds (chopped fine), equal parts. Dose, one ounce every night in the food.

Changres in diet, exercise, aud management, calculated to fulfil the indications allurled to above, are indispeusable. So soon as cousiderable improvement is perceptible, the aromatic tincture 
should be omitted; and, instead of giving one ounce of the alter ative as a lose, give half an ounce night and morning. A broken winded horse should always be watered from a bucket, regularly three times a day; and if he be a foul feeder, arm him with a muzzle, and only remove it at meal time. In addition to the above remedies, we occasionally allow a small quantity of garlic, say a couple of heads every other day, chopped fine, and mixed in the food.

\section{EXPLANATION OF CUT. - MALE ORGANS.}

1 Posterior vena cava.

2 Posterior aorta.

3 Supra renal capsiles.

4 Kidneys.

5. Ureters.

6. Bladder.

7. The bladder laid open to show its muevas cuat.

8. Vesiculie seminales, or seed receptacles.

9. Prostate glands.

10. Vasa deferentia; these transmit the semen to its receptacles.

11. Epididymis.

12. Testicle.

13. Tunica vaginalis, or covering of the testicle.

14. Spermatic arteries and reins.

15. Corpora cavernosa, or body of the penis.

16. Urethra.

17. Glans penis, or head.

18. Orifice of the urethra.

19. External tunic of the penis.

\section{DISEASES OF THE URINARY ORGANS.}

\section{INFLAMMATION CF THE KIDNEYS. - (Nephritis.}

In the horse the kidneys are considered the great emuncturies, their office being to carry off a large amount of superfluous $\mathrm{ex}$ crementitious fluid. If any one will examine the urine of an nninal that is allowed an unlimited quantity of hay and grain, he will find the urine thick, ropy, and of a bad odor. This is most 
TAE MODERN HORSE DOCTOR.

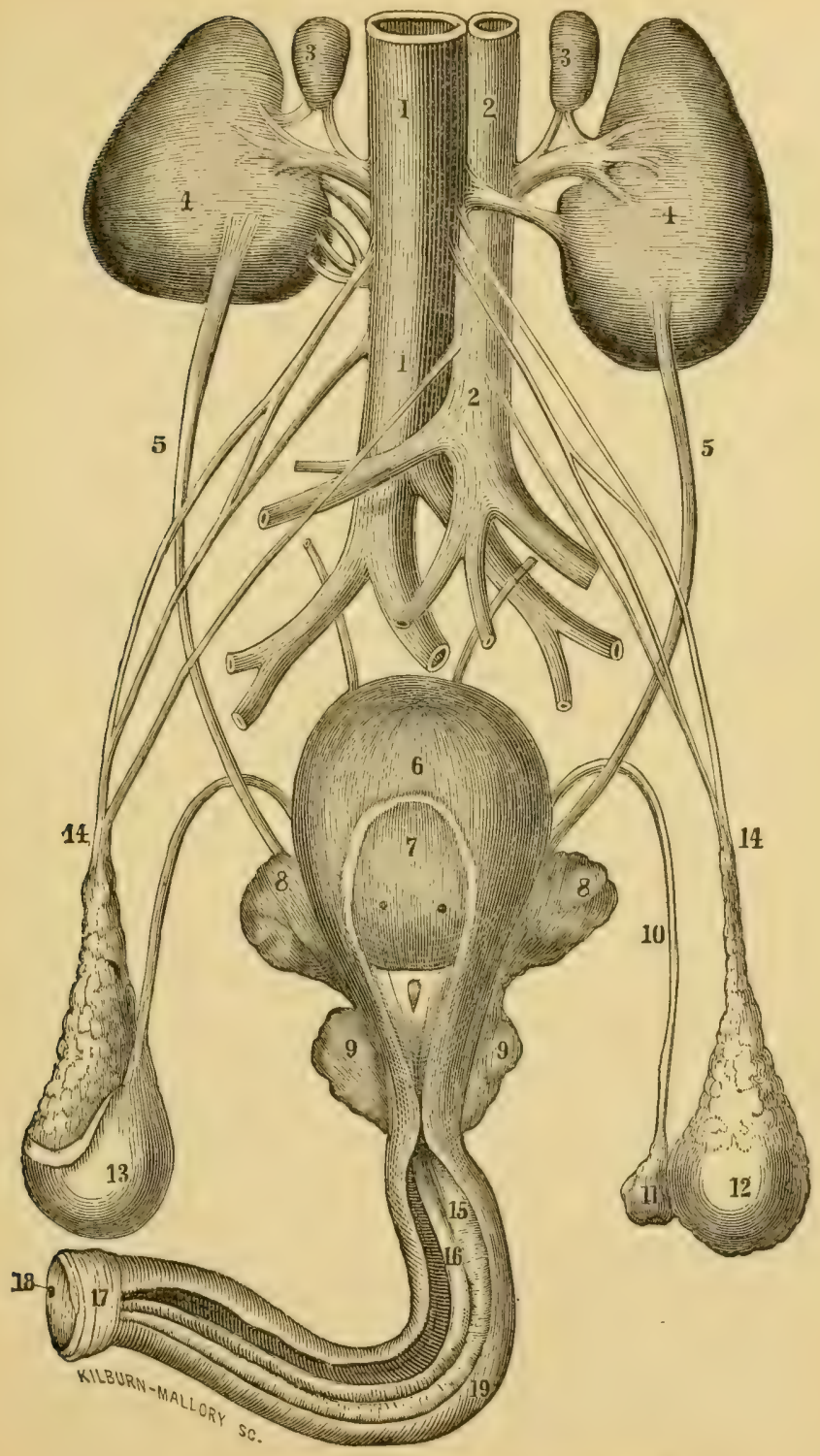

MALE ORGANS OF GENERATION. 
likely, howerer, to happen when the animal is not regularly worked. It is very natural to suppose that urine of this kind, abounding in morbific materials, should irritate the membranes lining the urinary organs, and result in a high grade of inflammatory action. Yet the disease may arise from other causes. We have known it produced by repeated doses of gin and saleratus, and spirits of turpentine; but generally, these agents involve the ureters and bladder in the inflammatory diathesis. It has gensrally been considered that the disease is often brought about by over-exertion, either in drawing heary loads, or in holding back (shaft horses) on going down hill; in fact, immoderate work of any kind might result in a disease of this character.

Symptoms. - A constant desire to void urine, although only passed in small quantities, high colored, and sometimes tinged with blood, though more generally quite natural. There is usually a peculiar stiffness in the hind extremities, especially when the horse is made to describe a circle. Pressure on the loing elicits symptoms of pain, and the pulse and respirations denote febrile symptoms.

Treatment. - Apply a cold water bandage to the loins, and administer á drench composed of

Linsecd oil, Mucilage of slippery elm, : : : : \}pint of each.

Enemas of warm water should be given daily. The less luid the animal drinks, the better; and the best drink, under the circumstances, is flaxseed tea. Should the horse refuse to partake of it, a sloppy mess, made of oatmeal and boiling water, will answer and he will probably prefer it to the former. In a few cases, which were considered of recent origin, we have preseribed a solution of muriate of iron, in doses of two fluid drachms, twict? - Aav, and we have reason to think that the remedy did srame good. The article should be turned into pure water, and offeres? so the patient in a bucket. This preparation of iron is a valuablo wnic, and in chronic cases will generally prove serviceable. In the acute stage, and after the bowels have responded to somo mild cathartic, either linseed oil, Glauber salts, or a decortion of marshmallows will have a beneficial effect. The decoction is thus prepared Take of marshmallow roots, dried and bruised. 
eigit ounces, water three quarts; boil down to two quarts. Whe cool, strain, and give a pint every six hours, until the lorse is relieved.

This simple treatment, aided by a light diet and rest, wi'l generally effect a cure. If, however, the disease arises from concretions within the cavity of the kidneys, the case will require the aid of a skilful veterinary surgeon.

The author has noticed in stables celebrated for the number of horges with a stiff, straddling gait, laboring under an attack of aute or chronic form of nephritis, that there is, generally, a bountiful supply of rosin on hand, and on several occasions has learned that the parties having charge of the animals are much in favor of diuretic medicine, and think it absolutely necessary to give a dose now and then. This haphazard dosing is no doubt the cause of the mischief; for diuretics, which generally act with extraordinary power on the horse, diverting the excrementitious fluids from the skin and lungs, are apt to produce inflammation, and thus induce chronic disease of the kidneys. Many horses that can rearlily be found suffering from what their owners term strain of the loins, are, no doubt, so many cases of chronic disease of these organs.

On chronic disease of the kidneys, Mr. Percivall writes, "I am inclined to think that nephritis, in a mild or subacute form, exists in many instances, wherein, from the trifling perceptible alterations induced by it in the ordinary health of the animal, we are apt either altogether to overlook the disorder, or else to re. gard it as too unimportant to notice. Horses are often broughı to us with complaints of pain and difficulty in staling - of the urire they pass being thick, foul, or bloody ; and which horses prisably may, on inquiry, be found to show some stiffress about the loins when first brought from the stable, though by use the parts soon griw pliant again. And yet in a general way they exhibit every sign of health. With these facts we may connect the circumstance of occasionally discovering, in horses which have died from other causes, purulent matter within the kidneys, and now and then disorganization of their substance, and without any thing having occurred during life to direct our attenticn tc those organs." 
As it is a common custom to administer diuretics to horgen when the urine does not appear just about right, it may be well for us to notice some of its variations :-

" 1 . In respect to age. In the foetus it is inorlorous, insipid, and almost aqueous; but as the young grow, it becomes more acrid and fotid, and in old age more particularly so.

"2. In respect to drink. The urine is secreted in greater quan tity, and of a more pale color, from cold and copious draughts.

" 3 . In respect to food. From eating the heads ct asparagus or olives, it contracts a peculiar smell; from the fruit of tho opuntia it becomes red; and from fasting, turbid.

"4. In respect to medicines. From the exhibition of rhuharb root it becomes yellow ; from cassia purple-green; and from turpentine it acquires a violet color.

" 5 . In respect to the time of year. In the winter the urine is more copious and aqueous; but in the summer, from the increased transpiration of the skin, it is more sparing, highly colored, and so acrid that it sometimes occasions strangury. The climate induces the same difference.

"6. In respect to muscular action of the body. The urine is secreted more sparingly, and concentrated by motion; and is more copiously diluted and rendered crude by rest."

From the above remarks, which to some extent apply to horses, and from the result of experiments made on horses, we learn that the urine is subject to great variations; and therefore, should it not appear natural, diuretics are not always indicated.

It is generally supposed that diuretics act on the kidneys in a much shorter time than other classes of medicines do on vario'x other parts of the animal economy. Magendie explains this on the principle that diuretics, in the fluid form, "are directly absorbed by the veins, and transported by them to the liver and Leart, so that the direction which these liquids follow, in order to reach the bladder, is much shorter than is generally admitted, viz., by the lymphatic vessels, the mesenteric glands, and the thoracic duct." Wo have said that simple treatment, light diet, and rest will generally effect a cure of nephritis; we must, however, have a curable case, and be permitted to attend to it in the zarly stage, for cases of this kind sometimes terminate in degen 
eration of the kidney, and result in death. A case of softening of the kidney has been communicated to the Veterina"ian, by $\mathbf{M r}$ Cartwright, who observes, "Each kidney was found to be in a romplete state of putrefaction, of a !ight bluish rolor; its texture so totally destroyed that the finger would pass through any part of $i$ t as through so much mud. The vessels of the kidneys did ucit appear diseased as I diew them out of the diseased masses."

Diseased kidneys are apt to terminate in abscess, mortification, bypertrophy, condensation, induration, \&c. Such cases are apt, however, to baflls the best medical skill. For information on these terminations of nephritis, consult Hippopathology, $D^{\prime} \mathbf{A r}$. boval, and the Veterinarian.

\section{BLOOIY URINE. - (Humaturia.)}

The voiding of blood with urine is generally indicative of as injury sustained by some portion of the urinary organs, either by falls, blows, bruises, or strains. It may, however, arise from in. juries directly inflicted on the tissues by urinary calculi, \&c.

A discharge of blood with urine is generally attended with acute pain, evinced by the peculiar motions of the animal, whick are readily recognized.

The voiding of such urine is often attended with danger especially when mixed with matter of a purulent character.

In some of the diseases of horses and cattle, manifesting a pu trid type, the urine is of a color resembling blood; such general ly terminate fatally. Now and then cows void very high-colored urine. It is considered, generally, a disease, and receives the appellation of red water, although in many cases it is a link in a chain of symptoms, which, if carefully traced, will be found to be connected with a disease of gastric origin.

If a horse voids pure blood, it may be known by inspecting the urine; some of it should be caught and examined, if found to contain small coagula, it may be pronounced bloodyurine; otherwise we must not be too hasty in our opinion; for at high state of inflammatory action pervading the urinary apparatus - the liver, \&.c., give rise to discharge of urine very much resembling blovdy. When the trouble can satisfictorily be traced to a blow 
strain, over-exertion, or whatever cause it may be, our treatmen is somewhat similar to that for inflummation of the bladder and kidneys. When owing to calculi being present in the ureters or Isewhere, our remedies must be palliative; mucilaginous driuks, enemas, warm or cold water bandages to the loins, rest, and an occasional aperient, if necessary, to clear out the bowels, are among the most rational means in use. To relieve pain, if it be very acute, let the patient be drenched with

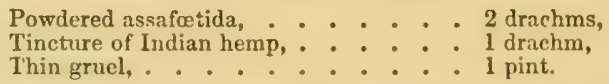

Mix, and administer from a bottle, once or twice, daily, as the urgency of the case demands.

The symptoms usually noticed by the attendant, in cases of hematuria caused by the presence of urinary calculi, are, that the patient appears dull, very uneasy, frequently lying dowu and getting up again. Urinary calculi can only be removed by a skilful veterinary surgeon.

\section{THICK (ALBUMINOUS) URINE.}

Those who have the care of horses frequently romplain that their charges pass "thich, ropy" urine; and, in order to remedy the supposed evil, they too frequently resort to strong diuretics, and in nine cases out of ten they do more harm than good. Thick urine is at times an evil that only exists in the imagination of the groom; for horses that are over-fed, or eren fed on grain of an inferior quality, are often known to pass albuminous, at least thick, ropy urine, and in the course of a few days it again uss:umes its natural properties. There can be no need of diuretics in such cases. It does not follow that becallse a horse pasees "thick" urine, his urinary organs are diseased; far from it. The chemico-vital powers of digestion cannot always control the heterogeneous aflinities that exist between the varions agents known as fodder, foul bedding, \&c.; consequently they often ferment or decompose, and thus give rise to noxious compounds, which must be eliminated or the animal would soon fall sick.

When a plethoric horse has copious sediments in the urine 
we may corsider that it is a favorable omen, and that the tissuer Hre relieving themselves of useless matter.

Albumen is generally presem in the urine in many dis sases of an acute character, such as inflamnation of the lungs, pleuran lirer, peritoneum, and heart, and hence can only, under the circumstances, be considered as a symptom, rather than a disorder of itself, and a favorable symptom, ton; for Dr. Bird has allincta eribunce to show that in many disorders there is a steady and colividerable increase in the quantity of solid excreta whenever the patient improved, and as remarkable a diminution when the symptoms relapsed.*

It is a well-established fact, however, that in cases of diseased kidney, termed Bright's disease, the urine becomes albuminous, but so far as our observation goes, the disease so prevalent in the human family is very rare in the horse. Should any disease of these organs exist, it may be known by the straddling gait, and other symptoms enumerated under the head of Inflam. mation of the Kidneys.

The urine, at times, has a thick, gelatinous, straw-colored appearance, containing a large amount of excrementitious material; this is not to be confounded with albuminous urine, for horses very frequently pass very thick, and to all appearances morbid urine, especially when fed high and worked but little. The urine of this kind can always be improved by proper attention to the horse's management. Albuminous urine is known by being of bright-yellow color, of the consistence of jelly, and can be lifted from the floor between the fingers, in the form of shreds or strings.

Should the owner of the horse feel desirous of doing somen thing to liquefy the urine, and give it a more nat xral appearance, - although we do not think that the lorse, in all casus, would be benefited thereby, - he may give the followirg:-

$$
\begin{gathered}
\text { Prwdered assafotida, } \\
\text { " } \quad \text { poplar bark, } \\
\text { juniper berries, }
\end{gathered}
$$

Mix; and divide the mass into eight parts, and give one night and morning, in the food. 
It may be: proper, in all cases where the horse passes, for any length of time, urine that appears to be albuminous, for the own. er to consult a veterinary surgeon.

\section{CAUSES OF ALBUMINOUS URINE.}

"M. Ed. Robin lately read a paper on the above sut ject beforo the Academy of Medicine of Paris. We subjoin an abstract of the same: In the normal state the albumen is burnt in the blood, and the nitrogenized residue of this combustion, viz., urea and uric a id, is eliminated by the urine. The combustion is, however, not so complete as not to allow some little albumen to escupe with the renal secretion; but this albumen, besides being very small in amount, is somewhat different from the ordinary kind. M. Robin thinks that if during a sufficiently long time the albumen underwent in the circulation a much smaller amount of combustion than is habitually the case, it might pass unaltered into the urine, instead of being thrown off in the form of urea and uric acid. The author cites the following facts in support of his opinion:-

"The urine becomes albuminous in croup, in complete ascites, and in cases of capillary bronchitis, with empliysema, accom. panied by much dyspnoa; in pulmonary phthisis, especially when complicated by pneumonia and marked with difficult breathing; in gestation, when sufficiently advanced to occasion an habitual congestion of the kidneys, owing to an impeded abdominal circu lation; and in such states of the system in which a very incom. plete respiration causes a marked diminution of combustion. The urine is also albuminous in cyanosis of whichever nature it may be; in affections of the heart, when they exist in such a degree as to keep the patient in a state of semi-aspliyxia; and, of course, in such cases where an obstacle to the circulation of the blocd, or a malformation of the heart, prevents the hamato. ais from boing as rapid as under ordinary cireumstances. The urine is likewise albuminous in idiopathic or traumatic lesions of the nervons centres, which cause a lowering of temperature, and thereby a marked decrease of combustion; in diabetes, a disease where very often a lesion of the nervous centre seems to be the 
origo mali; where the great abundance of sugar in the blond seems to be an obstacle to the combustion of albumen; and where, finally, the natural heat is lowered by one or two degreen with patients who are severely affected. The urine is albumi. nous in that kind of nervous exhaustion which characterizes the state of frame called lumbago, which exhaustion must be con. nectcd witls a great diminution of calorification and slow combustion. The urine is likewise albuminous in consequence of severe exposure to cold of a large surface of the body. Finally, Bright's disease, where the urine is always albuminous and anamic, is especially attributed to many of the causes which have been above enumerated as capable of exciting the passage of albumen into the urine.

"The author continues by stating that some useful data may be obtained from comparative physiology. As a general rule, the urine of the common mammalia and of birds contains no albumen. Among reptiles, on the other hand, the batrachia, so remarkable for the low temperature of their animal heat, yield urine in which albumen is always to be found. It now remains to be proved, says M. Robin, that the urine becomes albuminous under the influence of such agents as interfere in a marked degree with slow combustion. The author then adduces the following conclusions : -

"When the activity of the combustion which takes place in the blood is too feeble to burn the whole of the albumen which, in the normal state, should be consumed in a given time, the general vitality is diminished, and thus more or less albumen is allowed to pass unaltered into the urine, viz., just so much organic matter as escapes the transformation into urea or uric acid. The proportion of urea contained in albuminous urine should, therefore, be smaller than it is found in normal urine, and such is found to be the case in the following diseases, the only ones, according to the author, in which experiments have been inade, viz., pulmonary phthisis, diseases of cerebro-spinal axis, ex tensive and acute bronchitis, with intense dyspnœa, and Bright's disesse." - Percivall. 


\section{PROFUSE STALING.-(Diabetes insipidus.)}

Profuse staling - when there is an immoderate flow of urine of its usual color and odor - is technically named diabetes insipidus; but we doubt very much if it can with propriety be sonsidered as a disease, for mere angmentation of urine can be: brought about at pleasure; we have only to give the animul a dose of gin, juniper, or sweet spirits of nitre, or let him drink large quantities of water, as animals sometimes will when thirsty, snd then let the subject stand in a cold place; an immoderate flow of urine generally follows.

On p. 345 of Hippopathology, we read that "simple aug. mentation of urinary discharges, without any material change in the composition of the urine, is the effect of a multitude of causes, some of an alimentary, others of a medicinal, and others again of a nervous nature, and, when but temporary, cannot be viewed in the light of disease. Every horseman knows how very often certain kinds of hay and corn cause horses to stale more than they ought to do, and that drinking a large quantity even of plain wator will produce the same result. Medicines called urine bulls, or diuretics, are given for the especial purpose of increasing the urine. But nervousness will likewise do it; fright, or anxiety of almost any kind, will make a horse stale inordinately; how frequently do we see hunters at the covert side, when the hounds are about "finding," staling or continually stretching themselves out to do so; and I have seen horses having wounds conımence staling the moment the twitch was put on, from the remembrance that it was the prelude to some painful cutting or dressing they had undergone before."

The horse has four depuratory surfaces, viz., the skin, lungs, digestive surface, and kidneys; in health, and under favorablo eircumstances, there is an equilibrium of action in these parts, that is, a constant exercise of function, eliminating from the common mass of the fluids, such as would be injurious if retained. But exposed as horses are to sudden atmospheric changes, the harmony between the above functions is disturbed so as to produce essential changes in quality as well as quantity of the tuid 
eliminated. Diminution in function, ol suppressel cutaneous exhalation, excites instinctive movements in the tissues of kindred functions, and thus the discharge from the kidneys may he very large.

This author has long since, and continues, to discountenance nny unnecessary medication, believing that it is the duty of every physician to know when to do nothing - "let well alone." In a case of this character, when it has only existed for a short time, and there be no perceptible alteration in the health of the animal, medicine is actually unnecessary.

Strict attention, however, should be paid to stable management; if the animal is located in a stable or barn, the temperature of whish is much below that of the body, ${ }^{*}$ let him be removed to a warmer place, and clothed with a blanket, if necessary; the more fuid we draw from the surface, the less will there be left for the kidneys to eliminate; and this cannot be accomplished without heat.

Attention must also be given to the quality of the food, and water; the former must be of the best kind, and the latter pure and fiesh. Changes in the kind of food will often be of benefit

\section{INFLAMMATION OF THE BLADDER. - (Cystites.)}

Inflammation of the bladder is not in all cases to be considered as a primary disease, but arises in consequence of disease in the adjacent parts, or from calculi within its cavity. The urine mar

* "Every impression of cold admitted to the surface below the point of temperature that the subject has been accustomed to, instantly withdraw from the body a just proportion of its ealoric; and as this is taken away, so in proportion there is an assault made on the regularity of the functional exercise: although it may not amount to disease, yet the system is more exposed to other hurtful ugents.

"The effect of incompatible degrees of cold is to condense and contract the dermoid tissue, to embarrass the exhalations on the surface. When incompatihe degrees of cold are often reapplied, and followed suddenly by heat, the tissues acquire an increase of sensibility, by which they are more likely to be acted on by a subsequent exposure, and indeed to other exciting causes. Hence arises a state of predisposition, and cold in this instance becomes merely a remote cause of discase. But remate causes rarely produce active disease with. out some exciting za'se, and on a repetition of the exposure to old, it may vecome the exciting cause." - Gallup. 


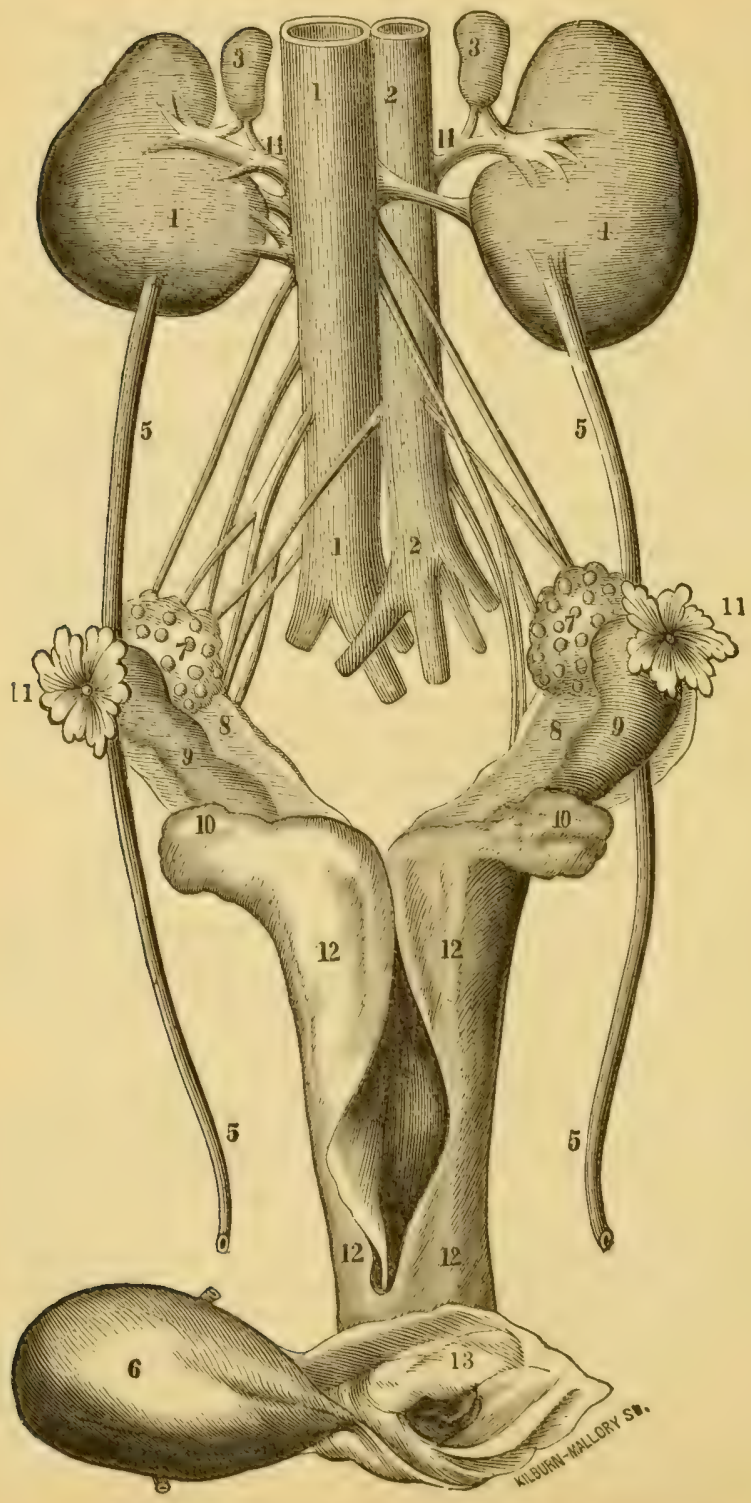

FEMALE ORGANS OF GENERATION 
also become acrimonjous, from perverted function in the skin and lungs, and thus set up disease in the bladder.

The symptoms of this disorder somewhat resemble those of nephritis: the patient will be seen to make frequent attempts to void urme, at the same time suffering from pain, and only succceding in passing a few drops at a time. The usual feverish symptoms are always present while the parts are inflamed.

Treatment. - There is very little chance of removing this dis order by the fleam, nor can it be removed by diuretics: we must undeavor to establich an equal circulation throughout the entire system, by warmth externally, and relaxing medicines given internally. The vapor bath, which has been so successfully iutroduced in human practice, and to a limited extent in veterinary, is an efficient relaxant of the tissues, and promotes both exhalation and absorption. The medicines to be given internally are, -

1. Nauseants. A compound of equal parts of lobelia and uloodroot in drachm doses, given at intervals of a few hours, is well calculated to diminish the vibratory action of the heart and arteries, and thus relaxes the tissues 80 as to induce a free circulation of blood.

2. Cathartics. Should the horse be plethoric, or labor under the least symptom of constipation, they are indicated, for they not only diminish the contents of the digestive canal, but the whole of the vascular tissues.

3. Lubricants. These are always indicated in case of inflamed mu ')us surfaces; a decoction of mashmallows is probably the best for diseases of the urinary organs. It follows, then, that if the functive of the skin be restored by the above means, the bowels kept lnose, the mucous surfaces lubricated, ar d the urine diluted. sie patient may soon recover.

\section{EXPLANATION OF CC r. -- FEMALE ORGANS.}

1. Descending or posteri or portion of the vena cava and its bifurcation.

2. Descending or posteriur portion of the great aorta - great artery - and its brfurcations.

3. Supra reual capsules

4. Kidneys. 
5. Ureters, throuch which the urine passes to the bladder.

6. Bladder severed from its ureters.

7. Ovaries.

8. Broad ligaments.

9. Fallopian tubes.

10. Cornua or horns.

11. Frimbrix of the fallopian tubes.

12. Body of the uterus.

13. Labia pudindi reflected over to show the vaginal membrane.

il Emulgent arteries.

\section{SUPPRLSSION OF URINE. - (Strangury, Ischuria, Dysurne)}

When a horse attempts to urinate, and a few drops only past ut a time, the case is termed strangury or dysurin.

A total suppression of urine is termed ischuria.

Strangury and retention are generally termed by stablemen "stoppage," or "stoppage of water :" and it is no uncommon thing to see horses, while laboring umler an attack of colic, unable to urinate; in such cases, the stricture at the neck of the bladder, or at whatever part of the urinary channel it may exist, is the result of sympathetic action with the muscular or nervous tissues of the alimentary organs; so that, if we relieve the patient of colic, and subdue the inflammatory symptoms of the one class of orrans, the others are almost sure to resume their function. Suppression of urine is so common an attendant with colic, that often what amounts to a mere retention only is consid. ered the disease, and the unfortunate creature is dosed with diuretic, which may increase the urinary secretion to the risk of Iife, but have no power over the paralytic or rigid state of tha bladder.

'I hose who are in the habit of treating colic must have noticent that the moment a horse gets relief, - that is, when the accinnu lised go: evacuates the abdominal channel, the faces come aw ay und the worst symptoms subside, - then the urine passes of freely - a sure sign of a quick recovery, and positive proof that the urinary orcans were not primarily affected.

Ine causes which give rise to strangury are numerous; disease of the kidneys or any part of their associate organs may, either lirectly or indirectly, produce it, paralysis, tonic spasm, pressur 
on the neck of the bladder from hardened frees or from an accumulation of gas within the rectum, urinary calculi, and powerful diuretics, - all tend to produce suppression and retention of urine.

Let the reader understand that the manner in which the urino is voided is moditied by many other diseases as well as colic. In some of them the secretion may be so scanty as to ead to the supposition of strangury or retention, when in fact the blad der is not distended beyond its healthy rapacity. Simple retez. tion of urine within the bladder may arise from snme physical obstacle within the urethra; this must not, however, he confounded with suppression, which implies that the secretion within the kidreys is suspended. We have seen horses in this state, and, on examining the parts, have found the orifice of the urethra occupied by a hard substance termed by hor:emen a "bean," on the removal of which the urine has sonn after passed in a free and full stream. This "bean" is formed from the secretion and filth that usually accumulates about a horse's penis.

A diminution of the uripary discharge, approaching almost to retention, accompanies hydrothorax and other dropsical affections.

Dr. Good considers retention of the urine a common symptom in all affections attended with coma, and also in diseases of the nervous system.

The author wishes to have the reader bear in mind that retention of urine, so often confounded with suppression, is more generally the effect rather than a cause of disease.

Any one, by making a simple examination per rectum, can easily ascertain if the case be one of suppression or of simple retention. Let the hand be introduced within the rectum; and if the bladder be found empty, there is evidently suppression, whereas, if the bladder be large and full, occupying considerable space within the pelvis, it is a case of retention.

I'ratment. - Suppression of urine must be treated according to its indications; the cause must be sought for, and, if possible, removed. Assafotida, uxa ursi, and cream of tartar are good to incrense the secretion when the kidneys permit of augmenta. tion. $B$ st on the whole, the safest plan will be to consult a veterinary surgeon. 
Retention of urine may generally be relieved by introducing a gum elastic catheter through the urethra into the bladder, or by simply removing any obstruction that may exist within the former.

Cases now and then occur in which, from some obstruction within the urethra, the catheter cannot be introduced; we have never met with such a case, however, but have generally succeeded - though for some time baffled - through the mans of patience and a well-oiled catheter, in accomplishing our object.

In case of failing to reach the bladder with the flexible catheter, there are two operations proposed, one or the other of which is now and then performed. One is called cutting through the perinæum* into the urethra. The operation is performed by first introducing a catheter within the urethra, which must be pushed forward until it can be felt in the perinæum. A whalebone staff, flattened and grooved at the end, is preferred by surgeons to the former. The next step in the operation is to make an incision through the integuments and subcellular tissue into the urethra; the bladder can then be reached and its contents evacuated through a straight or slightly curved hollow tube. The gum elastic catheter used on the human subject may answer in lieu of a better article.

The other operation referred to is termed "tapping the bladder." There are two methods of performing this; one consists in puncturing the bladder through the walls of the rectum, and the other consists in penetrating the bladder through the muscles of the abdomen. Either method is attended with some danger, even when practised by men of great veterinary acquirements. The author considers puncturing the bladeler after this fiasbion equivalent to a sentence of death. The former opera tion, provided an operation be needed, is the most safe, and can be performed by any one possessing a knowledge of surgical matomy. If the case is evidently one that can be medicinally relieved, give the following :-

- Perinaum, the space just helow the anus, defined in the mare as the apaco vetwcen tive anus and vagina. 


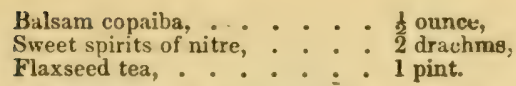

Mures nre not subject to this difficulty.

\section{DISEASES OF THE DIGESTIVE RAVITY AND ITS SURFACES}

BOTs

THE following cut is a representation of a cluster of bots found in the stomach of a horse after death. We were informed by the owner that the horse har for several months been subject to staggers, (rertigo.) During this period, his appetite failed, and the animal gradually lost flesh, and was at last unable to perform the least work without profuse perspiration. Finally, the horse lost so much flesh that he appeared like a walking skeleton, and the owner ordered him to be killed. Being in the vicinity at the time of death, we made a post mortem examination. and found the bots as represented. The internal surface of the stomach and alimentary canal was blanched, indicating indigestion. The lungs, spleen, liver, and kidneys were in a comparatively normal state. The external appearances were decidedly those of general emaciation, and, in our humble opinion, the horse, by a judicious system of medication, might have bcen saved. "The horse had been doctored for bots," without any regard to the general health, which should have been improved by the use of tonics, stinulants, and alteratives, after which vermifuges migint have been ventured on. If the bots, as we suspect, presented in part only a mechanical obstruction to the passage of food into tho stomach, his strength might have been preserved ly a daily allowance of flour gruel and by nutritious injections. The bots, generally speaking, are not so troublesome to horses as people seem to suppose; for it is very rare, in making post mortem examinations, that we do not find more or less in the stomach. We have heard some wonderful stories related of the bots burrowing 

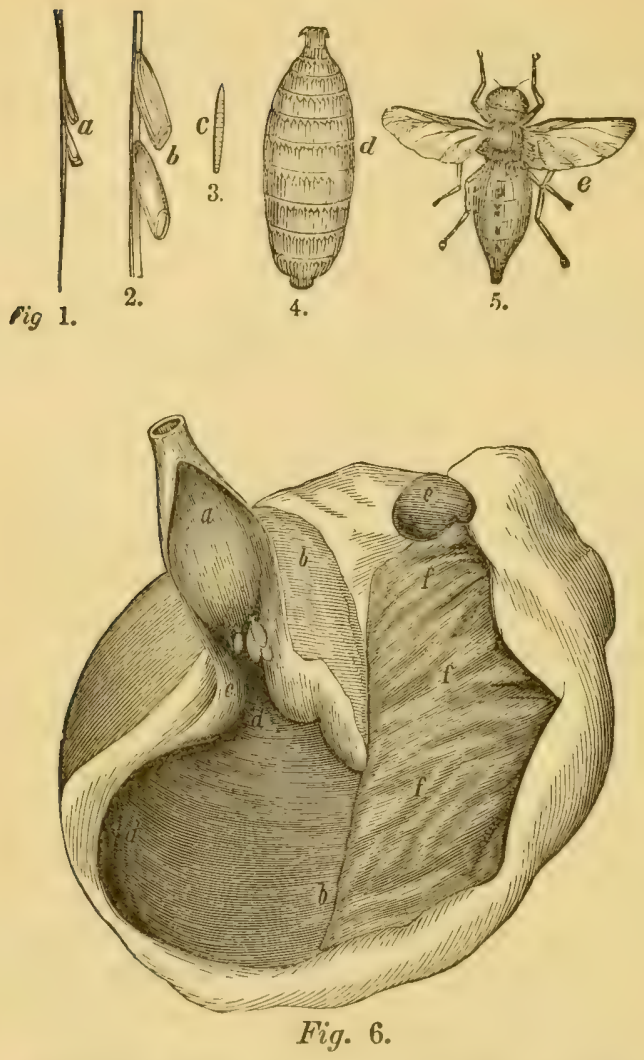

fig. 1, letter $a$. The eggs of the gadfly adhering to the hair of the horse Fig. 2, letter $b$. The eggs as seen throigh a magnifying glass.

Pig. 3. A bot in the progressive stage of development.

Fig. 4. A full-grown bot, detached.

Fig. 5. The female gadtly.

Fig. 6. Cut of the horse's stomach

" "letter $a$. The gullet, or axophagus, extending to the stomach; $b, b$, the margin which separates the cuticular from the villnus coats of the Etomach : $-c$, the entrance of the gullet into the stomach ; $-d, d$, the cutioulax portion of the stomach: - $e$, the communication betwcen the stomach and lirst intestines; $-f, f, f$, the villous or inucous purtion of the stomach, in which the find is principally digested. 
through the walls of the stomach. This we deny in toto, at least while the horse is alive. The little creature is too comfortably located to attempt its exit into a cavity where its destruction would be inevitable. If it be about to vacate its stronghold, instinct teaches it the most safe and expeditious route, which is the alimentary canal. We do not deny that bots are found in the ubdominal cavity, for the moment the horse dies all the various organs are subject to the laws of decomposition. Chemical action, which, during life, was regulated by the vital forces, now assumes the supremacy. Those powerful solvents termed the gastric fluids, which had previously dissolved nothing but food, now act on the stomach itself, and hasten its decomposition; and what had previously been good food for bots is now their bane, and they must themselves in turn be destroyed unless they escape from it. The peristaltic motion of the alimentary canal, which, during the existence of the horse, was so favorable to their exit by that channel, has ceased. Tiey are tou well acquainted with the intricate, labyrinthian outlet, (their usual route,) to attempt its passage. No. The same energies of one eternal mind,

"Pervading and instructing all that live,"

suggests the only means of escape. The stomach now offering Lut little opposition to them, being partly decomposed, they burst their prison-house, and hence are found in the abdominal cavity. And here they may be said to have jumped "from the frying pan into the fire." We are frequently called upon to visit sick horses, said to have the "bots," when there is no more connection between them and the disease than there is between the horse and the anvil on which his shoes are forged. It is all very well for as to say "a horse has the bots," and prescribe some medicine for their expulsion; but there is no practical advantage gained; ncither is the horse benefited by such decision or treatment. For most of the remedies used as vermifuges would kill the horse, while the former would not be injured in the slightest degrec. Mr. Bracey Clark says, "The slowness of the growth of bots, and the purity of their food, which is probably the chyle, nust occasion what they receive in a given time to be proportionably small; from which, prorharss arises the extreme difficulty of dif- 
stroying them by any medicine or poison thrown into the stomach After opium had been administered to a horse laboring under locked jaw for a week, in doses of one ounce every day, bots were found in the stomach perfectly alive. Tobacco has been employed in much larger quantities in the same complaint, and has also been continued without destroying them." Mr. White, V. S., says, "While making experiments on glanders, I found living bots in the stomach of a horse, though he had been taking. for many days, arsenic and corrosive sublimate." * Mr. Blaine Eays, "that he has kept them alive for some days in olive oil, and in oil of turpentine, and that even the nitrous and sulphuric avids do not immediately destroy them." The history and habits of the bot are thus alluded to by Mr. Clark: "Bots are not, properly speaking, worms, but the larvæ of the gadfly, which deposits its eggs on the horse's coat in such a manner as that they shall be received into his stomach, and then become bots. When the female fly has become impregnated, and the eggs are sufficiently matured, she seeks among the horses a subject for her purpose, and approaching it on the wing, she holds her body nearly upright in the air, and her tail, which is lengthened for the purpose, carried inwards and upwards. In this way she approaches the part where she designs to deposit the eggs, and suspending herBelf for a few seconds before it, suddenly darts upon it, and leaves the egg adhering to the hair by means of a glutinous liquor secreted with it. She then leaves the horse at a small distance, and prepares the second egg; and poising herself before the part, depusits it in the same way; the liquor dries, and the egg becomes anmly glued to the hair. This is repeated by various flies, till four or five hundred eggs are sometimes deposited on one horse. They are usually deposited on the legs, side, and back of the shoulder - those parts most exposed to be licked by the animal: in licking, the eggs adhere to the tongue, and are carried into the

* Very nice articles to experiment with, truly! And yet we are sorry to say that experiments - for they cannot be called any thing eise - are daily mado in this eity with agents whose therapeutic powers are so diversified that th: wisest of the faculty have never ventured to fix limits to their action. They ure like the torch in the hands of an incendiary. The healthy parts mu:s: satiou rqually with the diseased. 
horse's stomach in the act of swallowing. The bots attach them. selves to the horse's stomach, and are sometimes, though less frequently, found in the first intestine. The number varics con. siderably; sometimes there are not half a dozen, at others they exceed a hundred. They are fixed by the swall end to the inner coat of the stomach, to which they attach themselres by mears nf two hooks."

Cure. - It has been remarked that no effectual remcdy Lne erer been discovered for the cure of bots. Yet we venture to say that, in nine cases out of ten, if the snimal be permitted to run a short time at grass, when the bot has attained its full growth, and is capable of exercising an independent life, it will detach itself from the stomach and pass off with the excrement. We have frequently brought away large quantities of bots during the administration of the following articles, and we do not hesitate to recommend them as safe and efficient. As a vermifuge, they are unrivalled; at the same time they restorc the tone of the digestive organs.

\section{Compound for the Expulsion of Bots.}

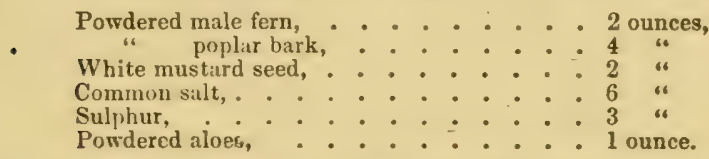

Mix; divide into eighteen powders, and give one, night anc morning, in the food.

The animal should have a daily allowance of green food if the season permits.

The author of Hippopathology writes, "It has been conjec tured tiat bots might prove serviceable to the animal by aiding 'he cuticular coat in the trituration of the food. That Nature should have created an animal, and designed it as an inhabitant of the stomach of another animal, without some good, but, I sus pect, unknown end, I think, in unison with others, highly im probabli - irreconcilable with her other beautiful and more readily explained operations; I am, however, for my own part, unable to draw up the curtain which is here interposed between fact and design. 
* Supposing that bots ic some way or other do good rather than hurt, surely we cannot be solicitous about removing them. for though we are unable to demonstrate their beneficial influ ence, we inay, from all the circumstances arrived at, at least assert that they in general are not injurious. Howbeit, we cannot persuade the world so; and, therefore, we must be prepared to in et the complaints of persons who come to us, at certain seasolio, and say that their horses have worms, which must be got rid of -- with a remedy for that purpose. Should any other malady exist at the time, no matter what, its; origin will commonly het traced to the presence of these mischievous vermin."

As far as our experience goes, we have no faith in medicine to expel bots, yet we have seen them voided with the excrement two or three times while the patients were under the influence of a dose of physic; the bots, however, were full grown. Dr. Clark thus reasons on the subject: "We can, it is true, force the medicine down a horse's throat, but we cannot afterwards get it into the throat of the worm, who is placed in his own element, and can refuse the food that does not suit him."

The nit or egg can easily be got rid of by greasing the horse's hnir and then rubbing it with a coarse cloth, or by applying warm water, which loosens their hold on the hair.

\section{ON THE HORSE'S STOMACH.}

Comparing the size of the stomach with that of the horse, we find it less capacious than in some other herbivorous animals. The os, for example, has a most complex form of stomach, conaining four distinct cavities, through all of which the food has u p pass ere it can be properly digested. In sheep, also, we find a similarly complex form of stomach; this admits the food as fast so the animal can crop it, from whence it is returned to the mouth to be masticated at leisure.

The capacity of a horse's stomach varies in proportion to the gize of the animal; thus in a small horse it is about eight quarts and in one of large proportious it sometimes exceeds thirty. It is eccasionally dilated to an extraordinary size. A case cam? under our observation a short time ago, of dilated stomach the 
subjest of which died from inflammation of the stomach and bowels. The owner labored under the impression that his horse had been poisoned, and, in order to satisfy his curiosity, employed us to make a post mortem examination. The mystery was soon colved. On exposing the stomach, it appeared about as large as two ordinary ones; and after cutting into it, out tumbled about half a bushel of stuff resembling brown sawdust, but whick turned out to be brown bread! The animal had been regularly fed for many months on brown bread, mouldy or not, just as it happened; he was the constant subject of colic, in consequence of which the stomach had probubly become gradually dilated by distention from gas, until acute disease terminated his existence.

Mr. Gamee, in his Descriptive Anatomy of the Abduminal Viscera of the Horse, quotes from a paper written by M. Colin. $H_{t}$ found the stomach of a very small horse to contain mily nine quarts, while in one of colossal dimensions the stomach held thirty-three quarts.

The stomach, therefore, not only varies in size with the dimensions of the horse, but also as to whether it be full or empty, adapting itself generally to the amount of food taken.

The horse's stomach is composed of four coats; the first or orternal one is a part of the membrane which covers the whole cf the abdominal contents, called peritoneum. This is termed the serous ccat of the stomach. The second coat is called the muscular; it is composed of three layers - inner, suter, and middle. These run in various directions, give strungth, and admit of a complicated muscular motion which greatly facilitates digestion.

The outer layer of muscular fibres is a continuation of the longitudinal ones of the œsophagus.

The libres of the middle layer embrace the stomach in circles, they admit of zonsiderable contraction and relaxation, and aro very powerful as they approach the lower orifice of that organ.

'The third or inrer layer of fibres runs in an oblique direction. The third coat of the stomach corresponds to the cellular tissun under the skin of man; it serves to connect the parts together nnd acts as a medium for the transmission of blood vessels; and jeing soft and cushion-like, protects them from injury or pressure 
The fourth or internal coat of the stomach corresponds to the mucous membrane of other organs; its upper or carliac portion is protected by a thick cuticular layer, supposed to be insensible like that found within the gizzard of the feathered tribe This membrane is a prolongation of the external covering of the body into its interior; its walls pour out or secrete a fluid which acts upon the food in such a manner as to dissolve it; and through its walle is also absorbed a portion of the food which is destined for the support of the system.

This cuticular covering of the stomach, to which we find the bots attached, terminates about midway. The other half, termed the villous, from its glistening aspect, extends to the pyloric ori fice, where it gathers into a fold, forming a kind of valve This valve opens and shuts by the muscular relaxations and contractions of the stomach and diaphragrn, and permits the food, when reduced to a fluid form, to pass into the first intestine.

The villous coat of the stomach, being thickly studded with bloor vessels and nerves, is highly susceptible of irritation; it is distinguished from the cuticular portion by its red, glistening appearance, and by being coated with a thick mucus.

It is a fact of great practical importance to the farmer to know that the gastric fluid, secreted by the glands and follicles of the villous coat of the stomach, is the real solvent of the food, and that a certain quantity can only act on a limited amount of fool ; iherefore if a horse, from a depraved appetite, takes more food into his stomach than the gastric fluid can dissolve, it remains there undigested, a source of irritation and mischief. The umount of gastric juice secreted at any one time is not in pro. portion to the amount of frod in the stomach, but to the wants of the system; so that if a horse be fed without any regard tc quantity, oscupying twenty out of the twenty-four hours in cran. ming his digestive organs, and the evil goes on increasing with every addition to their cavities, disease sooner or later must man. ifest itself, or else the animal becomes a depraved feeder, and living, yet half dead, drags out a miserable existence. 'These depraved feeders - often made so by want of foresight on the part of their owners - are to be found under all circumstances and among every variety of breed; which fact argues a general 
want of knowledge on the part of horsemen regarding the phys. inlogical action of the stomach. If a man ever becomes intem. nerate, it is generally from habit, and the same may be said of the horse. Those who have experienced the cravings of a depraved appetite can sympathize with the four-footed creature, who, after devouring his provender, sets to work on the bedding: and finishes his meal from the boards which compose the stall and crib. A very extraordinary case of a depraved feeder is recorded by a French veterinary surgeon: "Nither manger, nor rack, nor the fragments of the bars escaped him : he gnawed his halter, and licked the walls, and ate up all the earth he could get at. He was a contirmed crib-biter and roarer. For many years he had been subject to violent colics, which became latteriy more and more frequent. In one of these paroxysms, at last, he died. There were found in his stomach, after death, four pounds and a half of earth and sand. He had, as was learned afterwards, escaped from his groom on the morning of the day he died, and galloped to the riding school, where he was found eating the earth and sand composing the floor. A brass wire, about the size of a knitting needle, and eight or nine inches long, was found sticking in the intestines, through whose walls it had penetrated, and had run into the lumbar muscles."

Foreign bodies are sometimes found in the stomachs of horses after death, which do not seem to occasion much inconverience during life; thus many hundred bots have been found within that eavity without the subject being at all incommoded by them. The stomach terminates in that part known as its ryloric outlet, or inferior portion, from whence commences the dundenum: known as the second stomach. See cut of the stomach and intestines.

\section{LNFLAMMATION OF THE BOWELS.-(Enteritis.)}

Cause. - This disease arises under circumstances so whrlly dissimilar, that different and even opposite causes are assigned to the same affection; that is to say, different causes appear to produce the same results. Thus inflammation of the bowels may nupervene immediately after exposure in a rain storm, or from 
the application of cold water to the surface; also from the pros ence of some irritating substance within the alimentary canal Sudden change of diet, from dry to green feed, has often, apparently, produced this malady. In each case the apparent cause in somewhat different, and the disease may have had some common antecedent; as, for example, a congestion of the blood vessels of the alimentary canal. Therefore it is very difficult to determine, in every case of disease, what are the direct causes; yet we may wafely conclude that in many such there previously existed in the Bystem a peculiar predisposition, or, in other words, loss of vitality, ere the disease then present could have manifested itself.

Mr. Percivall thus alludes to the causes: "The causes of enteritis are both numerous and various. We have seen that colic may give rise to it. Constipation may be viewed in the light both of cause and effsct in its relation to it. Collected hardened frecs must naturally not only of themselves be irritative, but obstructive and subversive of the functions of the bowels, and in either one or the other way may lay the foundation for an attack of inflammation. Certain kinds of indigestible food, calculous bodies, irritating matter of any sort, within the bowels, may cause an inflammation of them. Obstruction of any of their passages - whether it be from the lodgment and immovableness of the matters they contain, or from entanglement of the intestines, or intus-susceptior - must in the end occasion inflammation. Over-fatigue, and consequent excessive irritation in the bowels, will bring it on.

"Cold, from exposure, and skin wetted while hot, and so forth, is commonly entered high up on the list of the causes of enteritis, ind, perhaps, with propriety. I must confess I have not inct with so many cases from this as from other "auses."

Symptoms. - There is some analogy between the symptoms of Lhis disease and colic; there is, however, one marked feature of the case which enables us to diagnose the disease with some degree of certainty, for when inflammation has fairly set in, there is little. if any, remission of pain; whereas, in colic, the pains are of a spas. modic character, so that the animal at times is quite easy. 'The' pulse, in inflammation of the bowels, is full, firm, and quick, in. reasirg in beat and volume as the disease increases in intensity 
The patient evinces pain when even the slightest pressure is made on the walle of the abdomen; the belly is quite tense, and drawn up towards the hips. On moving the horse, he groans, indicative of pain, and looks anxiously towards the flanks. When lying down, he stretches himself out at full length, throws his head hitck, and paws with the fore feet; sometimes he sweats profusely at the flanks and around the neck; champs and grinds the teeth together; the nostrils are dilated, and respirations hurried; at times the urine trickles away from the urethra involuntarily, and the faces are hard, and often covered with slime; the eyes appear bright, glassy, and the pupils are dilated. In the last stages of this painful malady, a cold sweat stands on the body ; occasional tremors set in ; the lips hang pendulous; the limbs, ears, and lip? feel death-like; and death soon puts an end to the scene.

Treatment. - In relation to the treatment of this disease, we remark, that most practitioners recommend, more or less, the abstraction of blood. Dr. White says, "Seven or eight quarts of blood may be taken with safety, and if no relief is given in the course of a few hours, five quarts more may be drawn away." Most writers, in fact, place the greatest reliance on the fleam for subduing enteritis. "The first and grand thing to be done is, to let blood from the jugular vein to the utmost extent the patient will bear; the blood can should not be taken from the neck until evident prostration demands it. Should this come on prematurely, however, - should the horse stagger and appear faint from loss of blood, although but a few pints have flowed, - pin up the vein, and administer to him his drench and an injection; and then, should his strength seem revived, have recourse once more to the feam; for blood he must lose, and in large quantities; upon thats muinly, d pends his recovery." - Hippopathology, vol. ii. p. 251.

Let the reader omit the bloodletting, and have recourse, if the nuture of the case requires it, to a drench and injection, together with such other restorative means as we shall recommend, and there will be no need of abstracting blood. As a single illustration of the truth of this proposition, we merely refer to the fact, that, during nine years' practice in the city of Boston, the author of this work has never $i$ i a single case of this, or any other form of disvase. had recourse to the practice of bloolletting. And the rearley 
san infer from the fact that we get a comfortable living, that on practice is, to say the least, somewhat successful - for were it otherwise, we should not enjoy the confidence and patronage of so many kind friends who have stood by us in our efforts to reform the abuses that have crept into the practice of veterinary medicine.

Practitioners seem sometimes to forget what Dr. Dixon is so anxious to impress on their memories, viz. : Nature is ever lusy, by the silent operation of her own forces, in curing disease. Iler medicines are air, warmth, foud, water, and sleep. Their use is directed by instinct; and that man is most worthy the name of physician who most reveres its unerring laws." Now, it is a well. known fact that the drawing of blood from a vein, though it lessens the volume of that fluid, does not mend the matter; "for it does not act directly on the diseased part; the action is only indirect;" therefore it is imperfect, and positively injurious injurious, because "blood is the fuel that keeps the lamp of life burning: if the fuel be withdrawn, the vital spark is extinguished."

The fact of bloodletting having been practised from time immemorial, for the cure of this or any other disease, is certainly not a clear proof of its utility, nor is it sufficient recommendation that it may be practived with safety; for " no man, however wise, can tell how much blood ought to be taken in a given case."

The indication of cure in inflammation of the bowels is, to equalize the circulation, and remove irritation and obstructions to vital action. This we accomplish by the aid of natural and medicinal antispasmodics, such as we shall recommend. They are simple, but efficient. We do not depend on their strength or power to produce given results, such as follow the sxhibition or aloes, antimony, \&ce, (where we judge of the valut of such agent simply by its effects, without reference to the injury done to delicate membranes.) The great secret is, to select such agents as shall produce a change, or, in other words, act in concert with the ancompromising laws of nature. Unfortunately, the medical world, as well as horsemen and farmers, have been accustomed to juige of the power of a remedy by its effects, and not in pro. portion to its ultimate gook. 'Thus, if a pound of salts be given to a horse or cow, and they produce liquid stools, - operate well 
- they are styled a good medicine, although they shall leare the mucous surfaces of the alimentary canal in a weak state, and ntherwise impair the digestive function; yet this is a secondary consideration. For if the symptoms of the prerent malady, for which the salts are given, shall disappear, nothing is thought of the after consequences. The animal may be constipated for several succeeding days, and finally refuse its food, and ultimately die; but who suspects that the salts were the cause of such result? If ever symptoms are altered by medicinal agents, they should be for the better.

It will be seen, then, that bloodletting is resorted to in view of a prostrating or sedative effect, which can be more sanatively brought about under the more rational use of laxatire medicines. Purgatives, however, cannot always be given with safety in inflammation of the bowels, because they might tend to augment the previous irritability of the alimentary canal. A dose of cathartic medicine may, however, be mixed with lubricants, - for example, slippery-elm, mucilage of gum arabic, or olive oil, - so as to deffend the sensitive parts, and at the same time not deprive the medicine of its cathartic properties.

After having ascertained the case to be one of enteritis. we administer the following:-

Linseed oil, . . . . . . 8 ounces,

Lime water, . . . . . 2 ounces

Another:-

Epsom salts,. . . . . . 8 ounces,

Thin gruel, . . . . 1 quart.

Another:-

Pulverized aloes, . . . . 4 drachms.

Mucilage of slippery elm, . . 1 pint.

Another:-

Common salt, : $:$ : $:$ : 6 ounces,
Warm water, 1 pint.

Frequent injections are to be given until the bowels respond; and if after a reasonable time they should not do so, one of the above prescriptions, in about half the proportion, may be ventured on; yet it is best not to be too hasty, for super-purgation induced by active cathartics would be equivalent to a sentence of death 
A handful of common salt to three quarts of tepid water forms a vory good injection

Whether the medicine be repeated or not, there is no safety nor ease for the patient until the irritating frecs have passed off. With a view then of diffusing the medicine, and diluting the hard. ened mass within, diluting drinks should be allowed; if the patient has no inclination to drink, some warm water must be poured down; at any rate, it will do no harm, for warm water is nauseating, and of course relaxing, therefore is a valuable antispasmodic.

Some practitioners resort to counter irritants, as mustard embrocations, tincture of cantharides, \&c. The former is prepared by mixing it to a proper consistency with hot vinegar ; the latter, by steeping powdered cantharides in spirits of turpentine. Still we think that warmth and moisture, in the form of warm water and flannel bandages applied to the abdomen, and renewed often, will fulfil every necessary indication.

We believe that counter irritation, in the form of external applications, does more good when applied to parts remote than when made in the vicinity of the morbid phenomena, as in the ralady we are now treating of.

Hence warm water must be faithfully applied; yet in order to deri e any benefit from it, the process of evaporation must be somewhat checked, by winding dry sheets over the wet flumels: this insures, comparatively speaking, a more equal temperature of the parts, and tends to relax the capillary vessels.

At times, especially when the patient is in great pain, fomen. tations of hops will be found of great benefit, for they are considered anodyne - soothing; and an occasional drench of hop tea may be given, instead of opium, which some practitioners recom. m ?nd. Hop tea may be thus made:-

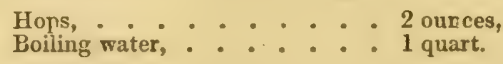

Pcur the boiling water upon the hops: when cool, strain and sweeten with honey.

The diet should consist, during the inflammatory stage, of thic 3lippery-elm gruel. After the acute symptoms have subsided, liay tea, thickened with oatmeal, may be allowed. To relinvo 
pum and tranquillize the nervous system, give a dose, as occasion may' require, of tincture of Indian hemp (canabis satives indicus), onc fluid drachm to a pint of warm water, two or three times a day. Diluted tincture of arnica, one sunce of tincture to a pint of water, has a good effect to lessen the pulse, and moderate inflanmation.

\section{INFLAMMATION OF THE STOMACH AND BOWELS.--} (Gastro-enteritis.)

This is a complicated disease, attended with considerable danger, and $\mathbf{r}$ yuires some knowledge of pathology in order to detect it when occurring in an animal destitute of the power of speech. The disease, probably, first manifests itself in the stomach, and, as it progresses, involves the inner membrane of the intestines, and from thence shifts to various parts of the system. Frow the following remarks by D'Arboval, who is considered the best authority on this subject, such an idea seems very plausible: "With other phenomena, preceding these, becomes united, in both forms of the disease, and in every case, more or less disorder of the functions of other organs. Divers phlegmonous complications make their appearance in other parts of the digestive apparatus and its dependencies - in the mucous membrane of the air passages, in the brain, in the urinary passages, in the organs of generati.n, and even, at times, in the skin. The sur-excitation of the nucous membraue of the mouth may be regarded as sympathetic, for it increases or diminishes in the same ratio as the gastro-enteritic disurder itself does. According as the attack is sudden or protracted, this membrane is dry or clammy; the tongue rarely preeerves its natural complexion and humidity; it has a more or lesy bright-red aspect, particularly towards its point and border; its papillze and murous follicles are more or less developed; its surface, blaached, white, or yellowiah, is covered with a blackisb epidermoid crust; the organ acquires volume and firmness, and exhibits sometimes along its under surface phlyctana, or else ulcerations more or less defp and extensive. In opening horses that have died, points of inflammation have been deterted upon the pliarvin and oesophagus ; somctimes even aphthat are found 
at the bottom of the mouth: I have seen them in many horses The large intestines are sometimes inflaned, and even on some occasions the margin of tl:e anus may be observed to have grown red The liver, with its peritoneal covering and excretory duct's participate in this same excitation. Gastro-enteritis rarely ex ists in intensity for any time without reacting upon the mucous membrane of the respiratory passages, producing that sympathetic phlegmasia which is known by a sort of rale; by a painful state of the throat and upper part of the windpipe; by embarrassed respiration; by dilatation of the nostrils; by accelerated hearings of the flanks; by a slıort, dry, hollow cough; by shakings; and oceasionally by a discharge from the nose of frothy mucous matter sometimes, but rarely, yellowish. Inflammation of the lungs may also be a complication; then the expiration becomes more frequent, the respiration short and quick, the expired air hot, and the pulse strong. Peritonitis and nephritis may likewise prove complinations. In the first case, the horse experiences abdominal pains, and rubs his lips; in the second, there is inflexibility of the spine about the lumbar region, and the animal evinces pain when pressed over the kidneys; the urine is also redder and less in quantity. In fine, when gastroenteritis is most intense, the consequent uneasiness and fatigue are often attributable to the brain; the derangement of which is indicated by the extended neck, the heat and heaviness about the head, the drooping attitude, the resting point that he makes of the manger, and the drowsiness he evinces. At the time, the sight and hearing become affected; the conjunctiva looks red and injected, or it assumes a purplish hue, which, at the bottom, often turns yellowish, and exhibits plilyctena; the eyeball is infamed, and the eye obscured; the muscles of the face are irregularly con. tracted; there is grinding of the teeth; often symptoms of veriign, and sometimes to that degree that some veterinarians - among others Dupuy - have regarded the gastro-enteritis of 1825 as a form of vertiginous affection. This combination is especially fatal, and quickly so, and particularly in old horses, and such as are oppressed with work beyond their powers, or othcrwise debilitated. Phlegmasia, sympathetically developed in the urinary nissuages nnd organs of generation, will account for the changes 
In the urine before mentioned, for the agitation of the tail ; the frequent desire to stale; the erections of the penis of the stonehorse; the outstretching of the legs of the gelding; the reddening of the mucous membrane of the vulva of females, and the sense of heat in introducing the finger into the vagina. The skin will not prove exempt from becoming sur-excited, as will be evinced by its elevation of temperature, its state of dryness or sweat, the slight adherence of the hair, its dull and rough aspect, and, moreover, in some epidemics, by the huttony eruptions manifest apon it. At the last, swellings rise upon the hind legs or hocks; œulema appears upon the belly, sheath, and breast; the scrotum becumes covered with a dried matter in place of the natural unctuous secretion; or else phlegmonous tumors form upon divers parts of the body; some we have observed upon the parotids and breast.

"Autopsies. - Post mortem inspections have shown different and various diseases, according as gastro-enteritis has set in more or less suddenly, been slow or rapid in its course, and more or less complicated with the inflammation of some viscus or other part, besides the stomach and intestine; for it is- to be remarked, that constantly one organ is especially attacked, and exhibits dis. ease violent in proportion as other organs are slightly affected. The mucous membrane lining the stomach is more or less reddened, particularly the portion within the right sac, the entire surface of which sometimes appears so ; besides which it is injected, and in some places ecchymosed. The red color - prouf incontestable of the existence of inflammation during life - appears under a great variety of shades; the deep-brown tint shows gangrene, a change also indicated by the friability of the part and its speedy progress to putrefaction after death. Patchee of redness are also visible in different places upon the membrane, (the mucous follicles being larger than common;) sometimes superficial ulcerations, petechix even, and gangrenous eschars, which may be nothing more than ecchymosis. Sincilar appear ances are found in the small intestines, whose mucous membrane in many parts is reddened, injected, softened, and studded with assemblages of pointed eruptions; a gray, thick, glairy murus, and some potechial spots, are also visible. In some cases, the 
matters contained in the small intestines are solid. and look ac though they had been dried, though this is an appearance more common in the large guts, unless there happened to have existed diarrhoea before death; in the cecum we almost always find this, and for some way also, though in a less marked degree, within the cells of the colon. More or less inflammation is observablu in the mucous membrane of the fauces; the sides of the tongu ure covered with ulcerations resembling aphthæ; and the surface of the pharynx, which is more or less deeply reddened, sometimes presents a cribriform or worm-eaten appearance. Its follicles also often acquire such considerable development that they might be mistaken for buds, with their orifices wide open. Some of these alterations are perceptible at times within the oesophagus. When the disease has proved complicated, we also tind, after death, alterations in those organs which have shown a dis. position to partake of it. The liver is often tumid, its veins are gorged with blood, and its substance is pale and without firmness; in some subjects ecchymosis and recent adhesions are apparent upon its exterior, evidently the consequences of inflammation. The lungs at one time are simply engorged; at another, within the anterior appendices and extremities of the lobes they exhibit the red induration; or they are hepatized in places, or inflamed around their periphery, and contain spumous blood. In certain subjects, the pleura is reddened and thickened, and novered with layers of albumen, a part of which forms false nembranes and points of adhesion to the walls of the thorax. Effusion is rare; notwithstanding it has been observed by me in two instances, and in one of them so considerable was the quan. tity that the case nowise differed from hydrothorax. Acerr. ing to M. Girard, whose observations we sre now borrowing, the heart is the organ most and oftenest affected. The pericar. diun, commonly infiltrated in substance with yellow fluid, containn more or less serosity, sometimes bloody, and affords er'dent marks if acute inflammation. In many subjects the heart is twice its natural volume, its substance pale and discolored, and roid of tenacity, rends with facility ; its exterior, in a state of inflammation, exhibits black spots, the effects either of ecchymosis or gansrene, (most probably of the former.) Its cavities always contair 
black, thick blood, semi-coagulated; and often yelluw, corsisting of fibrinous, albuminous concretions. These productions, large or small, exist sometimes, says M. Girard, in the right cavities, some. times in the left, and sometimes in both right and left at once; they always occupy the auriculo-ventricular opening, and more or less completely fill it. Such appearances would have escaped observation both in men and animals, had not M. Girard pointed them out in horses in the gastro-enteritis called the epidemic of 2825. Do they form during or after life? The former directur of the Alfort school entertained the first hypothesis, and thought that the concretions in question might prove the cause of death, by producing that suffocation which he had observed in horses which died suddenly and in a manner asphyxiated.

"Supposing it were so, adds M. Girard, we should obtain an easy explanation to the obstruction of the lungs, the engorgement of the liver, the phlogosis of the air tubes, and the presence of frothy mucus within them. According to the same authority, the internal surfaces of the cavities of the heart present vestiges of sub-acute inflammation; the redness is most remarkable in the tricuspid and mitral valves, and extends into the arterial and venous trunks; though it is not equally perceptible in all the cavities of the heart or within the renous and arterial trunks.

"In general, little alteration is visible in the brain, though in some subjects the exterior presents marks of infammation. M. Girard once observed inflammation in the right lobe; and M. Rainaud speaks of the injection of the veins of the brain, of effusion into the lateral ventricles, of slight yellowish infiltration, und of concretions of the same hue in the choroid plexus. When the urinary apparatus participates in the inflammation, the kidneys are redder than ordinary, and their tissue is extremely lacerable; the bladder exhibiting red spots, and the urine being saffion or brick-dust colored. In some instances, the wh'le of the sub-cutaneous, cellular, and muscular tissue is infiltrated, and its areola are flled with yellowish fluid - an appearance most remarkable in the breast, scrotum, and sheath, when such parts have proved œdematous during life.

"Such were the principal signs of disease observed in the horses that fell rictims to the gastro-enteritis of 1825 Thr 
principal and most constant lesion, however, - that which cos. stituted the disease, and from which all the others were derived, was inflammation of the mucous membrane of the stomach and intestines." - Hippopathology, p. 232.

Symptoms of Gastro-Enteritis. - The symptoms vary as the disease promresses and spreads over the digestive surface, so that it is almost impossible to give, with certainty, any symptoms that can correspond to a given case of this character; for the disease may be termed, and sometimes is, one of progression, beginning in the stomach, invading tissue after tissue, until the disease becomes general ; it is then said to be complicated, and as a matter of course, we meet with a variety of symptoms as the morbid phenomena develop themselves. Notwithstanding this, there are a few symptoms, which, if recognized, tend to mark the form and character of the disease.

Supposing the disease first to originate in the stomach, as it no doubs $\mathrm{d}$ s, we shall be assisted somewhat in our diagnosis if we are acquainted with the prominent symptoms, as they occur in the buman subject, selecting those, however, which apply to animals, either directly or indirectly. The symptoms, as they occur in our species, are, a violent pain in the stomach, distention, and flatulency ; thirst, restlessness, anxiety ; frequent, hard, and contracted pulse; great loss of strength; interrupted respiration; coldness of the extremities; clammy sweats, terminating in suppuration, ulceration, or gangrenc. On dissection, we find a highly vascular and inflamed gastric surface, having a layer of coagulable lymph lining its surface, and sometimes ulceration takes place, and the walls of the stomach are thickened.

The symptoms of enteritis (inflammation of the bowels) in the human subject are - it is ushered in with sharp pain, extending over the whole of the abdomen; obstinate constipation and vomitir g, (the latter does not apply to the horse ;) thirst, great anxiety, restlessness, quick and hard pulse. After a short time, the pain becones more severe, the bowels seem drawn together by a kind of spasin, which extends to the bladder, so that the urine is voided with grest difficuity.

Dissections show inflammation of the internal coat of the in- 
bestines, ul serations and moltification. The intestines are ohstructed, twisted, and one part frequently dips into another, so as to entirely block up the channel. Combine the symptoms of these two diseases, and we have a case of gastro-enteritis. We must remember that in the horse the inflammation extends more rapidly, and diffuses itself to other tissues, and that, ere ulceration or gangrene have set in, the animal frequently dies.

The symptoms of gastro-enteritis, in the horse, have thus been drscribed by D'Arboval: "When the disorder sets in rapidly, it is indicated by dejection, dulness, slight anxiety, head dependent and heavy, and hanging in the manger; infiltration of the eyelids, which are half closed; reddening with yellowness of the conjunctiva; tearful eyes; deep and jerking respiration. Soon the mucous membranes acquire the same hue as the conjunctiva, and are at times infiltrated and tumefied. To these symptoms are joined loss of appetite, often sudden ; a dry, clammy, foul tongue, red at the upper part and around the borders; more or less thirst; stiffness of the spine and hind legs, with difficulty in moving, and swelling of the latter ; staggering gait ; weariness ; alternate heats and chills about the ears; pulse at the commencement full, strong, and quick; afterwards small, hard, and thready. The belly becomes tense, but has rather a tucked-up than inflated appearance. On some occasions the attack is so sudden that the horse, saddled or harnessed, experiences all at once a remarkable heaving of the flanks, dilatation of the nostrils, dependence or incurvation of the head, griping pains, partial tre. mors of the muscles of the shoulder and stifle, staggering, sometimes squatting upon the haunches, or falling down and reposing the head upon the ground. Most horses camnot lio down; many maintain the trect position evidently with pain; others fear :o move lest they fall. The vital powers seem to concentrate them. selves inwardly; the skin becomes insensible; the coat loses its gloss, and turns dry and penfeathered; prostration supervenes; the discharges are rare and scanty; the dungballs small, dry, bluckish, and coated; the urine, equally scanty, is at one time reddened, at another limpid and crude, and not expelled without effort. Mos! horses, during the height of their complaint, will, 
ut intervais, grind their teeth; all experience considerable: hes under the foretop, across the whole parietal region. The horse predisposed to sulden attacks of gastro-enteritis are the young, vigorous, sanguineous, and irritable; in particular those over selj fed in proportion to their work." - Irippopathology, p. 225.

In this section of the United States, where so little attertion has been paid to hygienic rules as they apply to horseflesh, we find a large proportion of equine diseases originating in the atornach ; ordinarily, howerer, they manifest themselves more oy the nerrous and cerebral functions than on the gastric, princi pally through their sympathetic relations: there are cases, how ever, from the presence of a large amount of food in the stomach which that organ is unable to digest, where it may, by irritatirg the inner walls of the stomach, produce acute disease of that organ. So also as regards poisonous agrents: they act chemically, or as mechanical irritants, developing primary disease in the gastric cavity, which gradually extends to other organs.

Treatment of Gastro-Enteritis. - With a view of lessening the irritation of the digestive surfaces, we resort to mucilaginous drinks. Various articles are in use, such as gum arabic, slippery elm, flaxseer, flour porrilge, \&c. The treatment must, how. ever, have reference to the exciting causes. If a horse shows symptoms of this malady, and is supposed to have an engorged stomarh from food, a stimulating drench must be given, to arouse the digestive fumction. and thus get rid of the burden. It is gen. rrally customary among our race to take stimulants after a hearty meal, to assist digestion; and we generally find they have the desired effect. So. also, if we wish to empty a fill stomach and arouse the digestive function of a horse, we must do the samip thing, or we cannot remove tae exciting cause. Purges are of no sort of use for the purpose of liberating the contents of an orerloaded atomach; and if inflammation has fairly set in, they are injurious. On the other hand, the stimulants here recom. mended will do no harm while the stomach is gorged or otherwise, provided they be mixed with lubricants, or not, as the case requires. Physicians do not hesitate a moment about applying stimulants, such as tincture of myrzh, \&c., to wounds and abraded surfaces. The popular empyrical compound so divch in use at 
the present day, called pain killer, is a concentrated stimulant, and we are told that it does good.

Supposing that the stomach is in a torpid condition, we give the following drench:-

$$
\begin{aligned}
& \text { Tincture of ginger, : : : } 2 \text { ounces, } \\
& \text { Fine salt, } 2 \text { : } 1 \text { ounce, } \\
& \text { Essence of peppermint, : : } 1 \text { lounce. }
\end{aligned}
$$

At the end of four hours we commence to lubricate the digez. tive surfaces, by mucilaginous drenches. To guard against constipation, we resort to cream of tartar and sulphur, and if the pain is still severe, (which may be known by the patient's actions,) a dose of linseed oil and lime water should be given. Occasional clysters are advisable so long as the bowels are torpid and the excrement scanty. Counter irritants are indicated when the extremities are cold and the surface inactive; hand rubbing and wisping with straw in a downward direction tend to impart heat and a free current of blood to the surface, and of course relieve deep-seated inflammation.

If the disease is occasioned by the use of large doses of antimony or other mineral poisons, the patient should be drenched with weak soap suds, or lime water and linseed oil, equal parts, and afterwards be fed on starch gruel and mucilage of marshmallows. We cannot be expected to write all the necessary directions that may be needed in a case of this character; therefore, if the services of a reterinary surgeon can be obtained, thi: owner had better employ him.

\section{TTISTING OF THE INTESTINES. - (Volvulus, Intus-susception.)}

Drfinition. - (Intus-susceptio, and intro-susceptio; from intuce, witlin, and suscipio, to receive.) A disease of the intestinal tuhe, and most frequently of the small intestines; it consists in a por. tion of gut passing for some length within another portion.Hooper.

Volvulus, from volvo, to roll up. The iliac passion, or inflam mation in the bowels, ealled twisting of the guts. - lbid.

This trouble is quite common among horses, yet at post mortem exuminations it is not always evident; this may arise in conse 
quence of the intestine having slipped into place, either from handling the bowels, or from the relaxation that takes place at death. A circumscribed, strangulated, and discolored spot may perhaps be found, and in the absence of any constriction of the intestinal canal at this spot, we may suspect that intus-susception has existed.

Intus-susception may arise from various causes; the chief of which is a deranged state of the digestive organs. It is well krown that the difficulty often follows both flatulent and spas. modic colic, and these maladies are the sequel of the former. It is also well known that in colic a large amount of carbonic acid and other gases are generated within the intestinal canal, by which their volume is inordinately increased, and their position so changed that we need not be surprised to find them at times twisted into all manner of shapes. In cases of intus-susception, we have met with strictures in various parts of the small intestines; these contractions or constrictions of the canal may possibly be the cause of intus-susception - if so, then our treatment should be nauseating and relaxing. In the human subject, intus. susception is generally relieved by vomiting - inverted peristaltic action; but as that is rather an uncommon occurrence in the horse, we must not expect relief in this way.

The symptoms of volvulus do not differ materially from those attending colic, with this exception, that the animal is more tranquil when lying down, and does not paw with his fore feet when up, as he invariably does when suffering from colic. The pain also seems more persistent, as evinced by the distressing look and uneasiness of the head. The disease is apt to terminate in rupture of the intestine, diaphragm, or stomach - for which there is Der remedy.

Treatment. - Administer the following drench:-

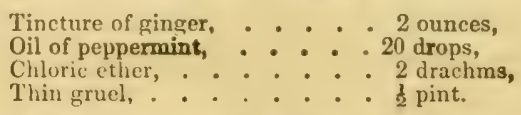

Rub the belly, and give clysters of salt and water.

We prefer to give the above medicine prior to the administration of nauseants, especially in the early stage of an attack, (when the symptoms are more of a colicky nature, ) because we have 
seen it accomplish wonders, in relieving the animal of flatus, and freeing him from pain in the course of a very few minutes. The reader may perhaps observe, that when relief is thus quickly obtained, the case is one of colic. Our answer is, that volvulus comes from colic, and if that is cured, there is an end of the mat ter. We have relieved several horses from this terrible affection ty the system of packing, after the fashion of homœopathy.

Bloodletting is almost universally practised for this complaint but we prefer to nauseate instead of deplete. It is one of the most painful affections to which the horse is subject, and in the course of a very short time the pain has so perverted the functions that blood cannot be spared, as will be seen on perusing the following article:-

\section{"Changes which the Blood undergoes during Pain.}

"M. Clement, in his researches on the alterations which pain, a long time endured, may occasion in the composition of the blood, intended to serve in aid of explaining respiration and nutrition, remarks, it appears that during violent pain -

" 1 . The water and coloring matter of the blood augment, or seem to augment, in quantity.

"2. The albumen and fibrine diminish.

"3. That while the fibrine and albumen in unison are diminishing I $^{7}$ б on an average on the one part, the coloring matters of the blood are increasing about $\frac{7}{100}$ on the other side.

" 4. That these facts, studied in relation to the influence of pain on the organism, show that severe pain, by the sure excitation of the organic functions it produces, must be expected to speed. ily and deeply wear the economy, so that this last, in order to sustain itself, has need to react strongly on the elements of ho blood.

"5. That the blood in this case loses part of its fibrine and part of its albumen, without losing any of its globules.

"6. That in relation to the study of nutrition and respiration, it would seem to result from these facts, and especially when we come to compare the chemical composition of the blood with that of the soft tissues, in particular the muscles: $a$, the fibrine, is to serve exclusively for nutrition; $b$, and that albumen, which wouls 
uppear to escape this physiological act, is d stined for the purpos" of respiration and to produce fibrine.

"7. That this supposition seems explicable on the double fact $a$, that the albumen, which exists is: great quantities in the blood, is, on the contrary, but little abundant in the muscles and other tissues; $b$, that the fibrine, which predominates in the muscles, for example, figures in a very small proportion in the compositiun of the blood.

"8. That, according to the same supposition, the albumen of the blood will be in part free, in part combined: and that the portion in combination would be with the fibrine in ordem to hold it in solution, and thus favor its circuation througt the vessels, and in its ultimate analysis, its assimilation.

“9. That in every respiration a part only of the albuman is combusted and converted into fibrine.

"10. That this dissolution of fibrine becomes necessary in order to oppose the coagulation of a principle whose dispositic.s is to become solid, and, as we all know, very firmly so.

"11. That, moreover, this coagulation is hindered by the inter. position and suspension in the blood and motion of the colored corpuscles.

"12. That the use of these corpuscles is to divide the albume and fibrine, to oppose the coagulation of the latter, and moreover to imbibe the oxygen of the air which is going to occasion a frest combustion in the woof of the living tissues, and so favor the normal accomplishment of the function of assimilation and nu. trition." - Translated from the French, by Mr. Percivall.

\section{COLIC.*}

In nine cases out of ten, colic is the result of impaired digestivy organs; the food runs into fermentation, and evolves carbonis acid gas. In view of prevention, then, it becomes a matter of importance to know what are the causes of indigestion; and the

- Saleratus is a favorite remedy among horsemen for ite cure of colic and Indigestion. Being an antacid, it is supposed to combire with the free acid cxisting in the digestive cavity, and thus neutralize it; the berefit which ruggis be derired from this alkali is prevented, oy mixing it, as many do, with 
nost fiequent may be said to be immoderate feeding - erating or Urinking whatever disagrees with the stomach, either in regard to quantity or qualicy. Every tyro in medicine knows that a drink of hard water will often produce colic, both in man and beast, provided the digestive function shall be impaired. $\mathbf{M r}$ White says, "When the Royal Dragoons were quartered at Cruydon, scarcely a day passed without one or more horses being attacked with flatulent colic, and, on examining the water made use of in the barracks, it was found remarkably hard." Our own experience confirms this fact, for before the introduction of Cochituate water into Boston, very many of our employers' horses were frequently attacked with both flatulent and spasmodic colic, which are now entirely free from it, since they use pure, soft water.

The treatment should consist, first, in the use of diffusible stimulants, (not alcoholie,) of a carminative nature, such, for example, as grains of paradise, caraway seed, ginger, \&c.; and these should be given in a liquid form. Stimulants of a sanative nature are always indicated in the treatment of colic; for if the stomach be distended with a load of semi-putrid food, how can we get rid of it except by the ordinary way, when the parts are in a healthy state? Men have strangely erred in recommending medicine - castor oil, salts, aloes, opium, turpentine, \&c. - for the cure of colic, and, perhaps, we ourselves are not free from blame in this matter. Experience, and nothing else, has changed our

milk, and sometimes with molasses; both of which contain an acid, and must therefore partly neutralize the alkali before it enters the horse's stomach, where it often does more harm than good. The action of an alkali, when use] in this view, is only palliative, as it does not correct that diseased state of tho digestive organs which favors the formation of acid or gas. The constant use of salerntus on horses tends to produce a disease of the alimentary canal, aLd thus lay tice foundation for future attacks of colic. Alkalis shorld always be sombined with carminatives, and sometimes tonics; and in no case should large loses be given. If the animal labors under pyloric obstruction, and the gas is supposed to exist in the stomach, the following is the best preparation -

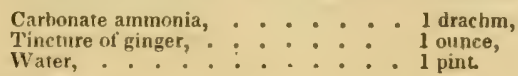

Mix, and drench the horse.

If the acid or gas exist in the bowels, substitute in e water for vmmonia, and ald half an qunce of tincture of reptian. 
riews, and we give them for the benefit of man and horse "Experience is the only true guide."

We select the following case as an example of treatment. The subject was a gray mare, seven years old, remarkable for her capacious belly. The attack was ushered in with the usual ap. pearance of uneasiness. We found her lying down, her lege gathered up, grouning, and looking anxiously round at the flanks. She would occasionally roll on her back, but the abdomen was so enormously distended with flatus, that it was with much difficulty she could get on her side again. We commenced the treatment vith the following:-

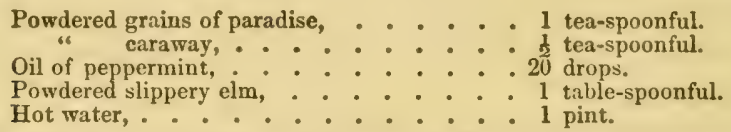

These were mixed together and given from a bottle. An injection of common soap suds was then thrown into the rectum. In a few minutes the mare voided a mass of excrement, accompanied with slime and wind. She now appeared to grow easier, and in a few minutes was free from pain. Very simple treatment, the reader may observe, yet we will venture to say very efficient. We have frequently cured alarming cases with a little pepper. mint tea alone; whereas, had the subject been treated after the fashion of some, the malady might, as it often does, have run on to a fatal issue. Those who prefer to use powerful remedies, as they are called, may ask, What good can peppermint tea accomplish? We answer, nature delights in simples; the mother finds it good for infants, and men almost invariably take peppermint, in some form, for the relief of colic; and we have tried it, and fund it good for horses.

Inflammation of the bowels is very apt to set in during ar attack of colic from the use of spirits or oil of tuspentine, and other popular nostrums; and it is much to be deplored that 80 noble an animal as the horse should be made to undergo such torture as he is known to do from the administration of turpertine. If any of our readers wish to satisfy themselves of the irritating properties of turpentine, let them just apply a small quantity to the skin of a horse, and they will perceive that it is 
un irritant of no ordinary character; the restlessness of the ani mal, his efforts to "get at the part," and the tumefaction that follows, all denote the pain be suffers.

An article of this kind, therefore, to say the least, is not a suitable one to introduce within the digestive canal, the surface of which may be considered equally susceptible to irritation. Neither are we compelled to resort to its use in view of curing colic, when the arcana of nature teem with an untold number of valuable carminatives and cantispasmodics. A few drops of tho oil of peppermint, or anise-sẹed, dissolved in a small quantity of alcohol, and given as a drench- in thin gruel or warm water, are worth all the spirits of turpentine in the world for the cure of colic.

The author is in possession of uncontrovertible facts, which show that furpentine alministered without the precaution adopted by those who know its properties, and are still in favor of its use, - which is, to mix it with mucilage, - that a vast number of valuable horses have been suddenly destroyed, and many others have lingered for several days before death, from an aggravated form of intestinal inflammation.

Lest the reader should suppose us singular in our opinion regarding the effects of oil of turpentine, we will just quote one sase to the point. A veterinary surgeon says (p. 432, vol. xxv. Veterinarian) that he was called to attend a horse with apparently colicky pains. "The village smith was summoned, who prescribed a large dose of oil of turpentine, which was repeated; but the symptoms increasing rather than abating, I was sent for. But, alas! ere my arrival the medicine had done its work, death having relieved the animal from further maltreatment. I at once proceeded to make a post mortem examination, and never saw more widely diffused inflammation. The whole of the intestines wrr bighly inflamed, and there was, besides, sufficient evidence of thr kidneys not having escaped intact, as also some of the other viscera. No cause being assigned, it is impossible to say whether the inflammation existed previously to, or was the result of, the administration of the turpentine. Even if the former were thy вase, it is certain the latter exacerbated the disease." 


\section{INFLAMMATION OF THE PERITONEUM.-- Peritomitis.)}

The peritoneum is a serous membrane, within the abdominal anvity, connected throughout the whole extent of the walls of the abdomen by cellular tissue. It forms a covering also to the whole of the risrera within that cavity. It is occasionally the seat of peritonitis, which does not differ from inflammation of the bowels; it is the same disease located on the outer instead of the inner membrane, and consists of a loss of equilibrium in the circulating fluids, or a determination of blood to the parts. It is supposed to arise from chilling the surface, or from mechanical injuries. The treatment is the same as for inflammation of the bowels; which see.

\section{DIARRHOEA.}

This is not a very common disease among horses; there is, however, a kind of feculent diarrhœa that often happens among gross feeders; yet, so long as it does not continue any length of time, nor prostrate the patient, it is rather salutary than otherwise; it is the only means by which the system can be relieved of the superabundant carbon which the depraved feeder often takes into his stomach at a time when there is no need of it; so that we should not be over-hasty in cheeking a diarrhoa of this description. A case which may serve as a warning to some occurred in this city some time since. The subject, a valuable dapple-colored stud, had an attack of feculent diarthoea; it had been on him about twelve hours, when the owner called on us, and stated that he wished to have the diarrlioe stopped, as he must ride the animal on the day following in a military procession. We represented to him the danger that might arise from suddenly arresting active peristaltic action, but our advice was not hefded. "Stop the diarhoa is all I ask of you; I risk the conserntences," said the owner; and accordingly we prescribed the following medicine:-

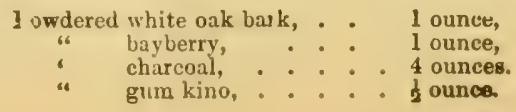


IIe ate the whole of this, mixed with dry meal, in the short epace of twelve hours. The diarhoca stopped; the horse per. formed the duty required of him to the satisfaction of his swer and, in spite of the most active treatment, died on the sererth day, of dropsy. We should use no efforts, therefore. to check a diarrhoe in its early stage, when occurring in a plethoric sub jett or depraved feeder. The occurrence should only serve as warning to us to dip a light hand into the meal chest, and diet the animal; perhaps a dose of sulphur, charcoal, and sassafras, in equal parts, to the amount of an ounce or more, may serve to arrest morbid action, and prevent fermentation. The form of diarrhoa for which our services have generally been required is the hepatic, in which there is an abundant watery discharge, mixed with fecal matter and slime, of a dark-yellow tinge: in such cases the disease runs into a chronic type; there is a marked coldness about the body and limbs; the appetite is impaired; the animal loses flesh very rapidly, and the discharges are frequent. The causes of the various forms of diarrhoa are, increased irritability of the intestines, which produce too rapid propulsion of the secretions; from a large collection of excrementitious matter in the digestive cavity; from perverted action of the liver; and from congestion of the mucous membrane of the intestines. These causes are often preceded by others which act directly or indirectly on the external surface; hence, if a horse, when in a state of perspiration, be suffered to cool off too suddenly, or if his body and limbs be sluiced with cold water when the exhalant vessels are very active, this disaase may follow. Some horses, when permitted to eat large zuantities of new oats and hay, are apt to scour : this form, how-ver, requires no medical treatment, for we have only to change the ditt, and there is an end of the matter Other animals of a weak, washy constitution are frequently attacked with diarrhœa wherever they are put to hard work; all that is needed in such asies is to change their work for something lighter, and give them an occasional dose of ginger and charcoal, equal parts.

Treatment. - As the disease is so apt to occur after the application of cold, we may safely, in all cases, excite capillary action on the surface, by heat and friction; the hody and legs may be 
clothed, as the case seems to recyuire, having previously rubled them with a wisp of straw; when there is great chilliness, wo find a loss of equilibrium in the circulation, and, of course, internal engorgements; and this state cannot always be altered by internal medicine alone; therefore we resort to the use of caloric externally, and stimulants internally. The following is fro quently used by us :-

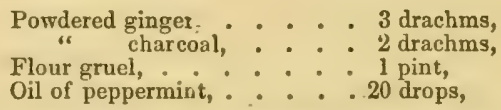

for a drench. Another dose may be given at the end of six hours, and is only contra-indicater by a too sudden stoppage of ths discharge, which we-must not be too anxious to check. A nutritious diet is always indicated in cases of prostration or debility. In almost all cases of chronic diarrhœa, we use a large quantity of charcoal, with the very best effect, allowing the animal also a liberal supply of flour gruel, seasoned with salt and cinnamon. If astringents are needed to chrck immoderate discharges, that have continued for several days, and apparently weaken the patient, we use hardhack, gum catechu, or hayberry bark. Diarrhœa occurring in a plethoric animal must not be immediately checked, but rather encouraged at first, by giving a dose of lin seed oil and lime water; two ounces of the former to six of the latter; it can then, at the proper period, be checked with the above remedies. If the disease depends on deranged digestive function, - the liver included, - give a few doses of the follox ing : -

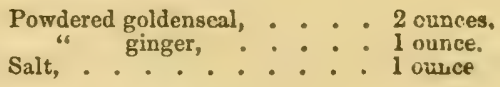

Uose, half an ounce twice a day.

\section{PALLING DOWN OF THE FUNDAIENT. - Prolapsus Ans;}

Falling of the fundament is generally occasioned by constipa. tion of the bowels, wherein a large quantity of fecal matter accumulates in such a manner as to cause a portion of the rectua to protrude beyond the sphincter muscle of the anus. This 
muscle, howerer, at times, seems to have lost the power of ccr tracting to its normal size, from the pressure from within out wards; hence the great difficulty of keeping the parts withir their limits, even after they have been returned.

The difficulty may also be occasioned from inordinate peristal. tic action, known as purging, looseness, and diarrhoea; it pro. ceeds then from debility, and besides using local astringents, the patient's health must be restored by means of nutriiious diet ard atterative astringent medicines. Powerful drastic cathartics and orer-exertion are clašsed among the causes of prolapsics.

Treatment. - If the case be one originating in constipation, the bowels must be evacuated with the following drench -

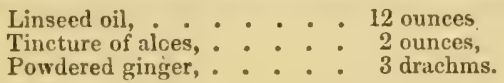

1t, however, the bowels can be evacuated with any of the saline aperients, such as epsom or glauber salts, they are to be preferred. The object is to unload the bowels, and the less medicine and the more mild its operation, the better. When the bowels have responded to the medicine, they must be kept soluble by scalded mashes, green food, if it can be had; a liberal allowance of salt will be of benefit, not only in view of preventing constipation, but also for the purpose of preventing the food generating the usual quantity of carbonic acid gas ; the result of which would be distention of the bowels, and great obstruction to the return of the gut. If the bowels are merely in a torpid condition, and the constipation has existed but a short time, the followiıg aperient will be indicated : -

Flowers of sulphur, * * : 1 ounce,
Powdered bloodroot, . * : 2 drachms,

To be mixed in a bottle, with half a pint of molasses and wat: $\mathbf{r}_{\text {. }}$ fir a drench.

The rectum must be returned by the most gentle means, and kept in position by pad and bandage. Before returning the parts, th ay should be freely bathed with cold water; the water may be made slightly astringent by the addition of a few drops of tincture of muriate of irom. or a small quantity of powdered alum. The cold water contracts the capillary vessels, and subdues 
inflummatory symptoms, and of course reduces the size of tho tumor, so that some time should be spent in bathing the parts ere the reduction be attempted.

A case of prolapsus ani was treated by the author a short time ago, which is here introduced as an example to illustrate the treatment. The subject was a bay gelding, nine years old, of plethoric habit; he had been used but little during the proxions three weeks, although kept on full feed; the groom had noticed that the animal strained hard in voiding the excrement, and that considerable protrusion of the rectum took place at such times. The prolapsus was of two days' duration ere the author's attention was called to it.

The protrusion was large, presenting a highly-inflamed lobular surface of thickened mucous membrane, very sensitive, and somewhat gangrenous near the anal opening; emitted a fetid odor and discharged a sanious Huid.

T'reatment. - A drench was given, composed of

$$
\begin{aligned}
& \text { Sulphur, . . . . . . . . l ounce, } \\
& \text { Creum of tartar, . . . . . . . \& ounce, } \\
& \text { Flaxseed tei, . . . . . . } 1 \text { pint. }
\end{aligned}
$$

After which, a clyster of salt and water, to avoid mortification, was auministered. It brought away some slimy excrement, yet agrgravated the prolapsus. The parts were then bathed by means of a soft sponge. with an astringent wash, (one ounce of tincture of muriate of iron to a bucket of water,) which, after a time, reduced their size. With a view of producing an astringent effect, and thus collapsing the rectum, a small portion of the liquid was thrown into the interior, taking care to let it flow from the syringe in a gradual mumer, so as not to excite peristaltic action.

Reduction of the Tumor. - A pad of linen, wetted with alum h at 2 , was placed on the tumor, and constant pressurc, aidec hy u zort of kneading of the fingers, was kept up for some time, but to no purpose, when the following expedimnt was resorted to: Ilaving procured a middiling-sized bladder, the air was pressed] out of it ; on being softened with warm water, a common horse catheter was intivduced through its neck, and there fastened with twine; after being smeared with olive oil, it was introduces within the rectum ; an assistant was now directed to place the 
other end of the catheter in his mouth, and gratually inflate the bladder. After being sufficiently inflated to occupy considarable space, it was gently pressed forwards, and by kneading and pressure on the external tumor, it was immediately reduced. On removing the finger from the open orifice of the catheter, which had been placed there to keep the bladder inflated, the latter collapsed, and was shortly after withdrawn. Pressure, by rxeans of pad and bandages, was kept up for several bours; at which time the patient showing signs of a desire to dung, the bandages were loosened so as to permit elevation of the tail. Some faces, accompanying the fluid which was thrown into the rectum, came away, following which a protrusion of the gut. This, by the aid of astringent lotion and manipulation, was easily returned. The animal at this stage was left in charge of its owner for the night, who was instructed not to let him lie down, and to return the rectum if it should again protrude.

On inquiring next morning, the attendant informed us that the patient had voided faces twice, and that the gut protruded each time, although much smaller than at first, and more readily reduced. Our own observation, at a later period in the day, dissovered that the tumefaction, irritable and inflammatory state of the parts, had subsided, and also that a portion of the mucous membrane had slonghed off, and the muscular coat of the rectum was perceptible; a f'ew soft, pulpy lobules of mucous membrane, of a gangrenous aspect, remained, and they were dressed with pyroligneous acid and pulverized charcoal. The following (antseptic and alterative) was given:-

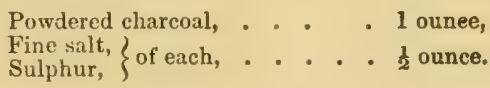

Stirred in a mess of scalded shorts.

Bathing the anus and the surrounding parts with cold water every two hours, and an antiseptic injection at niģht, concludes tha second day's treatment. The patient was deprived, from the first, of all food except a small quantity of fine feed slops, tho object of whish will be apparent to the reader.

Third day, the bowels were soluble; evacuations, howerer scanty; pulse and respirations, which had hitherto been disturbed were normal: no nrolapsus since yesterday: 


\section{Gave}

$$
\begin{aligned}
& \text { Pyroligneous acid, . . : : } 3 \text { drachms, } \\
& \text { Thin grucl, . . . } 1 \text { pint. }
\end{aligned}
$$

Cold water bathings were continued. This comprises about the whole of the treatment. The animal gradually returned to full dist, and from exercise to work.

Operation for Prolapsus Ani. - In the event of failing to return the engorged gut by the means here recommended, and the difficulty increasing, nothing remains but to operate by excision. Our first business is, to secure the patient, so as to guard the operator from personal injury: if the horse is of gentle disposition, a side line and twitch may suffice; but if ${ }^{\circ}$ he proves restive, and seems unwilling to have the parts handled, he must be cast; it is good policy, however, not to cast a horse unless we are convinced that it is our only resource. The instruments needed for the operation are, a common scalpel, tweezers, scissors, an armed needle, ligatures of saddler's silk, a bucket of water, and sponge. The tail is to be turned upwards and forwards, on the rump, and there held by an assistant. The operator then dissects the engorged mucous membrane from the muscular coat of the rectum, taking care not to injure the latter.

In the course of the operation, some ramifications from the rectal arteries will be divided; the sponge, and perhaps the water may now be needed, to wash off and absorb the blood, so as tc enable the operator to see and take up, with the tweezers or forceps, the blecding arteries; if they can be so taken up, they are to be secured by ligature; if any difficulty is experienced in getting hold of them, pass an armed curved needle partly around the bleeding vessel, including some of the mucous tissue, and thus secure it. After excising the parts, wash with cold water, an? ascertain if any bleeding vessels remain untied; being all secured, the operation is completed. Some persons dress with some sort of traumatic, viz., tincture of myrrh, \&c.; but, in a case that occurred lately, we used nothing but cold water, throwing, by means of a syringe, a pint into the rectum morning and evening. The patient must be kept on a light, unirritating diet, and hav walking exercise as often as convenient. If constipation super. renes, give a d sse of cream of tartar and sulphur. Any unliealthy 
appearance about the interior of the fundament, or fetid dischargs from the anus, which may occasionally happen in warm weather. irust be $\mathrm{m} \imath \mathrm{t}$ by antiseptics: diluted acetic acid, pyroligneous Bcid, solution of chloride of soda, are among the articles best calculsted to arrest morbid action.

\section{SCOURS AND CONSTIPATION IN YOUNG COLTS.}

A friend, residing in the Mohawk valley, informs us that many young colts are troubled in that vicinity with scours - diarrhœa after they become a week old; and that others, at the same age, die of constipation. As the disease, in all probability, is not peculiar to that regivel, we propose to give the reader our opinion on that subject. In the treatment of scours, or constipation, occurring in animals of tender age, too much attention cannot be paid to the mother; she, having just passed through a trying ordeal, the period of gestation, - and having brought forth her young, now requires, to say the least, what might be commonly termed a little kind nursing. It is a common element in the nature of mankind to sympathize with those in pain or distress, and our sympathies should at all times extend to domestic animals. At no time has the female greater claims on us than at the very interesting and to them trying period of parturition; and if that care be bestowed upon them which their condition requires, and which they are entitled to at the hands of their "lord and master," many maladies which are of daily occurrence, both to themselves and offspring, might possibly be prevented. In our estimation, it is not a feature of good husbandry, to say the least of it, to turn a mare out to grass, or elsewhere, to shift for hesself, immediately after foaling, particularly after she has been submitted to all the evils of domestication; for she may nct be able, from the scantiness of the provender, to obtain sufficient notrishment for herself and offspring; for the colt must now, and, indced, until it be able to masticate food, depend altogether on the parent's milk, and the latter cannot furnish it in sufficient quantities unless kept on generous food. It is pretty hard work for a mare that has always been pampered and fed on highly nutritious food to procure enough to supply her own and the 
foal's wants, and the practice has heen very appropriately termod "working for a living." We should have no hesitation providen the mare, having passed sately through the parturient process, is now doing well, in recommending that she be turned, for a few hours daily, into a good wholesome pasture; not, however, until twenty-four hours after her delivery. When taken up for the night, a wide stall, good bedding of clean straw, and a generous supply of her usual food, should be assigned her. Mr. Touatt durects that, "As soon as the mare has foaled, she should be turned into some well-sheltered pasture, with a hovel or shed to run into when she pleases; and if the grass is scanty, she should have a couple of feeds of corn daily. The breeder may depend upon it, that nothing is gained by starving the mother and stinting the foal at this time; it is the most important time in the life of an animal, and if from false economy his growth be now arrested, his puny form and want of endurance will ever afterwards testify the error that has been committed. The food should be given in a trough on the ground, that the foal may partake of it with the mother:' White also recommends, "that the dam should be well fed."

Now, suppose that, in consequence of a want of attention tr these and other particulars, (all forming a necessary part of stable economy, the mother shall be the subject of temporary functional derangement; and if so, the foal will also suffer in like manner; for the mother cannot have any derangement of the digestive function, however slight, but it will also affect the nursling.*

- The milk of a woman (and we may add that of a horse, tn a certain extent; differs, -

"1. In Respert to Food. - The milk of a woman who suckles, living upon regeto.animal focd, never acesces, nor coagulates spontaneously, although exposed for miny wecks to the heat of a furnace. But it eraporates gradually in an open vessel, and the last drop continues thin, sweet, and bland. Th.e reason appears to be, that the cascous and eremoraceous parts cohere together by means of the sugar; hence its acescence is prevented. It does acesce, if Inixed or boiled with vinegrar, juice of lemons, supertartrate of petassa, dilute 8ulphuric acil, or with the human stornach. It is coayulated by the acid of salt, or nitre, ar: by an acid gastric juice of the infant; for infants often romit up the co.tgulated milk of the nurse. The milk of a suckling woman who lires uznn regetable food only, like cow's milk, easily and of its own accord acesces, grid is ated upon by all coagulating substances like the milk of animals.

* 2. ' $n$ R.wject to the Time of Digestion. - During the first hours of digestion 
Hen $x$ our first duty is to attend to the wants of the mother establish her health if it be impaired; then, if the foal has scours, or constipation, we may set abou obviating the difficulty with some chance of success : even then it is not always good policy to administer medicinal agents to an animal of a few hours' growth; but we can, with safety, provided our agents are sar.ภ. tive, use them on the mother, and thus the foal will have the benefit of them through the lacteal secretion, for it is a well established fact that many medicinal agents pass into the living organism unassimilated, and can be detected in the various secretions: thus the color of the cow's milk is changed when that ani.

the chyle is crude, and the milk less subacid; but towards the twelfth l:our after eating, the chyle is changed into blood, and then the milk becornes yellawish and nauseating, and is spit out by the infant. Hence the best time for giving suck is about the fourth or fifth hour after meals.

"3. In Respeet to the Time after Delivery. - The milk secreted immediately after delivery is serous, purges the bowels of the infant, and is called colostrum. But in the following days it becomes thicker and more pure, and the longer a nurse suckles, the thicker the milk is secreted.

"4. In Respect to Food and Medicines. - Thus, if a nurse eat garlic, the milk becomes highly inpregnated with its odor, and is disagreeable. If she indulges too freely in the use of wine or beer, the infant becomes ill; from giving a purging medicine to a nurse, the child also is purged; and, lastly, children afflicted with torpor of the bowels, arising from acids, are often cured by giving the nurse animal food.

" 5. In Rospect to the Affections of the Mind. - There are frequent examples of infants being seized with convulsions, from suckling mothers irritated by anger. An infant of one year old, while he sucked milk from his enraged mother, on a sudden was seized with a fatal hemorrhage, and died. Infants at the breast, in a short time, pine away if the nurse be aflicted with grievoue cire; and there are also infants who, after every coition of the mother, or crea if she menstruate, are taken ill."

The use of the mother's milk is, -

"1. It affords the natural aliment to the new-born infant, as milk differs little from chyle. Those children are the strongest who are nourished longest with the mother's milk. [This we doubt.]

"2. The colostrum should not be rejected, for it relaxes the bowels, which in new-born infants ought to be open to clear out the meconium.**

"3. Lactation defends the mother from a dangerous reflux of the milk into the blood, whence lacteal metastasis and leucorrhaca are so frequent.

* Meconium; the green excrementitious substance that is found in the large intes. tine of the foctus in lying-in women, who do not give suck. The motion of the milk also, being hastened through the breasts by the sucking of the child, prevents the very commion induration which arises in consequence of the milk heing stagnated. 
mal is fed on beets; when fed on garlic, its odlor can be defected in that fluid; and every farmer knows that turnips impart their own taste to it also. Stock raisers might learn a lesson from nurses who attend human parturients; they give the old-fashioned dose of castor oil understandingly, knowing from long experience that it operates both on the mother and child. Hence, if the foal shall suffer from constipated bowels, and the mother be in the same condition, the medicine should be given to the latter: thus many young animals might be saved; that they do die from the effect of drastic purges we know, and our correspondent testifies to the fact, for he says, "Some have constipation, and are often killed by forcing salts down them." It must be evident that salts and aloes are not the best remedies in the world for colts but " $a$ few days or a week old." A human practitioner who could be so reckless as to administer like remedies to the new-born infant, would certainly be censured, and run a great risk of losing his patient. The milk of the mother, immediately after parturition, is the best kind of medicine to regulate the secretions and excretions of the offspring, and it generally has the desired effect, unless, as we have said, the mother is ailing. There may, however, be cases where, in consequence of exposure, the foal may have diarrhœa; then the little subject becomes an olject of special attention, as regards his management. IIe must be placed n a warm situation, with a view of restoring the exhalant function of the skin, for until this is restored there is but little chance for recovery. Having taken these preliminary steps, perhaps all that will now be needed for the cure is some warm ginger, or caraway tea; and a little of either of these simple articles, pulverized, may, with alvantage, be given to the mother in her food. If the latter be the subject of scours - diarrhœa - then our chief attention is turned to her; we administer such medicinal agents as the nature of the case seems to require; at the same time, if the patient is fat, and has not had sufficient exercise previous to parturition, we are not to be in a hurry to stop the discharge, but merely to bold it in check. If, on the other hand, our patient is in poor condition, and still losing flesh, then, in addition to medicinal agents, which should be of tonic and astringent properties, we give freely of gruel made of whent flour. Under these vir 
cumstances, and as long as the scours continue, the foal shuula not depend altogether on its dam for sustenance, but might have a daily allowance of boiled cow's milk, cooled to abou: the temperature of milk when drawn. Hay tea, to which a small quan. tity of cow's milk may be added, is an excellent drink for the young foal in the absence of its mother's milk. Try it, reader, on your calves, also, if you have occasion.

As regards costiveness, green food and scalded shorts are the antidotes, and the mother will partake of either with relish; some of the former, if the season permits, should be cut and placed before her soon after labor. If the articles fail to have the desired effect, a dose of aperient medicine - castor oil, or salts should be given, followed by thin gruel; in this way both dam and foal may be cured.

Astringent drink for colts :-

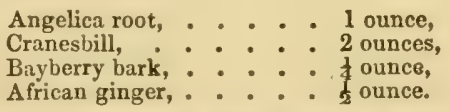

Pour on the above ingredients two quarts of boiling water; set them aside for a few hours.

Dose. - Half a pint every four hours until the disease is checked. If the discharges are fetid, add to each dose lialf a table-spoonful of finely-pulverized charcoal, and if the foal be weak and in poor condition, allow it hay tea, thickened with oatmeal.

Probably the safest laxative for young calves, suffering from constipation, is sulphur and cream of tartar, of each a tea-spoonful in molasses. Laxative enemata should, if necessary be ad. ministered.

\section{INDIGESTION.}

This is the great national disease of the United States; both men and horses are alike its victims; it lies at the bottom of almost every disease to which both are subject, cunsumption not excepted. The horse shows it by an unthrifty condition, and dry, pen-feathered coat; his body shrivels and contracts after the fashion of that of a smoked herring; he has a dry-sounding, bard cough, mostly noticed after meals, especially when he bas 
just madt a hearty one on foul litter, which he is very apt to do at other times, however, he is very fastidious, and, like his mast ter when suffering from the same disease, wili search for some thing nice; failing to find it, the subject has no objection to a little dirt, sand, plaster, or a small piece of brick. which he masticates with considerable relish. The deranged state of the digestive organs is generally indicated by an intolerable fuetor of breath; the excrement, too, has the same unpleasant smell, and is very variable in color and consistence, often hard and covered with slime; at other times soft, when the presence of intestinal parasites can be detected. The urine is scanty, and either colored or thickened with foreign material; in fact, both the functions of excretion and secretion are impaired. The animal is generally cross and irritable, and leaves the stable, at working time, very unwillingly; he requires considerable urging while travelling, and, of course, is incapacitated to perform his usual work. These are the main symptoms of indigestion; they are not noticeable at first, but gradually arrive at this state, increasing in intensity, diminishing, or running into other affections, according to circumstances. Acute indigestion is apt to terminate in acute diseases of a different character, and the chronic form in diseases of a chronic type. For treatment of acute indigestion, see Gastritis.

Causes. - The causes of indigestion are numerous: too little or too much of food, water, or work; bad ventilation ; exposure; poisons; damaged or highly nutritious food; working the animal on a full stomach, - are all operatire in producing indiges. tion in its acute or chronic forms.

Treatment. - In treating cases of disordered digestive organs, we first remove, if possible, the cause. In view of ascertaining that, we inquire into the history of the patient, and ascertain in what way the laws of his existence have been violated, and if successful, we apply the remedy, or remove the cause. It is impossible to lay down rules as to the quantity of food required by a horse, because his health and life are subject to various modifications, under a variety of circumstances; therefore it is folly to say how much this or that animal shall have, for the quantity suitable for one may be insufficient for the other, and 
vice versa. The amount of exercise, kind of work, and con dition of the animai, are the modifying circumstances which are to be taken into account, ere we can form any idea of the amount of food required. A foul feeder should, in the intervals between meals, be muzzled, or the bedding must be taken away. If the animal has been fed on dry food, let him have a mixture of boiled oats, shorts, and carrots, well seasoned with salt, to which add daily half a table-spoonful of white mustard seed. We Lare used brandy and salt, with very good effect, in several cases of this kind - one pint of pale brandy to four ounces of fine salt; dose, a wine glass, in oatmeal gruel, night and moming, just be. fure meals. A suflicient quantity of good hay will be needed, in order to distend the stomach to its bealthy calibre, yet the animal must not be permitted to spend half his time eating; for the digestive organs require regular periods of rest, just as other parts of the system do. Attention must also be paid to the water which the animal drinks: if it be inconvenient to substitute a different kind, throw a handful of pulverized charcoal, daily, into the water trough, this will improve the very worst kind, and render it innoxious and palatable.

In view of acting on the system at large, and improving the general health, take

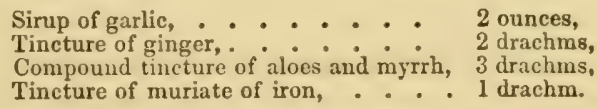

Mix; to be given occasionally in oatmeal gruel. Or, if it be more conrenient, substitute the following:-

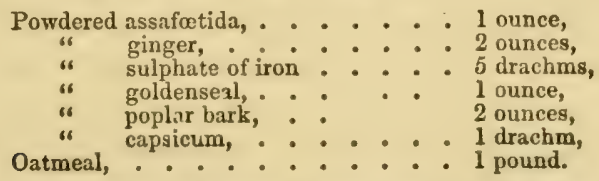

Divide the mass intc eixtoen doses; one to be giren, in firch very night. 


\section{DISEASES OF THE LIVER.}

\section{JAUNDICE. - (Icteris. $)$}

Definition. - A yellow discoloration of the tissues, caused $\mathrm{kg}$ an interrupted excretion of bile.

(In making post mortem examination of animals having been the subjects of this disease, we find the yellow tinge pervading every part of the organization. It is diffused through the whole of the muscular, fitty, cartilaginous, cellular, bony structures. and has also been detected in the brain.

Mr. Percivall considers " jaundice to be an unfrequent disease nmong horses; and one reason appears self-erident, as soon as we are put in possession of a knowledge of the camses from which it may proceed. I mentioned swelling or compression of the hepatic duct as one, in speaking of it as a symptom of hepmtitis ; * and probally this is the most common one. In the human subjeret, it frequently arises from obstruction of the ducts, either from collected or concreted bile in them, to which the name of biliury calculi is given; or it may be the ef ect of spasm in the ducts, or in that part of the auodenum $\dagger$ where tney terminate, but I am not aware that cases of this kind have oceurred in veterinary pratetice; and one reason, I repeat, is obvious. The norse has but a single duct, through which the bile flows at fast as it is secreted; it has no retrograde course to take, no receptascle to collect in and to conerete into gall stones; and, as a proof that this is one reason, dogs, and such other of our domestic quadrupeds as have gall bladders, are all of them much oftener jaundiced than horses. People who lead sedentary lives, such as corpulent subjects and women, are predisposed to jaundice; in them the bile often grows irsptssated $\ddagger$ in its ducts, and biliary calculi are now and then cietected in the stools: this is a cause

- Inflammation of the liver.

+ The first purtion of the intestines; sometimes called the second stomach In cattle it is known as the fourth stomach.

t Thickenad 
of disorder as I have said before, that we ean b .t rarely adduce in veterinary practice.

"Jaundice, produced from whatever cause it may he, consisto .n the absrrption of unchanged bile into the circulation, whish bile becomes diffused and conveyed to every part, giving rise to those nppearances that are so remarkably clatracteristic of its presence. It does not appear to originate either in defective or altered souretion; for, had not the liver done its office, how could wo explain the appearance of bile in the system at all?

"The yellow aspect that jaundice gives to the skin, the mouth, bud the eyes, at once betrays its presence. The skin is every where dyed yellow, though the change is only visible to us in places bare of hair. The nembrane of the mouth puts on the same appeararce. The conjunctiva (the membrane lining the eyelids) has a yellowish-pink hie, the cornea is obscured, a yellow sediment may often be pereeived floating in the anterior chamber, and the iris itself is tinged in places with this yellow dye. The bowels are costive; the excrement that is voided is hard, buttony, and dark-colored, besmeared often with a yellow, slimy matter, like bile diffused in mucus, and consists of dryish masses of ill-digested aliment. The urine is a deep-yellow on orange color, and is sparing in quantity. In the human subject, the absorption of bile into the system often generates considera. ble disorder, operates, in fact, like so much poisonous inatter, exciting an itching sensation of the skin, and depressing the strength and spirits of the patient; and the latter of these effects is often very remarkable in jaundiced horses. The eyelids are drooping or closed; the head hangs down; there is evident sinking both of strength and spirits; and often there is a degree of moping stupor present, which, at times, borders on vertigo, o that the animal walks unsteadily, or reels as he moves; lin pulse is about 60 or 65 ; his respiration is unaffected, and bis flank untucked up.

"In the treaiment of jaundice, our sheet anchor is purging. No time should be lost in exhibiting ten or twelve drachms of uloes; * and, if we can insure the administration of it, tho 
decoction is preferable to a bolus. If there was nuch st apor or vertigo present, I would bleed, but not largely. I would follow up the first dose of aloes with half an ounce in solution every twclve hours until purgation came on ; we need be under no approbensions of super-purgation * in these cases. As soon as the bowels are freely opened, apply a blister to the right side, and repeat it every twelve hours. $\dagger$ It may be necessary to recur in the renesection.

"Now and then jaundice terminates fatally, and when it does 80 . the event is commonly sudden; probably some time has elapsed before we are called in; the bowels resist our first dose of medicine; in the mean time the pulse rises in spite of our recurrence to the use of the lancet; the skin and extreme parts become cold; the animal grows senseless, and perhaps vertiginous, and in that state suddenly drops and expires. On dissection, the liver is found glutted with bile. I found the gland so prodigiously distended in one case that the right lobe of it had burst, and displayed a considerable fissure.

"Now and then we hear of cases of rupture of the liver. I have never been present but at the one mentioned above, myself, but I am told that large, heavy, draught horses are

\section{- Excessive evaclation.}

+ Humanity calls upon us to dispense with blistering if it can possibly be done. There is no necessity for resorting to such cruel means : when counterirritation is really needed - and we doubt if, under the circumstances, it could accomplish any good - there are a number of agents that we ean safely rely on to fulfil that indication, withouf putting the animal to so great pain.

The only method of getting rid of the bile, diffused in the system, at the same time favoring its passage into the duodenum, and palliating all urgent symptoms, consists in regulating the various secretions: this can only be do:e un general principles, for the disease is not only manifest on the surfaces, hut Iso in the serum of the blood, in the urine and excretions generally, and in nualy all the tissues of the body. Suppose jaundice results from indigertica; aill a blister restore the integrity of the stomach ?

The coloring matter, and other constituents of the bile, are known to exust originally in the blood; and it is reasonable to suppose that it may there accuinulate, producing a radical alteration of the latter fluid, a poisoning, as it has been called. Do blisters purify the blood ?

Then, again, if jaundice shall originate from an engorgement of bile, in cons quence of the closure of the outlets in the liver, - or the destruction of its becreting cells, - in either case a blister is the very last thing we showald think of resorting to, mucn less repeat it every twelve hours. 
more paxticularly liable to the accident, and that it happins in the violent efforts they are compelled to make in drawing heary ioads."

Should the bowels be freely opened, we think that both blister and venesection might be dispensed with, for human practitionere have found it advisable, in treating disease of this character, to dispense with both.

C'use of Jaundice. - November 2, 1851. - Visited a dapplegray gelding, the property of Mr. C. Found the animal standing in the stall with his head hanging below the crib; his position that of a weak (apparently lazy) horse; pulse 58, respirations 17 ; eyelids partly closed; on raising which, the membranes presented a yellow cast; the same was observed in the mucous surfaces of the mouth. We were told that the urine was of a dark-yellow color; the excrement dark, slimy, and hard. Commenced the treatment by giving

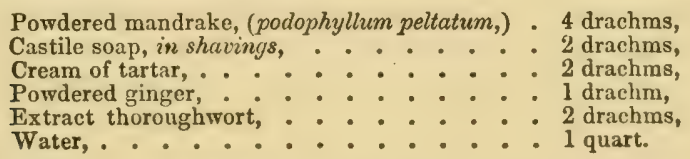

Two quarts of weak soap suds were now thrown into the rectum, which brought away a moderate quantity of fetid dung.

As the animal appeared to be in very fair condition, directions were given to keep him on a light diet of scalded shorts.

November 3. - The horse is in much the same condition as yesterday; the medicine, however, has operated. He has partaken of a very small portion of the mashes; has eaten some hay, aud drank, at various times, about three gallons of water. Gave the following in one quart of warm water:-

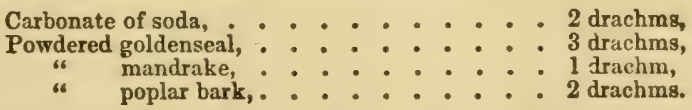

Thn mash to be continued, and a few carrots to be thrown int: the crib.

November 4. - The animal is apparently better; his motions sre more lively; appetite slightly improved; bowels relaxed; 
arine more abundant, yet of a yellow cast; the mucous surfices still tinged yellow; the pulse and respirations have not varied much from the commencement. As the bowels appeared to be sufficiently relaxed, the mandrake and soda were omitted, and the following tonic draught administered:-

Goldenseal, 2 drachms,

Extract thoroughwort, : . : : : . . 1 drachm.

Diet - the shorts to be mixed with an equal part of meal, und a small quantity of hay allowed.

Norember 5. - The animal has improred some since yester. day; is more lively and willing to move; the appetite is returning, and he has partaken of food with good relish; the excre. ment appears more natural, yet has a glossy appearance on its surface. We had no opportunity of observing the color of the urine, but were told that "it looked well." The yellow tinge has almost disappeared from the membranes of the mouth and eye : the latter is quite bright. Ordered the following:-

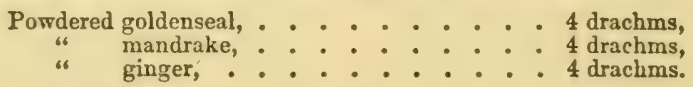

Which was divided into eight parts, one to be given in the feed twice a day; the animal to be well groomed, and have walking exercise in the open air.

Saw the horse again on the 7 th. The case had now assumed a favorable aspect; scarcely a trace of the yellow tint was to be seen. We gave directions to continue the powders, the horse to be regularly exercised, and return to his accustomed diet. This is the last we saw of the animal; but learned that be was taken out of the city the next day, and soon put to work.

This disease was probably induced by over feedingr on cracked corn and oats, which produced irritation of the stomach and intestines, and the liver became diseased purely by sympathy with those parts

\section{INFLAMMATION OF THE LIVER. - (Hepatitis.)}

T'he parenchyma, (cellular substance which connects the body of the liver together, ) and serous surface of the liver, are occasion. ally the seat of increased vascular action; rather unfrequent, 
howev'r, in horses: they seem to enjoy, to a certain extent, immunity from a disease which appears to have a greatır affinity for the livers of their masters; or else we have not been smart enough to detect it in our patients, having noticed but a few isolated cases. The most of the symptoms noticed in this affection do not differ materially from those noticed in jaundice; other local siens are required, however, to make out a case of acute hepatitis; these are, pain in the hepatic region, extending to the right shoulder, so that the patient is lame in the off limb, unsteady in he gait, and evinces signs of pain on our pressing in the above region. The pulse is strong, skin hot and dry, slight cough, loss of appetite, and dull, sleepy look. For consecutive symptoms and treatment, see Jaundice.

When the disease is located in the serous covering of the liver, it is called hepato-peritonitis. The treatment loes not differ from that for the preceding disease.

Softening, condensation, and tubercles are the result, in some cuses, of a chronic torm of hepatitis; for the demonstration of these states during the subject's life our diagnosis is all at fault, and therefore it is useless to write any thing about the treatment, other than to inform the reader that the author's remedies for the cure of diseases of the liver are, mandrake, ${ }^{*}$ soap, and carbonate of soda.

* Medical Properties of Podophyllum, (Mandrake.)-Podophyllum, when administered to man, is an active and certain cathartic, producing copious liquid discharges, without much griping or other unpleasant effect. Its operation resembles that of jalap, but is rather slower, and is thought by some to be more drastic. It is applicable to inflammatory affections, which require brisk purging. The common names by which this plant is known are May apples mandrake, \&c. It grows in almost all parts of the United States

From our own experience in the use of the article, we can safely 1ecommend it us an efficient cathartic; very permanent in its operation, generally leav. ing the bowels in a soluble condition. It seems to have a peculiar action on the liver, and when given to a horse, in repeated doses of from one to two drachms, every twelve hours, operates in the same manner as when calomel is prescribed; though less liable to do harm, in the hands of the inexperienced, than the latter article. In this view, we term mandrake "the calomel of the physopathist." Its range of application, however, is more extensive than that of calomel. It may be usol as a substitute for aloes, whenever an activ cathartic is indicated, in doses of from four to seven drachms, in the form of arcach. We have frequentl' used it as ar aperient, in inflammation of the 


\section{DISEASES OF THE EYE AND ITS MEMBRANES.}

\section{INFLAMMATION OF THE EYE.-- Ophthalmia.)}

Oplutral.min is a disease so familiar to every one, that a deecription of it seems unnecessary. Its seat is in the membrane which lines the inside of the eyelids and covers the white of the eye; its diagnostic symptom is vascular congestion. When seen and treated in the early stage, it generally yields to very simple treatment; if, however, it advance beyond the primary stage, structural and functional alteration takes place. A simple inflamed eye, to some persons, does not appear of much account; yet the author would inform such, that from this primary form of disease others of a more alarming nature supervene.

As prevention is much eheaper than cure, it must be obvious that it is of great importance to practise that system of management, with respect to feeding, exercise, cleanliness, and ventilation, which is most likely to prevent ophthalmia. When horses are put to regular daily work, their health will be best maintained by feeding them regularly three times a day with a mixed diet, composed of bruised oats, shorts, meal, crackeu eorn, and cut hay. These should be allowed in suflicient quantity, and no more; for too much food must impair the digestive organs and derange the general health.

As regards exercise, it is indispensable. No man or horse can ever enjoy good health unless habituated to daily exercise; it tends towards their health ard strength, assists and promotes a free circulation of the blood, determines morbific matter to the

langs and jowels, in doses of two drachms, repeated as sccasion seemed so require. With a view of preventing its local action on the mucous surfaces, is the latter diseases, we always give it in a thin mucilage of slippery elm. If $\mathrm{s}$ alterative is indieated, we prescribe it combined with equal parts of goldenseal, from one to two drachms of each, daily. We could say a great deal more in proof of its extensive therapeutic power, but refrain, in hopes that some of our professional brethren will give it a trial. We are not aware that it has ever been used in reterinary practice until of late. The therapeutic (curative) prop erties of podophyllum are dependect on the presence of a principle called Podophyllin. 
various outlets, derelops the muscular powers, creates a natural appetite, improves the wind, and finally invigorates the whole system. The exhaustion produced by want of rest is equally dangerous; such horses, at certain seasons of the year, are always anong the first victims, and when attacked their recovery is generally prctracted.

As regards cleanliness, the brush and curry-comb should be ased morning and evening; the latter, however, must be dispensed with when the horse is laboring under any form of cutaneous disease, at least while in its acute stage. Good mibling promotes the circulation of blood through the capillary vessels, acts as a counter irritant, and relieves congestions. Many of the diseases to which horses are subject, more particularly those of the alimentary canal, hare their origin in a filthy skin. We are decidedly opposed to the use of the curry-comb with a view of divesting the horse's legs of mud and filth, for the parts below the knee and hock are destitute of fleshy fibre; from which circumstance the periostcum, enveloping the bone, is more exposed to violence from the tceth and edges of the curry-comb. If a horse comes from his work covered with mud, the better plan would be to detach it, when dry, with a wisp of straw, after which a g od stiff brush will put on the polish.

The admission of light into stables, being a subject next in importance to the former, deserves a passing notice. Nothing is so detrimental to the eyes as sudden transitions from comparative darkness to a glaring light; and probably many of our readers have, at some time, experienced the very unpleasant sensation of mingled pain and giddiness, which is not readily dismissed, after emerging from a dark room, and suddenly coming in contact with the glaring rays of the sun; and if they have, they know how to Eympathize with a poor horse.

Treatment. - As soon as the inflammatory symptoms make their appearance, the patient should be placed in a situation where he shall be free from annoyance of every kind. A cool shed, rather darkened, will be the most desirable place; a very light diet of scalded shorts, or gruel, will be all the patient needs, until the inflammatory symptoms somewhat abate.

We commence the treatment by administering an actire or 
mild cathartic, as the case may seem to require: thus, if the Dowels are soluble, a mild dose is indicated, consisting of

$$
\begin{aligned}
& \text { Powdered Socotrine aloes, . . . } 3 \text { drachms. } \\
& \text { "gentian, .. . . . } 2 \text { drachms, } \\
& \text { " cream of tartar, . . . } 1 \text { drachm. }
\end{aligned}
$$

Mix with honey for a ball, or with warm water for a drench.

Should the dung appear hard, covered with slime, or even dnrk.colored, the following must be given:-

$$
\begin{aligned}
& \text { Aloes, . . . . . . . } 5 \text { drachms, } \\
& \text { Gentian, . . . . . . } 2 \text { drachms }
\end{aligned}
$$

Mix as above.

We do not wish the reader to suppose that in all cases of this complaint a cathartic is absolutely necessary; for in some instances a foreign body may have lodged on the sclerotica, the removal of which, and the after application of cold water, may be all that are required for the patient's relief. Whereas, to purge a horse, under the circumstances, would be both absurd and injurious. A careful examination, therefore, of the eye must be made, and the inspector having satisfied himself that there is no local cause of irritation, and that the nature of the case demands active treatment, then a cathartic will be indispensable.

Local means, for the purpose of allaying irritation, must now be resorted to. Authors recommend various articles; our favorite one is, -

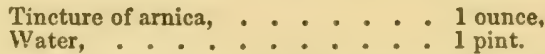

In bathing the eye, a piece of soft sponge should be used; at the same time bearing in mind that the eye is highly sensitive, and that any unnecessary handling of the part is liable to give the patient great pain, and increase inflammation.

The head should be sponged two or three times a day with cold water; nothing tends so much to allay superficial inflam. mation as the application of cold water- "It puts out the fire of inflammation."

It has been customary, and the practice has received the sanction of eminent surgeons, to abstract blood in this case from the jugu lar vein; but as the author has no sort of confidence in such procedure, he cannot recommend it. Bleed the horse through the 
alimentary canal, is our motto, by means of purgatires; * thus the superabundant fluids of the body can be drawn off, and the Esstem as certainly prostrated as in the use of the fleam; not tc the same extent, however, unless purgation be continued beyond the limits of reason and experience. Why should not a system, comparatively speaking, of starvation, be superior to the comn on mode of prostrating, viz., by bloodletting? for in withholding food we put a stop to the nutritive processes, and the animal, as it were, lives upon himself, thus reducing the fluids and solids of the body: this is just precisely what the practice of phlebotomy contemplates. At the same time we seriously protest against unnecessary use of physic. Cathartics may now and then be indicated, but bloodletting never. This is our honest conviction ; yet at the same time we have no ill feelings towards those who conscientiously practise the latter.

During the active stage of this disease, cooling drinks are useful, because they lessen the febrile symptoms, and at the same time prove refreshing to our patient; and, if composed of suitable agents, they tend to aid the exit, by appropriate channels, of all excrementitious matter. In this view we use cream of tartar or epsom salts. One ounce of either article, dissolved in a common bucket of water, answers the purpose.

This drink may be allowed, at discretion, during the time and after the medicine shall have operated; provided, however, the snimal be not griped from the effects of the physic, nor the evac.

" "Of the direct effects of a full dose of cathartic medicine on the syster, we have pretty satisfactory evidence. Not only does it influence the genera? distribution of blood by causing a preternataral determination to the abdominal viscera, but its operation is attended with a greater consumption of that fluid, in consequence of there being an augmentation of the intestir. , snd probably other secretions. And when we calculate the extent of the secreting surfacc of the alimentary canal, and take into our consideration that there may be an sugmented aflux of other secretions to it, in addition to its own, we shall be able to form some idea of the loss of rital fluid the system may sustain in this way; nothing indeed, can evince to us the debilitating effects of cathartics more strikingly than the quick depression of condition, and with it strength ard spirits, which supervene upon excessive purgation. Even as a depletive, therefore, next to bloodletting, catharsis is the most potent remedy we pos. vess; and it is chiefly with the intention of determining blood to the bowels, and of drawing it off in the form of secretion, that we employ purgation in mos! inflammatory disensos." - Percivall's J,octures 
uations profuse; in either case a small portion of ginger niay be ad hod.

If the constitutional and local treatment have not had the effert of changing the morbid action of the part, and it remains in an irritable state, a mucilaginous fomentation of slippery elm or marshmallow roots will be of benefit. If a profuse flu:d secretion takes place, the application must possess astrikgent properties. The following is a good example:-

$$
\begin{aligned}
& \text { Powdered slippery elm, } .: 2 \text { drachms, } \\
& \text { Hot water, } . .1 \text { drachm, }
\end{aligned}
$$

Set it aside until cool ; then strain, and it is fit for use.

Cold applications generally agree best with an inflamed eye; yet, in the cold months, it may be advisable to apply them with the chill off.

If what is commonly denominated a "speck" should appear, then take

$$
\text { Tincture of bloodroot, }: 1 \text { ounce, }
$$

Bathe the eye three times a day with this mixture, taking care to introduce some of it within the eyelids. If the "speck" be large and persistent, the tincture alone must be applied by means of a camel's-hair pencil. Let it be understood, however, that the term speck is merely applied to that opacity which is confined to the external tunic of the organ of vision, and must not, therefore, be confounded with cataract, which consists of an opacity of the crystalline lens or its capsule, preventing the rays of light passing to the optic nerve.

\section{CATARACT.}

In the early stage of this disease, a small white speck appenrs in the centre of the lens; sometimes, however, it is first observed at the upper or lower margin of the pupil ; it gradually increases in size until the sight is wholly obliterated. Human practitioners have been successful in the cure of cataract by operation, and we think the process of depressing or extracting the diseased lens in the horse's eye might safely be practised, provided it be: done before the retina (which is an expansion of the optio 
nerve) is diseased. Some authors urge as a reasor. for not performing s ıch operation on the horse that, the retractor muscle draws the eye back so powerfully and so deeply into the socket as to render an operation almost impossible. But this difficulty thanks to the discoverers of chloroform - can now te obriated; still we have doubts of such an operation as couching 'extracting) being of any benefit to quadrupeds, unless we can form some sort of a convex lens to place before their eyes.

We know of no remedy that can be depended on for the cure of this malady other than such as comes under the denomination of "alterative," calculated to improve the general condition of the patient; and perhaps such would be of little avail in the cure of what is generally considered an incurable disease. There are kinds of cataract, however, of a spurious nature, that can be absorbed. - For further information on this subject, the reader is referred to Percivall's Veterinarian and Hippopathology

\section{AMAUROSIS, OR GUTTA SERENA.}

This disease (commonly called glass eye) is attended with a diminution or total loss of sight. In most cases the pupil is dilated to its utmost extent, and incapable of contraction when a light is held near it. The eye has so bright and glassy an appearance as not to be mistaken.

The disease may be either symptomatic or sympathetic. In the first case, it arises from some injury to the brain produced by concussion, or from pressure on some portion of the cerebral mass. In the latter case, it arises from derangement of the organs of digestion.

Symptomatic gutta serena can only be made to disappear by the removal of the existing cause; if this be impracticable, then the trouble is incurable. But if it depend on acute or chronic indigestion, we may entertain some hopes of recovery. If the disease be of recent origin, and the patient in fair condition, we may entertain some hopes of a cure; yet, after all, that will depend on the nature of the case. Youatt and some others consider amaurosis in "incurable disease." These writers probably sefer to that form which originates in disease of the retina, optic 
nerve, or from tumor within the ventricles of the cerebral mass But the most common form of amaurosis in the horse is that denominated sympathetic. We have seen horses that have sud. danly become amaurotic from overfeeding, the subjects at the same time leading a lazy life in an air-tight stable, by which errors the digestive, as well as other functions, become impaired, snd reveal their pathological condition by external sign - arisu rosis. We remember the case of a young colt which dicd of chronic indigestion - debility. For several weeks previous to derth, the animal was amaurotic in both eyes: he would stand with his nose protruded, ears erect, and head raised to an unnatural position, and the owner informed us that if he attempted to move the patient, he would raise his limbs after the fashion of a dancing master. Such, together with the dilated pupils, are the symptoms to be considered in diagnosing this malady.

Sympathetic amaurosis, therefore, may admit of cure; and that cure consists in the restoration of whatever function may be deranged; the mere application of local remedies to the eye alone will be of no sort of use; we must go beyond - seek for first causes, and apply suitable remedies in the region of the actual disease; for, in nine cases out of ten, amaurosis is but a symp. tom indicating disease of an alarming nature, located, perhaps, in the digestive canal.

The causes assigned for amaurosis in the human subject are, compression of the optic nerves; from debility; from spasm; and from poisons; and probably the same causes may produce similar results in the horse.

The treatment of amaurosis must depend on the nature of the case; if the subject be in a state of plethora - fat and sleek administer the following cathartic drench :-

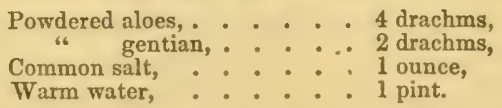

Krep the animal on a light diet of scalded shorts; sponge the head with cold water; give an occasional injection of salt and water; and let the patient have regular exercise.

If tho patient be in a state of ancmia - debility - we must have recourse to tonics and alteratives, with a view of invigor: 
ating the system. The medicine best calculated to producu this result is

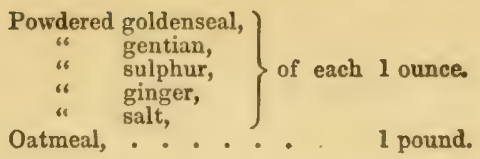

Mix divile the mass into twelve parts, and give one in the food, night and morning. The eye may be bathed twice a day with the following astringent lotion:-

Powdered bayberry bark,
Boiling water, - . - 1 ounce.

When cool, strain, and add a table-spoonftrl of tincture of blood. root; it is then fit for use. A good nutritious diet is indispensable.

Should amaurosis be the sequel of cerebral disease, little hope can be entertained of recovery. Should the reader, however, desire to treat such case, he must have recourse to counter irritation as well as internal medieation. As counter irritants, some recommend a seton under the jaws; but probably a mustard pultice applied behind the ears would have the same effect.

\section{SPECIFIC OR PERIODIC OPHTHALMIA.}

The specific or periodic form of ophthalmia differs from com. mon ophthalmia.

1st. The inflammation is deep-seated, and on examining the eye, after death, we find the choroid coat highly inflamed, presenting a scarlet appearance. The vitreous humor appear's of a light yellow tint; all the internal structures, and especially the lens and its capsule, are highly injected, presenting a network of blood vessels; whereas, in simple ophthalmia the tunica con. junctiva alone is commonly affected.

2dly. Specific ophthalmia, unlike simple, is considered constitutional, and is subject to regular paroxysms, lasting for two or three days at a time. The intermission is noticed by a disappearance of the acute symptoms, and a restoration of the sight. 'The intermissions are sometimes of several montls' duration, and we are often led to suppose that the disease has entirely 
subsided; but a relapse manifesting itself in one or buth eycs soon undeceives us.

Cuuses of Periodic Ophthalma. - The disease may be in. duced by a rariety of exciting causes; hereditary influence is supposed to be one among the many causes prolific of the malady get veteriuarians are undecided in their opinions as to whether the disease itself, or only the predisposition, is transmitted. Mr. Percivall considers liereditary influence as "predisposent only not excitant; nor sufficient of itself to produce ophthalmia." Professor Coleman teaches, in his Lectures, that "the disease is never seen prior to the domestication of the animal; never ocr urs on a common or in the open air, but is the product of the puison generated from the effuria of the breath, dung, and urine of horses standing together; in proof of which the disease is found to be more or less prevalent, according as the stables in which horses stand are ventilated. In stables that have the most cases of inflamed lungs, grease, and glanders, there we find the most blindness; and where these diseases are rarest, ophthalmia is least known. Coincident with the opinion of Coleman, and we may add Percivall and many other writers, is the experience of the author, and many intelligent horse dealers of the United States also; for the disease, in the first place, is not so prevalent here as in the crowded cities and barrack stables of the old world; and, secondly, we do not find so many blind horses here. Whenever a case of simple or specific ophthalmia occurs, we grencrally find the subject located in a filthy stable, or on low, marshy ground, or else he has been shut up for many hours in a milroad car, there respiring over and over again the foul products of combustion and excretion. The disease, as a matter of comre, may br: induced by mechanical means, - through injuries sus. tained, - or by violating, in the stable management of the animal, some jhysiological law. The disease induced in this way may at times, assume in its primary stage, the form of simple ophthal. mia, and afterwards degenerate into the disease now under confideration.

'The use of blinders, which are now fast going out of fashion, must tend to irritate the eyes of horses; and the sooner they are entirely dispensed with, the better will it be for both horse and owner. 


\section{Treatment of Periodic Oplthalmia. - The first thing to be} Lone, is to place the patient in a situation where he, shall be as tree as possible from exciting causes; the treatment may then be conducted with a ray of hope. Even should the animal be the recipient of hereditary predisposition, his removal from a crowded ablile to the country reduces him, as it were, to a state of nature, und tells wonderfully in view of both palliation and cure.

Antiphloristic measures, such as topical and gencral bloos. !rling, purgatives, \&ce, are usually resorted to in the treatment of common oplathalmia, and sometimes with remarkable success; but in a disease of this character, they are worse than useless. And lest this our opinion slould appear singular, we quote from Hippoputhology, p. 97 : "Blood has been drawn from the jugular vein of the same side as the affected eye, until the animal has quite staggered under the evacuation; the carotid artery of that side has been stopped by ligature; nay, the vessels carrying on the inflammation, themselves, as they ran upon the cornea, have been severed by scarification and by cauterization, and all to no other purpose than that of checking, or, to appearance, subduing an inflammatory action, which has been, after a time, sure to return with equal or even with redoubled force. A common inflammatiun, once fairly conquered, has no power to revive again; at least not in its original activity ; but as for the inflammation of periodic ophthahmia, it will return again and again, after having xeen, to appearances, overpowered; and, in opposition to olir most strenuous endeavors, will march slowly or rapidly on, according as the case happens to be acute or chronic, to the ultimate destruction of the eye."

Purgative medicine, also, which has been so highly extolled fur lis: cure of conjunctival ophthalmia, has generally failed to ben cit the patient: from these facts alone the reader may form gome idea of the disadvantages under which a medical mat labors while treating so formidable a malady. Hence we place very little reliance in the antiphlogistic treatment, but have greas confidence in the means which Gorl and Nature have provided for the maintenance of health, and for its restoration when absent. We therefore recommend the reader to study that branch of medicine - hygiene - which treats of the preses vatior of health 
for without a knowlulge of its fundamental principles we cannot cure disease.

Having then remuved the patient to a healthy location, we make some sort of change in the diet, calculated to have an alterative effect. All green fodder may be considered altera. tive; and after a horse hats been kept up for some time, and feel on stable provender, any description of green succulent herbage may be given, with the assurance that it will have a sanatory effect.

The medicine best calculated to coöperate with hygienic means, is, -

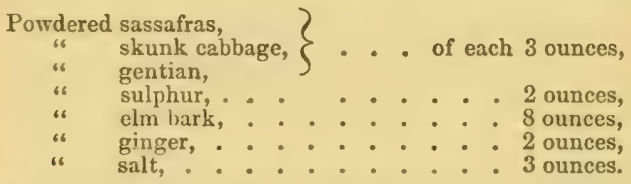

Mix ; divide into twelve powders, and give one every night is the food.

The following antispasmodic preparation must be applied to the eye two or three times a day:-

Tincture of Indian hemp, (canabis sativus Indicus,) . . 1 ounce.

Rain water, . . . . . . . . . . . 1 pint.

\section{DISEASES OF THE NERVOUS SYSTEM.}

\section{PALSY. - (Paralysis.)}

THERE are three varieties of paralysis to which horses are subject. - Variety 1. Hemiplegia, - affecting one half of the bedy, longiturlinally, that is to say, the limbs and body of one side only. Should the animal have a sudden attack, and, without warning, in an instant fall down, and remain there on the alfected side, deprived of the power to raise himself, hemiplegin is then considered "complete;" whereas, in "incomplete" hemiplegia. the horse remains standing, although, if urged to move, the extensor's of the limbs seem to have lost their power, and the lattes we merely dragged along. $W$ e remember treating a case of 
insomplete hemiplegia, occurring in a six year old gelding, supposed to have been brought on by overfeeding, followed by $a$ hard drive. The off side, which was affected, was insensible to the prick of a pin, and felt several degrees colder than the other; the head was drawn into an unnatural position partly round to the affecter side, and the patient seemed unable to straighten the neck; the eye on this side inclined backward, and the lower lip and right ear hung pendulous. This horse was left one evening in an empty barn, as usual, and next morning the owner called und informed us that the patient had fallen during the night, and broke his neck; that the head was doubled completely round on the side of the neck, and lay underneath him. We did not seo the patient after the accident, but from the man's description of the position of the horse, concluded that he must have stumbled against something during the night, and in the fall dislocated the first cervical vertebra at its occipital articulation.

Variety 2. Paraplegia. - This affects the posterior balf of the body, and the subject is found squatting on his haunches, at - the same time making incessant efforts with his fore extremities to raise the body; but his efforts all prove of no avail ; and after the primary excitement has subsiced, he will be found sitting dog fashion, merely making an occasional effort to get up. In this condition the urine and excrement often pass involuntarily. Paraplegia generally results from some injury to the spinal cord, received in slipping down on the pavements, or otherwise, or else through violent efforts at heavy draught; thus injuring the spinal marrow, either by laceration, or effusion into its canal. Such cases generally terminate fatally.

Variety 3. Paralysis partialis. - This is identical with pa. rolysis facialis of the human family, and consists in distortion of the parts about the head and face: ordinarily the muscles of the frce are drawn upwards - one side only; but in some parts $\mathrm{ct}^{2}$ the Western States such subjects have a most unearthly appearnnce about the face; it seems to affect them on both sides of the head, so that the upper lip is doubled completely upwards, and both eyelids are raised, so as to expose the greater portion of the upper part of the eye: there is, howerer, in the latter case, tremulous agitation of the head and limbs, and sometimes of the 
whole Lody, which does not take place in simple paralysis facialis.

Paralysis partialis is generally the sequel of indigestion; therefore the cure consists in restoring the digestive function to its normal state. A change of diet, laxative medicines, tonics, external frictions, light work, and pure air, are the means best calculated to restore the patient. The external irritant we gener ully make use of, in all cases of paralysis, is composed of

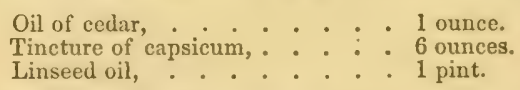

To be applied daily over the region of the spinal column, and in the vicinity of the paralyzed parts.

Whatever may be the cause of this disorder, we cannot err in combining antispasmodics * with whatever medicines are administered. There are three kinds which we are much in faror of, viz., assafoetida, garlic, and Indian hemp. The dose of the former is, one drachm of the powder; garlic we use in the forn of sirup - from one to three ounces; and the latter in the form of tincture - from one to three drachms.

Should the patient, in consequence of orerfeeding and want of sufficient exercise, be in a state of plethora, which may bo known by a sleepy, unwilling gait, redness of the membranes of the eye, constipated bowels, and thick, sometimes high-colored urine, the antispasmodic may then be combined with six or seven drachns of aloes, and a pint of warm gruel, with which the horse may be drenched. The diet should be fine feed, scalded, and well seasoned with salt.

Paralysis is very frequently a symptom of cerebral disease, and must be treated accordingly. See Staggers, dxc.

* Antispasmodics have been defined as "agents which orercome inordinato uuscular action;" therefore all nauseants - and among then tre include warm water and lobelia - are antispasmodic. The reader has probably experienced the relaxing and beneficial elfects of a warm bath, or a warm cup of tea; and to reason from analogy, he may conclude that warm fluid, applied either internally or externally, has the same effect on a horse. Under the head of Anti ppasmodics, Professir Morton enumerates alcohol, ether, oil of turpentine. spium, spirit of nitric ether. Professor Curtis considers all the essextial oils un tispasmodic. 


\section{LOCKED-JAW. - (Trismus, Tetanus.*)}

Tetanus is a disease of nervous origin, affecting tle muscle of external relation, through the agency of perverted nervol. force; it consists in a permanent spasm of some, and in the latter stages all, of the voluntary muscles; it is subject occasionally to glight remissiôns, but no relaxation.

In the human subject, we recognize three peculiar features .-

1. The body is bent forwards - anticus.

2. Body bent backwards - posticus.

3. Body bent sidewise - lateralis.

The horse, however, is most subject to that form of disease known as trismus, which means painful, fixed, and rigid contraction of the jaws, mouth firmly closed; and one or more of the above features are generally blended with trismus. Yet, at the onset, the locked-jaw may be the first symptom that arrests our attention, and so long as this symptom remains uncounected with spasm, or stretching of muscles of the trunk, (it seldom affects those of the limbs, ) the case is one of pure trismus locked-jaw.

That form of the disorder which is most prevalent in this country is termed traumatic, resulting from wounds - docking, pricking, \&c.; from injury to sensitive tissues; arising also

* S. G. Wilmot, member of the Royal College of Surgeons, who has great experience in the treatment of tetanus, communicates for the Dublin Medical Journal the following:-

"1. Tetanus depends on irritation, directly or indirectly, of the excitomotory system, or true spinal cord, by which it becomes surcharge 1 with motor influence; and that inflammation in or about the cord, or any appreciable lesion, is not an essential condition for the derelopment of the disease.

"2. That our grand object, in the treatment of tetanus, should be to sup port tine patient's strength, by the administration of stimulants and strong nourishment, with a view, as it were, to compensate the rital powers for their great exluaustion, consequent upon the expenditure of force, by the violent muscular contractions, which in some cases are excessive.

" 3 . That, as the removal of the exciting cause - when once the first evidence that irritation has been propagated to the spinal cord becomes manifest - doeg not in the least degree check the progress of tetanus, or abate the violence of its symptoms, all operations in traumatic cases are generally nct only unne. cossary, but injurious." 
from driving a nail (when shoeing) in the wrong direction, and from puncturing the foot, by picking $u_{p}$ a nail. It is generally supposed that when locked-jaw follows an accident of this kind, u nerve must have been injured: it may happen so in some cases, but we have known a horse to die of this malady, when the brum of the exciting disease was expended on the coffin bone and navicular joint, which were extensicely ulcerated; there wert no signs of any injury to the nerrous filaments, axd, if a nerre had been injured, would not its abnormal action have merged into the more formidable one progressing in the cartilaginous and bony structures? For it is generally supposed that two distinct diseases, one of the nerves and another of the osseous structure, could not coëxist: hence the locked-jaw must have yielded, if it had existed in consequence of injury to a nerve. The lockedjaw was, no doubt, sympathetic, and probably a great proportion of those cases termed punctured nerve, are of sympathetic origin.

That locked-jaw frequently occurs as a sympathetic affection, we have abundant evidence. Many horses, whose digestire organs have acquired a morbid habit, and have gradually arrived at a certain state of intensity, are finally attacked with trismus, and die with their jaws set as tight as if held in a vice.

That locked-jaw is generally a sympathetic affection should be known to every man, for a great deal of useless medication and unnecessary pain is inflicted on animals, when, if the exciting cause was understood, the poor brute might oftener be relieved than he now is.

The very absurd idea promulgated by many, that locked-jaw of the traumatic species always results from injury to a nerve, anc from no other cause, should now be exploded; the idea receives no advocacy from modern veterinarians, and only existy in works of doubttul origin. On consulting Hippopathology, p. 48 we learn that tramatic tetanus may arise from various causes. One case originated from a wound under the eye inflicted by tho lash of a whip. "The late Mr. John Field mentions one case in which all that he could find to account for it was a saddle gall; and in another there existed only a wound in the neck. Jn one occasion it succeeded cauterization of the jugular vein. 
Two cases are related also, occurring after stranglis; in one of them, however, there existed some gastro-intestinal irritation.

"D'Arboval informs us, that at a remount, depot for caralry established at Bec, (department de L'Eure, twenty-four horses were castrated on the same day, and afterwards were four times a day made to take a cold bath in water derived from an ex. ceedingly cold spring; the consequences were, that sixteen out of the twenty-four died of tetanus between the tenth and fifteenth days."

Sympathetic Tetanus. - This is supposed to arise from irritation, or some derangement of the digestive organs; we have seen and treated several cases of this character with success; the chief remedies were, assafoctida combined with mineral tonics, (carbonate of iron;) stimulants; frictions, with liniment, to the jaws and spine; injections and fomentations. The worst case of sympathetic tetanus we ever treated was that of a ten year old gelding. It occurred in the stable of Mr. J. Gilson, West Cambridge Centre, during the latter part of 1852 . The animal had, previous to the attack, been noticed as a ravenous feeder; and although he ate enough to support two common horses, his condition was not benefited by it, for he lost considerable flesh; his coat looked bad, and he was the subject of constipation and occasional slimy discharges. This state of things had continued for some time; when the owner, on going into his stall one morning, to feed, found the animal's jaws locked. We saw him a few hours after wards, and found the jaws unnaturally fixed, yet not closed with that vice-like tetanic spasm that is seen in some cases of acute teianus; the jaws could be opened so as to admit a body the size of a man's finger between the nippers. The eye had the usual appearance, being drawn backwards, and partly covered by the membrane nictitans (haw.) The ears were erected, no:trils ex panded, and the neck was rigidly extended forwards; the countenance presented that anxious and distressing look so easily recognized by those who have once seen a case of this character; the muscles of the back and the recti of the abdomen were the seat of tonic spasm; the hind limbs were widely separated. and the fore were slightly advanced, being in the most farorable position for affording support to the inflexible borly : the yaw: 
remained in the state just allided to for the space of sixteen datys there was no lateral motion to the jaws, but the patient could readily imbibe thin oatmeal and flour gruel, and also the therapeutic agents, which consisted of the articles just named, and an occasional laxative to keep the bowels soluble. The animal, however, came near losing his life of the very night after the jaws relaxed. He had been fed, watered, secured for the night, and was left doing as well as any poor horse in his circumstances might be expected to do. Next morning he was found down, his eyes tumefied, skin knocked off in various parts of the head and body, belly enormously swollen, \&c., all going to show that he had, during the night, and was now, suffering from flatulent colic. A barrel of beans scattered on the floor, one side of the stall lying flat, and every thing alout the barn presenting the utmost confusion, went to show, that during the night our patient got loose and went on a royage of discovery within the limits of the baru; in the course of his travels he came across a barrel of beans, a savory meal for a half-starved horse, and no doubt he tried the strength of his masseter muscles, which had of late been quite useless. The sudden change from gruel to hard beans was too much for our patient's digestive organs; hence the colic. By the exhibition of diffusible stimulants, carminatives, steaming, rubbing, dcc., he got over the trouble, but was a long while before all his external injuries healed; he is at the present time owned in Roxbury, apparently as well as ever. If we take into consideration the animal's previous protracted illness, it seems remarkable that he should have recovered. Wre should therefore never despair. Another case of sympathetic tetanus occurred in the same town, which was brought to a favorable termination: the jaws relaxed on the fifth day, when the patient, in consequence of being fed immediately with too bountiful a hand, died a few days after of gastro-enteritis. We have lately riewed with favor the theory of our veterinary luminaries, that tetanus in most eases is of sympathelic origin. Some very interesting remarks occur in Hippopathology bearing on this point, which we shall bere introduce as valuable acquisitions to our poverty-struck vetr rinary literature.

"Th sympathetic disorder," writes Mr. Percivall, "as I shall 
call the other form of centripetal tetanus, (having liscussud me traumatic variety,) is that which, from the absence of all wound or injury, we have got into the habit of considering as i liopathic; though, in point of fact, while some cases so considerzil are, no doubt, central, i. e., originate within the spinal marrow, others, there seems good reason for believing, must be dependent upon some irritation, either within the alimentary canal, or in some other part of the body. Should this turn out to be the case, our pathology of tetanus will have undergone essential improvement; and we shall be able to account, in a measure, for our therapeutic agents succeeding in one case and failing in another-a fact that has hitherto led us either to regard the asserted remedy as useless, or to attribute its failure or success to an erroneous cource. In a word, by endeavoring to discover the real seat and nature of two kinds or forms of disease which have hitherto been confounded under the epithet idiopathic, it is manifest we are in the road to a very considerable amendment of our method of treatment."

Mr. Percivall quotes also the opinions of Messrs. Karkeek and Henderson in support of his own opinion as to the sympathetic origin of tetanus; and he introduces, with a view of substantiating this theory, the opinion of that distinguished surgeon, Mr. Abernethy, who, he says, "was of opinion that the injury, whatever it might be, leading to tetanus, first produced disorder of the digestive organs; and that disorder occasioned derangement of the functions of the spinal marrow, and, through it, of those of the system at large, which latter derangement constituted tetanus." On page 51 of Hippopathology, a passage occurs, so full of interest to the American reader, that we take the liberty to transfer is to our pages.

"Mr. A. Henderson, V. S., London, who presented the Vetcr. inary Medical Society with a good practical paper on tetanus in 1832, 'doubts if the horse has ever the disease except from sym. 'pathy ;' and in confirmation of this opinion stat ss, that althoury cluring life the symptoms have proved insufficient to direct his attention to the seat of the source of irritation, examination after death has manifested appearances which left no doubt on the mind of Mr. H. about the nature of a case which he had at first 
considered to be idiopathic, i. e., central. And in the positiur: which Mr. H. has taken, I am very much disposed to think, that (although I do not believe his theory complete) he stands very strong.

"I feel no doubt myself, that a very large proportion of our cases of tetanus originate either from wound, discovered or not discorered, or from some other cause of local irritation; and that cause Mr. H. has found frequently to be 'an unusually vascular appearance of the large sympathetic nerves, through their various ramifications in the chest and abdomen.' In one case, in combination with this appearance, he found distention and redness of the stomach, with crimson spots upon its pyloric portion; in a second case, with the same, an enormous quantity of bots, several of which had eaten through the coats of the stomach; in a third, with the same, an immense number of worms, called terites, in the stomach and small intestines, and in some parts of the droulenum and jejunum, sufficient to block up the passages. The ressels of the pia mater were also unusually distended, the brain in this case being examined; and there was more water than usual in the ventricles. To this it may be right to add, that Mr. H. found the sympathetic nerves similarly affected in a case of tetanus apparently caused by broken knees. Mr. Karkeck, V. S., has since made the same observation on idiopathic tetanus; and in regard to it, coupled with the consideration of other facts, bagaciously remarks, that 'tetanus depends, if any disease? does, opon sympathy.' And in another place, says, 'I am of opinion that a diseased state of the digestive organs is invarially the primary cause, as, on dissection, I have ever discovered it to exist. Thus confirming Mr. Abernethy's opinion."

The reader must bear in mind that the nerrous system of or. ninic life and the sympathetic nerres, - originating from the hpinal marrow, - form a network of ganglia and fibrils, which are distributed to the various parts of the nutritive and secretory upparatus, the fibrils forming a plexus upon the walls of blood vessels, and with them ruming to the rarious parts of the body They possess the power of exciting muscular contractions in the variods parts to which they are distributed, by reflex action on their stinal origin, from whence they derive motive power. 
Mence it will readily be perceived by what moans a diseased condition of a certain organ produces sympathetic disease. Again let it be understood that all vital manifestations in the animal economy, are entirely dependent on the nutritive function; that the properties of all tissues and organs are deperdent for their integrity on a supply of perfectly elaborated blood; that respiration, circulation, and secretion cannot go on unless the nervous forces are well balanced; and that the harmony of that rast and complicated apparatus, known as the nervous system, is in furn dependent for the performance of its legitimate function on nutrition. Then we can perceive that many diseases, including tetanus, may readily arise from perverted nutrition, and independently of any external causes. External causes, however, produce the same result, but not so of ten as people suppose. The reason why we thus labor to change the current of opinion in favor of the sympathetic origin of this malady is, that a more rational system of medication will then follow, and instead of blistering, bleeding, and cauterizing, as recommended by Youat and others, - tormenting a poor, dumb brute to no purpose, we may be led to look beyond the imaginary limit, find the real seat of the difficulty, and treat it accordingly.

Treatment of Tetanus. - The author does not wish the reader to suppose that all cases of tetanus are curable, or that his treatment is always successful; there are cases now and then occur. ring which, with the very best veterinary skill, must terminate fatally. Tetanic symptoms sometimes develop themselves in horses of a peculiar diathesis, which opposes rather than contributeg to the harmony of the vital forces; the subjects are not able to bear up against the encroachments, which are continually giving on during the long siege of sickness, nor to improve their otherwige unhealthy condition, and, consequently, they sink in spite of our best efforts. Then, again, cases hare come under our wbservation, in some of which the subject's jaws had been locked for wo, and even three, days, ere any thing had been done for the animal; some of the owner's suppusing that the horse had lost his appetite, others that the throat was sore, \&c. ; so that, under such and other circumstances, too numerous to name, yet understood by medi al men, we cannot expect to be alwnys successful. 
The treatment, in order to be any thing like successful, must bo conducted with enlarged views of the animal economy as a whole - we must realize how much one part is dependent on, and contributes to, the support, perpetuity, and identity of function, o 1 another, and that all parts are united by a common bond of sympathetic continuity, as well as cellular structure, and aro destined, in certain stages of disease, to suffer in common frum a common exciting or predisposing cause.

We must also take into account, that the debility present, or uhich may ensue during the progress of tedious or prostrating disease, must be met by prompt agents favorable to health, for debility (functional or general) may with certainty be consid. ered as the principal cause of premature deatb. With a view, then, of promoting the living integrity, and producing an equilibrium of function throughout the whole economy, we must, in. stead of prostrating the system by bloodletting and purging, - so strenuously urged by most writers, and, indeed, practitioners administer tonies, antispasmodies, stimulants, and laxatives; for there is nothing that we know of so prostrating to the system of man or horse as acute pain. Long-continued pain, such as a tetanic subject is known to suffer, clianges the very elements of the blood: so that the fluid on which our very existence depends for - using a homely expression - its bread and butter (carbon) is deficient, and the patient may die for want of fuel to support pulmonary combustion. There is really no necessity for the abstraction of blood in tetanus. For it has been shown by Dr. Radcliffe (see IIalf-yearly Abstract of the Medical Sciences, vol. xvi. p. 312, and also No. 17, p. 222, January to June, 1853) and by other eminent surgeons, that convulsive, spasmodie, and tremulous diseases depend on a decided and unequivocal deticiency in the due amount of that stimulus which is supplied to the muscles from the blood, nerves, and other sources, and not upon ar increased aftlux of such stimulus. Dr. Radcliffe clearly lemonstrates, in the papers alluded to, that these, as well as other muscular disorders, depend upon the same want, and are manifested in a state of general or local debility, and not in une of health and vigor. Hence the plan of treatment here reconimended, and by which we have saved several valuable horses, is superior to 
that which contemplates prostration of the vital forces. It would be exceedingly interesting to follow Dr. Radcliffe in his arguments sustaining the proposition just broached, (the state of the circulation in convulsive and spasmodic disorders;) but our limits will not allow us to do so. With a view, however, of sustaining nur own opinion, we quote the following:-

"The state of the circulation in tetanus may be illustratel by two recent cases. One of these was sent to The Lancet by $\mathbf{M r}$ Salter, of Dorset. It was that of an old man, upwards of seventy. three years of age, whose foot had been partly destroyed by a threshing machine. The spasms set in after a prolonged employment (for three or four days) of strong purgative mixtures of salts, senna, and tartar emetic, along with morphia and aperient pills During the spasms the injured foot was pale and numb, the skin moist, and the countenance cadaverous. The state of the pulse is not specified; but what this was is to be inferred from the foregoing particulars, as well as from the adoption of vigorous stimulation with brandy and ammonia when the spasms occurred. Indeed, in a man so old, so injured, so antimonialized and purged, only one conclusion is possible, namely, that the circulation must have been very greatly depressed. This appears also from the sequel, which was this, under the new mode of treatment the system rallied, and the tetanized parts relaxed; and this rallying and relaxation lasted for several days, at the end of which the symptoms relapsed. This was after an exhausting and agitating interview with some friends. Again stimulants were had recourse to, and again the spasms disappeared, not to return. In the relapse, the pulse is stated to have been extremely feeble, an 1 of a typhoid character. In the second patient, the state of his system is stated to have been such as to contra-indicate tho nse of any lowering medicines, the spirits being faint and low, the countenance anxious, the pulse 98 and weak, and so on. Quinine, ammonia, and turpentine were had recourse to; and the result of the treatment was, that the system rallied, and the epasms subsided. These instances illustrate the large borly of cases of tetanus, for certainly the majority are in no way com. plicated with any kind or degree of rascular activity; but d: they illustrate the rule? Are there no exceptions in which 
there are plethoric or other active symptoms? The answer, as t seems to us, is clearly in the negative. It is stated by all au. thorities, and must be evident to all who have had any experience In the disease, that there is no fever in tetanus; and this of itself' is almost sufficient to prove our position; for so anxious have medical men been to find some fever in maladies of this class, that 10 admit its absence is almost equivalent to admitting the opposite. Undoubtedly the vascular state in tetanus assumes many uspects, and some of these are such as to deceive an unpractised eye or an impatient finger. There can be no mistake in such cases as have been described, but they may very readily be in irritable subjects. In such persons, owing to the excitement of examination, or some unusually severe pangs at the moment, the pulse, when first felt, may beat with considerable force and fuluess, and so give rise to an impression of fever or plethora; but this rapidly passes off, and the color fades; the pulse flags and falters. 'The pulse, indeed, is eminently changeable, and any excitement which may be manifested in it is quite momentary, in comparison with the almost constant state of depression. It must also be borne in mind, as confirming the same view, that in fital cases the spasms of tetanus continue, and often increase, in spite of the progressive failure of the circulatory powers - a fact that is only explicable on the supposition that the spasms are dependent upon the very reverse of rascular activity. The same conclusions arise also out of the cadaveric rigidity; for in this case we have a state of tetanoid, or, rather, cataleptoid contraction, which subsists with stagnation and death of the blood, and which endures untiringly until the muscles are broken up by incipient decay. In spasms, therefore, as in tremulousness and convulsion, there is abundant evidence of a decided lack of circulatory power. It would seem, also, as if that lack wero greater in convulsion than in tremulousness, and in spasm than in conrulsion. * * * Tetanus, we learn from many surgeons, is most apt to occur when soldiers are dispirited, exhausted, ill fed, and exposed to cold. Cadaveric rigidity is the work of denth. In short, the causes of tremor, convulsion, and spasm sre such as go to confirm the deductions arising out of the ronlition of the vascular, nerrous, and muscular systems; and the 
condition of these systems reacts in confirming the idea that these causes are, as they seem to be, of an anti-vital character."

Taking into consideration, then, that tetanus is a disease of a deprossing character, we must support the vital powers; and if the case is one supposed to originate from the introduction of a foreign body within the hoof, or from any other injury evolving pail, the sooner we commence to give stimulants and nutritive food the better. Flour or oatmeal gruel, made thin enough for the animal to suck up, and seasoned with salt, should be kept before him; and whatever medicine seems requisite may be administered in this way. As a standing daily medicine, we use the following, and we can conceive of no case that would contraindicate its use. Take

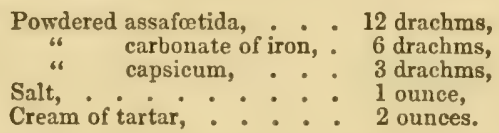

Mix; divide the mass into twelve parts, and give one every night. The jaws and spine are to be rubbed for at least two hours, daily, with a portion of the following :-

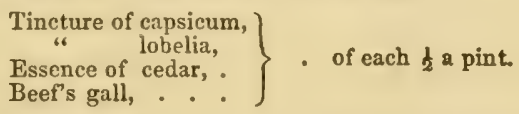

The parts are also to be occasionally lubricated with olive oil ; the jaws to be encircled with flannel. Should the horse have been pricked in the foot, take off the shoe, and having found the orifice where the nail entered, examine it, and see if there be any foreign body within it; if so, remove it; enlarge the outer orifice with the point of a knife; then, haring cleansed the part, apply the follow. ing poultice :-

$$
\left.\begin{array}{c}
\text { Powdered hemlock bark, } \\
\text { " lobelia, } \\
\text { slippery elm, }
\end{array}\right\} \text { equal parts. }
$$

Moisten with boiling water, then add a handful of soft soap. When sufficiently cool, apply it to the foot in the usual manner, renewing it daily. If at the end of three or four days no discharge appears, it may be discontinued, and a common dressing of tuncture of aloes applied 
injections. - In view of evacuating the lower bowels and ren, tum, we give clysters of soap suds, and in view of supporting tho strength, (after evacuating the former,) we resort to meat broth and flour gruel, to be used as occasion may require. If the patient be of plethoric diathesis, we need not be in too great hurry to a Iminister nutriment, ${ }^{*}$ but should simply keep the bowels in a soluble state, by a dose of cream of tartar and sulphur; four drachms of the former to about six of the latter, being about the right proportion. If any exciting cause exists, we, of course, pay attention to this, and to the relaxation of the jaws. If they are rigidly set, and the external application fails to give relief, wo may try warmth and moisture. A lobelia poultice applied around the jaws, and kept moist with warm water, will generally do good, even in the very worst cases.

Some patients, at the commencement, show unmistakable symptoms of debility; to all such we give, with a liberal hand, strong sage tea, or infusion of gentian, sweetened with honey. The cases that have terminated favorably, have been treated somewhat after this simple fashion. We have tried chloroform, and cold water, and feel satisfied that they did more harm than good, and thus hastened the death of several patients.

The disease frequently sets in after docking and nicking. In such cases the books tell us to prick, or nick deeper, and dock a little higher up. This looks very well on paper, but fails in application. We never saw any benefit derived from the barbarism; we think, however, that a good poultice of bayberry bark and lobelia, applied to the tail, might answer a better purpose. But the trouble is not in the tail; yet it might be gangrenous; then, in view of remoring exciting causes, it must be amputated: at such stage, however, we have doubts of its efficiency, for tho disease is beyond the reach of the knife.

Very little improvement has taken place in the treatment of tetan'is. Veterinary surgeons have generally followed somewhat

- Nutritice Enemata. - A horse may, for a long time, be supported on nutritive enemata, composed of flour, or fine oatmeal gruel, mixed occasionally witn a little salt. There is a case recorded in the Foreign Quarterly Retro. ipect, of a man unable to swallow, who was supported thirty-nine days on nutri. arent adrainistered per rectum. 
in the footsteps of human practitioners, whose aim and view of eure, Hooper tells us, is, -

"1. To remore the local cause or irritation, which may appear to have excited the disease.

“2. To lessen the general irritability and spasmodic tendency.

"3. To restore the tone of the system.

"If a thorn or other extraneous substance be lodged in any part, it must be extracted; any spicula of bone, which may have brought on the disease after amputation, should be removed; a punctured wound ought to be dilated, \&c. Some have proposed dividing the nerve going to the part, or even amputating this, to cut off the irritation; others paralyzing the nerves by powerful sedatives, or destroying them by caustics; others, again, exciting a new action in the parts by active stimulants ; but the efficacy, and even propricty of such measures are doubtful. To fultil the second indication, various means have been propesed. The abstraction of blood, recommended by Dr. Rush, might perhaps appear advisable in a vigorous plethoric habit, in the beginning of the disease; but it has generally proved of little utility, or even hurtful, and is rather contra-indicated by the state of the blood. [Mark that, ye who advocate bloodletting.] Purging is a less questionable measure, as costiveness generally attends the disease; and in many cases it has appeared very beneficial, especially when calomel was employed. It has been found, also, that a salivation, induced by mercury, has sometimes greatly relieved the disorder, but in other instances it has failed altogether.

"The remedy which has been oftenest employed, and with the most decided advantage, is opium; and somet:mes prodigious quantities of it have been exhibited : indeed, small doses of it are useless, and even large ones have only a temporary effect, so that they must be repeated as the violence of the s, mptoms is removed; and where the patient cannot swallow, it may be tried in clyster, or rubbed freely into the skin. Other sedative and antispasmodic remedies have been occasionally resorted to, as hemlock, tobacco, musk, camphor, \&c., but, for the most part, with less satisfactory results. The warm bath has sometimes proved a useful auxiliary in cold climates; but the cold bath is much more relied on in the West Indies, usually in conjunction 
with opium. In Germany, alkaline baths, and the internal use of the same remedies, are stated to have been decidedly serviceable. Others have adrised the large use of bark and wine, which seems, however, rather calculated to be preventives; or tc fullil the third indication; yet wine may be employed rather as nourishment, since in serere eases little else can be taken. Electricity seems ton hazardous a remedy to be tried in a general affection, especially in the muscles of respiration; but if confined to the jaw it may be useful in a mild form." - Hooper's Dic. tionary.

\section{SPRINGHALT.}

This peculiar spasmodic affection of muscles in the hind extremities is not so common among American horses as it is qmong the French and German breeds. It is an affection over which the veterinary surgeon, armed with the whole materin nedica, has rery little power; for, in the nerrous system first originates the cause, which subsequently gives rise to the peculiar gait termed springhalt; and the practitioners of all creeds have acknowledged their inability to direct medicine to the nervous structure, even after they have secured its digestion in the stomach. To introduce medicinal agents into the lrtter is an easy matter, but to make them reach that wonderful and delicate organized substance, the brain, and its nervous filaments, is another affair. These remarks, howerer, apply to cases of springhal1 depending on some lesion of nervolis filament, pressure, or atruphy of the nerves of nutrition. Minor derangements, resulting in spasmodic action, may be relieved, by removing the cause or the morbid habit which induces them. To do this, our treatment must be general; that is, we must restore healthy action to tho whole animal structure, and remove obstructions wherever they exist.

Before alluding to the treatment, we shall introduce to the =ader's attention a selection from Mr. Percivall's lectures, delivered some thirty-tive years ago; and, if the reader will compare that author's views with those of the surgeons of the present day, he will find that they have nothing new to offer.

The distinguished lecturer on veterinary science remarks 
- We reed give no description of the action or peculiar gait of a horse said to have springhalt : the greatest novice easily detects 't, and seldom fails to make objections to purchase an animal thus affected. Mr. Feron, one of the few writers who hareno. ticed springhalt, says, 'I am convinced, however, by long experi ence and observation, that springhalt, as it is called, is no disease, therefore can require no remedy.' And in another place, 'In. aced, in Spain, France, and Germany, it is esteemed extremely graceful in their riding schools, or manege, particularly when there is a springlult ir. both hind legs.' This writer has, however, admitted it to be a disease, to the full scope of the word, in the very outset of his description, by defining it to be 'an involuntary convulsive motion of the muscles, which extend or bend the hock.' In some particulars, springhalt bears some aflinity to what in human medicine is called chorea. IVe do not mean, however, to assert that they are essentially the same disease; much less do we imagine that a similar mode of treatment could have any good effect; all we wish to infer by such an analogy is, that they are both spasmodic or convulsive diseases, in which the will has lost more or less of its control over certain voluntary muscles. Not unfrequently, when the animal has lifted his hind leg from the ground, which is always done with a convulsive twitch, the fetlock nearly approaches the belly, and, by some other remarkable irregularities in its action, before the foot can be replaced upon the ground, (which it seldom is in the most advantageous position,) displays such unnatural movements as to convince us that volition has but little power over it during its suspension. Sometimes this irregular action is confined to one leg, but we believe that it is more commonly seen in both. It is seldom or never removed.

"Such writers as offer any opinion of its nature suppose it to be a muscular affection, mistaking, we conceive, the effert for the cause. We choose rather to refer its seat to the spinal marrow, or to the nerrous trunks passing between it and the affected muscles; an opinion we were first led to adopt, from having observed a broken-backed horse exhibit all the characteristic signs of springhalt, which in this case was clearly only an accompany. ing symptom of the former disease. It was stated in the fore 
going part of this lecture, that section or compression of the spinal marrow paralyzed muscles, and that irritation of it con rulsed them. Now, we know that many cascs of broken back terminate in palsy; and, if this be true, why slould not others be productive of springhalt - since the one arises from compres. sion, while the other is merely the result of irritation? It is $\mathrm{nct}$, lowever, necessary that a broken back be present; for any other (ause of irritation, we apprehend, would induce this disease. Horses are very subject to injuries of the loins - much more so than we seem to be aware of - from being suddenly stopped o* turned, or from being overweighted about those parts; accidents that arf but too seldom detected, since they may not be severe enough to constitute broken back, though they may so far disturb the nervous functions as to cause springhalt. Should the injury, or the consequences of it, be confined to one side, then oniy one column of the marrow will be affected, and but one leg convulsed: the nature and extent of disease in it will perhaps de. termine the degree of springhalt.

"Such is our theory of a disease whose nature, we believe, has up to this time remained unexplained; whether we have taken a correct view of it, experiment and special attention to these cases in future can alone decide. We have long had it in contemplation to attempt to induce springhalt by artificial means; and we intend, as soon as an opportunity presents itself, to institute some experiments for this purpose.

"We so seldom know any thing of the origin and progress of these cases, and, even if we did, they have generally endured so long, that it would be labor lost to treat them. Should, however, a rucent case present itself, in a horse of value enough to revider dis recovery an object of consideration, we may pursue such $m$ sans as have been recommended in the equally hopeless sno of broken back."

Regarding the Treatment. - It will be proper, when the attack is sudden, to let the horse rest; for, in a sudden attack, we might naturally suspect that some irjury, either by blow or strain, had been done to the nerves of roluntary motion: in that case, cold water bandages, (around the body,) rest, light diet, nauseating medicines, with an occasional light dose of cathartic medicine, to 
clear out the bowels, will be indicated. Fumentations, ligh. frictions with antispasmodic liniment, and the zapor bath, may assist materially in the recovery of the patient.

In chronic cases of long standing, all hopes of recovery must be abandoned: should the subject, however, be ir a state of debility, the general health may be improved, and the spine should be daily rubbed with embrocations calculated to restore ncrvous energy; in this view, we recommend the following smbrosation for springhalt -

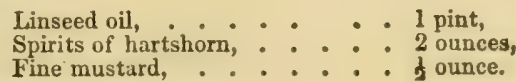

The medicine to consist of

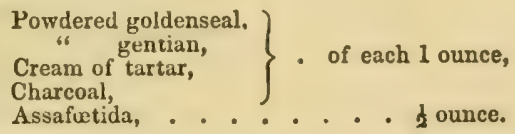

Mix; divide into eight parts; one to be given morning and evening, in the food.

\section{HYSTERIA IN MARES.}

Hysteria is derived from a Greek noun, signifying the womb: the disease is of a nervous and spasmodic character, and is supposed to arise from derangement in the organs of generation. In the human subject, plethora and suppression of :he menses are assigned as the chief causes of this affection; yet these condicions, probably, had another antecedent, which is quite common among various species, viz., dyspepsia; for we know that there is a lia bility of two or several organs to be affected in succession by a disease commencing in one of them: the stomach therefore, and uterus, which are conjoined in the performance of special functions, - nutrition and reproduction, - although having no direct anatomical connection, are very apt to display morbid sympathies, commencing in one and ending in the other: this is accomplished through the nervous connections between distant parts.

From what the author has been able to observe and glean, it is his opinion that hysteria occurs most frequently among virgin mares, after the age of puberty; and in such as have had a foal 


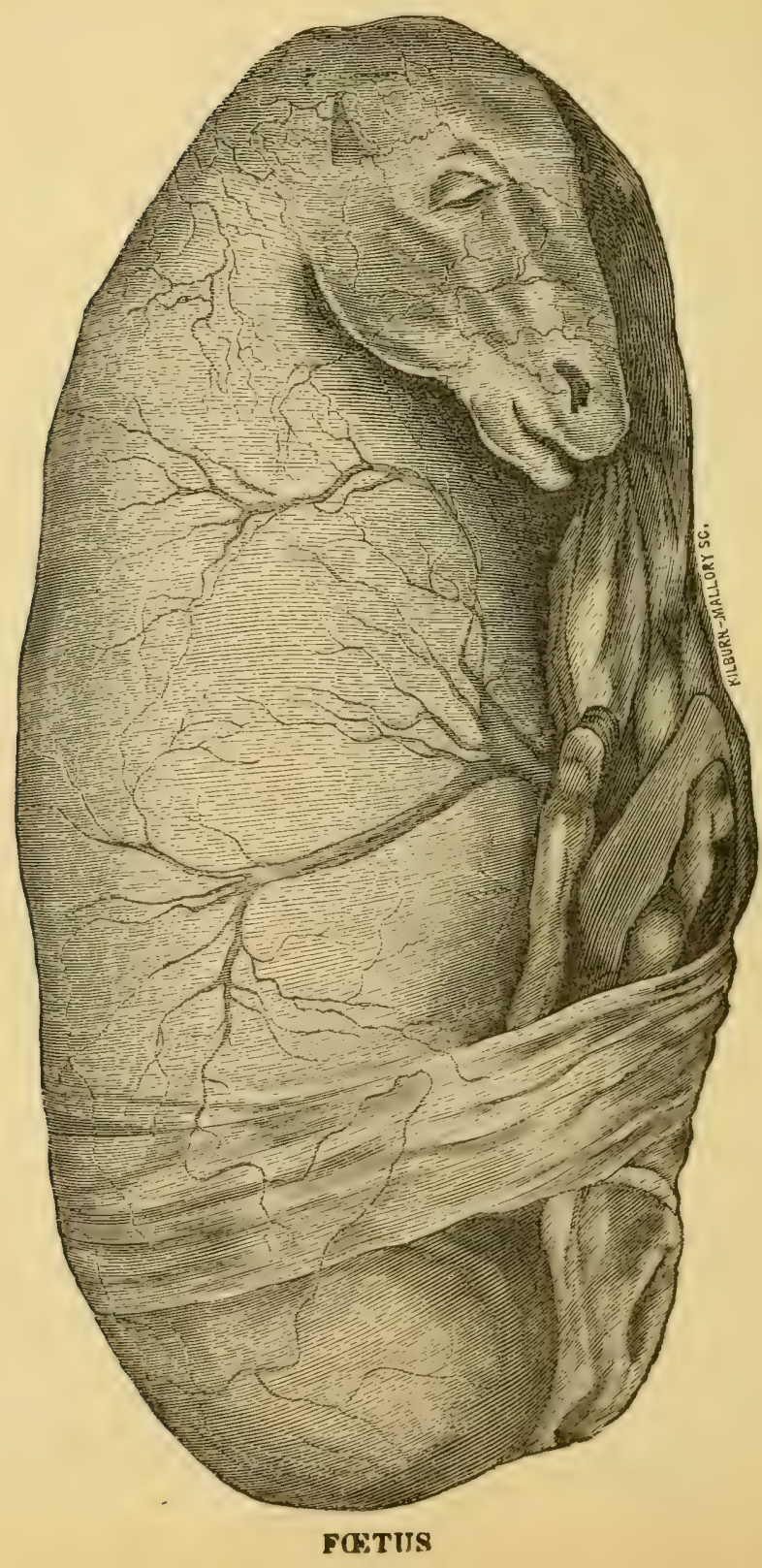


and afterwads deprived of sexual intercourse. The disnase is more apt to make its appearance about the menstrual period* than any other; at such times the mare should be fed light, and excused from every sort of active work; perhaps a saline aperient

- The following communication on menstriation in maree has been received by the author, from Dr. C. H. Cleaveland:-

"Probably all kuow that mares of the proper age, and at certain seascms of the year, menstruate, or, in other words, have uneasy' turrs, get 'foolish. t. 3 they say in Illinois; and that, at such times, they seem unwilling to perforn. their usual task, either as travellers or as draught horses; that they seem fres ful, and often ill tempered, vicious, spiteful, and frequently get a most thorough Hhipping, because their masters also get 'foolish.'

"Now, the simple fact is, that the mare knows more than her master in regard to her then condition, and she is trying to drive into his foolish noddia that, on such days, she should be left quiet, and be subject to no labor beyond the most gentle exercise.

"If the reason why this course should be pursued, in preference to the hard work and the whipping which your mare has had bestowed upon her at such times, is not now plain and satisfactory to you, mosi sapient reader, just inquirs of any old mitron within the circle of your aequaintance, and she will tell you that I am correct, but perhaps 'without a why or wherefore."

"The reproductive organs, in all animals, are intimately connected with the nervous system, and of course exert a vast influence over not only the nerves, but also the entire bedy, mind, and disposition; and when those organs are deranged or diseased, the cntire animal economy must suffer, aud be rendered in a greater or less degree unfitted to perform its usual labors. In the female, these organs exercise a still more powerful influence upon the other parts of the system than in the male; and as they are liable to periodical derangements or excitements, it becomes obviously necessary to be strictly cautious not to tax the animal's powers of endurance at those periods.

"Mires that have been ridden under the saddle, or driven in harness, during their periods of heat, and have performed no more than their usual amount of labor, are frequently discovered to be corered with perspiration across the loins, while all other parts of the surface are cool and dry; and the hostlers will say that they have been unable to rub those moist spots dry, even after the lapse of many hours; and the next day the mare is obserred to drag her hind legt after her, almost as though her back were broken. Indeed, her back is lams. weak, and painful. She urinates with difficulty, and there is evident inflara. mation of the kidneys, the ovaries, and the uterus.

"From slight injuries of this class mares will readily recorer; but if they are of too frequent repetition, or the injury be of too grave a character, the chances are, that the animal will be unable ever after to perform well, and will soon become nervous, irritable, and weak, and will be passed from jockey to jockey until she dies; a martyr not to her own ' folishness, - for her waywardness at those times are wise admonitions to her master, - but to the folly of those wac wull not learn to understand nature, because "they know all abou their hormos, and do not wish to be instructed by any book doctor." 
may be of some use in correcting any existing morbid hajit of body. When the disease occurs in mares that have once foaled it may be confounded with hysteritis, (inflammation of the womb.! In order, therefore, that the reader shall be able to draw a distinct line between the two diseases, we inform him that hysteritis generally occurs a few days after delivery, or abortion; and on examining the vagina, it appears augmented in bulk; its lining membrane redder than usual, and the anus free from those violent twitchings and loss of motor power which are present in hysteria.

Symptoms of Hysteria. - A mare during the menstrual period, or perhaps a f€w days subsequent, will be seized with a paroxysm resembling a fit; although there is no cerebral apoplexy nor stertorous breathing. (symptoms of cerebral disease,) and lies or falls down, and while the paroxysm lasts is unable to get up again : during this brief periol the pulse is accelerated; respirations rapid; the flanks are bedewed with moisture; there is a peculiar rigidity of the muscles of locomotion, attended with paralysis of the hind limbs: as the paroxysm declines, the use of the limbs is gradually restored; the animal becomes more calm; the pulse lessens in volume and heats; the respirations become more natural. At this stage, the owner of the mare may observe that she is not herself, (as the saying is,) being excessively nervous and irritable, and is excited by the least noise: the mare, however gradually becomes calm, and then is suddenly seized with another paroxysm; or they may follow each other in rapid succession, in which case death often puts an end to the scene, or it results in cerebral disease. Veterinary Surgeon Haycock remarks, that out of three mares attacked with hysteria, two of them every now and then strained violently, and ejected, per vaginam, excessive quantitues of coffee-colored urine, which consisted principally of blood: this, as far as the author's observation goes, has not betu confirmed. Our observations, however, have only extended orer a few cases; in which we noticed that the animals passed neither dung nor urine until they arose, and then the urine was but slightly colored.

Treatment. - It is useless to give medicine while the patient is in a paroxysm; all that san be done is to give the animal, whilo 
down, an injection of warm water and salt, to which add an ounce or two of tincture of assafœtida; let the external surface be well rubbed with wisps of coarse straw ; as soon as the fit is over, give § drench of

$$
\begin{aligned}
& \text { Powdered assafœtida, . . . } 2 \text { drackms, } \\
& \text { Tincture of valerian, . . . } 1 \text { ounce, } \\
& \text { Sirup of garlic, . . . . } 2 \text { ounces, } \\
& \text { Thin gruel,. . . . . } 1 \text { pint. }
\end{aligned}
$$

If the animal be not relieved in the course of six hours, repeat tha dose, and clear out the bowels with a dose of glauber salte, to which add a small quantity of ginger.

\section{HYSTERITIS. - (Infammation of the Womb.)}

The causes of inflammation in the womb are, difficult and protracted labor, abortion, and retention of placenta or fotal envelopes. Mares most subject to this disease, as well as premature expulsion of the fotus, are the plethoric; it generally comes on a few days after labor, and, unless early arrested, will terminate fatally. The objects in treating this disease are, to contract the womb, (encircle the loins with cold water bandages,) and palliate urgent symptoms; keep the animal on gruel, and give a pint of bethwort tea every four hours; attend to the state of the bowels; if they are torpid, give a pint of olive oil, and follow it up with faxseed tea. Should the disease be connected with vaginitis, (inflammation of the vagina,) the treatment is the vame, with the addition of cold water to the pudendum.

\section{PEVER IN HORSES.}

Fever should not always be treated as disease; for, in a grent majority of cases it is only symptomatic of some local or general derangement.

Fever is the same in its essential character under all circum. stances and forms which it exhibits. The different "grades," as they are termed. are but varieties of the same condition, produced 
by variations in the prevailing cause, or regulated by the amount of vital power in each given case, and are therefore an index pointing to the progress of the disease, operating to ward off the malady and restore health. An eminent physician has said, "Our indications of cure and modes of treatinent are to be learned from those manifestations of the vital operations uniformly witnessed in the febrile state. If fever marks the action of the hiealing power of nature, which we must imitate to be successful, why should we not consult the febrile phenomena for our rule af uction? Now, what are the indications of cure which we derive from this source? In other words, what are the results which nature designs to accomplish through the instrumentality of fever? They are an equilibrium of the circulation, a properly-propor. tioned action of all the organs, and an increased depuration of the system, principally by the excrementitious outlets."

Suppose a horse shall be suffering from a form of disease known as gastro-intestinal, occasioned by an accumulation of partlydigested food within the stomach ; the mass acts as an irritant, an exciting cause, - and the result is inflammation, (local ferer;) then general excitement, or sympathetic action, which is manifested by increase in number and volume of pulse, hurried respiration, superficial heat, \&c. Now, it is evident that the inflam. mation - local fever-is not confined to the stomach alone, but becomes general, as we have just said, through the sympathetic relations. The effect of this general abnormal condition is to mitigate the force of the disease on the primary tissue, or tissues, to shift the weight of the burden, and so apportion it to the sev. eral parts of the system, as to lessen its intensity.

The heat at the external surface shows that the circulation is active. "Without heat there is no ritality in the system," and without blood there is no heat. Then the blood must be sent to the surface for the purpose of relieving the internal organ, and thes efore fever must, under some circumstances, be considered favorable to the cure of disease. Hence the reader will perccive that the practitioner whose creed is, "The more fever the more bloodletting," is one of the greatest opponents nature has to deal with, and it is no wonder that so many animals are said to die of Rever: it is rnost probable, however, that many die from the 
Ireatment. The practice of indiscriminate drenching, under the circumstances, with salts and aloes, may sometimes prove just as aestructive as the injudicious use of the lancet; for purgatives of this character act on the alimentary surfaces as mechanical irri tants, and then and there set up a pathological action, to counter. act which nature recalls her forces from the external surface, and equploys them in the vicinity of parts where they were not wanted, until man's unwise interference conflicted with the well-planned arrangement; in short, made nattre turn a somerset. When the increased action and heat are manifested on the surface, does it not prove that the different organs are acting harmoniously in self-defence? Is not this same action manifested through the same channels in a state of health? And if morbific materials are present in the system, and are the cause of fever, will the mode of evacuation be different from that of health? Certainly not. Hence the marked tendency of fever to evacuation by the skin in profuse perspiration, from the nostrils in the form of catarrh, by the bowels as in diarrhoca, and lastly, by abscess. Therefore the great secret of curing diseases consists in accurately observing by what critical evacuations nature casts off whatever may be the cause of her infirmities, and in following and assisting her agreeably to her indications, for she acts with great regularity.

When an animal has taken cold, and there is power in the system to keep up a continual warfare against encroachments, the listurbance of vital action being unbroken, the fever is called pure or persistent. Emanations from animal or vegetable sub. stances in a state of decomposition or putrefaction, or the noxious miasmata from marshy lands, if concentrated, and not sufficiently diluted with atmospheric air, enter into the system, and produce a specific effect. In order to dethrone the intruder, who keeps up a system of aggression from one tissue to another, the vital rower arrays her artillery, in good earnest, to resist the invadir:g fos; and if furnished with the munitions of war in the form of sanative agents, she generally conquers the enemy, and dictates her own terms. While the forces are equally balanced, which may be known by a high grade of vital action, it is also called unbroken or pure fever. The powers of the system may becomi exhausted by efforts at relief, and the ferer will be periodically 
reduced; this form of fever is called remittent. By remittent fover is to be understood that modification of vital action which rests or abates, but does not go entively off before a fresh attack onsues. It is evident in this case, also, that nature is busily en gaged in the work of eștablishing her empire; but being mors exhuusted, she occasionally rests from her labors. It would be ns absurd to expect that the most accurate definition of fever in one animal would correspond in all its details with another ease, as to expect all animals to be alike. There are many names given to fevers; for example, we have milk or puerperal fever, symptomatic, typhus, inflimmatory, \&c. Veterinary Surgeon Percivall, in an article on fever, says, "We have no more reason - not near so much - to give fever a habitation in the abdomen, than we have to enthrone it in the head; but it would appear from the full range of observation, that no part of the body can be said to be unsusceptible of inflammation, (local ferer, though, at the same time, no organ is invariably or exclusively affected."

From this we learn that disease always attacks the weakest organs. The same author continues, "All I wish to contend for is, that both idiopathic and symptomatic fevers exhibit the same form, character, species, and reyuire the same general means of cure; and that, were it not for the local affection, it would be dillicult or impossible to distinguish between the one or the other."

1)r. White, V. S., says, "Some practitioners do not admit the existence of fever in the horse as a primary disorder, [they are sensible men,] but consider it as a symptom dependent on internal disease. 'Then why not attend to the internal disease, insteat of attempting to cure the fever? It would be a very diflicult task for us to convince mankind generally that ferer does not require to tre treated as the real enemy; for ferers are very fashionable diseases, and it is a very easy matter to convince a man that his horse has 'got a fever,' and he is always willing to pay for its treatment."

Mr. Blaine, V.S., refers only to three different kinds of fever - the common or simple fever, symptomatic fever, and malignant epidemic fever. Mr. White, V. S., thus refers to fever: "The fevers of horses (for it is of little importance whether we call them fuvers or inflammation) are generally connected with 
Inflammation either of the mucous or serous inembranes, or both in other words, fever may be of the catarral kind, as in the epidemic catarrh, or the violent influenzas which sometimes pre. vail in the spring or beginning of summer. Fever may affect the mucous surface of the stonach and bowels, when it causes great languor and debility."

The day is not far distant, when a practitioner will as soon think of confining his treatment to scraping off a patient's coatcl tongue, when suffering from a bilious attack, as to think of treating :l.e febrile manifestations of a local disease in the horse, in view c. curing the latter.

Our own definition of fever is, that it is a symptom of disease arising in consequence of sympathy of the system with disease in some particular part. Pleurisy, for example, consists in inflammation of the serous rembranes within the thorax; and at the commencement, and indeed during the rarious phases of the malady, fever may be present, manifesting itself in the usual manner; bat are we to treat the fever, the mere manifestation of the disease - pleurisy? or shall we not find it more in accorlance with the principles of reason to endeavor to cure the latter? Fever is present in all cases of an inflammatory character; therefore we would warn our readers not to let fever in the horse so engross their attention as to overlook the real malady. Next to inflammation, fever is the great scarecrow of the empyric, when, in fact, there is nothing very alarming about the fever itself; yet it leads us into the by-paths of ignorance; for if there were not previous lisease, there could be no fever, so that he who merely treats fever is playing the part of mountebank tc the disease then present. A few illustrations will serve to ex. plain: A man, for example, manifests paroxysms of sold, hot, and sweating stages; these phenomena may prevail in differert d. grees, and their mode of succession vary; but if the three differc1 t stages are evident, the case is called intermittent fever. Now "dissections of those who have died of intermittent fever show a morbid state of many of the viscera of the thorax and abdomen; but the liver, and organs concerned in the formation of bile, as likewise the mesentery, are those which are usually most affected." - Hooper. Why, then, should men trifle with the livas 
of their patients in curing fevers of this type, when such inpor tant organs as the above are the primary ones involved? Thes acrain, in cases of typhoid fever, post mortem examinations reveal inflammation of the brain and riscera, and more particu. larly of the stomach, intestines, and Peyers glands. Is it not rasonable, then, for us to suppose that fevers - the febrile symptoms - appear subsequently to the above diseases? that Hiny derelope them in so slow and insidious a manner as not .o he noticed until what men are pleased to denominate fercr sets in ; this being, at that stage of the disease, the most marked symptom; and not haring the privilege of inspecting the patient's intermal organization, and of course being in the dark as to what is going on there, we jump at the conclusion that the patient has some sort of a fever, and name it according to its type and intensity. It is then treated secundum artem.

A horse may all at once show signs of febrile phenomena; but who is so wise as to be able to demonstrate that an error in i' $n$ r.ral management had not previously deranged the equilibrium of the vital forces ere the first symptom of fever appeared? So in the case of a cow, the subject of puerperal fever: she may have been for months in a state of plethora, (an abnormal condition,) which is generally the case with such animals; the disease perhaps has been in a state of incubation for some time, but at length it arrives at a stage when the vital forces succumb - a general febrile state speedily follows - hence the fever is not $\mathrm{l}_{1} \mathrm{e}$ real malady. Our limits will not admit of further discussion umler this head, other than to remark, that this as the age of reason, - "godlike reason," - and the world should be dotted over with medical investigators, who are willing to solve the prohicms of disease and health according to the principles of reason, disregarding the stereotyped conclusions of by-gone days

Three forms of fever occurring in the horse are alluded to by the author of Hippopathology. 1st. Common ferer; 2d. Idio. pathic; and, 3d. Symptomatic. The first is but a general dif. fuse inflammation. The second arises without any apparent local injury; and the third from some local cause or irritation. The above distinguished author, however, is evidently aiming st perfection, for he has classed these three under the significatiou 
of "one common kind;" and he also alludes to two of a kind that are uncommon, which he names specific, arising from some special, mysterious, or unknown cause. - See Hippopathology, vol. i. p. 149.

Treatment of Fever. - Under the iron heel of medical despotinm, we are bound to "arrest its progress, and to mitigate it violence." But suppose we do. Are our patients any better vff? The records of the past will show. A rational system of $\nabla$ terinary medicine contemplates, in the treatment of febrile syroptoms, nothing more than a kind of expectancy. If the patien: be in the cold stage, administer warm diffusible stimulants and diaphoretics, aided by warmth and moisture externally ; friction on the extremities, and, if necessary, stimulating applications to the chest and extremities. In the hot stage, and when the superficial heat of the body is great, cooling drinks are indicated water, acidulated with cream of tartar, makes a good febrifuge. The patient may be occasionally sponged with weak saleratus water. The alkali has a beneficial effect on the cutaneous vessels, while the water lessens the temperature of the body. No treatment, however, can be of any rational use, unless it contemplates a restoration of the healthy equilibrium of the whole system. Let the doctor treat the disease, and a good, attentive groom can manage the fever.

\section{SIMPLE SCARLET FEVER. - (Scarlatma.)}

Mr. Percivall, in referring to scarlatina, says, the first account of it was published by himself in the Veterinarian for 1834. "This since has received such confirmation from other quarters as to leave no doubt in my mind that, rare as the malady inknowledgedly is, and hitherto undescribed as it has remained, it will one day find a place in our established veterinary nosology."

It is difficult to say to what extent scarlatina prevails in this country, for there are very few persons qualified to define such s disease; in fact, the majority of men do not know that such an uffection ever manifests itself in horses. From the fact however, that we have seen two cases within the past four years occurring in this city, we are led to suppose that it may, at certain seasons. prevail to some extent. 
The symptcms are very minutely defined in the following arti rle by Surgeon Haycock :-

"Simple Scarlatina. - This form of the disease usually appears in association with epidemic catarrh : it seldom, or, perhaps never manifests itself simultaneously with epidemic catarrh, but usually on the thirr or fourth, and even as late as the sixth day from the commencement of the former. The animal affected with charrh will, perhaps, be fed and left at night in what may be considerod a fair way of recovery; but when the attendant enters the etrable on the morning following, the patient may be found affected in a very peculiar manner ; the hair about the neck, the fore and hind limbs, will be elevated in blotches, while the limbs themselves will be found in a swollen condition. The blotchy elevations, generally speaking, are not large, but they are exceedingly characteristic of the malady. If the hand be pressed lightly over them, scarcely any corresponding elevations can be found upon the skin beneath. The mucous membrane of the nose will have upon it a few scarlet spots of variable size; the pulse, in some instances, will be increased in action considerably, while in others, even when the disease appears most severe, not so much. If the epidemic catarrh, or the disease under which the patient labors, be attended with soreness of throat, that soreness may become greatly increased, or it may not. Sometimes the blotchy elevations are confined to the hind limbs, and the scarlet spots to the membrane of one nostril, while in other cases all these symptoms are present, but in such a very mild degree as not to excite the attention of any one but a closely observing prao. litioner. If, at this stage of the disease, the animal be judicious. ly treated, and the stable be dry and comfortable, the whole may pass off in a few days without any further mischief ensuing ; but if the treatment be improper, the stable cold and damp, and the animal otherwise unfarorably circumstanced, it is probable that the disease will become more virulent, and either assume the malignant form, or pass into what is called 'purpura hæ. morrhagica, and the life of the animal, in either state, become greatly endangered."

Treatment. - This is one among the many diseases $\mathrm{w}$ hich are Brnsidered self-limited; that is, they will run a regular course. 
up to a certain intensity, and then, all things being favorable so regards the patient's previous health, management, \&c., the un. favorable symptoms subside gradually, and the subject convalesces into a normal condition. Some medical treatment, arlvice at least, may be needed. A veterinary surgeon should be consulted if possible; he may do nothing by way of medical treatment, but his advice will prove invaluable, and, in the end, of great pecuniary advantage to the patient's master. The treat. mont of small-pox or scarlet fever occurring in human subjecto in the London hospitals is a rery simple affair to what it was a few ycars ago, and, in consequence, those maladies are less fatal So with reference to scarlatina in the horse - the medicines, if any are indicated, must be few and simple. The owner of the horse cannot err in carrying out a proper system of hygicne, so strictly observed in well-conducted hospitals. As a febrifuge, water acidulated with cream of tartar is the best: this may be given at discretion; it allays inflammatory symptoms, cools the thirst, promotes the secretions and excretions; in short, is just the drink for a fever patient.

A kind of sloppy diet may at first be used, composed of scalded fine feed, \&c.; a small quantity of sweet hay will be required, to keep the stomach employed, and to distend it to a bealthy capacity; yet, in the early stages of this disease, we need not be very solicitous about the quantity of food necessary; for if we should half starve the patient just at this time, it is of littl importance, provided he has an abundance of good water and sloppy gruel to drink. When the disease has so far advanced as to exhaust the patient's strengrth, then it is time for us to loosen the string of the meal bag.

If the bowels become constipated, at any stage during the frogress of this affection, a dose of sulphur and cream of tartar one sunce of the former, and half an ounce of the latter) muy with perfect safety be given, and also repeated, if necessary. It ts hest to gire the medicine in the form of drench. The after treatment depends altogether on circumstances; if the patient has had a careful nurse during his sickness, he may not requirt any medicine, 


\section{MALIGNANT SCARLET FEVER.}

Malignant scarlet fever is a sequel to the preceding disease, and may be said to commence where the other terminates: it is difficult, however, to determine the exact line of demarcation where one ends and the other commences; yet, when the patient has passed through the usual probation of simple searlatina, and, instead of appearing better, grows worse, we may reasonably suspect that the disease will terminate in the above form. The author's experience is so limited as regards the symptoms of this malady, that he prefers to give those detailed by Surgeon Haycack, who is considered good authority.

Symptoms of Malignant Scarlet Fever. - "The patient for sone days may have manifested what is usually considered to be influenza, or epidemic catarrh, the symptoms of which will, for the most part, consist of sore throat of an obstinate nature, with fever more or less serere, with cough, loss of appetite, discharge of purulent matter from the nostrils, and general debility: when, suddenly, the whole changes; the limbs begin to swell, which swelling presents either an uneven surface, (occupying the whole of the limbs,) or it appears in lumps, or masses, which are both large and numerous, also hot, hard, and painful, while those portions of the skin which are free from such swelling present the blotchy elevations so common to the simple form of scarlatina. The membrane of the nose becomes, also, covered with large-sized spots of an intense scarlet color, while from the nostrils is discharged a mixture of blood, purulent matter, and serum. At this stage, the soreness of the throat becomes excessire, accompanied, of course, with a corresponding degree of diffi ulty in swallowing; the cough also becomes worse, and of a suffocating character. The pulse increases in number, reaching, at times, 90 , or evan 100, beats per minute, and is always of a weak or ferble character. The swollen limbs are excessively tender, and if the patient be left alone, he will stand for hours nailed, as it were, to one place and in one position; it is only with the greatest difficulty that he can be mate to move at all. As the disease procecds, or assumes more intensity, large blisters or vesiclea 
uppear upon the limbs, particularly arnund the joints, these recicles burst, and discharge a bright amber-colored fluicl, which is very corrosive in its effects on the adjoining skin. In other cases again, some extreme portion of the organism, such as the ears, for example, will suddenly present a blanched appearance, the skin of these organs wili shrink, and become hard and dry, as though frozen, and in the course of a day or two these blanched portions snap off, leaving a raw surface, which speedily suppurates. The appetite entirely disappears, and the secretion rom the bowels becomes checked, and what is denominated constipation ensues; the urine is scanty, and of a thick, yellow, or brown color. In the course of twenty or twenty-four hours from the commencement, (and in many cases eren less,) the scarle! spots on the membrane of the nose enlarge and pass into the purple-colored patches, and these patches slough, and leave a raw surface, from which is secreted an abundance of purulent matter; at the same time, a similar sloughing goes on around the joints, where the blisters or vesicles first appeared. If the animal does well, the fever will generally abate (in the milder slates at least) about the fourth or fifth day from the commencement of the more acute stage, while in the more malignant kinds it is seldom that a change for the better occurs before the seventh or eighth day."

Treatment. - The medicines must be of a stimulating, antisf.ptic, and laxative character - stimulants, of a permanent character, to arouse vital action, and carry on the various functions of the body; antiseptics, to arrest decomposition, and ward off the typhoid state; laxatives, to carry off the morbid producte, as fast as they accumulate within the dige surface. The dicease is now supposed to have invaded all the tissue to a greater or less extent, and requires to be promptly met with medicines of this description, aided by a nutritious diet easily digested, such as coarse oatmeal, dry, or in the form of thick yruel; equal parts of flour and fine feed may also be used in this view, with an allowance of boiled roots - carrots, potatoes, parsnips, or beets. Every means that the urgency of the case demunds must be put in force to make the animal as comfortable as possible. The rectum must be occasionally emptied, bv means 
of injections; and if the throat be sore, or, from any other cause, the patient cannot swallow sufficient food to support the vital forces, his strength may be kept up by nourishing enema buef tea, flowr gruel, \&c.; at all events, a supply of hay tea, thickencd with some farinaceous substance, ought to be kept in the (rib; it is a tempting delicacy to sick horses, and they often give it the preference to all other kinds.

The following compound is considered the best, in view of fulfilling the indications just alluded to :-

$$
\begin{aligned}
& \text { Powdered capsicum, . . . . } 1 \text { drachm, } \\
& \text { " charcoal,. . . . . t ounce, } \\
& \text { Sulphur, cubebs, : : : : } 6 \text { drachms, }
\end{aligned}
$$

To be given at a dose. How this shall be given is not for the author to say; that will depend on circumstances. The throat may be sore; in that case it will not be prudent to drench the patient; hence it must be introduced into the stomach along with the food. The patient may have no disposition to eat; if so, we must give him medicines of less bulk, which, through patience and care, we may at last succeed in getting down the throat. Our remedy then is brandy and salt, in wine-glass doses, o.:

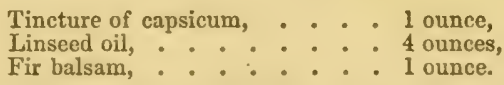

In the event of the patient not swallowing the whole of this, it will have the effect of lessening the pain within the throat, even should it only come in contact with the mucous surfaces. Let the medicines be given in broken doses, at intervals of a few minutes; in this way we may succeed, even should the throat be sore.

The blotches over the body should be sponged daily with alkaline wash - weak ley of wood ashes, or saleratus water. So soon as abscesses appear, they are to be moistened with

Pyroligneous acid, . . . 4 ounces,

Water, . . . . . 1 pint.

The case will very soon be decided; the patient will either grow worse, or show symptoms of amendment; if he should however, appear better, the above treatment, with the addition 
If some tonic medicine, such as gentian or goldenseal, may gradually complete the cure.

\section{TYPHUS FEVER.}

Discase of the above type is more frequent in the Westcmi than in the Eastern States, and more commonly occurs among cattle than horses : the main fealures of it consist in a tendency to rapid putrescence of the solids and fluids, and great prostra. tion: it is generally complicated with disease of the lungs or intestines. Its diagnostic symptoms are, pulse quick, soft, and feeble; tongue coated with a yellow-brown fur on its centre; its margins are of a light-red culor, and cracks or fissures are occasionally observed. The teeth have lost their natural, and are now of a dark brown color; the gums are red, and dischurge an ichorous fluid; the breath is very offensive; the color of the nasal membranes almost resembles that of the tongue; yet they more frequently present symptoms of pulmonary congestion, having, however, a dry appearance, with dark, reddened patches. The eyes are suffused, and the countenance has an expression of turgidity. If typhus is complicated with pulmonary disease, the respirations are hurried and the bowels sluggish. When connected with intestinal disease, the dung is slimy, black, and fetid; pressure in the aludominal region elicits signs of pain. There is also great thirst and loss of appetite. On carefully passing the hand over the patient's body, we discover a morbid heat, and perhaps some elevations or eruptions. These are the diagnostic symptoms; others, common to various diseases of a low febrile type, are present, varying in duration and intensity, according to the nature of the case. Post mortem examinations show no other constant pathological changes that can be depended on ; so that the external signs appear of more value to the surgeon than the internal. Its last stages are marked by a putrid type; mortification puts an end to the patient's sufferings. We consider the disease, at a certain stage, both contagious and in. fectious. (For treatment, see Malignant Scarlet Ferer.) The prophylactic means are, ventilation, cleanliness, nutritious dies and fumigation. 


\section{PUTRID FEVER.}

This disease is somewhat rare in this section of the Cniled States, but sometimes prevails to an alarming extent in the South. Western. The following communication was lately received by the author from a veterinary surgeon of Pennsylvania -

\section{"BuckingHaM, November 26, 1853.}

"Respected Friend: Agreeable to promise, I will now esdeavor to give you some of the causes, symptoms, diagnoses, prognoses, and treatment of the disease that has recently been prevailing, not only with your horses, but with many others, in different sections of Bucks, Montgomery, and New Jersey with horses differently fed, exercised, stabled, and groomed, as is common to arise from the different avocations and peculiar views of their different owners. I have never attributed the disease to any kind of feed, exereise, stabling, or grooming, particularly; but I attribute the remote cause of the disease to atmospheric influence, and the proximate cause to debility, however induced. This theory of the cause of the disease I will endeavor to give you some reasons for. First, the disease has always prevailed to a much greater extent in the fall of the year than at any other time, when the weather is frequently changing from heat to cold, and from cold to heat.

"A change from cold to heat has a relaxing and debilitating effect upon the whole system; the perspiration flows freely on the least exertion, showing great relaxation of the skin; and when the horse is in this relaxed condition, perhaps the weather changes suddenly to a cold, damp, north-east wind. This change makes a great demand upon the caloric of the system, cr, in ther words, extracts a great proportion of animal heat, closes the pores of the skin, thereby throwing the perspiration back upon the internal vital organs, which impedes their free, full, and bealthy functions - particularly so in the fall of the year, when the hozse is changing his summer for his winter coat, or what is called the moulting. As the moulting is a process extending over the whole of the skin, requiring a very considerable expen. 
diture of vital power, which, taken in conjunction with the othes causes binted at above, renders the horse more susceptible or predisposed to diseases of a low grade, such as I am now consid. ering, that energy and nervous and rital influence, which should support the whole frame, are in the moulting season to a great degree determined to the skin, and the horse is languid, and un. nble to bear as much hard work as at other seasons of the year; and if he is pressed beyond his strength, be will be liable to be. come seriously ill, and that illness will be, in a great majority of cases, of a low, malignant, or typhoid type, in which the systr at in never able to react, so as to produce a disease of an inflammatory order. Hence the frequency, at this season of the year, of the disease in question, which consists essentially in a great prostration of the living principle. In some attacks of this disease, it is so severe that it destroys life in the space of from six to twelve hours, and on examination of the cadaver after death, there will scarce be the slightest trace of the disease left behind: because the force of the cause of the disease was so powerful that it took life at once, as if it had been taken by a blow on the head, or as if a large dose of arsenic had been given, which immediately destroys the power of the system to produce heat and nervous energy, and death takes place without any reaction, or without leaving any perceptible effects of the poison behind. Precisely so is it with this disease when it takes life without re. action. But if the attack is not severe enough to destroy life under three or four days, there will be some reaction, and traces of gangrenous imflammation may be discovered, on dissection, to have taken place on the mucous membrane of the windpipe, lungs, \&c. And again, in a still milder attack, where the horse will linger along from a week to two or three weeks, his wbolf body becomes one mass of putrefaction, and wholly unfit to be even cast to the dogs. Such, then, is the malignant nature of the disease produced by poisonous agents in the air, acting on horses predisposed to receive it. It not unfrequently, when it prevails as an epidemic, destroys two thirds of those attacked. Bidding defiance to every remedial means, it boldly marches on its course, until its work of destruction is complete, and then in reems as if occupying the desolated spot in triumpl. 
"Symptoms. - The first or premonitory symptoms of putrid iever are a peculiar wrangling of the body and striding of the limbs, as if the horse was conscious of his inability to walk. At the same time, there will be some difliculty of swallowirg, and some thirst; the horse will appear as if drinking a great deal, and will delight to continue at the water a long while, when in fact $l_{w}$ s getting little or none down. These symptoms are scon followed by extreme muscular debility - a weak and intermitting pulse. The horse gets down, is totally unable to rise, or to swallow either food or drink; not from any swelling or obstruction in the throat, but from want of strength in the muscles of deglutition to perform their functions. IIe lies on his side, paws with his fore feet, struggles, and seems in great distress; now commences breathing short, rattles in the windpipe, (which is full of a substance like lively soap) suds, which exudes from the mucous surface of the windpipe and bronchial tubes,) coughs so as to shake the entire frame, although it is a peculiarly weak, ineffectual cough, brings nothing up, nor does it afford any relief From the weakness of the circulation, there will be, at every round thereof, more or less of blood deposited in the lungs, till they become congested, or filled with blood. This congestion of the lungs is often mistaken by inexperienced persons, as well as those poor in diagnosis, for primary inflammation of them, and the lancet is resorted to, (although the pulse would forbid its use if they knew how to consult it,) which hurries on, at a rapid rate, the very congestion which they were expecing to relieve, by producing still greater debility in the system,. which is the sole cause of the congested condition which the lungs are frequently found in after death. In some cases a great discharge of saliva takes place from the mouth; breath very offensive; bowels cos. tive, and when a discharge does take place from them, it is generally covered with a white, slime-like substance, though in some instances a purging takes place, but by no means a common cecurrence; legs and ears cold; the heat of the skin is generally 100 low, although in some rare instances it rises to a high degree, anl is acrid and burning to the touch. The countenance expresses some anxiety. Uis eyes preserve their healthy look til] near death, whan tears nay be seen rolling around in them. 
Lizunnosis. - It may be distinguished from inflammatory sore muat by the sudden and great prostration of strength, by the putrid tendency in the system; by the typhoid type of the fever: and low, intermittent pulse, and putrid smell of the breath. There is no soreness evinced when the throat and windpipe are pressed betwen the fingers, nor is there any pain manifested in making an eflort to swallow, as there is in inflammatory sore throat.

"Prognosis. - Favorable: The countenance preserving ita natural state; the look firm and clear; respiration not disturbed; pulse but little altered; but slight difficulty in swallowing; the prostration of strength not great, the horse continuing to feed without an increased secretion of saliva.

"Unfavorable : Extreme anxiety of countenance ; difficult respiration; great prostration of strength, without the power to swallow either food or drink, although they will continue to try almost constantly; copious flow of saliva, of a tenacious, white appearance; increased arterial action, with diminished muscular power; unable to stand but for a short time, and almost constantly struggling whilst down, and if turned on his breast, the nose will rest on the ground; he has not strength sufficient to hold it up.

"Treatment. - In attacks where the prostration of strength is not great, give a drachm of camphor and half an ounce of nitre, both finely pulverized and dissolved in half a pint of warm water and give as a drench every six hours, till you give two doses; then omit one dose, and give one ounce of powdered aloes, and half an ounce of capsicum, dissolved in a pint of warm water; drench with it, but never raise the head higher when drenching than is unavoidable, taking especial care not to strangle him. In six hours after giving the physic, commence with the camphor and nitre as before, and give it every six hours, till it has con. siderable of a diuretic effect, or till the horse shows symptoms of returning health, when three doses in twenty-four hours will be sufficient. But if the horse should be losing strength, the nitre must be left out, and from two to four drachms of capsicum added to the camphor in its place, and given every four or six hours. Should the physic not operate in twenty-four hours, half the above quantity must be giver; it is not proper that severe purging should be produced, but sufficiently so to warrant the belief that the alimantary canal has been thoroughly cleansed. 
"But should he still be losing strength, in taking the capsicun and camplior he must have added to them, night and morning. from three to four drachms of finely-powdered cascarilla. Injec. tions must be used twice a day whilst the bowels are costive, composed of half an ounce of castile soap to a quart of warm water, and four ounces of epsom, salts dissolved in a quart of warm water, alternately. The throat must be gargled every two hours, with a tea made by pouring half a gallon of boiling water on six draclıms of capsicum, and when cool add a pint of good vinegar. The throat externally must be well rubbed with the following mixture three or four times a day: half a pint spirits of hartshorn, ditto of turpentine, ditto of camphor, all mixed and kept well corked. If the horse is down and unable to get up, he must he helped whenever he struggles to get up.

"I have now given you a short outline of the causes, symptoms, treatment, \&c., as you desired me to do. I have not carried nut in detail the different heads alluded to as $I$ could have desiled, but I trust the hints which I have thrown out will dispel some of the doubts and darkness that hang over this disease; and if the prescriptions here given are timely and judiciously applied, they will arrest the disease in a number of cases, and stay tho astonishing waste of property that we so frequently hear of.

"With respect, I remain your friend, "Isaiah Mrchener, V. S."

\section{DISEASES OF THE MOUTH}

\section{SLAVERING. - (Augmented Salivary Secretion.*)}

SLAvering horses are frequently met with in farming districts, where clover is used as an article of fodder. There seems to be some peculiar property about the flowers of clover which rendera

* Shoving the alnundance of the Salivary Secretion. - Mr. Charles Dickens, a leterinary surgeon of Kimbolton, has taken the trouble to ascertain the amoun $n t$ saliva secreted by a parotid gland; he was enabled to make the experiment 
them a source of great irritation to the mucous surfaces and salivary appraratus of the horse. Some horses, however, will partake of clover without the least inconvenience; in fact, they "get used to it," as the saying is, and, with the addition of other grain, grow fat and sleek.

Lobelia and tobacco have about the same effect on some green horses as clover, always inducing an increased flow of saliva These articles may induce an increased secretion of this fluid in two ways:-

1. By irritation; the article coming in direct contact with highly sensitive secretory surfaces, which always pour out their fluids on the application of an irritant, so long as it remains an irritant, and prorided the parts retain their normal sensibility.

2. Through the medium of absorbents: thus calomel affects the salivary glands, and causes them to secrete and pour forth an amount of fluid at times almost incredible. Any irritating body placed within the horse's mouth may produce an increased flow of saliva. It is the custom among horsemen in Hungary, to place on the horse's bit a small piece of corrosive sublimate, or arsenic, and very soon he begins to foam at the mouth, which is considered a mark of high temper; and, strange to write, his general appearance improves - he gains flesh; the coat lies smooth and sleek; he is all life and ambition. But the day of reckoning comes; the poison accumulates in the system, and the highmettled plethoric steed loses all his artificial qualities, so much admired; his mettle and ambition desert him, his muscles shritk, and he soon becomes food for the ravens and other beasts of prey. The sharp edges of a worn-down tooth, or a tooth in a state of slceration, may give rise to profuse salivation; then again, \& rough bit, and a hard master may be set down among the direct causes of this complaint.

on a horse which was the subject of fistulous parotid duct. He found that while the animal masticated hay, from eight to ten drachms of saliva per minute flowed; but if the jaws were quiet, from six to eight drachms only. Now, if wo take the medium at one ounce per minute, and suppose an equal secretion from the opposite gland, it will fall little short of a gallon per hour, in a compara tively small anima?. Adding to this, therefore, the submaxillary, sublingual Rc., secretions, the amount secreted in a given time must be very great 
Lastly. Indifferent fodder of any kind, and impaircd diges. tive organs, are apt to produce augmented salivary secretion.

Treatment. - The causes must be diligently sought for, and if practicable, ought to be removed: this important step may, of itself, procure relief. If the trouble can be traced to a cari. ous tooth, let it be extracted, or should the edges of a tooth irritate the inside of the cheek, apply the tooth rasp, and make all smooth. If any irritation exists about the glands of the throat and mouth, apply a stimulating application to them, composed of hartshorn and olive oil. When the malady is supposed to originate in consequence of the presence of some robnoxious article in the fodder, change the diet, and give the following :-

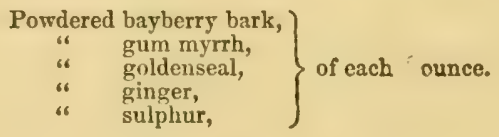

Mix; divide the mass into eight parts, and mix one in fine feed night and morning.

In some cases we have used gargles, composed of decoction of witch hazel, bayberry bark, tincture gum catechu, and a solution of alum, either of which is good when an astringent is indicated. There are cases, however, that often baffle our utmost skill, such, for example, as are supposed to depend on some lesion of the nervous structure, known by a partial paralysis of one side of the face.

Mr. Cox relates, in the Veterinarian, the case of a cow, "which was said to be constantly slavering, and more so when she was ruminating. The symptoms were, one eye half closed, caused by inability to raise the eyelid; the ear, on the same side, lang. ung down; and likewise the upper lip on the same side. It was avidently an attack of paralysis which was the cause of these appearances. The treatment was, blisters applied round the base of the ear, \&c., and laxative medicines given. In a month she appeared well.

"Another, having the same symptoms, was cured by a like treatment.

"Another case yet, of like symptoms and treatment, with the 
addition of the insertion of setons, never recovered; her eyelid, and ear, and side of her lip, remained down, and she continually kept slavering, until, at last, I lost sight of her.

"I knew a mare in which the saliva ran out of the mouth in a most astonishing manner. The cause $I$ found to be a slight at tack of paralysis on one side of the upper lip.

"My attention was once directed to a cow that had been slaver. ing for apwards of nine months previous. Gallons of saliva migl:t be caught in the course of twenty-four hours. I examined this cow orer and over again, but never could find any apparent cause for the morbid secretion. She had milked well the greater part of the time, and had never failed in her appetite. Although she had become very poor, she was sold to a slink butcher. I had not an opportunity of making a post mortem examination. The person that opened her could discover ' nothing the matter.'

"In another case of a cow, which presented the symptoms of the case last described, and which had been amiss about a month, we treated thus : a gentle purge was first given; afterwards, an occasional stimulant and tonic were administererl; and the region of the parotid and submaxillary glands well blistered; and this was repeated. She ultimately recovered."

\section{INFLAMMATION OF THE TONGUE-(Glossitis.)}

This is generally supposed to arise from injury to the tongue; but cases frequently occur that cannot be traced to this source. We treated a case of this kind occurring in a horse, the property of Mr. Thomas Bancroft. The animal had performed his usual labor, when, on putting him up at night, the tongue was observed to he swollen, and the tip protruding on one side. On careful examination, no lesion nor injury of any kind could be found. Next day, the tongue was enurmously swollen, so that the patient was unable to close the nippers; he had also infammato. ry sore throat, and considerable fever. The treatment consisted in applying stimulating liniment to the throat; the mouth was kept constantly moist with salt and water, occasionally cram. ming a handful of salt between the jaws; he sub:isted on thin ortmeal gruel, acidulated with (ream of tartar, and got well in 
six days, without any medicine. Another case was treated in the same manner, which ended in abscess under the jis, and the subject quickly recovered.

At times, inflammatory action runs high, when it will be necessary to give a dose of glauber salts; dose, ten ounces.

\section{WOUNDS OF THE TONGUE.}

It is very fortunate for horses that wounds occurring in this aseful appendage to the mouth generally heal very rapidly: ai] that is necessary is, to let the animal rest, keep him on a sloppy diet, and apply tincture of arnica to the parts.

\section{LAMPAS.}

So long as horse owners believe "lampas" to be a discedue, nnd men can be found to "burn it out," as it is sometimes termed, just so long will the error exist, and the barbarism continue.

Lampas is a term used to signify a state of tumefaction existing in the palate, about that part known as the bars, situated in the vicinity of the upper nippers. The tumefaction arises, -

1. From local emphysema, - windy swelling, - rendering the palate elastic and augmented.

2. From induration, - abnormal increase in the consistence of the palate, - owing to an accumulation of dense particles of blood, which resist a free circulation of that fluid through the parts.

3. From congestion, either passive or active.

In passive congestion, there is an excess of blood, in consu. quənce either of weakness in the propelling force, or of an obstacle to the exit of blood from the congested membrane: this state gives rise to swelling of the veins in horses' legs also Active congestion is a determination of blood to the part, in consequence of local irritation, teething, \&c. In aged horses we frequently find the bars of the palate in a state of hypertrophy; but as this is only an exaggeration of a natural state, we take no nuticu of it; in fuct, arising from whatever cause it may, (cxcept tecth. ing, lampas does not cause the animal any inconvenic neo 
This opinion, we are aware, will conflict with that of a greas many horsemen, who make a practice of searching a horses mouth whenever he shows the least signs of illness, to see if the "lumpas are down;" but let it be understood that the bars or ridges of a horse's mouth correspond to the hard palate in man which every one knows is not very sensitive, and therefore cannot be the cause of ill health, nor prevent the animal from mas. ticating his food. Hence the practice of burning the bars is an unnecessary barbarity, which should never be countenanced. The most that we ever do in cases of lampas is to wash the mouth with a weak solution of alum, or infusion of bayberry bark; but it often happens that subjects with lampas are brought to us for examinatizn, and in a great majority of cases we find them laboring under some derangement of the digestive function, the restoration of which allays the owners' apprehensions about lampas. The reader, if he still considers that "something must be done for lampas," may, possibly, change his opinion on perusing the following from the pen of Mr. Percivall :

"Lampas is a name given by writers on farriery to a swelling, or unnatural prominence, of some of the lowest ridges or bars of the palate. I should not have thought it worth while to have taken up time with this supposed malady, but that it has called forth the infliction of great torture on the animal by way of remedy, and that it has been a cloak for the practice of much imposition on those who have been in the habit of consulting farriers on the diseases of their horses. I allude to the cruelty and barbarity of burning the palates of horses so affected: equally consistent would it be, and were it consistent, more requisite, to cauterize the palates of children who are teething; or the truth is, the palate has no more to do with the existing disease. (if disease it can be called) than the tail has. Lampas is neither more nor less than a turgidity of the vessels of the palate, consequent upon that inflammatory condition of the gums which now and then atten ts the teething process; but notwithstanding this plain and simple truth, the horse continues to be perse ruted for it, even by some professional men, as well as farriers. Tiu pructice is a stigma upon our national character, and a disgraco to the professors of veterinary science. 
"Teething in clildren is now and then a season attended witk restlessness and pain, and was one, before surgeons were in the habit of using the gum lancet, of anxiety and danger; but it is not so with horses; they never have any feverish irritation croated in the system, though they may have some tenderness of the gums and palate, and though some few, in consequence of this ter derness, cud their fool, or refuse to eat any but what is soft and unirritating. In such a case, if any thing requires to be done, wu ought to lance the gums, not the palate; but I do not remember ever to have had to do this but once; and this happened in the case of a horse, then in his fifth year, which had fed so sparingly for the last fortnight, and so rapidly declined in condition in consequence of it, that his owner, a veterinary surgeon, was under no slight apprehensions about his life. He had himself repeatedly examined the horse's mouth, without having discovered any defeet or disease; but another veterinary surgeon, to whom he had shown the animal, was of opinion that the averseness or inability manifested in masticating food, and the consequent cudding of most of that taken in, arose from a preternatural bluntness of the faces of the grinders: these teeth, therefore, were filed, but no benefit esulted. It was after this that I saw the horse, and must contuss that I was just as much at a loss, in my first examination, to offer any thing satisfactory on the case as many others who were then present; for his teeth and mouth appeared to us all to be perfect and healthy. As I was ruminating, however, after my inspection, on the apparently extraordinary nature of the case, it struck me that I liad not seen the tusks. I immediately betook myself to a reëxamination, and then discovered two little tumors, red and hard, in the siluations of the posterior tusks, which, when pressed, appeared to give the animal insufferable pain. I instantly took a pocket knife, and made crucial incisions through these prominenccs down to the teeth, from which time the horse recovered his appetite, and was restored."

Tumefaction of the mouth, arising from whatever cause it may, indicates cooling and astringent washes: a weak solution of alum will probably answer every purpose, with which the mouth may be sponged two or three times daily; an infusion of witeh-hazel or bayberry batk will answer the same purpose. 
A hot, tender, or inflamed mouth, unattended with disease may be relieved in the same manner.

\section{APHTHE, OR THRUSH.}

This disease of the mouth is very common among young horses. It consists of small red patches and vesicles on the inside of the cheeks, also on the tongue. 'The mouth is hot and f:verish, and the animal will frequently allow the food to fill out of it, from inability to masticate. The principal means to be employed are, a paste made of equal parts of honey and powdered bayberry bark or borax; the parts to be anointed every night. To promote healthy action and purify the blood, give

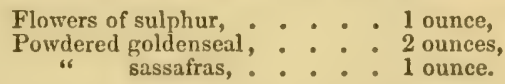

Mix ; divide into four parts, and give one every night in scalded shorts. This treatment applies to all classes of live stock.

\section{DENTITION. - (Teething.)}

There is no doubt that a colt sometimes suffers considerable pain from teething, in consequence of the resistance which the teeth encounter from unyielding gums. The pain does not arise, as some suppose, from the point of the tooth pressing upward against the gum, but from the downward pressure, - the roots of the tooth compressing the dental nerve, - consisting in local irritation, which, if not relieved, deranges a part or the whole of the nervous system. The remedy is a sharp gum lancet. Make an incision right down to the point of the tusk, or tooth, and the animal generally experiences relief. If he labor under sympathetic fever, appears irritable and nervous, give hirn a drachm of assafoetida in thin gruel, keep the bowels soluble, and let the dict be light.

\section{SHARP AND PROJECTING TEETH.}

Owing to the unequal wear of some horses' teeth, their edgor project and become sharp; they are then apt to irritate and 
wound the mucous membrane on the inside of the cheek. In suct casea we notice an increased flow of saliva, imperfect mastica tion, and loss of flesh. The remedy is a mouth rasp.

\section{IISHOPING.}

Bishoping consists in making artificial marks on horses' teeth, to give them the appearance of youth. It is a species of imposition so reprehensible that all honest horse dealers have set their faces against it, and we are not aware that it is to any extent practised here. Mr. Youatt says, "It is called bishoping from the name of the scoundrel who invented it. The horse of eight or nine years old is cast, and, with an engrarer's tool, a hole is dug in the now almost smooth surface of the corner teeth, and in shape and depth resembling the mark in a seven-year old horse. The hole is then burnt with a heated iron, and a permanent black stain is left; the next pair of nippers are sometimes lightly touched, to imitate the brown color of the natural mark." However dexterously the operation may be performed, the fraud is easily discovered by those who are in the habit of examining teeth. If the horse is aged, it may be known by the general appearance; such as gray hairs, sunken eyes, deep hollows above them. The bones are prominent; lips flabby; and the nippers of the lower jaw, instead of appearing angular, approach, as the animal advances in years, to the horizontal.

\section{LAXENESS FROU STRAIN AND OTHER CAUSES.}

\section{OBSERVATIONS ON LAMENESS.}

THE principal difficulty surgeons meet with in the treatment of lameness is, that their services are not called into requisition in the first instance, - so soon as the trouble is discovered, some owners thinking that the lameness is too slight to lay the mimal up, and therefore they work him, hoping it will pass off 


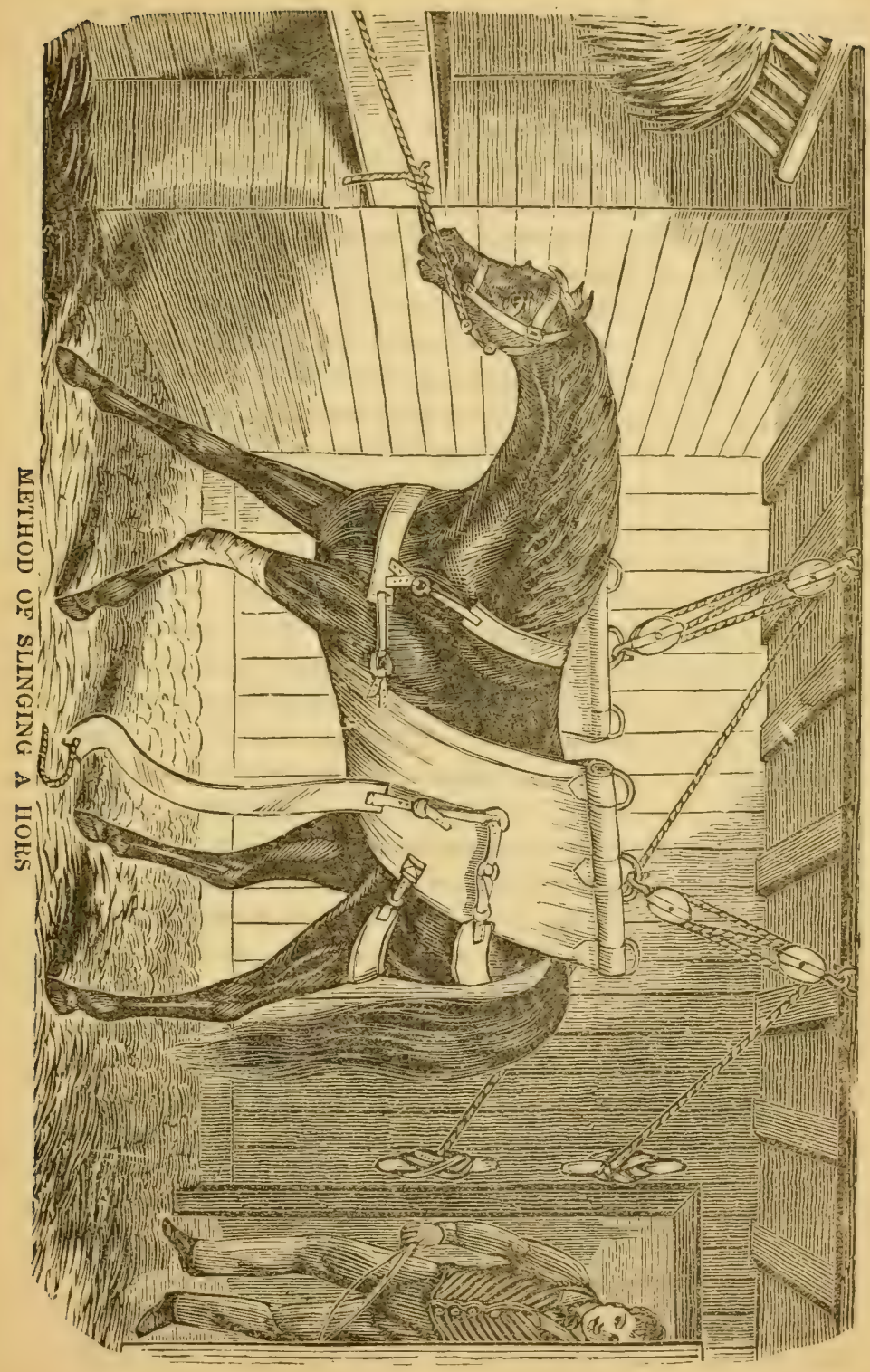


or they aroue, should he grow worse, it is then time enough th :all about doctoring him. This puts us in mind of the story told alout the sailor, who, having just left port, was one day overha'ling his kit, when out tumbled three or four pairs of stockings, having small holes in each heel. His shipmates, knowing him to be a married man, let off a few jokes at his wife's expense, for not mending them. In order to excuse the wife's seeming negligence, he stated that she informed him just before he sailed that "the holes were too small to require daming, and not large enough for a patch; and that next voyage she would see to shem." She did not believe in the doctrine that "a stitch in time saves nine;" nor does the horseman who waits until the horse becomes lamer. And in the event of increased lameness, it is not always that science is consulted, even at this stage; for there are alwars enough men to be found, who consider "that any borly can doctor a horse," more especially a lame one; and who are ever ready to offer an opinion as to the seat of the lameness, (very frequently an erroneous one,) for we often see their prescriptions applied to the whirl bone, as they call it, when the lameness is evidently in the hock. The same mistake occurs when a part of the forward limb is affected. It would be quite amusing to notice some of the remedies, from new rum and wormwood down to a hot slovel, that are in such repute among these amateur savans; but, the cause of science would not be benefited by it. We feel thankful, however, that this practice of doing worse than nothing is fast dying out, and that more sensible horse owners begin to realize that it requires just the same skill to manage the diseases of a horse as it does for those occurring on the owner. The very moment a horse becomes lame, he should be excused from du's, because, if it should be of a trivial nature, rest may perform a rure. Indeed, rest, in the early stage of any sort of lameness, is beneficial, because it lessens whatever inflammation may le about the part, which, if it should exist, work would only aggra-ate. If, on examination, the owner cannot discover the cause mu' seat of lameness, he had better not trust to his neighbor's opinion, but consult some one skilled in the anatomy of the liorse; and although it may cost him a dollar or two, it will be the cheapk est in the end. Prompt aid in the primary stage of any lame 
ness, apparently trivial, might prevent much of the chronic lameness that we now see, and perhaps prevent many a spavis and ringbone, and other deformities known to rriginate in ligamentary lameness. Lameness may arise from a great variety of causes. A horse with flat soles may be shod so that the solt rests on the shoe, and while travelling on soft ground he may go without the least sign of lameness; but the moment he comes on to the pavements, he all at once becomes dead lame from bruise of the sole, or he may get a small pebble between the sole and shoe, and thus produce the same result. A horse may, in trarelling, pick up a nail, or insinuate some foreign body into the sensitive part of the foot; if so, he soon shows it by limping: he may not, however, limp in a slow walk, but shows it more when urged to a trot. Knnowing how apt horses are to pick up foreign bodies in the road, should an animal become lame all at once, the driver ought to dismount and see if he can discover the lame limb. If there is sufficient pain present to arrest the animal's attention, he will generally endeavor to show it by some peculiar motion, such as pointing the lame foot before its fellow catching it up, or flexing it. Having discovered in which limb the lameness exists, the foot must be carefully examined. By scraping out the parts, any foreign body between the shoe and sole can be easily got rid of, and thus the cause is removed; but if a nail should be discovered, it is not so easy to remove it, for it often requires some tact, and strong pincers. We remember being called once to draw a nail which had previously resisted the efforts of a strong man. The horse had to be cast, and it was found necessary to cut round the nail, so as to enlarge the exter. nal orifice. On withdrawing it, the point was found to have been bent, probably by coming in contact with the coffin bone; it harl thus formed a sort of hook, which explained the reason why it could not be got out until the external wound was dilated. 'The horse was a long while ere he recovered, for a fungous growth was continually sprouting through the orifice of the sole, which made the cure very tedious. The nail being removed, we generally dress with fir balsam, or mixed soap and sugar, - whichever happens to be at hand, - and bind some oakum on the part. to kepp out the' dirt. 'The subsequent tratment will depend upon 
circumstances. For every other kind of lameness on the road, except that arising from the introduction of a foreign body, and provided the animal is not actually incapacitated for travel, the dricer has no remedy but to get the horse to his quarters, letting him go at his own gait.

We now come to the consideration of the various kinds of lamencss, which are to be discovered either by the motions of the animal, or through manipulation; and we set out with the understanding that it is no easy matter, at all times, to discover the real seat of lameness; even those who are best qualified often disagree both as to its seat and nature. We shall endeavor, however, in a very brief manner, to give some diagnostic symptoms by which an intelligent man, having some knowledge of normal action, may detect abnormal. We commence with

\section{HIP JOINT LAMENESS.}

This is a very rare lameness, although we constantry hear complaints that such a horse is "lame in the whirl bone." Overexertion and immoderate work, which are considered the chief causes of lameness, are more apt to produce it in the lumbar region, and from the stitle downwards, than at the hip joint. This form of lameness is quite common in man, and frequently results in anchylosis; but we must recollect that the limbs of a horse, in consequence of the complexity of their bony and cartilaginous structures, are better calculated to sustain concussion than the former. There is no joint in the horse that is so well protected from blows and every external injury as the thighjoint: the enormous muscles that surround it act as cushions, and successfully guard it from injury of this kind. If a borso falls on his side, and brings the hind quarters to the ground tirst, Je is more likely to injure that part of the hip known as its anterior superior spinous process; in short, he knocks the hip down, as it is termed, or fractures the pelvis, instead of injuring the hip-joint, as some would suppose; and even should he slip down on the haunches, and force a limb outwards, the abductor muscles, which limit the action of it in that direction, are more apt to be torn from their attachments, than that the joint should 
De injured Mr Percivall has remarked that "the adrances made io veturnary science have satisfactorily shown that the farriers opinoo was tor the most part founded in error; the halting action. which they considered as denoting hip lameness, more critical observation, combined with post mortem results, has demonstrated $u$ have its ongu in disease of the hock, for the most purt: indeed w spavin the diseuse is a fruitful source of Inneness behmid, trequently insidious in its rise and progress, Ecrietimes difficult of detertion, ocedsionally in rapable of demonstration; no wonder, therefore, thar it stuuld of often lead the unwary and inexperienced into error' sympathetic lameness of the femoral region, however. Is nor uncummon; for we find that long-continued pain in the fow will produce, through the sympathetic relations existing between remote parts, tenderuess, heat, and sometimes corded glards in the groin. We shall not contend that lameness never occurs in this joint, but that it is rare; for we know that, like other joints, it is sometimes the seat of synovial inflammation, ulceration, and suppuration.

The diagnostic symptom of hip joint lameness is a halting, or kind of hopping gait, and difficulty in turning.

Treatment. - Rest, refrigerating lotions, and light diet are indicated in the inflammatory stage; and stimulating liniments in the chronic form. See Liniments.

\section{LAMENESS OF THE STIFLE JOINT.}

The bones composing the stifle-joint consist of the patella, lower part of the femur, and upper part of the tibia; they are retained in position by capsular and connecting ligaments, and are liable to sprain and injury. The diagnostic symptoms of sprain are heat and tenderness, and the limb is advaneed with difficrlty : rest, fomentations with infusion of poppy heads, cold water, and sometimes physic will be the most proper means of cure. For chronic stifle lameness, originating in adhesions, or infiltrations of the surrounding tissues, a few applications of the acetate of cantharides will probably effect a cure.

Horses frequently injure the parts around the stifle joint by eaping fences and stone walls : the treatment is the same as fo: 
bruise of any other part, when it is not convenient to fument $\rightarrow$ a diluted tincture of arnica (one ounce of arnica to a pint of water) may be used; or perhaps a weak solution of acetic acid may answer the purpose. Should the part be wounded, as it often is, it may be necessary to employ sutures; but if the accident is not discovered early, sutures are of no use. The com. pound tincture of aloes and myrrh will expedite the healing process; and when suppuration commences, use pyroligneox ncid. We saw a horse a short time ago, which, in jumping a wall: or scrambling over it, inflicted a wound about two inches below the patella; considerable tumefaction followed, with a profuse discharge: the former yielded to fomentation and physic; in order to stop the latter and heal the wound, it was thought advisable to introduce a seton below it, and there set up an artificial discharge, by which means a cure was effected. A horse may be punctured in this region. A case occurred in a ship yard at Medford, which may be proper to notice: A sliver had entered on the inside of the patella, and passed several inches backward; it was extracted and dressed; next day the limb from the hock upward became dropsical, hot, and tender: refrigerating lotions, cathartics, and diuretics were used the swelling gradually subsided, and the wound healed; but a large abscese formed just above the hock, which was opened, and the horse finally got well. Another horse, standing in a stable in this city, was punctured with a hay fork, on the outside, yet close to the patella; synovial inflammation and discharge of synovia took place; the case was protracted, but finally yielded to astringent injections; the horse was lame for some time after, owing to adhesions that had taken piace. Punctures of this character must be treated the same as open joint. See Dislocation of the Patella.

\section{LAMENESS OF THE HOCK.}

Lameness of the hock is generally ligamentary, except when originating in spavin; and some contend that even spavin first commences in ligamentary tissue; however, we have nothing to say about spavin just now, except to refer the reader to thut article. Lameness in the hock, from strain, ore -work, or blow, is evident from the heat, pain, and tumefaction about the parts, 
the animal will flinch when the parts are handled, and sometimes catch the leg up; if you back him out of the stall, and make him step forward, it will be observed that there is fr se motion in the fetlock joint - the foot is pls.nted on the ground with that freedom denoting there is nothing the matter with it; he can raise the leg, showing that the stifl; joint is all right; and there is perfect freadom about the hip joint, so that the seat of lame. ness is evident. This is the state of affairs in the early stage: let the animal be the subject of lameness for two or three days, and we observe sympathetic affection; that is to say, stiffnesp and pain, which is the cause of lameness in a remote part of the limb. And this peculiar feature is not one of singularity, for we find the same thing takes place in man: persons laboring under hip joint disease are often heard to complain of pain in the knee, the opposite extremity of the diseased bone. There is nothing better for recent lameness of the hock than arnica, either in the form of diluted tincture or infusion. The parts are to be kept wet, by means of a sponge, so that a cooling process shall go on during the inflammatory stage; and even should the case prove to be one of incipient spavin, such treatment is well calculated to meet it. Rest, also, is one of the principal means of cure: those who work a horse lame in the hock must not be surprised if he should ultimately prove spavined. If the horse shows symptoms of an inflammatory diathesis, or morbid habit, a dose of medicine and a few messes of scalded shorts will do much good.

\section{LAMIENESS OF THE SHOULDER.}

IJameness is more apt to arise in the shoulder than in the cor respuuling part of the hind extremities; the latter having a bony union to the body, which prevents, or rather limits, undue cxtension of the muscles. The lameness may exist in the muscular tissues, or at the point of articulation between the shoulder blado and the os humeri.

Symptoms. - The principal diagnostic symptom is, that the hurse, instead of advancing the leg straight forward, moves it in a ircular manner; and the action of the shoulder is quite differes. from that of the other side; it will be observed also, that the 
animal throws the weight of the body as much on the sound side ns possible.

Treatment. - The treatment of shoulder lameness will depend altogether on the nature of the case; if it be one of muscular origin, caused by heary drawing, violent tugging, or galloping on hard roads, rest, fomentations, and a light dose of medicine are irdicated. Should the animal still be lame after the inflammatory eymptoms have subsided, use the following liniment:-

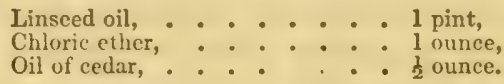

Mis; and apply to the shoulder night and morning. If the disease is confined to the joint, counter irritants are indicated: some recommend blisters. What we have used of late is the acetate of cantharides, to be applied occasionally over the parts affected. A stimulating liniment may, however, answer the purpose, composed of

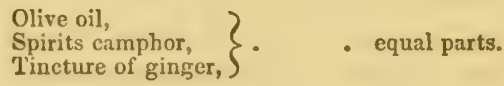

\section{ELBOW JOINT IAAMENESS.}

This joint is more liable to disease than any other in the body: we mean, however, not to restrict such disease to the joint proper, but to the immediate surrounding parts, which go, as a whole, to make up the joint for the uses to which it is put in propelling the body forward. The immense muscles which are attached to the point of the ellow render it necessary that the union between the ulna and radius should be very strong. The principal power, so far as the fore limbs are concerned, required for the propulsion of the body, are to be found in this ricinity; and therefore acci. 3ents, for several reasons, are more apt to occur.

Lameness arises very frequently in consequence of symovial inflammation, and from ulceration of the cartilages of the bones. Synovial inflammation arises from violence, directly or indirectly applied; it is indicated by tenderness, pain, swelling, heat, and tumefaction around the joint, with inability of free motion, \&c. 'I'he treatment must be on the antiphlugistic plan. A dose of 
cathartic medicine should be given to lessen the hort's action anodyne fomentation of hops may prove useful; if high heat pre. rails in the surface of the lame region, refrigerating lotions - vin egar and water - are indicated; we have frequently used arnica with good effect. Very little benefit can be derived from any treatment unless the animal be kept at rest, and on a light diet. Some will say that this is very simple treatment; but it is suitable, and the author has frequently essentially mitigated deep-seuted inflammations by time and just the same sort of treatment.

Ulcorations of the articulating surfaces of the bones comprising the elbow joint are more difficult of cure, and to the non-professional man still more difficult to detect. It may be present without any of the physical signs by which deep-seated diseases in more sensitive tissues are discoverable. If a horse, however, is lame in this joint for a great length of time, and the lameness gradually grows worse, and is always greater during exercise or work, though a few days' rest improves the action of the limb, yet seldom cures it, we may suspect ulceration.

Ulceration may arise from sub-acute or synovial inflammation from external injuries, such as a kick or blow. We hare specimen of fracture of the ulna, (point of the elbow,) and extensive ulcerations and osseous deposits on the bones entering into this joint, following the injury; the fracture had united, but the horse was subsequently destroyed, in consequence of the incurability of the ulcerations. Ulceration also follows a breach of the synovial membrane.

Treatment. - The bowels are to be kept in a soluble state by means of saline aperients and messes of scalded shorts; these counteract a tendency to constipation, which is sure to follow the , est absolutely necessary for the cure. The treatment should not be rery active at first, for the ulceration may be only a sequenco of injury to the synovial membrane. It is sufficient to attend to coxstitutional treatment, subdue any morbid diathesis that may cxist, and sweat the parts by applying the following two or threo limes a day:-

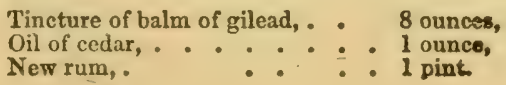


In the later stages the application of acetate of cauthamdes may be persisted in. If the ulcerations are very superficial, not involving the joint, but merely confined to the heads of the bones, they can be detected by manipulation, and we may entertain some linpe of restoring the animal to some degrec of usefulness; whercas, in the former disease, our best efforts and hopes are ofien met by failure and disappointment.

L.umeness from Tumor on the Elbow. - An encysted tumor may Luk 3 its appearance just below the elbow, small at first, but gradually enlarging to about the size of a man's double fist: some perscns are in the habit of excising them. We saw a case, a fery suonths ago, in which the tumor, including the integument, had been sliced off, leaving a most awful gaping wound, which was left to heal by the slow process of granulation. Such an operation argues but very little on the score of skill or humanity, and is more indicative of the age of barbarity than that of reason. There are chronic cases occasionally brought under the surgeon's notice, in which an operation becomes unavoidable; and that is when the tumor has degenerated into a dense fibrous mass, and interferes with the action of the limb: ordinary lameness, how. ever, is not an accompanying symptom, for many horses can be found in this city with medium-sized tumors that are never known to take a lame step. These tumors ultimately become indolent, neither inflamed nor painful, and finally degenerate into a fibrous mass, which may be nothing more than an eyesore.

Cause of Tumors.-They may arise, like tumors in any other part of the body, from bruise or accident, and they sometimes occur without any visible cause; we strongly suspect that the effused fluid comes from the parts above, - articulatory surfaces of the shoulder, - at this point the common integument being l/osc, forms a sort of sac, - a receptacle for the accumulation of ach fluid, - and it ultimately becomes enveloped with a sac of fb-in formed out of its own deposits. Some persons have supposed that these tumors are enlarged bursa: if that were the case, they would take on extensive inflammatory action when opined, as bursal sacs invariably do: on the contrary, they are punctured, setoned, and even excised, and seldom, if ever, any high grate of inflammatory action results, so that they cannot be tho 
urdinary bursal sacs, and must therefore originate in cffusion of lymphy fluid.

1reatment. - We hare now and then seen cases of elbow tumor brought on by bruising the parts with the calking of the shoe while the horse is lying down in the stable. Here the cause is evident; we have a common bruise, and if it were treated promptly with cooling applications, effusion might be prevented ; but it happens in many cases that the injury is not perceived; and if it is, very little, if any, notice is taken of it, until, by a repe. tition of the act, a callous or morbid local diathesis is confirmed, and we observe a chronic tumor.

The treatment then, in the early stage of bruise or injury to the part, is the same as for bruise or injury in any other location mild, soothing, and refrigerating. In the case of a chronic tumor, we first ascertain if it have a fluctuating feel: if that should be the case, we puncture it with a common trocar, and canula, or an incision may be made into it. If, on the other hand, we can cleariy ascertain that there is a dense tumor to deal with, the best course is to cast the horse, make an incision, and dissect out the tumor : the cavity should be sponged with tineture of myrrh, (to set up adhesive inflammation,) and the wound may be brought together by sutures, leaving a small opening at the most dependent part of the sac for the escape of pus. In view of promoting healthy action, the part may be dressed daily, after being washed, with compound tincture of myrrh.

In a tumor that has no perceptible origin, but may be supposed to arise in the manner just alluded to, viz., by effusion from the scapular surfaces, the moment fluid can be detected at the point of the elbow, pass a seton through it. We have tried all tho usual remedies, from a common irritant to a blister, in view of sbsorbing the fluid, and have found nothing equal to a seton; but it should be resorted to early, before a layer of fibrin has been formed.

\section{CURB.}

A curb is an enlargement which makes its appearance on the hind legs, about two inches below the hock. It is sometinee accasioned by a blow but the most frecrent cause is strain of 
the sheath through which the flexor tendons pass If seen in its early stage, it would, in all probability, yield to rest and cold water bandages. But if neglected until effusion takes place, or the surrounding tissues become injected and hickened, and the hurse becomes lame, then a different course of theatment must be alopted. Our usual remedy is

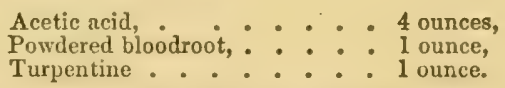

T'o be applied to the part night and morning for at least a week atierwards to be bathed daily with common vinegar.

There are cases, however, in which coagulable lymph will form, and may thus leave the parts in a state of callosity for bome time, which only patience, constant friction, or the application of some stimulant, can overcome. Among the various applications in use, we prefer the following:-

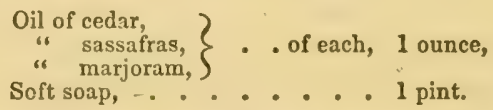

To be used daily, always rubbing in a downward directior:

As regards excrcise, the inflammatory stage requires rest, and in the chronic form, exercise will be indicated, provided, however, the horse be not lame.

\section{NAVICULARTHRITIS. - (Disease of the Navicular Joint.)}

Mr. Percivall, who is the best authority on navicular disease, defines navicularthritis to be "a disease of the navicular joint, giving rise to lameness."

The Nature of the Disease. - It consists in deep-seated sprain, injury, or morbid action, within the hoof, first manifesting itself by inflammatory action, heat, and tenderness, terminating in ad. hesion, ulcertion, and caries; at times, however, in ossification of contiguous parts.

Symptoms. - The most important diagnostic symptom is, that he horse generally points the foot, viz., adrances it, while stand. ing in the street or stable, a few inches - sometimes more - be yond its fellow, the fore feet being the ones generally affected 
the heels are sometimes hot and feverish, and, on making pressure with the finger (into the space formed by the quarters and pastern bones) in a downward direction, the horse shows signs of pain. There are times, however, when symptoms of pain canuot be elicited by pressure; and that is when the disease commerces in the navicular bone, and before the sensitive tissues are involved. But even should the disease commence in the former, the horse will at times point the foot forward, and occasionally be caught limping, not lame enough though to attract the attention of any but a close observer. As the disease progresses, the heels contract, and curve towards each other; the hoof appears dry and brittle; the sensitive and nutritive tissues are now involved; the supply of synovial fluid is partly or wholly suspended ; friction corumences; adhesion forms, gluing parts together, preventing the free articulation of the joint; the horse goes perceptibly, yet gradually, lamer, up to the period of ulceration. The final result is often fracture of the navicular bones. The diagnostic symptom - pointing of the foot - is a persistent feature of navicular disease; for not only does the animal show it at rest, but also, while travelling, the toe touches the ground before the heel. On examining a horse's foot, therefore, supposed tm be the subject of this disease, we shall find the under surface of the shoe worn more at the toe than at the heels. These symptoms, coupled with observation that hard work aggravates the lameness, and that there is no abnormal action or enlargement elsewhere, will go to make out a case of navicular disease.

When both fore feet become affected, the horse is said to be groggy. Surgeon White defines grogginess to be " a tenderness and stiffness about the feet, from hard trotting upon the road, which causes him to go in ar uneasy, hobbling manner, particu. 'ariy when made to trot down a hill without any support from the bridle." So much for the symptoms; and, in order to give the reader more light on the nature of grogginess, we refer to Percivall, who informs us that "the epithet groggy was suggested by the unsteady, rolling, unsafe action of the lame horse heing com. pared to that of a drunken man." The pathological researches of later times have demonstrated that groggy lament.ss has its origin in navicularthritis. 
If we except the few veterinary surgeons that are scatter over the United States, scarcely any one else knows any thing about the history or pathology of this disease. Dr. Wood has lately called attention to it in an article published in the Boston Cultivator; aside from this we do not remember ever reading any thing on the subject. In England, the attention of the faculty was directed to the subject by Mr. Turner, V. S. See Lippopathology, p. 131.

Ireatment. - If the lameness is seen in the early stage of na. ricularthritis, our general custom is, to remove the shoe, and apply cold poultices, composed of oatmeal, vinegar, and water, to which add for each poultice a handful of fine salt; the poultice is to be fairly spread over the surface of the hoof and heels, then to be confined by means of thin cotton cloth, secured just above the coronet. A mixture of equal parts of vinegar and water should be kept ready to moisten the mass whenever it becomes dry, so as to keep up a retrigerating action of the foot. Three or four poultices will generally suffice, employing one every twenty-four hours, on removing which the foot must be washed with soar and water. At the end of four days, substitute for the poultice

Tincture of arnica, . . . . 4 ounces,
Water,

Mix; and sponge the foot three times a day. Give the patient $\Omega$ dose of medicine; keep him on scalded shorts, seasoned with salt, allowing a small quantity of hay, and let him have rest. If it should turn out, on discontinuing the poultices, that the heels are tender, the animal being unwilling to bring the frog to the floor. some soft clay must be placed under him, and so disposed of that he can stand on it. We consider this treatment best adapted to the early sub-acute stage of the malady. Some persons recommend hot poultices and fomentations; but we prefer cold to the inflanmatory, and hot applications to chronic stages of dcepseated, and even superficial disease. Should the case be one of a chronic type, we follow up the above treatment with counter irritants. A prenaration known as the acetate of cantharides (which can be procured of the apothecaries) has been, in our practice, instrumental in removing lameness of tlis description. This, bowerer or any other remedy, would have but little effeet 
in restoring a part to soundness that was in a state of caries As a palliative, we can with confidence recommend it, Lqvins witnessed good effects follow its use.

It the animal be not restored to usefulness under this treatment, let him run to grass, if the season permits, having tips nailed on the feet to guard against fracture of the hoof; and after the lapse of a few weeks, if he still be found lame, as a last resort, neurotomy may be tried. See Neurotomy.

\section{OPERATION FOR NEUROTOMYY - (Nerving.)}

Neurotomy consists in a division or excision of a portion of rervous fibre. The operation has, to some extent, received the cold shoulder from very many horsemen in this country, whose horses, after being operated on, have actually walked off, leaving their hoofs behind them. We feel safe to say, however, that this unfortunate occurrence may have been the fault of those who a few years ago went about from one place to another, operatinc without the requisite skill necessary for the ultimate success of the object, and destitute of that knowledge necessary in the selection of suitable subjects for the operation. This is evidently the case ; for some of the animals thus operated on were the subjects of ucute laminitis - a form of disease that no regular veterinarian would ever think of relieving by neurotomy; so that many who now decry neurotomy have had but a partial opportunity of judging of its merits. If a man lacking the requisite skill undertakes to amputate a person's limb, and at a certain stage of the operation fails to secure the main artery, and in consequence the patient bleeds to death, where does the blame rest? Not with the science, - that has its regular law of rule and contingency, but on him who thus ignorantly misperformed the operation. Sc of neurotomy, if (and we are confident) it has here been performed in direct opposition to the established rules of science and the principles of practice, the results should be no criterion of its general application or usefulness. Neurotomy was never in. tended, nor is it calculated, to relieve every form of aisease uccurring within a horse's foot, no more than trepanning is caicu. laind to cure all diseases of the brain and its appendages; but in 
n case of depression, or when a small portion of bone has penc. trated the cerebral mass, and the patient is comatose, relief by trephine is almost with absolute certainty calculated on. Hence we advise the readers not to be over-hasty in judging of the value of this surgical operation, until they have satisfied themselves that the operators were qualified to select suitable subjeots for it. For it is only calculated, like many others, to give relief in certain morbid conditions, and at a certain progressive stage of the infirmity. The author's experience, as regards the utility of the operation, is rather limited, he having only performed it in a few isolated cases, and then at the particular request of the subjects' owners. Many horses have been brought to him as subjects for neurotomy, laboring under chronic diseases of the foot, for the cure of which he has preferred other means, with probably better success than might have attended the operation. We have always maintained that in the event of a lame horse being restored to usefulness after being neurotomized, it is no proof that he might not have been restored by less objectionable means. We shall now furnish the reader with some of the views of Professor Percivall, whose works, occupying, as they do, so elevated a position in veterinary literature, are consulted authoritatively. Our quotations must be incomplete,-merely a eynopsis, - in consequence of our prescribed limits.

Mr. Percivall awards the credit of introducing neurotomy into veterinary practice to Surgeon Moorcroft; and to Professor Sewell, he argues, "belongs the credit of practically demonstrating its utility for the removal of foot lameness of a navicularthritic description; also as a remedy for the removal of lameness in cases where medicine is confessedly powerless, together with the serviceability of neurotomized horses, not for diving ın!y, but for riding, and even for hunting." Mr. Moorcroit's views regarding the operation are learned from a passage which occurs in a letter, communicated by him, eighteen years after his first operation, to the editor of the Calcutta Journal.

. * * * I recollect not the number of horses operated on by me successfully, though it was somewhat considerable. Some of these were worked by myself; and the general impressions or my mind at this interval are, that horses so operated on, wher: 
they did not again become lame, were more apt to stumble with the limb operated than with the other, and that this mode of treatment was likely to be more usefully applicable to coach horses than to horses intended for single harness or for the saddle.

"The remote Effects from Neurotomy looked for. - Whether the nutritive and secretory functions of the foot, deprived of nervous power, would proceed as before; and, further, what difference neurotomy might make in the animal's action or tread upon the ground. Moorcroft had observed that, under the loss of nervous energy, "the repairing powers of the foot were not injured so far as they depended upon the action of blood vessels ;' and subsequent experience has confirmed this observation. In. flammation appears to be the same process on a senseless as it is on a sensitive foot, and the secretion of horn goes on as well in one as in the other: the grand and important difference between the two is, that, supposing the neurotomized foot to receire a prick or bruise, and inflammation and suppuration to follow, matter may collect and burrow underneath the sole or frog, or other part, and the horse, incapable of feeling any hurt in his foot, can of course give no intimation of mischief, by showing pain or lameness to his groom or master; and consequently, un. less the latter should detect the evil himself, suppuration may proceed to that extent to cause the hoof to separate and be cast off the foot - a catastrophe which has happened more than once, and one that has been brought forward as a fearful argument against the practice of neurotomy. A neurotomized horse may receive a stab, in being shod, from a nail taking a wrong direction, or be may pick up a nail on the road, and no intimation what. evar of the injury be given, unless his farrier or groom happen to discove- it. Such accidents, howerer, are not of every day's occurrence, neither are they, in the hands of expert farriers and careful grooms, likely to happen without their knowledge, and therefore have no right to be regarded in the light of arguments against neurotomy, further than such hazard, remote though it may be, tends to the diminution of such horse's value in the market."

Mr. Percivall decides that " neurotomy not only destroys the afeguards of the foot, but the horse does not maintain the same 
step and tread he used before." As an offset to this, he intro duces several very interesting cases to show the benefits derived from neurotomy, with the accompanying remark, that "he feels cunvinced that when the subjects for the operation shall have been properly selected, and the fitting time chosen for its performance, similar results may be sanguinely and pretty surely snticipated."

'The cases here referred to clearly show that the operation on them was eminently successful. The rule laid down by Mr. P is, "to operate on no other but the incurably lame horse; and whenever this has been attended to, not only has success been more brilliant, but indemnification from blame or reproach has been assured."

"To command success in neurotomy, three considerations require attention:-

"1. The subject must be fit and proper; in particular, the disease for which neurotomy is performed should be suitable in kind, seat, stæge, \&c.

" 2 . The operation must be skilfully and effectually performed.

"3. The use that is made of the patient afterwards should not exceed what his altered condition appears to have fitted him for."

A number of cases are next alluded to, going to show that "for lameness in the foot, coronet, or pastern, incurable or unrelieved by therapeutic means; for navicularthritis and its consequences; for the effects of chronic coronitis and laminitis, barring sunk soles; for ossified cartilages, for ringbone, for contraction, the operation of neurotomy is especially applicable - nor will practitioners who regard their own credit, or that of the operation, fecl desirous of extending, for lameness at least, its splere of ajpliancy."

Mr. Percivall warns veterinary surgeons against performırg the. operation when there is any detectable inflammatory action about the foot; but recommends them, first to subdue by the usual antiphlogistic means, any acute symptoms that may he present; he urges as a reason, that surgeons never perform (if it can possibly be avoided) an operation on the human subject in an inflamed locality. Another reason might be added for subduing iuflammatory action prior to operating; for aftel having dont 
Bo (there might be such a case) the lameness may subside, su that the owner would be spared the expense, and his horse the pain, of an operation.

Neurotomy, observes Mr. P., "has other objects besides th: removal of lameness. Both the œstral and generative functions have been restored through neurotomy. Brood mares that har6 p.oved barren in consequence of painful lameness annihilating in bcin all sexual desire, and that have ceased to have at the usual season any return of the cstrum, have, from losing such pain, had their natural generative functions restored, and become again good breeders."

"In 1822," writes $\mathrm{Mr}$. Rockwood, " a chestnut mare at Oakley, the property of the Marquis of Tavistock, went very lame in the near foot behind, in consequence of complete ossification of the lateral cartilages and extensive ossific disease around the coronet. She scarcely ever placed the foot upon the ground, but generally moved upon three legs. Her sufferings prevented the periodical œstrum. She had not bred for years. About two months after the operation, she went to work, and moved round; she has bred several healthy foals, and works as usual." In this view the author looks upon neurotomy as a curse rather than a blessing, tor the United States can already outdo any nation on earth in the number of her horses laboring under some form of ossific distase; and for them to call in the aid of neurotomizers only to add to the countless host of deformed animals would increase their number to a deplorable extent. A mare having "complete ossification of the lateral cartilages and extensive ossific disease around the coronet," ought never to be put to a stud; the suppression of her periodical cestrum, and the annililation of her sexual derise, would be a public benefit, to say the least, while it should teach us that nature strives by all the means in her power to perpetuate nothing but what is calculated to retain the stamp, perfection, and beauty of its original type. The suppression of the generative function is in this case, as also in many others, the operation of that law which limits all animated creation to certain hounds, beyond which they cannot go without forfeiting their right and title to the protection of those harmonious laws which the God of nature has thrown around them. 
Let people neurotomize horses for incurable lamenes, for the relief of pain which no other means can accomplish, and wo eall them philanthropists - the handmaids of nature. But when neurotomy is resorted to for the purpose of forcing nature to tesm with deformities, it should be set aside as a curse to the four footed race; and its advocates should be rebuked. W€ consider an unsound animal, as the mare evidently was, just about as valıable for breeding purposes, in view of perfect symmetry of form, endurance, and long life, as a diseased potato would be for the production of a succession of perfect germs and a supply of healthy food for man. The deformities of the parent, and the imperftctions of the vegetable germ, may not at once appear; but the day of reckoning must come ere many generations have passed away, or many harvests have been gathered; and if nature condemns the one to barrenness and the other to premature decay, it is done to assert lier empire. In justice to the talented author just quoted, we remark, that the practice of neurotomy for the purpose to which we allude does not receive his advocacy: he merely observes, that neurotomy has other objects besides the removal of lameness; and introduces a case from the pen of another individual by way of illustration.

As regards the success of the operation in the United States, when performed by qualified persons, so far as the author has been able to ascertain, it has been quite as successful as in the old world; and there is no reason why it should not be, when practised by qualified veterinary surgeons.

We now come to describe the operation of neurotomy; and we recommend that, in all operations of this kind, the subject be etherized, not only in view of preventing pain, but that we may, in the absen se of all struggling on the part of our patient, perforno the operation satisfactorily, and in much less time after etherizalioz has taken place than otherwise. So soon as the patient is under the influence of that valuable agent, we have nothing to feir from his struggles, provided we have the assistance of one experienced to administer it. We generally use a mixture of shloroform and chloric ether in our operations, and consider it far preferable, so far as the life of the patient is concerned, to purv shlox of orm. 
Whichever article is used, care should be taken not to introIuce it into the respiratory organs too suddenly. A sufficient quantity of atmospheric air must be amalgamated with it; and this is insured by moving the sponge to and fro before the nostrils for a short time, when the sponge may be placed in a common breathirg apparatus; * in many cases, however, when operatumg in a barn, or any where under cover, we use nothing but a large circular sponge having a deep concavity, which admits of the horse's nose. The horse having been cast and etherized, we release one of the fore legs from the hobbles, and if the limb be found in a perfect state of relaxation, the subject having no control over it, then is the proper time to commence the operation

The limb is now to be brought into its natural position, and thus held by an assistant. Supposing the horse to lie on the off side, we now make an incision over the region of the plantar nerve, on the outside of the near limb. The incision commences just Delow the head of the pastern, to the extent of one inch, or a trifle more: having exposed the nerve, we pass a director beneath it; a simple incision into the groove of the director separates the nerve. If it is desirable to excise a portion of the nerve, we seize the lower end with a small pair of forceps, and cut off a small piece with a pair of scissors. If both fore legs are to be operated on, we first operate on the inside of the off leg; then, by rolling the animal over, we have an opportunity to repsat the same thing on the opposite side. Most surgeons bring the edges of the wounds together by sutures; and if we could be sure of uniting them by what is called first intention, it would be proper to do so: it is certainly in accordance with the principles of rational surgery, and looks more workmanlike thus to close the incisions; but $\mathbf{n}$ friend of ours residing in Maine, who has operated on quite a number of horses, informs us that he never uses suture, but dresses with a balsamic liquid, and over all a cold watex bandage, and the arimals show but a slight blemish. In the few cases we have operated on, sutures were used, and bandages, which some recommend, were dispensed with, for they only tend to irritate the wounds and keep up an unnatural heat about the part : our ex-

- In all sases of etherization at the Massachusetts Hospital, a simple sponge a used. The complicated and expensive breathing machines ara als bensod with 
perience is, that bandages do not agree so well with horse as with human flesh. Various instruments are in use for the perform. ance of this operation, which we do not deem necessary to describe here. The success of the operation depends more on the skill of the operator than on his tools; for a good auatomist can at any time divide the nerve with a common penknife: in fact the thing is often done.

The reader will perceive that we have merely described the operation, without entering into its details, or the anatomical points involved: to place on paper all the minutia necessary to constitute every man a neurotomist would be a work of impossi. bility; hence we advise those who desire to have their horses operated on to employ a professional man.

\section{PLEURODYNIA. - (Inflammation of the Muscles of the Chest and fore Extremities.)}

This is a disease to which the attention of veterinarians has lately been called by Mr. Haycock, in his work on Veterinary Homcopathy, who observes, "I am perfectly satisfied as te the existence of this disease, and also of its having been overlookec." We have frequently treated animals presenting some of the peculiar symptoms here enumerated, and, for the simple reason that we had no other name for it, called it rheumatism, or founder.

The symptoms are as follows: "One great difference between pleurodynia and pleurisy is, that in the former affection the disease exhibits little or no variation, while in pleurisy, the variations are remarkable, and constitute one of the principal features by which it is to be distinguished or recognized.

"In pleurodynia, the animal moves in a very rigid manres; he steps short and very slow; he is greatly dejected and cast down; the back is arched; the skin over the surface of the body exhibits great tenderness, whether he be handled roughly or delicately; he also grunts a good deal, and great tenderness is sometimes present upon one or both sides of the chest, and the skin presents that state of corrugation easily recognized. The respirations are short and limited, and the pulse will gene-ally rango 
from fifty to sixty-four per minute, but on some occalsions it is not at all disturbed. If the ear be applied to the chest, the nurmur can generally be detected very clearly throughout, particularly in the superior regions of the cavity, while, if the ear be held close to the lowest part of the inferior region, a sort of rumbling sound is heard; but this can only be detected when the skin over the part is more tender than elsewhere, and when if is contracted into folds, and mores, and when such contractible motion is continuous. This sound I entirely attribute to the tremulous motion which is going on within the subtextures; for if the ear be kept firmly to the chest, the motion soon ceases, together with the rumbling sound; and, provided we remain quiet, and the animal be pacified, we can then distinctly hear the clear, natural respiratory murmur, though somewhat suppressed from the constrained manner in which the chest itself is expanded. The hair over the entire body is dry, and very unthrifty in ap pearance. If the animal be made to walk up hill, it is performed cleverly, but great difficulty is experienced in coming down again; the patient travels as though his feet were actually inflamed; the appetite is bad in some cases, and moderately good in others; the urine is scanty, and the dung is dry looking; the patient does not lie down well; it is seldom or never that be coughs. In this state the animal may remain for weeks, without the least variation, save that the pulse becomes lower, falling to about thirty-eight or forty-two per minute; but the majority of such cases, if properly treated, are generally cured in from three to six days."

The causes are, over-exertion and exposure. "If the disease be from an inflammation excited within the muscles of the chest and fore extremities, and also of the cellular tissue investing or surrounding such muscles, the fact, I think, will in a great meas ure be simslactorily demonstrated. Should the animal have been subjuct to long-continued and very severe exertion, this, togetler wilh the tenderness of the muscles, and the assistance which aus. vultation will afford us, will be sufficient to enable us to decide. In conclusion, I may add that pleurisy, pleurodynia, and inflamma. tion of the muscles may either exist as separate affections, or two or more of them may exist in association, or any one of them, or 
all of them may also exist in association with disease of the hr: 2 rt." Treatment, homucopathic. The best remedies we know of for an affection of this character are, rest, laxative medicine, light diet, and cold water packing - supposing, howerer, that it is brought on by severe work. Should it be occasioned by exposure, treat it the same as a common attack of rheumatism.

\section{ACUTE RHEUMATISM, OR FOUNDER.}

This is a very common disease among horses, and probably occurs more frequently than people would suppose. We havo treated quite a large number of cases during the past few years. Some of them yielded very readily, and disappeared just as suddenly as they came; others were protracted, became chronic, and left the subject with stiffened muscular fibres, contractions of muscles and hoofs, effusions into bursal sacs around the fetlocks, \&c. and two cases terminated fatally, in one of which the autopsy showed high inflammation of the interior of the heart - endocar. ditis: the internal membrane of that organ had the appearance of purple velvet, with effusions of lymph on its surface; the tendinous curds of the lateral ventricles were strang with fibrous de. posits to such an extent that they must have had interference with the heart's action. The second case was complicated; the external covering of the heart - pericardium - had several adhesions, and its surface next the heart was studded in several places with lymph granules; slight effusion had also taken place. The internal appearance of the heart was the same as in the preceding case, excepting the fibrous deposits on the corda tendire. (This rare specimen is now among our collection of morbid anatomy, for the inspection of those who may wish to see it.) We strongly suspect that many diseases of the fibrous and ten. dinous structures have their origin in rheumatic disease; and if the horse could only speak, he would often tell us of his flying aches and pains, long before we discover any thing of the sort 'These horses, from the first, had febrile symptoms of an acute inflammatory character, which active cathartics and counter irritants seemed to have no effect on. The first subject died on the fiftl day from the attack, and the latter on the ninth. In tha 
buman sulject, rheumatism and cardiac affection arc twin brothers. In some subjects the diseases appear, now and then, to go land in hand; cardiac disease is liable to end in rheumatism, and vice versa Gallup thus alludes to the subject: "It rheumatism shows a propensity to migrate more than some other affections, it claims this rignt by keeping within the range of it kiudred tissues. It goes to the tissue of a neighboring joint of the sane family, and its way is prepared by an altered and excited state of all these tissues, when the morbid habit has been established. If it steals its way to the heart, it there occupics its family seat in the fibrous tissues. But it is not very common that it makes this stride; when it does, it is liable to be a fatal one; it commouly abides there to spend its rage and subdue its victim. It acknowledges the same predisposing causes with ofher acute diseases, which are aided by an idiosyncrasy. It is a dis. ease chiefly of cold seasons, but does appear in the predisposed from the influence of relative cold, from sudden changes in warm seasons."

"The concentrations of local affections in disease often pass from one part to another with equal facility, before the part has suffered essential lesions by their ravages; and, indeed, in some cases, when this is the fact, without carrying with them the alterations they have already made. The localists and humoralists have always been confounded with their own theories, because they never could apprehend how their materia excitans should so easily migrate the capillaries as to get so far without their being able to ken its march."

Here we have an explanation of that peculiar state of the system, termed by some writers body founder, which is nothing more nor less than rheumatism in its chronic stage. In a case of this kind, the whole muscular system seems affected. White thus describes it: "At first the foundered horse appears as if every part of the body were affected, and sometimes this is the case; at others, the fore parts or the feet appear affected; and in some cases, the loins or hind parts generally. This disorder is similar to acute rheumatism, or rheumatic fever, [it is identi. cal,] and appears to depend on inflammation of the muscles. zometimes affecting the muscles of respiration, and sometimes 
even the heart itself." There is no difference, then, netwets ucute rheumatism and founder, their terminations are in harmo ny with each other; and this proposition is confirmed when we notice the causes of the latter. Founder is produced by chilling the animal when exhausted or much fatigued; he may be chilled after a brisk drive, by exposure to the weather, by external influences, or he may be chilled by imbibing cold water in quantity sufficient to reduce the temperature of the system too suddenly. The author last quoted says, "Founder is produced by driving a horse, when in a state of perspiration, into a pond, ex.. posing him to cold wind or rain, or tying him up in the stable yard while the hostler washes his legs or thighs, and sometimes his body ; but excessive exertion alone will, and often does, produce every kind of founder." Here we hare the causes of rheumatism. Who can deny it? Take a plethoric, over-fed horse, and let him be exposed even to a slight exciting cause, an affection is generated, and propelled, with railroad speed, from tissue to tissue, constituting acute rheumatism - boly foundor; or, as in the cases just alluded to, it may spend its force on the heart, and extinguish the vital principle. The disease is apt, at times, to locate in circumscribed situations, about a joint or mus. cular region; but the treatment will not differ much.

Treatment of acute Rheumatism. - Our first prescription is invariably the following nauseating cathartic: -

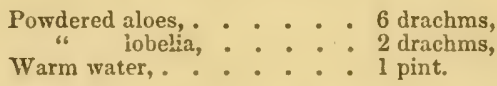

Free action of the bowels must be persisted in, and they must af?erwards be kept soluble by means of some such remedy as the following:-

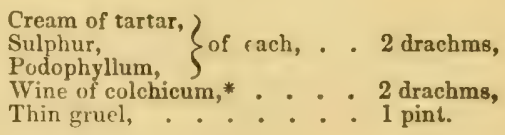

Mix, and give as a drench.

- Vinum Colch ar seminis of the United Status Dispensatorv. It can be precered of any ap.thecary. The author has a preparaticn 'of colchiruw 
This medicine shoult be confinued as orcasion may require for example, suspending it when the discharges are frequent, and again exhibiting it when peristaltic action is tardy.

In view of increasing cutaneous exhalation, we give an infusion of lobelia and pleurisy root, half an ounce of each to half a gallon of boiling water; when macerated sufficiently, strain, and add a gill of honey. Dose, one pint every four or six hours.

As regards large and repeated Doses of Medicine. - When cur ried beyond a certain point, these are sure to do harm; for this disease is located in tissues that are under the dominion of the nerves of external relation : these tissues may be highly $6 x$ cited and painful, in consequence of the congested state of the capillaries; at the same time, the vital fluid - blood - is deficient in the region of nutritive tissues: at such times cathartics have a disastrous sedative * tendency, very prostrating and uncontrollible.

It is a fact not generally realized, that there is more danger ir giving too much, than too little, medicine. It is astonishing how little medicine will at times favor the physiological state, and thus restore a patient to health; while we have abundant evidence going to show that ours, as well as the four-footed race, have been almost universally over-dosed. We generally keep the rectum empty by means of saline injections; should the bowels respond to the medicine as often as seems proper, they may be dispensed with.

As regards external Applications. - If steam can be so conducter to the vody of the patient (see Steaming Apparatus) as to keep up a relaxation of the capillaries, external liniments may be dispensed with. In the event of failing to secure diaphoresis, the capillinry absorbents must be excited with the following cxterual application :-

Which he prefers to any other; he has termed it the acidulnted tincture of $n$. checum. It is made in the following manner:-

$$
\begin{aligned}
& \text { Take of colchicum, bult and seeds, ..... 2 ounces } \\
& \text { Pronf spirit, . . . . . . . } 1 \text { pint, } \\
& \text { Diluted acetic acid, : }: 0^{\circ} 1 \text { pint }
\end{aligned}
$$

(Diluted acetic acid is formed by mixing one part strong acetic acid with fou p.rts water.) Let the preparation stand for the space of a fortnight; jou off the cleur liquor, and run it through fine linen and it will be fit for use:

- All cathartics have a sedative effect. 


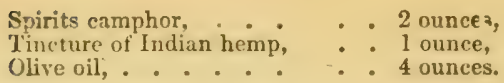

Mix; and lulericate the stiff and pamful regions daily, and cover them with flamiel.

The diet during the inflammatory stage should be light, con. sisting of sloppy mashes. Linseed tea, and water acidulated with cream of tartar, form the best drink for fever patients. An acute case may generally be treated somewhat after this fashion. There is, to be sure, much diversity of cpinion as regards the means; for while one recommends us to bleed with one hand ant give opium with the other, (by which means the system is pros. trated,) another recommends stimulants, to exalt the circulation, and thus secure its equilibrium, so that there shall be no excess of blood in any part; a third advocates cold water; and a fourth, homoopathy. Finally, in many cases the subjects ga:t well without one particle of medicine. The physician who his studied his profession with care will know when to give and when to withhold medicine: at all times he should endeavor to see how little medicine he can get along with, for by so doing he studies the interests of all concerned.

The diagnostic symptoms of acute rheumatism are, great pain elicited by pressure or motion; swelling of the limb or body, as the case may be; febrile symptoms are present; some thirst; the urine has a very pungent odor; the pulse is full and hard, and peristaltic action is slow. Some other portions of the case deserve notice. The disease occurs very suddenly in subjects not far advanced in years; there are regular periods in the course of the twenty-four hours, from day to day, when the patient will be worse. In the human subject, night is the period when the pain 8nd fever are greatest; and in four-footed subjects, confined in illventilated stables, we have noticed the same thing; yet in many cases the disease leaves the subject very suddenly, or migrat 3 to other tissues, so that this feature is not so persisten: as in matu. The disease has, to our certain linowledge, gravitated to the feet; it is then called acute laminitis - another name, in a majority of cases, for founder in its acute stage.

The diagnostic symptoms, when the heart becomes affected, are, palpitation, diflicult breathing, and great cipresion. These 
Bymptoms are to be met by saline medicines and counter ir ritants

\section{CHRONIC RHEUMATISM.}

Chronic rheumatism is occasionally a sequel to the acute form; yet it may come on without any previous perceptible acute attack, and entinely independent of it. The principal difference between this ard the acute disease lies in the less activity of the attack and inflammatory fever, and the indefinite duration of the symptums: the lameness is not persistent, but goes off after exercise, and returns again while the animal is at rest.

As regards the Canses of this Malady. - It is known to be of hereditary origin; sometimes arising in a sort of spontaneous manner, without any assignable cause: it frequently follows hard driving, exposure, and chilling the surface with cold water.

Horses, after having been driven a long distance, sometimes come into the stable in a very exhausted state, and instead of rubbing them dry, clothing them with a warm blanket, and paying that attention to them which their circumstances demand, they are suffered to drink cold water, driven perhaps into a cold corner of a stable, neither wind-tight nor water-proof; the legs are sluiced with cold water to clear them of mud, and the knight of the stable, a humane man perhaps, out of charity for the poor "devil," gives him a double allowance of food just at the very' time when the digestive organs are unequal to the task. Next morning, on attempting to back the horse out, his fore, and sometimes the hind, limbs are as stiff as a poker. "My horse is founderea," exclaims the owner - a term very expressive of the ruined condtion of the poor brute. The founder, or rheumatism, which. eres the reader pleases to call it, may finally locate on the muscles of the shoulders and fore extremities, or it may run to the feet, and there spend its fury, in the form of laminitis, - in. nammation of the lamina of the feet: this finally becomes ehronic; produces atropley - a wasting of the muscles. The horse is then said to be foundered in the chest. When the disease locates and remains within the horny covering of the foot during its several stages, and finally leaves the foot in : contructed, ruined madition, the horse is said to be foundered in the feet. We da 
not mean to give the reader an idea that all cases of laninitis arise in this way, for it is known to be the sequel, through a pro. cess termed metastasis, to diseases of the respiratory and other organs.

With regard to the treatment of chronic rheumatism, that which is known to be the sequel of the acute kind, without swell. ing, going off by exercise, and attended by a sort of chronic fever. This form is alway's benefited by the warm bath, and if a steam. ing apparatus could be brought into requisition in such cases, we could reckon with some degree of certainty on a cure. Cold water, and even a cold, moist atmosphere, only aggiavate the malady; the patient must be placed in a moderately warm box stall, and lave the benefit of local warm water bandages, followed, in some cases, by frictions, with liniment of ammonia and rose. mary.* 'The internal medicine (and we are satisfied this is the best) consists of

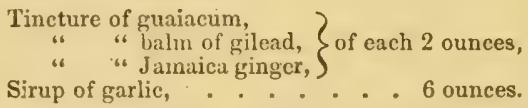

Mix, and give one sixth part of the mixture in a pint of camomile tea, night and morning.

This medicine will go the rounds of the circulation, and there excite action in the remote parts, differing from the morbid, and thus assist in removing the affection. We have found that flannels saturated with warm vinegar and water, bound on the limbs, and occasionally removed, have a beneficial effect. Finally, time persevering in the use of simple means, and proper attention to diet, will do all that can be expected.

\section{SPASM OF THE MUSCLES.-(Cramp.)}

Horses, as well as men, are subject to spasmodic affections of the muscular system, which sometimes appear and disappear with equal rapidity. A horse attacked with cramp chowE it oy

- Nomfround Liniment of Ammonia. - Take

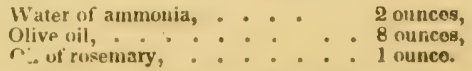

s1ix. Tu be applied by means of a piece of soft tlannel. 
vecoming suddenly unable to more the limb, and when compelled to step forward, drags the affected part after him. At other times he is travelling on the road, and becomes, without any warning, read lame, limps or steps short, and after standing a few mo. ments, regains the use of his limb, and proceeds onwarl to tha jouriiey's end without a reattack. Horses that have once has as attack of this sort are liable to relayses, unless the exciting caus 3 be removed. What are the causes? Some physiologi.iol considerations are necessary in order to understand the subject. Every movement of a muscle produces a correspondirg waste, and thus exhausts the vital principle: the waste must be supplied by the blood, and the blood in its turn depends on nutrition. Hence it follows that when a horse is compelled to perform great muscular action, he requires an amount of blood equal to the loss sustained; and that blood has to be manufactured in its chemico-vital laboratory, out of a corresponding increase of food. But suppose nutrition is perverted, or that the fooc', which in quantity seems sufficient, is deficient in nutrition; then we can perceive how spasmodic affections of the muscles may arise, knowing, as we do, that spasm arises from inal-nutrition.

The cure consists in restoring the tone of the digestive function, should it be impaired : a few doses of gentian, ginger, and salt, equal parts, will generally answer the purpose. The limb may then be rubbed daily with common hartshorn liniment, and the cure is completed.

\section{SPLENT.}

Definition of Splent. - An exostosis - i. e., a callous of csseous tumor - growing upon one, or contiguous to one, of tis? splent bones. - Percivall.

A splent seldom accasions lameness, except in the prinury stare of inflammation of the fibro-cartilaginous substance whith unites the splent to the canon bone; or, in cases when the spltent is high up, in close proximity with the carpal bone - (which rests on the upper part of the inner small metacarpal) - splent somm mes involving more than one of the carpal bones; and from the size of the tumor, it being large, lasving a very rough 
eurface. In such cases we may expect lameness; but it seldom lasts long, for the bones soon become anchylosed - glued together; and should the tumor be rough, so as to produce lameness, there will soon be thrown out on its contiguous tissues a fibrous layer, which to some extent prevents friction. This form of splent, having eminences, depressions, and a rough, irregulat Aspect, may be denominated tuberculated splent: it genera'ig interferes with the motion of neighboring parts. A splent of the circumscribed kind-a tumor about midway between the superior and inferior ends of the canon, on the inside - generally differs from the above, in presenting a smooth eminence, with a well-defined outline, varying in size from that of a bean up to a walnut.

Cause of Splent. - A good deal of speculation is afloat as to the cause of splent. We are aware that it may be produced by a blow, or injury in the form of sprain. If it come from a blow; we should be apt to consider that the animal himself was the cause of it, by striking with the opposite foot; although he generally strikes the fetlock, or else the inside of the knee; but he may once in a while have an ill-adapted shoe placed on his foot, and then, in consequence of being reined up suddenly, or getting one foot into a hole, may, without the knowledge of the person riding or driving, inflict a slight blow on the inside of the limb, which may prove, in a predisposed sulject, the exciting cause of this affection. Predisposition may lurk in breed; and from the fact that many animals are now to be met with carrying about with them miniatures of ancestral deformity, spavin, ringbone, \&c., we may presume that splent, at times, comes under this category.

Treatment. - In the early stages, supposing some inflamma. tory symptoms present, we resort to cooling, evaporating lotions: these are various. The following will probably answer the pur pose; we have used it extensively, and found it efficient:-

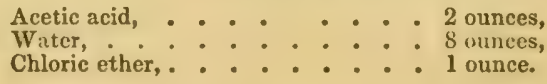

Mix ; take a pad, composed of three or four folds of cotton cloth immerse it in the mixture, place it over the seat of splent, ther. 
mnfine it, so as to produce slight pressure on the tumor, the outer bandage to be moistened as often as convenient. Rest af this stage is highly important, because the periosteum, or else the interosseous fibro-cartilage between the splent and canon, is inflamed, and all motion aggravates it.

In a case of long standing, and even in one havitı a well marked tumor, stiffiness and lameness may be relieved by the uecasional application of acetate of cantlurides.

Some surgeons blister for the cure of splent; others saw off the tumor; and periosteotomy has been resorted to in view of cure; but, unfortunately, splent is no more curable than spavin. when once the cartilage has been converted into bone; and as in the majority of cases it is but an eyesore, and detracts but little from the value, and still less on the score of usefulness, of the hors, it may be well to pause ere we operate for the cure of an incurable disease.

\section{EXPLANATION OF CUTS.}

Cut 1. - Appearance of the hock before dissection and maceration.

Cut 2. - Appearance of bones composing the hock after maceration.

1 Os calcis.

2. Astragalus.

3, 3. Large and medium cuneiform bones, united to each other, and coated with bony deposit.

4, 4, 4. Bony prominence, or spavin tumor.

5. Canon or metatarsus magnus.

6. Snall (inner) metatirsal or splent, the head of which is involved in orsigc disease, so as to be immovable.

7. The articular cartilages being ossified, the canon is united to the oone above. The whr.le surface of diseased parts, as delineated, have a rotgh, uneven, and spongy applearance. This is one of the hocks alluded to in article Suavin. The diseased parts were obtained from Messrs. Freeman \& Scs.te日, sivners of the house

SPAVIN.

It is most astonishing that in this age of imp"orement means are not discovered for the prevention of this, one of the most common diseases of the horse's hock. It has got to be so com. 


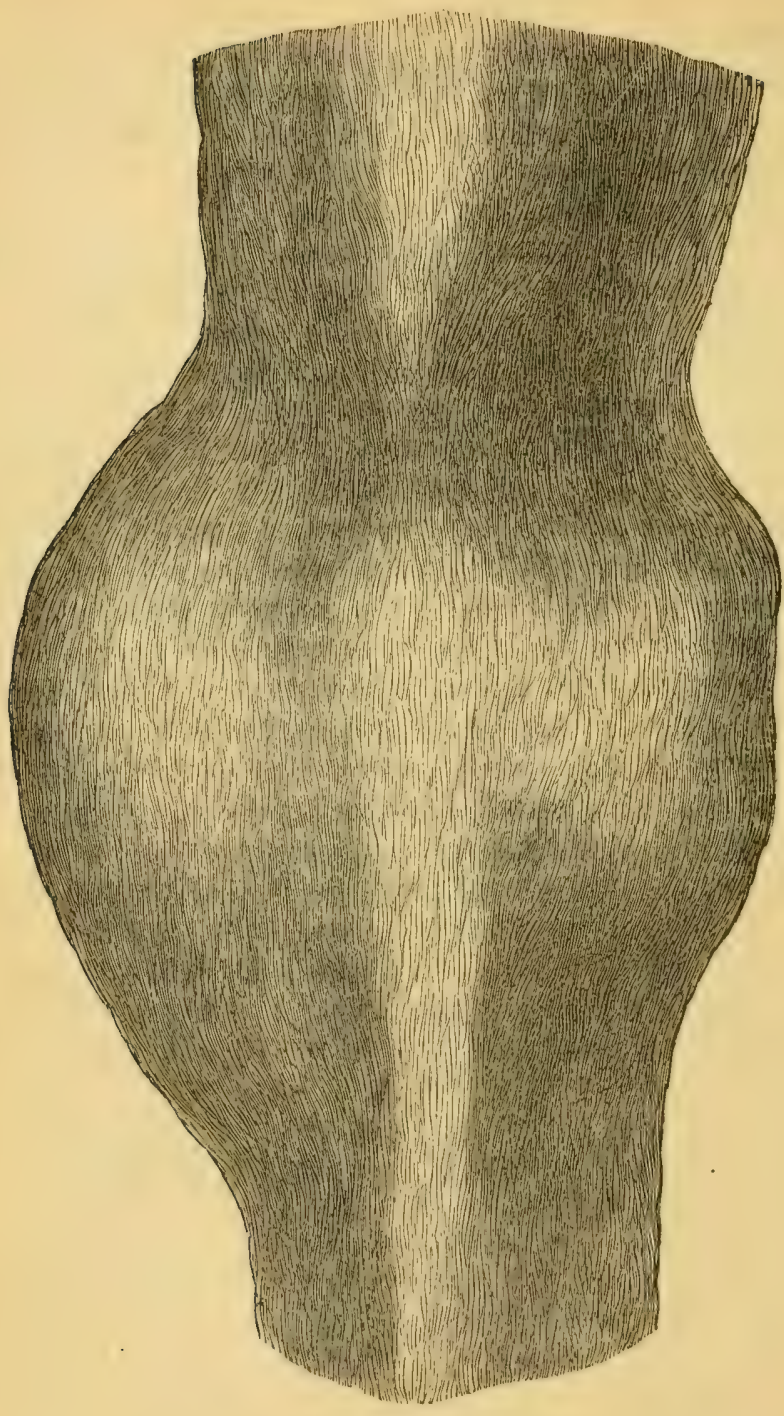

Cur 1.

APPEARANCE OF THF SPAVIN TUMOR BEFORE DIE SECTION AND MACERATION. 


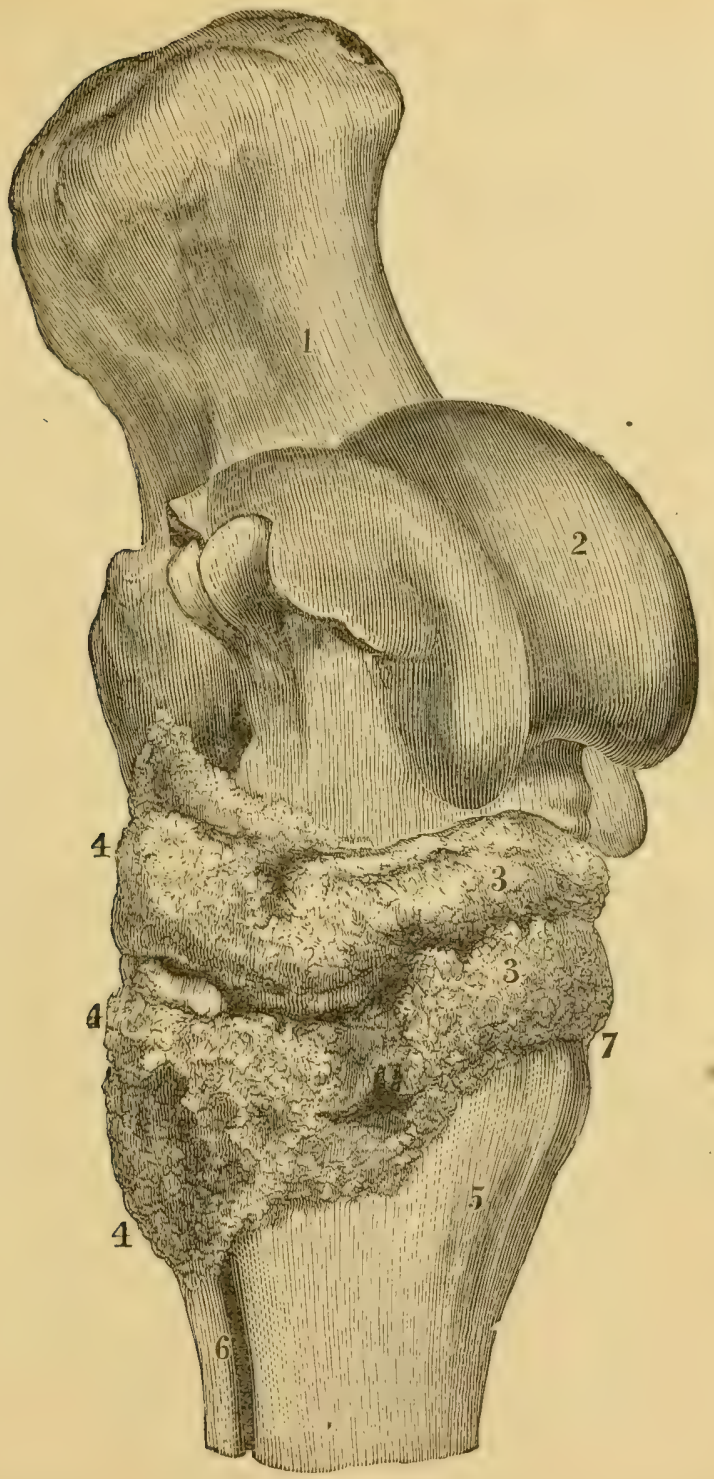

CUT 2.

APPEARA, 'E UF THE SPAVIN TUMOR AFTER DISSFC'TION AND MACF,RATIIN. 
mon a disense of late, that if a purchaser finds a horse free from blemish of this description, he consider's himself fortunate. By way of showing how little some people think of spavin, the following incident is related: The author was lately travelling in the eastern part of Massachusetts, and had occasion to use a team, which was procured at the village stable. The owner kindly consented to drive to our destination, some four or five miles distant. During the journey the conversation turned upon horseology. Our friend appeared to be well posted - knew every horse in town, his cost, and present value. We remarked to him that the horse he was then driving had a couple of spavins. " $O$," exclained the man, "that is nothing; the horses in these p.rts are all spavined!"

"Pray," asked we, "what do you attribute all this to?"

"The chief causes are, breeding from old, broken-down, spavined mares and worthless studs; and permitting the foal to run by the side of its mother while she is in harness."

Our own experience has taught us to look in this direction for the causes; and we feel assured that if breeders would be more particular in the choice of both sire and dam, and leave the colt at home, instead of trotting it to market, by the side of the mare, - as is the fashion in the country, - and also pay attention to the conditions which the law of physiology imperatively demands for the maintenance of health and vigor, then there would be few spavined hurses. Here, then, is where our preventive measures must commence; for as sure as "like begets like," so sure are spavins transmitted from parents to offspring. Not that we would have the reader suppose that every case of spavin is brought about in this way, or that every case is transmissible; for we know that hard work on our paved streets must tend to inflame the inter-articular cartilages between the small bones of the hock; and this inflamed, bruised state of the parts may bu considcred the primary stage of spavin. Concussion on pavements, when the horse is in the act of drawing heavy loads, has much to do with the production of spavin; still, in the country, where there are no pavements, we find the most spavined horses. How shall we account for this? It seems very probable that great muscular exertion, in drawing a load up hill, or, in fact, descending a slope rapidly with a load, may overtax the liga 
mentary tissues; and especially so in cases where there is some pre. disposing taint lurking in the system: so that there are various causes for spavin. Our views of the cure of spavin - that is, if anchylosis can be considered in the light of a cure - are, that, in order to render the animal capable of future usefulness, we must follow in the path of nature, and aid her. For example, on discovering a horse lame in the hock, having the usual symptums of spavin in its incipient stage, we shonld release him from lubor, or even turn him out to grass, thus, tc some extent, guarding against the irritation and inflammation which usually follow hard work; for we know that in the early stage of the diseass inflammatory action is active, and that hard labor and use of the joint must aggravate it; therefore any measures that are taken, calculated to control or lessen pain and irritation, must prove beneficial. By such means we place the patient in the most favorable position for nature to perform a cure (anchylosis) in her own time, and after her own fashion.

Some people have an idea that nothing short of firing or blistering can be of any benefit; yet experience has shown that the practice is unsatisfactory, as the reader will perceive on consulting English authority. The fact of a few horses having been restored after the application of the hot iron or blister is not proof positive of its efficacy; for, as we have said before, both horses and men will sometimes get well in spite of all we can do to prevent them. We have succeeded in rendering horses as freo from lameness by mild means, as, we think, can ever be accomplished by the scientific, yet barbarous mode of fire and blister. Our general advice is, during the inflammatory stage, let the ani. mal have rest, and apply cooling, evaporating lotions to the parts. Our usual remedy in this stage is

Muriatic acid, $\quad: \quad: \vdots: 4$ ounces,
Water, 2 quarts,
Tincture of bloodroot, : $:$ : 6 ounces.

A pplied daily by means of a sponge.

Another equally useful remedy may be thus prer ared: Taks

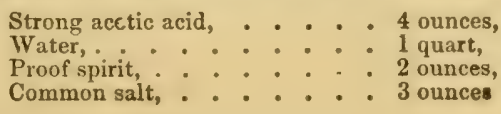


rur usual mode of application is as follows: Take a piece of spo'ige, slightiy concave, corresponding as near as possible to the fort: and size of the hock; by means of a few stitches, affix two pier $₫ s$ of tape or linen, so as to form an $\mathrm{X}$; each pifce must be 'ong enough to encircle the joint two or three times; after dipping the sponge in the mixture, it must be applied to the inside of the hock, and there secured, and afterwards kept constantly ncist. By a faithful application of the above, the inflammatory symptoms (which are not confined to the joint alone, but prevail is: the surrounding tissues) will soon subside, and anchylosis progresses in a slow, yet favorable manner, without the usual pain and irritation.

Much of the lameness in spavin arises in consequence of the tumefied state of the ligamentary and sub-cellular tissues around the joint. We knew a horse, some time ago, that was regularly worked on the lead of a city truck, he being the subject of spavin on both tarsal joints, which were enormously swollen; and any perion not acquainted with the nature of the case would suppose that the bulk of the enlargement was of a bony claracter, it being dense, hard, and unyielding. On dissection, however, the bulk was the result of a general thickening of all the parts in th? vicinity of the hock; the exostosis, or bony enlargement, was but trifling, and the tarsal bones - composing the hock - were in a perfect state of anchylosis. (See cuts of spavin.) The animal, up to the period of his death, was considered "a very lame horse." Now, the lameness must have been of a ligamentary character, and not bony nor cartilaginous; for the bones werc united as firm as a rock, leaving not the least trace of interarticular cartilage.

In our collection of morbid specimens can be seen two excel. leut specimens of spavin, taken from a horse formerly the property of a teamster doing business in Boston. The owner infurmed us that at the age of eight the horse s'lowed symptoms of spavin; .e was immediately taken from work, and for upwards of a year was permitted to lead a life of comparative rest in the country, part of the time at grass; the remainder was spent in barn and yard life. During this time, he was more or less lame; yet nothing, by way of treatment, was done for him, except an occasional dash of cold 
water on the diseased joints. The horse, on being put to wurk, showed little more than the usual stiffness consequent on anchyInsis, - which had probably then taken place, - and he continued to perform daily labor for the space of eleven years, and died at the age of nineteen, of congestive pneumony. The important features in the case are, that there was less of lameness, tumefac. tion, and bony enlargement than we ever remember to have scen; and this fivorable result was, no doubt, brought about by the rest and cold water treatment. The owner of this horse was "dead set" against firing and blistering, had no faith in the curability of spavin, and still less in "meddlesome medication," as he termed it

If the cure of spavin, then, consists - as we are told it does by some of our employers - in merely freeing the horse from lameness, so that the owner may get rid of him without much loss, or if the animal shall be restored to his former usefulness, yet still having an enlarged hock (an eyesore) and a little stiffness of the joint, - all this can easily be accomplished by promoting anchylosis.* We shall be told that these are no cures at all. We have examined several of these wonderful cures wrought by tho firing iron, and find that they all amount to about the same thing. For if any of our professional brethren ever cured a case of anchylosis, which is often a concomitant of spavin, we should like to know it. Sir A. Cooper has pronounced it positively incurable. In fact, partial anchylosis is a desirable event in the treatment of spavin, and one which we always endeavor to indıce. If a horse happens to have an enlargement on the inside of the hock, and goes a little lame, which he is very apt to do under the crrcumstances, it is set down as a spavin; and the poor brute, if he were put into the hands of a humane man, who would probably give him rest, and perhaps foment the limbs, would soon recorer from the imaginary spavin. But it often happens that with the very best intentions on the part of the owner, the patient

- Anchylosis. This denotes an intimate union of two or more bones which were naturally connected by a movahle kind of joint. All joints originally de. signed for motion may become anchylosed; that is, the heads of the bone? forming them may become so consolidated together that no degree of motion wh stever can take place. In such cases the interarticular cartilages are airorbed, or bacomae ossifiec (changed into bone.) 
is handed over to his tormentors. Who are his tormentor's? They are not men who have devoted a great portion of their lives to the study of this truly valuable and important branch of science; for if they were, they would not make such a gross mistake as that alluded to. But the very converse of this is the truth, and such will be the case until the American prople shall educate our young men, and qualify them to practise, on corrert priniciples, the veterinary art.

However well qualified, by observation and experience, the la:ter class of men may be to prescribe for simple forms of disease, they cannot be trusted to perform an operation, one of the most difficult and dangerous, and one that requires a knowledge of anatomy and physiology, in order to first diagnose it with any degree of accuracy. Surely, when men unacquainted with the mechanism of a joint undertake to restore it to a healthy state by means of agents whose action is to them unknown, then their weapons are like a sword in the hands of a madman. It is a consolation, however, to us, and also to every friend of lumanity, to know that the veterinary honors have, in a great majority of cases, been forced on this class of practitioners, and that they are willing to relinquish them so soon as the legitimate candidates make their appearance.

We repeat, then, that spavin cannot be radically cured; for if anchylosis is induced, the joint is still in an abnormal state. The cartilages,* (between the bones,) which, in their healthy state, yield to chemical analysis one third their weight of bony matter, are now turned wholly into bone; therefore they cannot be restored to their elastic condition.

If spavin exists in the form of periosteal $\dagger$ exastosis, $\ddagger$ then w6 luink that, by exciting absorption, the deposits might be got rid of.

- These are placed on the surfaces of bones, on their movable articinations, and not only serve as a cushion, to prevent concussion, but also to facilitste motion, and cornect bones together.

+ From periosteum, a membrane which covers the bones. It is very strong composed of fibres, highly organized, having numcrous arteries, veins, nerves. and absorbents.

\$ Periosteal exostosis. Sir A. Cooper defines this to be a hony deposition seated between the external surface of the bone and the interual surfa se of thr periostoum, and firmiy adkerent to both. 
Almost all the veterinary surgeons of the olf world have re. sorted to the firing iron or blister for the cure of spavin; the cure, however, we contend, is only imaginary. The restoration of the horse to comparative usefulness is the object, and tha does not always follow; yet, in justice to those whose position and long experience entitle them to the confidence of the world, we are constrained to acknowledge that their practice is often accompanied with astonishing success. The practice of fining, however, we do seriously oppose ; it is a barbarism that should long since have been discontinued. We never performed the operation but once, and have ever since been sorry for it.

As to blisters, we regard them in the light of a last resort, yet, when applied understandingly, we are not sure that it would be good policy to oppose their use; for they are used by human practitioners in urgent cases with marked success. Cases are constantly occurring in large cities, in which, for several reasons, it is our.duty to hurry the process of anchylosis, and thus put the subject into working condition in less time than by the ordinary method of nature! The remedy in this view is acetate of cantharides, applied occasionally, so as to keep up an active state of inflammatory action, by which means the usual transformations are effected. The remedy is contra-indicated in all cases of high inflammatory action, attended with heat, pain, and unusual lameness: these states are to be subdued by the usual refrigerating and anodyne lotions, ere we resort to any preparation of cantharides. The above preparation does not produce so much pain or irritation as a common blister.

Nature and Seat of Spavin. - Spavin is a compound of two diseases, known as exostosis and anchylosis: the former signifies hypertrophy of bone, (hyperostosis,) - morbid enlargement; anchylosis signifies stiff joint - absorption of inter-articular car tilage and substitution of bone. Anchylosis, however, does not take place in what is properly understood as the hock joint, com. posed of the tibia and astragalus - although a very common oc. currence in the human subject; but it generally occurs beneath the true join: within its collateral or inferior articulations, knowr as the tarsal bones. Spavin, therefore, may commence in exoowsis and end in anchylosis, and vice versa. The seat of spuvin, 
then, 1 s on the inside of the hock, in the region of the turso bones, and beneath the trie joint, from which point it may both spread and atoquire magnitude. Hypertrophy, or enlargement of the bone beneath the tarsal articulations, occurı ing on the upper part of the canon, does not constitute spavin: in England such an enlargement is denominated " a jack."

As regards the Cause oj" Spavin. - From what has preceded, the reader will see that it has two origins: 1. Hereditary. 2. Exciting.

1. Hereditary Predisposition. - Facts have proved conclufi zely that spavin, as well as predisposition - morbid tendency to the same, is transmitted from parents to offspring. It is probable, however, that predisposition is more frequently transmitted than actual disease; for the latter does not make its appearance fo early as it otherwise would were it transmissible. Spavin is not peculiar to colthood, but to adult life, and even then can often be traced partly to an exciting cause - strain, injury, over-work, \&c. Predisposition may not always have an hereditary origin; still it will not differ in its mode of action from the former; for all predisposing causes produce in the economy certain changes which may be said to prepare it for disease; anc, therefore, pre. disposition, whatever its source, may be considered as the incubative stage of disease.

2. Exciting Canses are those from which this disease seeng to have direct origin - such, for example, as strain, injury, orerwork, \&c. ; yet these fail to produce spavin in a great majority of cases; in confirmation of which we have only to look into the history of our truck horses, particularly those used for sevelal zears in the shafts. The herculean strength necessary to back a lond which requires the united strength of two or three to draw would, one would think, be likely to produce spavin; yet a great proportion of such are exempt from this disease; therefore we may infer that exciting causes are in some cases inoperative, unless conjoined with predisposition.

Symptoms of Sparin. - Unfortunately for the poor brute, lameness is not generally of that character which incapacitates him for work; and thus he is urged to the performance of his ruties, the disease progiessing, and his sufferings increasing. 
sritil the owner sees that the lameness is not to he driven off: The generality of non-professional men are unwilling to believe in the existence of spavin, unless they can brth see and fecl it, and are therefore more prone to refer primary spavin lameness to some other joint, until, after a few months of intermittrnt lane. nes;, they are, by ocular demonstration, convinced.

Spavin commrncing in inter-articular cartilage is not demonatrable in this manner; there is no circumscribed tumor, nor irc gularity; our diagnosis must, therefore, be made up from the jigns revealed - from the heat and tenderness about the part; of a sub-acute character - from the absence of tumor - from the manner of catching up the limb -- and from the intermitten? nature of the lameness, which is progressive, yet fluctuating. The history of the case, also, must be considered. If a sort of irregular lameness has existed for some months, referable to no other joint than the hock, and the difficulty has of late gradually increased, so that the joint appears stiff, all doubts are set aside, for anchylosis is hastening towards completion; after which we may expect to observe a tumor on the inside of the hock. A tunor once formed in the region already referred to needs no wise man tu puint it out; it can be both seen and felt; and this, accompanied with hock lameness and ligamentary tumefaction, is the diagnostic symptom of spavin in its exostotic stage.

\section{BOG SPAVIN. - (Enlarged Bursa Mucosa.) BLOOD SPAVIN. - (Local venous Congestion.)}

Bog spavin is the term usually given to enlarged mucous cap. sules, or to a distended state of the sub-cutaneous veins in the regiun of the hock. In the latter case it is termed blood spavin. It will be seen, on referring to article Sparin, that the above a hormal states bear no resemblance to the latter; therefore the term is misapplied, and should not be made use of by any per. son! professing veterinary know ledge. Enlarged mucous capsuled in the one case, and local venous congestion in the other, are significant terms, and by them we understand the nature of the case, and also by what means they are to be treated.

The remedies for enlarged mucous capsules are, in the early 
stage, cold water and refrigerating lotions: in the latter stages strong infusion of bayberry bark ; and lastly, brandy and salt, perseveringly applied. Congestion may be treated in the same manner, aided by friction.

\section{WINDGAILS. - (Enlarged Bursa Macosic.)}

The bursal capsules located just above the fetlock, as well as in the vicinity of the hock, secrete a synovial fluid, corresponding "w what some persons term "joint sil," the use of which is to facilitate $m$ ition. In cases of this character, either the walls of the expsıle are hypertrophied - augmented in bulk - or the synovial secretion is inordinate, or else its flow is obstructed. Cnunter-irritation, bandage, friction, and regular exercise are the best remedies, and yet they often fail to remove the eyesore.

\section{EXPLANATION OF CUT.}

1. Superior pastern.

2. Inferior pastern.

3, 3. 4, 4. The joint anchylosed - immovable.

5. The bony tumor, extending laterally, and diffusing itself in front of the joint.

\section{RINGBONE.}

Definition. - Ringbone is a bony tumor--exostosis - situ. ated on or in the vicinity of the pastern bone, frequently ending in anchylosis of the pastern joint. Scme very curious notions are entertained of the nature of ringbone. As an example, a late writer in New England tells us that ringbone is fed by a bludder situated at the posterior parts of the tumor, and recommends for its cure the extrartion of this bladder. This erroneous view of the matter would not amount to much, only it has led to the in. fliction of a useless and cruel operation, which only tends to make 


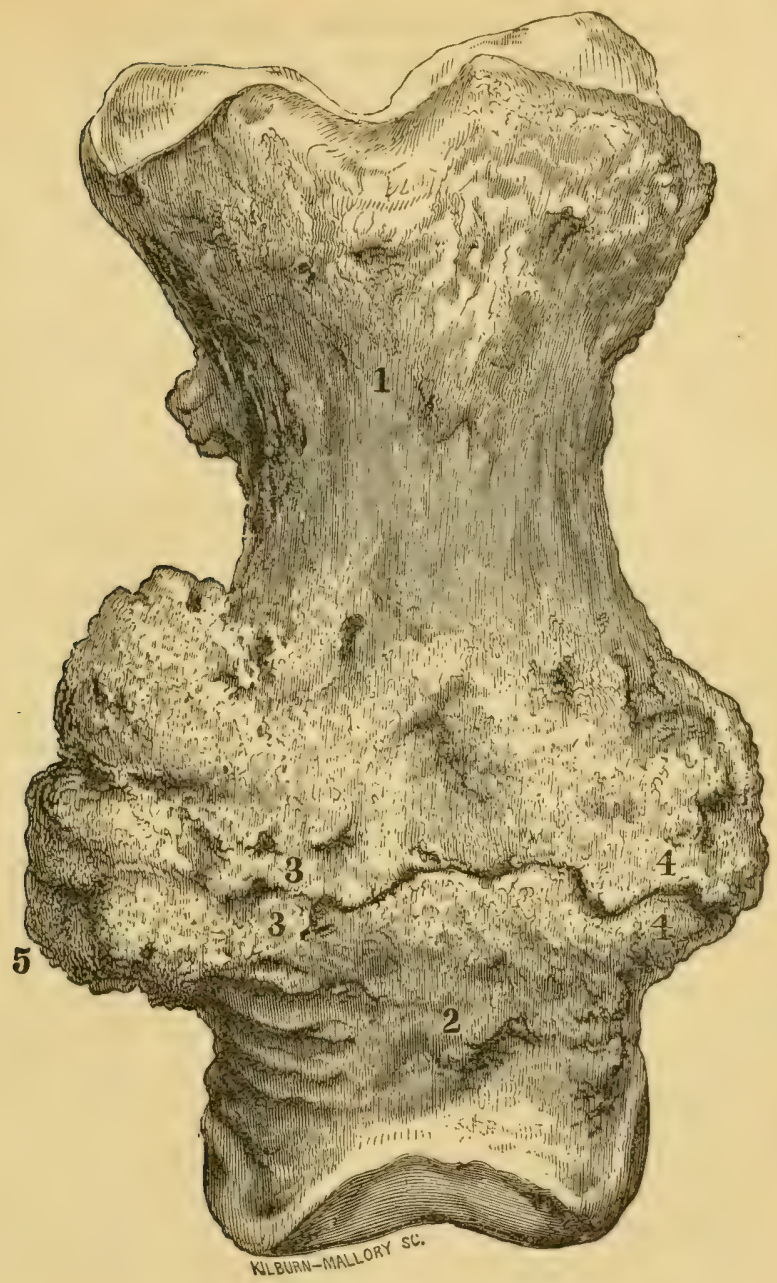

RINGBONE ANI ANCHYLOSIS 
bad worse, and exhibit its advocates in the light of barbarians It is not enough, forsooth, for the poor subject of ringbone to suffer the excruciating torment attending tendinous, ligamentous, or periosteal inflammation and ossification, but he must, in addition, be compelled to submit to atrocities unheard of in the history of Luman medicine, and for which the veterinary science of the present day furnishes no authority, but, on the other hand, one of uriversal disapprobation. It has been our painful duty, occasienally, to take in charge subjects that have been most shame folly maltreated for the cure of ringbone. One case, which wo can never obliterate from memory, happened to a poor aged ani mal, that for a long period bad been a faithful slave to his master For many years he had been the subject of this disease, and his owner had long since given up all hopes of cure, till, at length, one of those exotic, pestiferous specimens of inhumanity, termed horse doctors, - but who have no more claim to the title than a maniac or a wild Indian, - undertook, for the sum of five dollars, to cure an hereditary incurable disease. The owner, through the deceptive arguments of the barbarian, consented to an operation, which for cruelty would have outdone an inquisitor. It consisted in cutting through the integuments down to the bones, for both hind legs were operated on; a red-hot iron was then ireely used over the exposed surfaces; some oil of turpentine then being poured into the horrid wounds, it was set on fire; and thus the brutal operation terminated. What a pity the horse had not the power to make his tormentor exchange places with him, and pay him in his own coin! The disease was not benefited by the operation, as any veterinary surgeon, had he seen it, would lasv foretold; the case being one, not only of common ringbone, but also anchylosis of the pastern and coronet joint. Without uceupying the reader's attention any longer in this direction, wo shall at once proceed to causes of ringbone, its nature and treatment.

C'auses of Ringbone. - We have no better anthority on this bulject than our oft-quoted Percivall, who teaches that there are "three kinds of causes - hereditary, structural, and incidental.' Our attention was first drawn to the hereditary origin of ring. bone from a remark made by an extensive dealer i. horses, in 
reply to a question put to lim, how it happened that but a fev. ringbones were now met with, compared to the number that at tracted notice in times past. The reply was, "Because nc breeder of horses nowadays will send a mare to a horse laving ringhones." (A very good example for American horse-breed. ers tu follow.) There appeared something like reason and trutt. in this; and we felt more inclined to attach faith to it, when we came to read in Sollysell's work, "The ringbone is some limes hercditary; though it is usually occasioned by a strain taken in curvetting, bounding turns, and violent galloping or racing."

"That form, as well as breed, is concerned in the production of ringbone, we have sufficient living demonstration. A coarse or half-bred, fleshy, or bony-legged horse, with short and upright pasterns, is, we have observed, the ordinary subject of disease; and there exist satisfactory reasons why we should expect him to be so. 'The pastern and colfin bones constitute the nethermost parts - the pedestals - of the columns of bones composing the limbs; and being so, they receive the entire weight and force transmitted from above. The pastern, when long and oblique in position, receives the superincumbent weight in such an indirect line, that, bending towards the ground with the fetlock, nothing like jar or concussion follows. The very reverse of this, however, happens every time the foot of a limb, having a short and upright pastern, comes to the ground. In it, instead of the weight descending obliquely upon the sesamoids, and the fetlock bending therewith, it descends direct, or nearly so, upon the pastern, making this bone entirely dependent upon the bone beneath it the cotfin - for counteracting spring; and should any thing occur to destroy or diminish this spring, or to throw more weight, n sullen weight, upon the coffin bone, than it can counteract, jar of the whole apparatus ensues, and an effort of nature to strength en the pasts, by investing them with callus and ossification, is likely to be the ultimate result. For we would view ringbone, disease though it most assuredly must be called, as frequently, in young horses, a resuluce of nature whenever the [pastern] bonea are found unequal to the exertions or efforts required of them."

The excitir $q$ Causes of Ringbone. - "These may be said to 
consist in any acts or efforts of speed or strength productiv of concussion to the bones of the pastern. Some have ascribed the presence of ringbone to blows. Undoubtedly, a blow upon a bone would be very likely to produce exostosis; but the pastern, the lind pastern in particular, is rather an unlikely part to be struck. After inflammation from any cause, even after that produced by a common blister, very often we know an enlargement of tha pastern will be left; and though this is not called ringbone, it may be regarded as something very analogous to it."

Nature of Ringbone. - "Ringbone is but a species of exos. tosis - a bony tumor, which in one situation constitutes ring. bone, in another splent, it. another spavin; yet the three differ as well in their origin as in their effects. Ringbone has an external origin ; and though it may, from spreading; interfere with the motion of a joint, still it does not, that we know of, produce any affection of the synovial membrane; spavin, on the contrary, seldom sonfines itself to the external or ligamentary tissues, but affects the synovial membrane as 'well; and splent originates in the very joint - the fibro-cartilaginous - which it afterwards blocks up and grows from.

"Ringbone is either a ligamentary or a periosteal affection, or both. From the situation in which we commonly find it, and from the causes which are known to give rise to it, we beliere it usually to be ligamentary in its beginning; though, when once formed and given to spread, no tissue, save the tendons, escapes conversion, to contribute to the osseous mass; and even the tendons themselves have been known to become partly ossified. In fact, when the exciting cause has been great, or when there exists an evident proneness in the constitution to ossific action, such is the extensive and varied form ossification takes on, that we can hardly say when it will end, so long as any soft tissules yet remain to be converted. Writing in the year 1823 on this subject, with a hundred and fifty morbid specimens of the kind upon the table before us, we find we were led at the time to make the following remarks :-

" By far the most common seats of [ossific] disease are the pastern, coronet, and coffin bones. Out of the said hundrerl and fitly specimens there are 
5 complete anchylosis of the fetlock joint, 40 do. do. of the pastern joint, 18 do. do. of the coffin joint.

The others are either simply incrusted, more particularly arnund their extremities, with layers of new bone, or are variously de. formed by exostosis of different shapes, many of which are very large, and several of them confined to one side. Upon (ine of this pastern bones a complete osseous ring is formed, the result of nsaification of the flexor perforatus tendon. In nearly all, tho disease appears to have taken its rise at, and to have spread from, the pastern joint; there being but few specimens in which some nsseuus accretion is not observed around the lower end of tho pastern bone and the upper one of the coronet bone; which is the kind of deposition that gives rise to ringbone."

Treatment of Ringbone. - The old method of treating exostosis by fire and blister is fast giving way to a more rational procedure. It has been discovered that there is not really any cure for this malady, more than there is for spavin: if we can relieve the horse from lameness, that is all that can be expected of us; but even then the disease is not cured - an eyesore still remains, and perhaps a stiff joint. We treat the disease, whe first discovered, just as we would a recent splent or spavin - by cooling, evaporating lotions, cold water bandages, \&c. ; rest, too, so much disregarded by physicians, and not mentioned by some veterinary authors, is of some importance. Human practitioners realize how much is gained by their patients, when laboring under diseases of the joints, by strict attention to rest; for by that means inflammatory action is kept within bounds. To conrol inflammatory action, and by that means lessen pain and irri. tation within or around a joint, should be our first business : from this we have seen great benefit derived. Our business as phy. sicians is to follow in the footsteps of nature, and observe by what means she repairs injuries and performs her cures. Te al.all find that her cure of spavin and splent consists of anchylosis; all that she requires for it is rest: if any thing more be needed, it is revealed to her handmaid, the physician. The parts are hot and inflamed; cooling applications are needed: now they are coli and inactive; warmth, moisture, and perhaps 
stimulants are indicated; and so on to the end. If the physiciar. has learned to interpret the language of nature, he is indeed he: handmaid. In the case of hip disease occurring in children - the natural cure of which is anchylosis - physic ians enjoin rest, which favors union of the discased bones. If such means favor anchylcsis in the human subject, we cannot dispense with them when treatirg the horse. 'The author has tried such means, and is satisfied that he is on toe right track. In all cases, then, of early diseaso of this character, whether it be periosteal, bony, cartilaginous, fibrous, or muscular, cooling lotions, fomentations, light diet, and rest are the means most calculated to do good, whether the in. tentions of nature are anchylosis or not. In chronic cases 10 use acetate of cantharides, applied daily, until the parts appear hot and tender; we then substitute cold water bandages, and repeat the process if necessary.

\section{STRAIN OF JOINTS OR MUSCLES.}

What we understand by strain is a common wreweh, stretching a fibre, tendon, or ligament beyond its physiological capacity, with or without extravasation of blood, generally followed by pain, lameness, and sometimes deformity. In human practice, the word sprain is u-ed to signify an incomplete luxation, accompanied with stretching, and more or less laceration of the ligaments of a joint, and sometimes with rupture of a tendon. Both terms appear to apply to the same state; yet, as strain is the word generally used in horse practice, we prefer it to the other. A strain in the horse is a very different affair from what it is ir man; for rest - which is the principal means of cure - cannot be insured; when the patient, instead of cooperating with us in kecping the limb quiet, often keeps it in constant motion, thus counteracting our best methods of cure. Then, again, if a man sprains a wrist or ankle, he immediately adopts the best method of cure, and keeps the limb quiet until the inflammatory symptoms have subsided. But strain occurring in a horse is not thought much of by the majority of horsemen; and therefore the services of a physician are not called in until the horse is as vame as a kitten. 
The treatment of common strain, if seen early; is a vers sim. ple affair, and may be conducted somewhat after the following manner: Take tincture of arnica and pure water, equal parts bathe the parts in a thorough and careful manner, and apply a cold water bandage, and continue the treatment until relief is obtained : in cold weather, the wet bandage must be covered with dry cinthê, or packed.

\section{STRAIN OF THE FETLOCK.}

Strain of the fetlock is frequently occasioned by beading the joint in a lateral direction, and injuring the capsular ligaments of the joint. Lateral motion in these joints is very limited; therefore, if a horse treads on a round body, or gets his foot in a hole, and the strain comes upon the side of the joint, lameness is generally the result.

Treatment. - If a loss of continuity has taken place in any of the tendons or liganents, a starch bandage must be applied, in the form of figure 8. If it is nothing but a sprain, the cold water bandage may suffice. Any morbid habit, however, must be subdued by alterative medicine. See Alteratives.

\section{STRAIN OF THE KNEE.}

Treatment. - The same as in strain of the fetlock.

\section{STRAIN OF THE COFFIN JOINT.}

Treatment. - Rest, cold water applications, cooling medicino, and light diet.

\section{STRAIN OF THE BACK.}

Strain in the back or lumbar region arises from causes very evident to those who pay any attention to the anatomical struc. ture of the horse. Considering the heavy loads he is often compelled to carry or draw, it is astonishing that he should be so fren as he is from lameness in the back. The diagnostic symptoms of this form : strain are. pressure over the "umbas 
region elicits symptoms of pain ; the part feels hot; and the horse when compelled to describe a circle, shows, by the careful mannex in which he turns, that it gives him great pain.

Treatment. - Rest; applications of cold water; light diet; and cream of tartar water as a drink. One ounce of cream of tartar to a bucket of water, daily. It was customary, but a few years ago, to apply charges, and plasters, to the back, for the cure of strain and lameness. But the day of plasters, in human as wel: as veterinary practice, has gone by; they are now only used by those who have never taken the trouble to understand the exhalatury function of the skin - which salutary function plasters obstruct; the wet sheet next the skin, and a blanket over it, will be more likely to do good than a plaster. Should the horse show mole than ordinary symptoms of pain, a fomentation of hops should be resorted to; if, after a day or so, the pain is still manifest, the trouble is something more than mere strain, and the owner had better consult a medical man.

\section{STRAIN OF THE SHOULDER.}

Treatment. - The part must be sponged, two or three times a day, with diluted tincture of arnica. In fact, a common strain of any part of the muscular system may be treated in the same manner; at the same time attention must be paid to the state of the bowele

\section{THOROUGHPIN. - (Enlargsd bursa.)}

'Thoronghpin makes its appearance in the form of bursal swelling, the fluid of which can be squeezed from one side to the other : it is located in the region of the hock, in a space bounded by the os calcis, tendo achillis, and lower end of the tibia. It seldom occasions lameness, but is considered a sad blemish; for the removal of which, Mr. Gloag, V. S., recommends acupuncturation and pressure. The following case, from the Veterinarian, illustrates his mode of procedure:-

"July 11, 1850, a chestnut mare, aged four years, admitted with a large thoroughpin, off hock. This had existed four or five months, and seemed to be increasing in size. It was proposed to 
Ine that the hock should be extensively fired; but, instead of so loing, the following plan of treatment was adopted:--

"I cut a slice transversely, about half an inch in thickness, off a large bottle cork, and this was pierced by four common-sized darning needles, so that their points projected about half an inch from the surface. The cork was used in order to give the neelles a fin $\mathrm{m}$ position, and to admit of the distances of their projecting puints being graduated according as required. I then plunged the needles into the enlarged sac, on each side, which was ful. lowed by a slight oozing of serous fluid. The hock was afterwards ordered to be well fomented. This treatment was daily repeated until the

" 16 th, when no particular change had occurred. The opera. tion was to be daily continued; but, instead of fomenting after the puncturing, the parts were to be well smeared with an ointment composed of hydriodate of potass one part, mercurial ointment one part, blister ointment half part, and lard ten parts.

" 25 th. The thoroughpin is evidently somewhat reduced. After each operation the swelling partly subsides, but subsequently fills again. The ointment is occasionally discontinued for a day. I was now resolved to try the effect of pressure. For this purpose I applied a spring truss to the hock, upon the enlarged bursa, which was to be daily punctured, as before, with the application of the ointment as often as it could be safely used. After the first application of the truss, it was quite astonishing to observe the difference in the enlargement, which had become quite soft, and evidently showed that its contents would be absorbed. The mare wore this truss day and night, and took her walking exercise in it daily. I need not follow the case in de'ail, but simply state that, on the

10th Aug., the enlargement of the hock was almost gone, and Lat, in a very short time afterwarls, it became as clean as the other joint. The truss was discontinued on the

" 20 th Aug., when the mare was discharged. Up to the present time there has been no appearance of a return of the affection.

"Remarls. - This is the fourth case I have treatrd sucessfully in this way; and, from what I have seen of the plan, I am quite satisfied it is extensively applicable. The late Mr. Ions, of 
Waterford, many years ago, was the first person who mentioned to me about puncturation with needles: he told me it was a very common practice with him. This case, however, did not fully answer my expetation; and the matter remained unsettled in no mind until I saw in the pages of the Veterinarian a drawing and account of a spring truss for the bock, where the two remedies, puncturation and pressure conjointly, struck me as being very feasible; and now I am quite satisfied that they will answer in many cases. I do not think that bursal enlargements can with safety be opened in any other way than by puncturation with needles."

\section{OPEN JOINT.*}

Open joint, or broken knees, as some term it, is generally occasioned by falling on them; open joint, however, is an opening into its capsular ligament, which may also be made, by accident or design, with any sharp instrument. Cases of open joint very

* Open Joint. - On page 377, No. 67, third series, London Veterinarian, we find a communication from E. Mayhew, (a part of which we submit to the reader,) on the treatment of this lesion:-

"For a long time it occurred to me, that the present treatment of open joints was based upon false principles. What could Coleman mean by the free use of the budding iron, which he both tanght and practised? In the first place, when a knee is opened, the injury does not stop there; we know little of the real state the part will ultimately assume for three days or a week; we must wait till the slough has taken place before we can pronounce a definite judgment of the extent of the wound; then applying the hot iron, even supposing it upon each application to act as the late professor intended, was merely to singe that which must eventually come away. It must, however, be a goodsized budding iron, which is to fit the orifice left, after the vast majority of di ughs have fallen off. But setting aside the folly of that remedy which is if $\mathrm{n}$ use when we most require assistance, did it never strike the adrreates uf the iron, that, if it is sometimes reparative, it is more often destructive in its ugency ? Is it fitir or prudent to employ upon other people's property a remedy which, if its chance of doing good do not answer, is certain of doing serious harm? Yet I say too much, when I allow it has a chance of loing good. Heat an iron to any extent that it may piease the operator, then plunge it into the white of a broken egrg. Iold it within the substance till the iron cools, or is of a dead heat, and then withdraw it. In what condition will the iron be when it is taken out? Yet this is exactly the basis upon which Mr. Coleman used to advocate the use of the badding iron. 'Ihe iron plunged into white of egg will be coated with its coagulation, and the same weapon inserted among Eynoria will be covered with the like product. The substance which was to ha 
seldom occur; the lorse, in falling on his knees, merely lacerates the integuments, and, perhaps, punctures the sheath of the extensur tendon which passes over the linee, from whence synovial fluid escapes, and this is mistaken for the true joint synovia Such an injury, althongh simple: as it may appear, often termi nates in anchylosis of the carpal bones.

Treatment. - Supposing the horse to have just fallen, let the part be cleansed of foreign bodies; then remove all the pendent kin and clip the hair short, (it is of no use to try to heal by first intention - therefore sutures are useless ;) we then ascertain, by probe, if the joint be opened; but whether it be so or not, our first dressing consists of a pledget saturated with tincture of aloeg and myrrh, over which apply a cold water bandage. Rest and a light diet follow. The dressing is not to be removed until suppuration commences, which will be in the course of two or thres days; then cleanse and apply a paste of charcoal and fir balsam, and bandage as before. In cases of open joint with profuse discharge of synovia, add an equal quantity of pulverizeri bayberry bark to the charcoal, and dust the parts frequently with the same, without removing the dressing; for the wound must not be exposed, unless absolutely necessary. We once cured a rather bad case of open joint by covering the chasm with paste formed of fir balsam, powdered myrrh, and charcoal ; over this was placed a piece of lint, and a nicely-adjusted splint was fixed to the back of the knee joint, and over the whole a starched bandage three inches wide and five yards in length.

left behind to serve as a plug will come away, and the injury be aggravated, the bad effects alone being left behind. I know the iron is now recommended for small openings alone ; but there may be a small opening in the first instance, which, when the slough takes place, shall prove a large one; and what can is the ser rics of a remedy which is uncertain in its action, injurious in its appli crizin and which does not provirle for the natural after-consequences? Ther? remains ye. another mode of treatment to be mentioned: this consists simply in mechanically stopping the flcw of synovia, - plicing a cork in the orifice, a 1 have heard it elegantly expressed. Now, as open joint is generally accorupanied by a lacerated wound, a lacerated wound must close by suppuration then, in thus plugging the orifice, they not only prevent the escaj e of synoria but at the same time they lam up the pus. It matters not whether lime, cor cosive sublimate, compourd tincture of aloes, with a pledget of tow and bard ages, India ruliber, or brown paper be used ; the principle is the same." 


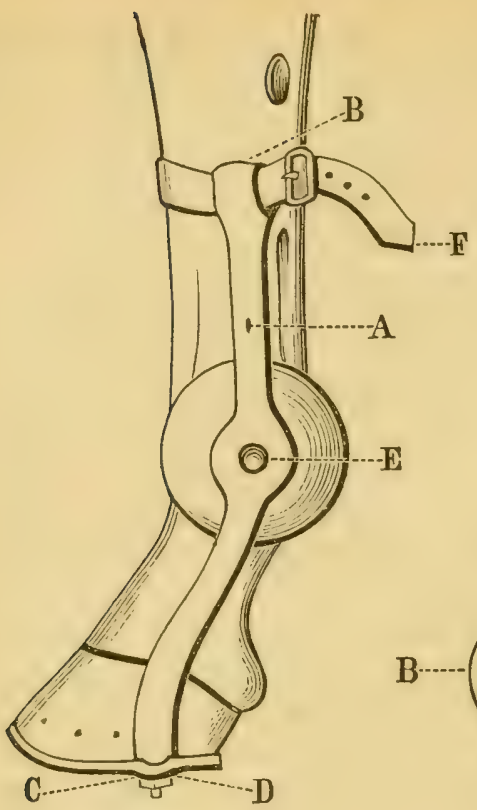

Fig. 1.

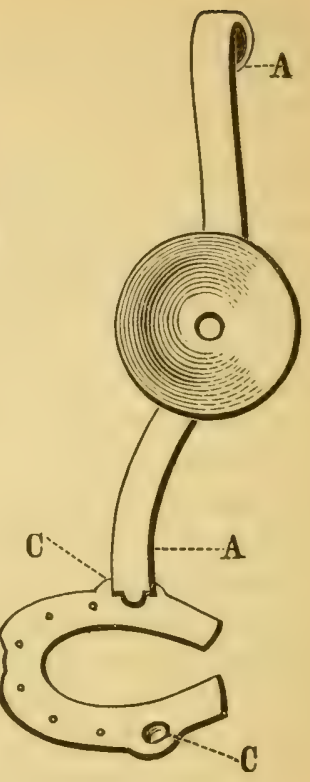

Fig. 2.

\section{APPARATUS FOR DISLOCATION OF THE FETLOCK.}

\section{EXPLANATION OF CUT.}

Fia. 1 represents the outside of a horse's leg, with the apparatus fixed.

A. One of the supporters of the leg, extending from the ground surface of the font to within a little of the hock, made of stoutish iron, curved and adapted to suit the convexity of the fetlock joint; its upper portion, $B$, being rounded and turned downwards, to prevent abrasion, and to form a loop to receive and keep a leathern strap in its place; its lower having a screwed end, which is passed through a hole in the projecting portion, $C$, at the side of the shoe, and firmly fixed by means of a nut. D.

E. A plate of iron, riveted on the supporter, having a convexity on its exter nal and a concavity on its internal surface, to receive the joint.

F. A leathern strap, with buckle attached, to be fastened round the leg.

Frg. 2.

A, A. The corresponding internal grupporter.

B. The shoe, unattached, showing its two lateral projections, C, C, coutsinung holes for the reception of the supporters. 
The bandage remained on for six days; during which time the patient was kept on his legs. On removing the bandage, care was taken not to disturb the lint; some fresh paste was smeared over it, and a cold water bandage substituted for one of starch. The chasm was finally healed by the use of collodion and fir balsarn without bandage.

In slight wounds of the knee, it is sufficient to cleanse the part, and wet, occasionally, with arnica - two ounces of tincture to ono pint of water, accompanied with rest.

\section{DISLOCATION.}

$\mathrm{Br}$ dislocation is meant the displacement of a bone from its articulating socket. The most common accidents of this character occur in the stifle and fetlock joints, although, excepting the elbow and coffin joints, all articulating surfaces in the horse are susceptible of dislocation. In this country, very little attention has ever been paid to the treatment of either dislocation or fracturs, and, in consequence, very many valuable horses have been condemned, or abandoned by their owners for a mere trifle, that might have been restored to comparative soundness. Horses have been known to recover from dislocation of the spine, shoulder, hip, and we have had several cases of this kind, occurring in the stifle and fetlock, that have terminated favorably.

Dislocation of the Neck, or cervical vertebræ, is occasioned by a horse pitching forward, or suddenly falling at a time when his bead is turned in a lateral direction; or he may get into what is termed an awkward fix, across the stall, or under the manger, urable to extricate himself, and thus dislocates the bones of the neck. The diagnostic symptoms are, muscular paralysis, unnatural curvature of the neck; the head at the same time being more or less pendulous, and at a certain point on the convex side of the neck will be felt a space and fulcrum of motion.

The means of reduction are, warm fomentations to the con. cnve side of the nerk, gradual extension, and manipulation. 
The extension, however, consists of little else than slowly and steadily turning the head to the central part of the body, while the operator presses with one or both knees on the most frominent part of the convex angle. The animal is supposed to be lown. and the ordinary precaution taken to secure his limbs in hub. bles or by means of rope. It not unfrequently happens that the muscles on the convex side of the neck are lacerated: in that zuse, eren after reduction, the neck would still incline to an angle: to obviate which, a sort of concave splint must be applied to the concare side, reaching from the angle of the jaw to tha stoulder, being curved and padded at each end, for the recep tion of their respective parts, and then confined by rollers straps, \&c.

Dislocation of the Shoulder is reduced also by extension and manipulation; but, owing to the shallow cavity of the lowes part of the shoulder blade, it is rery difficult to retain the party in apposition; still the animal is not to be sacrificed until means have been tried, which are, continual pressure backward on the head of the humerus. The diagnostic symptoms are, prominence of the head of the humerus, and inability to bring the limb forward.

Dislocation of the Hip. - Very little hopes can be entertained of reducing so formidable a displacement; for the hear of the thigh bone is generally thrown ont of its socket on the pelvis, and the abluctors exert such a powerful force upward that it is almost impossible to counteract them; still we should not de epair. There is a horse now in existence within a few miles of Boston, that, three years ago, slipped on turning a corner, and dislocated the thigh bone, the head of which could be distinctly seen and felt. The unfortuante subject was carried home on a sled; the owner treated him on the hydropathic principle, and left the case to nature, without making any attempts at reduction. At the end of six months, he could hohble aiong pretty well; all that could be noticed was, a prominence on the hip and a shortening of the limb. Up to the present time he has gradually improved, so as to become quite useful in doing light work The means are simple, and the author has no better to iffer 
Dislocation of the Stifle Bone. - If we should believe all the Btories that are told us of horses having the stifle out, the diffi culty would appenr to occur very often, which, in fact, is not the case. We are frequently called to see horses said to have their stifle out, which, on examination, turn out to be sprain of the fetlock, or punctured foot. The error arises in consequence of a lack of anatomical knowledge; for the symptoms of $\mathrm{fach}$ are so different that it is almost impossible for a veterinary surgeon :0 make sush a gross mistake. The stifle joint is composed of the lower end of the femur, upper end of the tibia, and patella, the latter corresponding to the kneepan of man. So soon as the pa. tella - stifle bone - is luxated, the horse is unable to advance the limb; it is stiffened and protruded backwards; and, on exploring the region of the patella, it will be found outside the ex. ternal condyle of the femur. When the bone is dislocated in wards, the limb will be drawn upwards, the animal being unabl to rest on it.

The reduction is effected by bringing the limb forwards and upwards, at the same time pressing the patella towards its original position. After the bone has been replaced, it must be held there until the muscles have regained some degree of contractility. The parts must then be kept wet with cold water, until an infusion of bayberry or white oak bark can be prepared, which may be used pretty freely about the joint for several days.

Dislocation of the Fetlock. - See cut, p. 288. The author has no personal experience in the use of such apparatus delineated in the cut ; yet it is spoken highly of by some veterinary surgeons.

The best method the author knows of for treating dislocation of the fetlock is by means of starched bandages. A dislocation of this joint is easily detected. Its reduction can be effected by any one: a little starch and a narrow bandage, five yarls in length, are all the appliances needed. Rest, light diet, and attention to the patient, complete the cure. 


\section{DIKGADES OF THE SKIN AND SUB-CELLULAR TISSUES.}

\section{GREASE, OR SCRATCHES.}

"The prev"nce of grease is a pretty infallible test of negli gent grooming." - Rercivall.

Grease, or what is t.1ore generally known in the United States as scratihes, is a discine of frequent occurrence. It probably originates, like many otis $\mathbf{r}$ cutaneous affections, in a foul habit of body - a retention of norbific materials in the system, or more properly speaking, casgestion of the superficial capillary vessels. The disease is saij to be most prevalent in the cold months. We know that at thi particular season the function of the skin is more or less inten'.pted; the insensible transpiration, being neither so regular ucr profuse as in the warm months, must result in an accumulati $\mathrm{n}$ of excrementitious material; hence the difficulty.

The cavicy just above the heels of a horse, like that under the axilla, or armpit, of man, is furnisled with a large number of exhalants - secreting and excreting glands; and when the ani mal is in a state of health, and these vesscls in a normal condition, the moisture (if it may be so terme 1 ) keeps the parts soft and pliant, lubricates the external surface., thus preservirg them against friction, irritation, and disease; at the same time the system is relieved from the burden of a large anount of morbid matter. Sometimes the morbid materials are retained in the immediate vicinity of the parts, in consequence of the accumulation of filth on the surface, or from the chilling influence of a draught or cold air on the legs after they have been washed.

It is well hnown that variations of temperature always have $\mathrm{f}$ tendency to disturb, and partially check, the cutaneous exhalations; yet they cannot be set down as direct causes of grease, though they may be classed among the indirect.

Mr. Percivall, in his lectures, thus refers to this disease "The etiology of grease throws considerable light upon its veritable nature. Horses which are at pasture or in straw yards in situations, in fact, where heat and cold are not naturally, and 
cannot be artificially, made suddenly operative upon the heels ravely have grease. Those that have grease in stables aro mostly coach and cart horses, with thick, fleshy heels and white legs; which are subject to get their heels wet, and do not commonly have such pains bestowed upon them, to dry the legs, as hackneys, hunters, and racers have. Indeed, among the latter, grrase is a very uncommon disease. Such horses al o stand in stables hot and filthy from dung and urine, the very exhalations from the litter of which proves an additional excitement.

"Grease formerly made great ravages in the English caralry and ondnance service; whereas at the present day the disease is scarcely known. This change for the better is ascribed to three causes - to proper ventilation of the stables; the greater attention paid to grooming; and to the presence of a veterinary surgeon, who checks, at the onset, such a casual occurrence."

Sainbel, who wrote $A n$ Essay on Grease, for which he was presented with a prize by the Royal Society of Medicine in France, thus commences his paper: "Grease is, in general, a cutaneous, chronic affection; sometimes inflammatory, sometimes infectious, and I have known it contagious. It invades the legg of horses, asses, and mules, but seldom attacks those of the ru minating species. We are told that cow-pock had its origin in the transfer of the matter of grease from the heel of a horse to the teat of a cow, and that the disease may be communicated to the human subject by inoculation with this matter, the same as with that taken from the ulcerated teat of the cow. Some have gono further than this, and said that glanders and farcy could be gen. erated in this way. The accounrs of these strange transactions, however, have made but little impression; for we hear nothing of them nowadays; and that is not a very bad criterion of their want of truth and foundation altogether. I have heard Proftssor Coleman say, that there never was a well-authenticated case of cow-pock being produced from grease; and I verily believe myself - though I do not know that the fact has been experimented on - that there is no truth of its being communicable among horses. In certain seasons and situations, the disease is certainly sporadic, (affecting a few at any time or season;) but then, the causes are too manifestly operative among horse 
under the asme circumstances, to refer its production to inf tiun or contagion."

The reader will perceive from these remarks that proper ventilation of the stables, good grooming, (which includes care and attention to the general management of the animal,) and the knowledge obtained of the laws of animal life and the conditicns requisite for its perpetuity, derived through the medium of the reterinisy art, are the means of prevention best calculated to remedy the evil.

Symptoms of Grease.-In the early stage of grease, the primary symptoms attending common inflammatory affections, viz., heat, tenderness, and tumefaction - are generally present. On applying the hand to the heel and fetlock, the parts will be found hot, and, under pressure, the animal will evince signs of pain; the parts har, a greasy feel, and the morbid matter, which oozes through the tegumentary tissues, has a fetid, unpleasant smell. As the disease progresses, the parts become swollen, - infiltrated with serum of a morbid character, - thus increasing the inflammatory symptoms, and causing the animal much pain, which he usually evinces by occasionally catching up the foot, as it is termed. The offensive matter on the surface o: the heels now becomes more profuse; the hairs stand out horizontally, and sometimes, even a long time after the animal is considered cured, the hair still continués to wear an unnatural aspect. This is owing, probably, to the fact that the disease has extended to the hair bulbs. When the disease attacks both hind legs, the pain is sometimes intense, especially if the horse be plethoric, or his system is charged with morbid humors. In the latter case, the greasy discharge is very profuse; for the pent-uk waste matters have now found an outlet, which, according to principles purely hydrostatic, admit of a free discharge of the fuids of the body.

The symptoms, howerer, thus far detailed, apply to grease in what may be considered a comparatively mild form, as we oftea observe it in horses used for general purposes in this city. In such cases, rxercise and light work rather tend to lessen the swelling and pain than otherwise; and the patient, after having travelled a short distance, under a light load, seems comparativel 
free frum lameness, which, together with odema, again returns after standing a few hours in the stable. If the disease is at this stage promptly met with skill in the application of suitable medicinal agents, it generally yields; but if neglected, it is very apt to nssume the form of a pustular eruption, and, subsequently, granulating excrescences.

During the year 1852, a mild form of grcase, usually denominated scratches, has been unusually prevalent in the New England States; the subjects of which disease, in a great major. ity of cases, were in a state of plethora. In short, there was an svident disproportion between the daily allowance of food and se amount of labor performed, or, in other words. an unequal proportion between the oxygen respired and the amount of carbon (in the form of food) taken into the system at any given time.

Some of these cases yielded very readily to local treatment, while others required active general treatment - a purification of the fluids and a restoration of the healthy secretions.

The disease, after having passed the primary stage, as just alluded to, assumes a more malignant character. Granulated excrescences and an offensive discharge appear. Sainbel compares such granulations to the "outward coat of a pineapple;" and some call them grapes. The disease at this stage affects the general health, more or less; and the patient has sympathetic fever; the appetite is impaired, and other functions, in a certain extent, are perverted. Cases of a very malignant character are recorded by veterinary writers; but the disease is so readily recognized, even by the merest tyro in veterinary matters, that the writer deems it unnecessary to extend these remarks further than to advise those who wish to perfect themselves in this peculiar branch to consult the works of Mr. Percivall.

Treatment. - This will depend somewhat on the stage and in. tensity of the malady, and the state of the patient's health. It is worthy of remark, however, that a great change for the better has taken place during the past twenty-five years. Among those who have been foremost, both by their influence and daily prac. tice, in producing so favorable results, stands the name of $\mathrm{Mr}$ Percivall. In the early period of the history of our art, notwith. standing popular prejudice fave red the ancient barbarous method: 
of cure, this individual advocated a system of medication tem pered with mercy, instead of barbarity. Let the reader under stand, that, in those times, the most inhuman atrocities were perpetrated on the bodies of uncomplaining brutes, and the nost destructive "remedies" were called into requisition, to fill up the measure of their woes; the law of humanity, as applied to the brute creation, was generally disregarded - for it was only until cruelty to animals was made a penal offence that the masse were ratrained in their shameful career of ingratitude. Contrast the treatment recommended by this distinguished surgeon with that of some others, whose chief agents for the cure of grease were, corrosive sublimate, muriatic acid, antimony, lead. \&c., and we are led to exclaim, that a humane surgeon is more to be admired than the hero of a hundred battles.

In the early stage of disease attention must be paid to diet, ventilation, and cleanliness. If the heels are hot and swollen, apply the following poultice:-

Slippery elm, powdered, . . : $\frac{1}{2}$ a pound,
Fine salt, . . . . : 2 ounces.

Mix to a proper consistence with hot water, and when cool, spread a portion on cotton cloth, and bind it on the parts. Should the horse be "humory," or even in "good condition," fat, - a mild cathartic will be indicated, consisting of

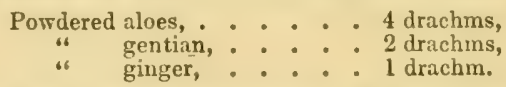

Mix the above (if a ball is required) with honey; or, if it be more convenient to ardminister a drench, clissolve the matss in one pint of warm water, and sweeten with molasses.

On the other hand, if the horse shall be in poor condition, the medicine can be dispensed with, and a generous diet allowed, together with a meal of grass occasionally, if the season permits. If the patient does not improve in condition, we may infer that the disease will not mend until the health is restored; and ic riew of accomplishing that object, we recommend

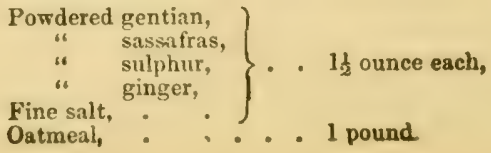


Mix; divide irto twelve parts, and give one, in the focd, 1 ight and morning. In either case, it will not be good policy to continue the poultices for any length of time; for, knowing as we do, from actual experience, that warmth and moisture combined, in the iorm of a poultice, are relaxing, and therefore enervating, and that gruase, in its early stage, is merely augmented issue, the: poultice might have the effect, if repeated, of inviting fluids to the parts. Still the ingredients might be so combined as to poo sess astringent properties. The following is an example -

$$
\begin{aligned}
& \left.\begin{array}{l}
\text { Slippery elm, or flaxseed, } \\
\text { Powdered bayberry bark, } \\
\text { charcoal, }
\end{array}\right\} . \text {. ad libitum, } \\
& \text { " equal parts. }
\end{aligned}
$$

Mix. Perhaps, with the addition of a small quantity of salt and bloodroot, this poultice would form the most proper one in the advanced stage of the disease ; for we are taught that astringents have a tendency to suppress the secretion, and the discharge sconer or later, becomes arrested. After poulticing the parts, as the nature of the case seems to demand, we then endeavor to aid nature in her efforts at restoration, both by local and general means. If, for example, the heels crack, become dry, hard, and contracted, the surface should be smeared over with

$$
\left.\begin{array}{l}
\text { Linseed oil, } \\
\text { Powdered charcoal, } \\
\text { sulphur, }
\end{array}\right\} \text {. equal parts. }
$$

Mix the charcoal and sulphur with a sufficient quantity of oil to make it of the consistence of cream, and apply it to the parts, with a brush, night and morning.

The general means imply a restoration of all the secretions and excretions, by the use of alteratives. The following is a good oxans:je -

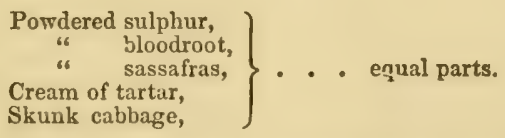

Dose, half an ounce, night and morning, mixed with the food. There is one remedy which the writer has found well adaptea to almost every case of grease, or scratches and it is highly recommended by Professor Morton, of the Royal Veterinary College. It consists of 


\section{$\left.\begin{array}{l}\begin{array}{l}\text { Pyroligneous acid, } \\ \text { Linseed oil, } \\ \text { Turpentine, }\end{array}\end{array}\right\}$. of each equal par s.}

Mix; let the heels first be washed with lukewarm water and castile soap; after wiping them dry, apply the mixture. Repeat night and morning.

In order to keep down morbid granulations - denominatrd hy some "proud fles" - the parts may be sprinkled daily witb one of the following articles:-

$$
\begin{gathered}
\text { Powdered bloodroot, } \\
\text { "6 burnt alum, } \\
\text { baybery bark. }
\end{gathered}
$$

Put on a good coating of one of the above articles; cover the sore with dry lint, and apply a bandage over all. It should be borne in mind that bandages should always be dispensed with, if possible; for they invariably irritate and inflame whatever parts they are applied to. This is owing to the high state of sensibility in the skin of the horse.

\section{HARDENING OF THE SKIN. - (Induration.*)}

Hardening of the skin generally takes place in consequence of pressure from some portion of the harness; it often occurs, however, from laceration of the integuments and sub-cellular tissue; by the calkings of the animal's shoes; and we sometimes find that it is the result of fungus, or morbid growths, after they have been removed by caustics. An excellent application for these indurations is, the acetate of cantharides, prepared thus:-

* Induration is an abnormal increase in the consistence of an organ or part. and may exist under various circumstances. It may be owing merely to a defiency of blood in a part, in consequence of which its denser particles are more closely aggregated, and therefore offer an increased resistance. There are various parts of the animal structure which are often the seat of induralion. The lings, for example, in consequence of previous inflammatory actior, become hepatized this is identical with induration, and is owing to the deporit and coagulation of that portion of the blood known as fibrin. The liver now and then becomes the seat of a fibrinous deposit; the organ first enlarges, but afterwards gradually contracts and hardens: as it is reduced in size, it be. comes uad and tough; here we have schirrus of the liver - induration. Othet varieties of interstitial deposit are nnown to the profession; and the reader. if disposed, can also learn rhat is kuown of this branch of pathology foom stan dard works. 


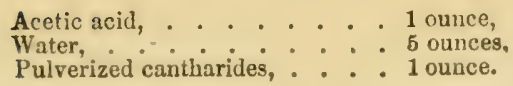

Mix; let it macerate for fourteen days; then filter through linen or blotting paper, and add one ounce of spirits of wine : it is then fit for use. To be applied occasionally, by means of a small piece of spouge.

A preparation which answers the same purpose is composed if equal parts of oil of turpentine and olive oil, to be applied es $\mathrm{ab}$ 've.

\section{MALANDERS AND SALANDERS.}

The above terms are usually applied to scurfy eruptions, accompanied with oozing crusts and cracks in the skin, situated either in front of the hock or at the posterior part of the knee joint. They probably produce some sort of an itching sensation; oceasional pain, and even lameness, have been known to arise from them.

The disease is said to arise from long travelling on bad roads, want of cleanliness, \&c. ; but probably it originates from that peculiar state of the system which favors the production of cutaneous diseases. ${ }^{*}$ The disease does not prevail to any great

* In the treatment of cutaneous affections the readar must always bear in mind the fact, that a local disease seldom, if ever, exists long ere the constitution suffers; and that almost every case of an eruptive nature is either symptoma:ic or sympathetic. But lest we may be charged with uttering sentiments exclusively our uwn, we quote from an article on Disenses of the Skin, by T. Hunt, Esq., F. R. C. S. His extensive practice in the Irestern Dispensary for diseases of the skin entitles his opinions to the highest confilence.

"* * * A local disease can so seldom exist per se, independently of some tasion of the genenal system, that to argue in favor of the constitutional origin or nature of any particular local affection, may seem superfluous. If a chils alis into a tub of hot water, the whole surfice of the body 's blistered - is a local aflection; but how soon do the symptoms show that $t$ is one in wi sh the whole system participates? A carbuncle, an eruption of saull-pox, scarlatina, or measles, and an attack of erysipelas or vesicular fever, are all so many illustrations of the fully admitted truth, that a severe affection of the skin, whether caused by accident or otherwise, involves the constitution in the general disturbance. In the milder forms of skin diseases the general lesion may be less obvious; but from analogy we are bound to conclude that it exist: . If a person be inoculated for small-pox, and but one pustule appears, that pustule is preceded and accompanied by some degree of fever. Nor is it possible 
extent in the United States. The author has :een twc (asea securring in subjects of the scrofulous diathesis, which has led him to suppose that the disease is of a scrofulous character: at any rate, it sometimes depends on internal causes; and therefore, in addition to the local remedies, some sort of medicine of an alterative character must be given. See Alteratives.

The term mulanders is applied to the disease when the fore lega are affected, and salanders when it is located in the hind ones. As both are supposed to proceed from the same cause, the local treatment consists in washing the parts twice a day with an alkaline wash - lime water - or saleratus; and after the part or parts are wiped dry, the following application must be used :-

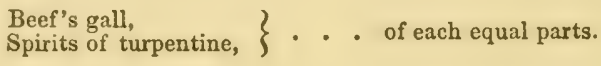

\section{POULTRY LOUSINESS IN HORSES.}

Poultry lousiness, one of the evils of domestication, has probably never occupied much of the attention of horse owners in this country; yet it is important that such should be made acquainted with the facts in relation to it, because a knowledge of them may explain the origin of many cutaneous diseases - attended with loss of hair - that seem to have a spontaneous origin, and at the same time resist the ordinary treatment. It is very necessary

for a pimple to be thrown out spontaneously on the surface of the body without some previous lesion, however slight, either of the solids or the circulating fluids of the system; else we should have an effect without a cause. In like mann r, every cutaneous disease, whether arising spontaneously, like lepra of herpes, or whether resulting from contagion, as scabies or porrigo, either originally or ultimately involves the constitution, more or less obviously, in the changes which are taking place in the capillary syotem. As the brain takes onguizance of every disturbance in the extremities o the nerves, sc the heart reccives and reflects an impression when the minute vessels, however distant from the centre of circulation, become congested or inflamed. In fact, a sympathy exists throughout both systems, and in all parts of the frame; so that cvery part of the body suffers with every member, and each member with the who e borly - the local disease, when communicated from without, becoming the cause of the constitutional disturbance, and vice versa; the genera? eachexy, when it exists primarily, becoming, in its surn, the cause of the lcea wrection 
Also that fowl breeders (who, in a great majority of cases are horse owners) should know that there is such an eril in exist. ence; having, as will be seen hereafter, a well-defined cause oper. ating, not beyond their comprehension, but which, in such cast is invariably present, and cognizant to the perceptive faculties of every thinking man.

In the ireatment of disease, our first business is to discover, an npar as circumstances permit, its cause, and then, if possible. It mn: sve it. In such a case as this, we might treat the cutaneous uffection, but with little credit to ourselves or profit to our $\in \mathrm{m}$ ployer, unless the cause be removed. A writer in thr Rural ITew Yorker thus alludes to the matter:-

"During the early season of my keeping fowls, I had their roosting-place adjoining the stall where I kept my horse, with a partition between. I think it was the second year after I kept my hens in this manner, that I discovered there was something the matter with my horse. He showed a disposition to rub and bite himself; but for a long time I paid little regard to it, thinking he would soon be over it; but it seemed to increase upon him I could fit up no stall nor partition of sufficient strength to resist his efforts. I could leave him nowhere unhitched; and if 1 hitched him, he would soon break loose, and get to some place where he could rub. For six months or more, he continued in this manner, before I ascertained what ailed him. I tried various remedies for humors in the blood, bled him copiously, drenched him with physic till he could hardly stand; and all to no effect. He was a large and valuable horse commonly, but at this stage of matters he was truly a sight to behold. He was minus his mune, and was in nearly the same condition with his tail; his sides lacerated and naked, in consequence of his continual rubbing ard biting. At last the thought struck me that the animal might tie lousy; and, on close examination, I found he was literally roverud with small hen lice; and they adhered so closely to the stin, that it was almost impossible to comb out one with a fine comb. I now changed my course of docturing, and by dint of perseverance, through the applieation of various remedies for the destruction of lice, in the course of six or eight weeks I succeeded in effecting a perfect cure 
"The tirst thing $I$ did after this was to remove my hen roost, and scald and whitewash the stable. I have not been troubled with hen lice getting on my horse since. I have heard of similar cases, where horses hare been afflicted in the same way; hence I consider it safest not to build a hen house behind the stable."

This affection has become so common of late among horses in tl $\mathrm{e}$ United States, and as the majority of their owners are almost in the dark regarding it, we here introduce to the reader an interesting article from the pen of Mons. H. Bouley, translated from the French, by Mr. Percivall :-

"Amongst these there is one, interesting alike as regards its cause, its mode of manifestation, and its treatment, which has been confounded with general itch or mange; to which, indeed, it bears some resemblance, in consisting, as it does, of the existence of a parasitic animal, and which must be destroyed ere the disease will disappear. To this variety of phthyriasis* M. Bouley has given the name of the Poultry Lousiness, (phthyriasis des oiseanx,) on account of the unique cause giving origin to it, as well as by way of distinguishing it from the pedicular $\dagger$ disease peculiar to horses.

"Its commencement is instantaneous. All at once the horse is seized with a riolent, continued general itching. So sudden and irresistible is the desire the animal possesses to scratch himself, that he is not easy for a single moment. He rubs his skin against every resisting body near him, stamps the ground continually, strikes his belly, bites every place be can reach with his mouth; manifesting, by his continual movements, the burning itching by which he is devoured. At night his torments increase; so much so, that should the animal be abandoned to himself, he ruhs and bites himself to that degree, that he tears his skin, and carries portions away in his mouth, denuding himself extcnsively of his scarf skin; nor does he relax until smarting pains succeed the insupportable torments of the itching.

"At the time these symptoms of prurience $\ddagger$ are making their Rppearance, the skin is the seat of an eruption of very small vesi. cles; $\S$ some solitary - others, in greater number, congregate

- Lousiness.

† From pediculus, a louse
‡ Itching.

S Small eruptions containing fluid. 
ccupying more or less extent of surface. These resic. ss contain, at the period of their maturity, scarcely serosity enough to raise the epidermis, * which becomes detached, dragging the hairs with it that run across, leaving behind it a small bare surface, perfectly circular, of the diameter of a lentil, or the smallest silver coin This bare part becomes covered with a crust of dried serosity which soon exfoliates, $\dagger$ and is replaced by a new epidermis, p 5 r fertly smooth.

"'This primary stage of the disease is difficult to meet with because, ordinarily, horses are not submitted to examination vefore depilation has commenced - the sequel of the desiccation of the resicles.

" $\Lambda$ t the second stage of the poultry lousiness, the most pathognomonic $\S$ lesion is the depilation \| consecutive on the vesicular eruption; and this is so characteristic, that, once the disease olserved in its true form, and traced to its cause, a simple coup d'æil $\uparrow$ is all that is necessary to recognize and distinguish it from all other cutaneous affections.

"The depilation is of that remarkable character that it reflects exactly, in the general impression it makes upon the skin, the form of the resicular eruption, solitary or confluent, of which it is the latest vestige. In fact, the surface is marked by regular circular patches, of the diameter of a lentil, giving it the aspect of tiger spots. In places where the eruption has been the most con. fluent, the depilation spreads between the resicles, and so extends orer a considerable patch of surface; but, even in these places, the circular disposition of the denuded patches, the primary expression of the original vesicular eruption, is still maintained in the smooth condition of the epidermis.

"This depilation spreads, like the resicular eruption of which it is the consequence, with very great rapidity. In two or three lays, the Lorse, with the most shining coat, may have it spottrd over with circular patches bare of hair, and in the course of a

- The outer or scarf skin.

+ Separates from the living skin.

\pm Drying up.

\$ A term givea to the symptoms which mark the disease. Lesion means injury.

I. Loss of har.

al Glanco. 
week will the hair and epidermis be destroyed over a large extent, corresponding to the parts where the eruption has been the most confluent. wuch is the rapidity of the depilation that we are but too apt to date the disease back to a long period, when it in, in truth, but of a few days' duration.

"It is only at this stage of the phthyriasis that horses ordinarily come under observation; and therefore does it become difficult at srch a time to assign to the disease any specific character; the resicular kind of eruption serving to distinguish and classify it liaving left no trace upon the skin, save circulatory depilation. Sometimes, at this stage of the disease, sorts of solid papula* form within the substance of the skin, which become crowned with secondary vesicles, whose progress is identical with that of those we have already pointed out, disappearing after the formation and detarhment of the crust succeeding the secretion.

"During the whole of this stage, as at the first breaking out of the disease, the patients are tormented with continual burning itching, causing them to rub themselves incessantly and without relaxation; so that we observe upon the skin, in those places the most rubbed, lesions, which we may call traumatic, $\dagger$ consequent on the violent action occasioned by the bodies against which the animal rubs himself. Those epidermic excoriations $\ddagger$ appear either in series of lines or in broad patches, or in places irregularly circumscribed, according to the regions in which they are found and the nature of the bodies against which the friction has taken place. They are principally remarkable upon the lateral § parts of the head and neck, upon the back and croup, upon the sides and flanks, and upon the internal parts of the limbs. They look either very angry or bloody, when observed immediately afte1 alse rubbing, or they are covered with red incrustations more or less adherent, according to the length of time they have existed; or else they appear in a state of granulation $\|$ and suppuration, whenever the skin has become sufficiently deeply injured. Bus these superficial lesions of the skin do not by right belong more properly to poultry lousiness than to any other pruriginous

- Elevations.

t Like wounds.

I Abrasions of the skin.
\$ Side.

\| Grain-like, theshy bodies 
disease; and so far from being considered as one of their peculiar features, we ought to look upon them as simulating those affections to which they in truth belong, and which they stand in the place of.

"This disease in no way interferes with the integrity of the general functions. Apart from the violent excitement the ani mal may experience, and the consecutive irregularity of his respiration and circulation it may occasion, he presents all the aspect of the most perfect health. When, however, the disease becomes of long duration, the subject of it will be apt to fall off his appetite, to grow thin, and to lose his condition for work from the gralual wasting of his powers. Indeed, there occur cases in which this privation of rest (from continual excitement) brings on complete marasm,* and such inability for work, that the proprietor feels himself compelled to get rid of his horse at any price.

"Such is the nature of this singular affection, whose most striking characters are, the suddenness of its appearance and the rapidity with which it spreads over the entire surface of the skin, leaving every where uniform marks, vestiges of its presence, viz., depilation in circular patches of the skin, and a terrible sense of itchiness, without intermission and with evening exacerbation." †

In order to destroy the vermin, and at the same time to cure the cutaneous eruptions, and restore the hair, take

$$
\begin{aligned}
& \text { Linseed oil, . . . . . } 1 \text { ounse, } \\
& \text { Pyroligneous acid, . . . . } 4 \text { ounces, } \\
& \text { Spirits of turpentine, . . . . } 1 \text { ounce. }
\end{aligned}
$$

Two or three daily applications of this compound will generally suffice. The parts to which the application has been made must be washed with soap and water. The vermin can also be dostroyed by sponging the body with an infusion of lobelia.

\section{RAT'S TAIL.}

Rat's tail is a name given to a narrow streak of denuded hair which occasionally appears on the upper part of a horse's tail

- Emaciation. † Increase in violence ff symptoms 
It generally arises fr om a sort of exanthema, or cutane, us ei up tion, causing an intolerable itching; the horse is constantly rub. bing the part against the side of his stall, and thus the pilous covering is worn off. The remedy is

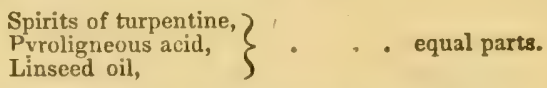

Wash the parts daily, and dress with the above.

\section{HIDE BOUND.}

This term is generally applied to horses whose coats are "staring," the skin tight on the ribs, and otherwise out of condition. The appearance generally denotes derangement of the digestive organs, and therefore can only be considered as a symptom of disease. At times the skin appears very scurfy, and the exhalants of the external surface seem to pour out an unusual quantity of morbid matter, the more volatile parts of which evaporate, precipitating on the surface the more solid par. ticles in the form of thin scales. It gives the horse a very filthy appearance, and requires some care in grooming in order to make the animal appear any thing like decent.

"The condition of the skin and hair," says Mr. Spooner, "will afford a true indication of the state of the health in a general way. 'The horse is unhealthy in his coat,' is a very common expression, and this sign should never be neglected. The hair of a healthy horse is smooth and sleek, and the skin soft and expansive. This is indicated by the touch, as in cattle. When the system is deranged, the skin loses its pliancy, its surface be zomes hard and dry, and the hair, to use another common ex. pression, 'stares on end,' and is rough and rusty. These symp. toms accompany almost every constitutional disease, especially disorder of the digestive organs. The sympathy existing between the skin and alimentary canal is very corsiderable, and it follows, in almost every case, that when either of these become affected, the other takes on sympathetic derangement."

Some writurs on farriery would have us believe that "lido nound results from worms;" and they recommend strong and 
dangerous medicine. That worms should be focind in suck horses we are not surprised; but to set them down as the cauve is absurd; for their presence in the digestive canal is merely owing to perverted nutrition, and they may be found in many horses whose coats are as smooth as glass. The cure of hide bound, then, consists in restoring to healthy action whatever organs are diseased. The general health must be improved ere the coat will assume its natural sleek appearance and soft, pliant feel. If no particular discase can be detected about the animal, let some change be made in the diet, his body be warmly clotherl, and mix the following alterative in his food night and morning:-

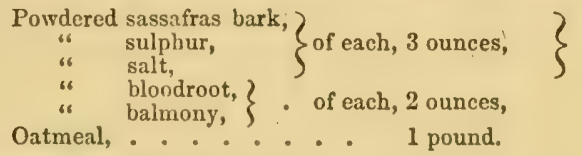

Mix; and divide into twelve parts.

Treatment of cutaneous Affections. - Any system of medicino that contemplates the cure of cutaneous diseases must include change in diet, or it is almost inert. On this subject Surgeon Hunt has written as follows :-

"Man is an omnivorous animal. This circumstance is both an advantage and a disadvantage. It enables him to sustain lifo for a short time on almost any kind of aliment, animal or vegetable; but it likewise induces a necessity of a considerable variety of diet, or frequent change, in order that he may retain health and strength for a long time together. Chemistry has not yet detected the reason of this necessity; and as the proximate elements of animal structure are found in bread and water, as well as in milk and rarious other articles, it does not appear that change should be necessary at all. But it is known to all graziers and feeders of cattle, sheep, and other animals, that clange is necesaary and salutary for them; and much more is it for man. Patients recover under homœopathic treatment, because a rigorous system of diet is imperatively prescribed. 'The system is not founded on any science or principles which will bear a mument's examination. 'The things to be avoided are perfectly harmless and wholesome, but in the very absurdity and btrangeness of the diet prescribed cunsists its value. It is a 
great change. The digestive organs have to pick their alimeni out of a new arrangement of the elements which support animai life, and this new work is refreshing. There is more or possibly less defecation required than before; there is more or it may be dess work gicen to the kidneys than before. Turpid organs are aroused, wearied organs find repose, blood is supplied with less nervous exhaustion, and the brain participates in the relief and vigor of the whole system. Under these circumstances local disease often finds a spontaneous remedy either in the improved condition of the circulating fluids or in the circulation itself, and the whole mystery of this dietetic cure is nothing but the relief of change - just such a relief as is afforded by change of air, change of habits, change of country, or of pursuits. The want of change in diet is obviously a frequent cause of disease in the skin, where it occurs in large boarding schools, where the diet is too simple, plain, restricted, and unvarying, to maintain the system in vigorous health for a long time together. Accordingly a change of diet — the more sudden and violent the better — will generally remove the most of the difficulties in the way of recovery; and if to this be added change of air and change of habits, the muscles of the lower extremities being duly called into exercise as well as of the upper, the mysteries of the case are explained, the inveteracy of the disease is destroyed, and it yields to ordinary treatment, or even to the spontaneous efforts of the system without any medical treatment whatever."

\section{FALLING OFF OF THE HAIR.-(Alopecia.)}

There are various forms of eruptive diseases which induce a falling off of the hair; and these external cruptions which ap. pear on the skin are not always the disease, the real enemy to be overcome, but are oftentimes the manifestations - products or symptoms - of some inte nal affection. So soon as the eruptive disease extends to the hair bulbs, a sort of morbid action commences within them, which loosens the hair, and it falls off.

At times we find small vesicles which are elevated above the okin, often in very considerable numbers; they pour out on the kkin a fluid, which, by the process of evaporation, forms crusis : 
these clusts are sometimes converted into minute ulcers, whick deepen, until they destroy the ruots of the hair. They generally produce intolerable itching, which obliges the animal constantly to ruh himself, and thus destroy the hair. The eruption sometimes occupies a single spot, which soon extends so as to cover a large space; some:imes it appears on the tail, at others on ine neck and on the flanks, whence it gradually extends. This form of eruption is called humid exanthema. There is another form, known as dry exanthema, which appears in the form of small pimples: they soon scale off, and the place they occupied is corered with a farinaceous powder. The animal seems to suffer the most excruciating torment, and is constantly rubbing hinself. The best local remedy for either case is, -

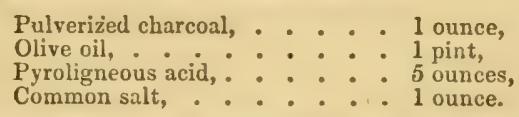

Mix, and lubricate the parts daily with a sponge.

The internal treatment should always commence with small doses of sulphur, sassafras, and bayberry bark, given occasionally in the food. For further information, the reader is referred to article Poultry Lousiness.

\section{RINGWORM.}

Ringworm presents itself in the horse in the form of circular, and sometimes irregular, patches denuded of hair, having on their surfaces a morbid secretion, and incrustations of the same. It generally locates on the sides of the neck, and occasionally on other parts. We have never seen any thing on the subject in dmerican books, and presume there are but few who ever suspect their horses to be subject to ringworm. In fact, the author would have been in the dark regarding it, had he not seen an article on the subject, written by Mr. Percivall, who was the first to call the attention of English veterinarians to it. Since reading Mr. Percirall's account of it, we have come into possession of Mr. Haycock's Veterinary Homoeopathy, and there find a case, which, for the bencfit of the reader, we here introduce. 
"Case. * * * The driver informed me that for several days past he had observed the horse to rub hinself a good deal against the sides of the stall - a practice which he was not ir the habit of doing; and that he had also observed upon various parts of the skin a number of raw-looking spots of a round form. 'The horse at the time was in excellent condition, and in good health in every other respect.

"Present State.-1. The skin of the animal presents a $f \in w$ round and raw-looking spots completely denuded of hair ; they are present on both sides of the neck, and also upon the skin of the left cheek.

"2. Upon the skin on both sides of the neck, upon the superior part of both shoulders, upon the back, in the region of the lumbar vertebra, and particularly upon the hind quarters, are a number of peculiar-looking spots or patches, each of about the size of a shilling.

" 3 . The appearance which these patches present is somewhat as follows: Some of them are round, while others are of an irregular form. The hair in connection with them is of a dirty gray color, and it appears as though a portion of fine dust had been placed upon it, and then a gummy fluid had dropped anongst the whole, and, being allowed to dry, had become incrusted.

" 4. If the fore finger is placed firmly upon any one of these patches, and at the same time forced forwards, the incrusted mass slides, as it were, away from its matrix, and a raw surface is exposed to view, which, if examined with a common magnifying lens, a number of pits, or cavities, are observed, some of which are filled with purulent matter; while running, as it were, around these carities, is a red continuous line of variable thick ness.

"5. The incrustations I found to consist of the hair aggluti nuted together, from the presence of a gummy substance excreted from the diseased part beneatlı."

Treatment. - Wash the parts with a strong infusion of bay. Serry bark, wipe dry, and then smear the denuded spots with a nixture of 
The washing ard dressing to be repeated until heallhy action ts established. If the disease does unt readily disappear, give

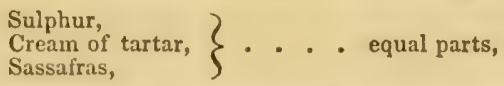

Dnse, six drachms daily. If the disease still lingers, sporige the denuded parts with tincture of muriate of iron.

\section{SWELLING OF THE LEGS. - (Anasarca)}

This is a species of dropsy, which shows itself in the legs of horses; and sometimes the tumefaction extends to the sheath, and along the abdomen, as far as the pectoral muscles. The swelling generally appear's towards morning, after a night's rest, and disappears again after a few hours' work.

Ordinarily, the hind limbs are the most prone to become ana garcous; except in cases of effusion inte the whole cellular tissues of all the limbs - such as we observe in general dropsy, or when the subject is laboring under an attack of intluenza, "pink-eye," \&c.

Cullen enumerates five species of ancasarca, viz.:-

1. Anasarca serosa; as when the due discharge of the serous or watery matter of the blood is suppressed, de. 2. Anasarca oppileta, as when the blood vessels are considerably presied during pregnancy, dc. 3. Anasarca exanthemata; this hitppens after uleers, and various eruptive disorders. 4. Anasarca ancemin happens when the blood is extremely poor, from considerable losses of it. And. 5. Anasarca debilium; as when feebleness is induced by long illness. The last three are the kinds we gener ally have to contend with in veterinary practice

Anasarca exanthemata appears simultaneously with farcy, (or Jisease of the superticial absorbents, and in various cutane ous eruptive diseases. A swelling sometimes appears in the fower parts of the legs, (which feel hot,) and occasions to the ammas a sense of itching, and an acute pain, whenever the part receives pressure; although at other times there appears little or no pain. At length a serous filuid discharges itself through the cutaneous vessels, or pores of the skin, corroding the skin, and tinally ends in the liswase termed "grease." 
Anasarca anæmi happens in horses that are bled at certain seasons of the year, under the foolish notion of improving their condition; also when repeated bleedings have been practised for the cure (!) of inflammatory diseases. In such cases, there exists a morbid habit of body, and the serous fluids are apt to migrate from tissue to tissue, so long as this common morbid habit continues; unless the fluid accumulates within the thorax, the ventricles of the brain, or abdomen; then the case will terminate fatally.

As the oedema swelling (a synonyme of anasarca, grenerally used to express this kind of swelling) is confined principally to the legs, absorption may be promoted by friction and bandages At the same time, the patient must be put on a course of medicine, with a view of restoring the general health.

The following compound, if accompanied with generous feed, friction, and bandage, will be found efficient:-

Pulverized assafotida, : : : : $\frac{1}{2}$ ounce,
Cream of tartar, $:$ : 1 ounce,
Powdered gentian, : : : : 2 ounces,
Ginger (African), : : 2 ounces.

$R \cdot b$ the ingredients together in a mortar, until they are mixed; then add four ounces of finely pulcerized poplar bark, (populus (remuloides,) and divide the mass into six parts; one to be given every night in the food.

Anasarca debilium, which often accompanies chronic disease, must be overcome by invigorating the constitution with tonic medicines, such as gentian, goldenseal, and balmony; and if there be languid circulation, stimulants may be proper. In this event, we resort to grains of paradise, ginger, and capsicum. The diet, too, must be nutritious. Regular exercise, such as the patient can bear, must not be neglected. The proportions of the absre compound are,

Powdered goldenseal, " goldenseal,
" balmony, (snakehead,) $\}$. of each 1 ounce,
bseed, ..... $\frac{1}{2}$ pound.

Mix ; and divide the mass into six parts, and give one, uight and morning, in the food.

In order to excite the absorbents, so as to remove the fluid effused into the cellular tissues, it is sometimes necessary (beside 
resorting to friction) to use the following liniment, which nusy be rubbed on the legs every night:-

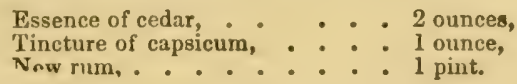

Another:

$$
\text { Spirits of hartshorn, : : * } 2 \text { ounces, }
$$

nlive nil, . . . . . 8 ounces.

\section{Alix together.}

The stimulants referred to may be given in the following propurtions :-

$$
\begin{aligned}
& \text { Powdered grains of paradise, . } 1 \text { ounce, } \\
& \text { " capsicum, . . . . } \frac{1}{2} \text { ounce, } \\
& \text { “ ginger, . . . . . 1 ounce, } \\
& \text { " slippery elm, . . . } \frac{1}{2} \text { pound. }
\end{aligned}
$$

Mix ; divide the mass into six parts, and scatter one on cut feed, night and morning.

It may be well to observe, however, (for fear the reader should make a mistake, and consider a case of scarlatina, scarlet fever as one of anasarca) that simple malignant disease of this type, so well known to our race, does (though somewhat rarely) attack the horse; in either form of which - simple or malignantswelling of the legs more or less prevails. There are some fraures in the latter malady by which it may be distinguished from every other form of disease.

Swelling of the belly, sheath, and breast arise from effusion of fluid into the cellular tissues of the parts, and are nothing more nor less than local dropsy, and consequently can be treated in the same manner as anasarca.

\section{STINGS OF BEES.}

Many rases are on record of horses dying in consequence of un attack by an army of bees. There may, possibly, be no $\mathrm{L} / \mathrm{lp}$ fir such cases; yet we cannot witness the excruciating torments under which the poor animal lahors. without striving to do something for its relief. When the stings are not very numerous, immediate relief may be obtained by lubricating the parts with $\|$ mixture of 
In more aggravated cases, the whole body must be first sponged with lime water, and afterwards smeared with linseed oil. Tho patient must be drenched with eight ounces of epsom salts, and be kept on scalded shorts. If lime water cannot readily be pro. cured, a weak solution of saleratus and water may be substituted.

We have found the above preparation (olive oil and lime water) a most valuable exterual application for allaying the irriLition of the skin after a horse has been stung, or bitten, by some of the various tribes of winged insects. The relief which the application gives is remarkable, and in many cases it acts instintaneously. The remedy is much used in human practice, by the most distinguished of the faculty, in severe burns and scalds, and it never fails to mitigate the pain of the unfortunate sufferer. More prompt is it to act on the horse; for of all the oleaginous compounds known to the profession, not one is so readily taken up, or absorbed, as linseed oil: you may give a dose internally, and in the ccurse of a few hours it will have pervaded the whole cellular strueture of the animal, and can even be detected on the sclerotic membranes of the eye, by merely applying a piece of clean linen, which on removal from the eye will have both the peculiar odor and greasy appearance of the article. Hence an article so highly diffusible as this has proved to be, must have advantages over many others used in the same view. Among the many cases recorded of horses being stung by bees, we select the following, translated from the Réc. de Méd. V'ét., by the editor of the Veterinarian. The case occurred in the practice of M. E Clichy, V. S. "Of the five horses attacked by the bees, one was dead on M. Clichy's arrival; while the four others, which had been withdrawn from the scene of the accident with considerable difiulty, after having cut their ropes, were in an extraordinary stiste of exasperation. One three-year-old horse, particularly, of very strong constitution, when turned into a loose place, became go outrageous that approach to him was impossible. Under continaal agitation, he lay down and rose again incessantly, or he threw limself against the walls of his ab.ule, and t.re his flanks He was deaf to the voice of the man looking after hin, and under extreme excitability; while the eyelids were so swollen as to completely cover his eyes; his respiration, laborious from agita. 
tion, was rend red yet more so by the tumefaction of his nostrily. No treatment could be put in practice, and he in a short time died.

"The three others, though difficult of approach, received some trcatment. They were less agitated than the one deceased. though their symptoms were the same. In addition to oppreseed breathing, and full, strong, and very quick pulse, they had injected membranes; pupils dilated to an extraordinary degree; the burders of all the natural apertures swollen; the tongue larger than usual; exhibiting black spots, from the stings sticking on the mucous membrane.

"Treatment. - Dry frictions, to eradicate the stings implanted into the skin; frictions with ammoniacal liniment; bloodlettings from the jugulars. The blood appeared thick and black, and quickly coagulated. Injections were thrown into the mouth. All the horses died.*

* And that such a result should happen we are not surprised. Only think ! a horse suffering the most intense agony, - the surfaces highly injected, and a housand fold more sensitive than at any other time, - is now to be submitted to dry frictions! This is similiu similibus curantur with a vengeance. A high state of infammatory action is to be auginented by dry friction. To be charitable, we remark, that such may not be the object of the practitioner; but ths practice must produce such result. For example: Let a person, on a chilly day, seat himself sefore a comfortable fire; he soon feels a glowing sensation all over the body; the oxygen from the fire stimulates the nerves of the exposed parts, such as the face and hands, and the blood mounts up to the latter with a rush. How has this been accomplished? Not so much by increased arterial action, as by excitation of the nervos sensibility, which always invites an alllux of blond, and raises the sensibility of a part by means of the mutual relations existing between the capillary and nervous systems. In this stite of primary inflammatory action, what is to be done to reuluce it? Are we to urder the person to give his face a sound rubbing? The reader will see the inconsivtency of such an act; and in the case of the horse, he laboring under inftamma. tory accun ul eien a more aggravated nature, dry friction, which increases irritation, must be conducive of more harm than good. Among the many reasons we may urge against bleeding a horse after being stung, we just alludo to one; and that is, that the blood is not at fault - that the pain arias from rerveus infuence. The blood has no other purpose in the economy of the horse than to convey nutrition into the neighborhood of parts where it is wanted. If too much accumulate in a given part, it is owing to some irritant; remove or lessen the irritation, and thus allay nervous excitement, and the pain ceases. If ever a horse is to be relieved when suffering from the exciternen: and pain described above, it can only be accomplished by some such lubricating agent as just recommended. 
"Post Nortem Examinations. - In all of them a great quantity of stings were found sticking in the skin, especially ar sund the nose, eyes, mouth, ears, anus, flanks, sheath, and internal surfaces of the thighs. The borders of the natural orifices were much tumefied; excoriations about the body from frictions and blows. Some of the horses had their teeth broken. Besides which, there were to be seen infiltrations un ler the skin, and sub-cutaneous collective tissue in different parts, especially where the bones wero projecting, where there were stagnations of blood."

Bleeding revar relieves stagnation.

\section{CUTANEOUS ERUPTION AND ITCHING.}

A rery slight eruption of the skin will sometimes cause violent itching. There are various forms of this disease, but they are only varieties of the same condition, and require nearly the same means of cure.

Treatment. - Changes in diet, according to the condition of the horse, will often cure a simple case without any medicine. If it does not yield to this, let the animal be sponged daily with a weak ley of saleratus water, into which throw a little sulphur; and give a few doses of sulphur and sassafras, equal parts. Dose, one ounce daily. The covering of the body, which may be needed in consequence of sponging, should be linen, instead of thannel.

\section{MANGE.}

Mange is a disease to which man, as well as a great variety of animals, is subject; although when occurring in the former it is generally denominated itch. It is known to be a highly contagicias disease, and therefore an infected animal should be located by himself. Various opinions are entertained regarding its nature: the most popular opinion is, that it is dependent on the presence of animalcula - minute insects - to which Mr. Percivall gives the name of mites, or acari. Our own opinion is, that the mites are the effect, and not the cause; that they are generated in the metamorphosis of the cuticular tissues. Poverty and insufficient food have been assigned as among the causes of mange; but this cannot always be the ease, for we know that it often occurs 
in horses that have been well fed, and it occasionally oceurs in dogrs that eat a large quantity of aninal food. It probably origi nates more frequently from deranged digestive organs than from any other cause: uncleanliness, without doubt, may give rise to it, but it occurs in dogs that have the very best care and attention as regards cleanliness. In fact, the author is so well satisfied of its digestive origin that he never attempts to cure it without consticutional, as well as local, treatment.

Treatment. - Before making any application to the skin, let tho animal be sponged all over the body with lime water; after the skin becomes dry, anoint it, by meaus of a sponge, with

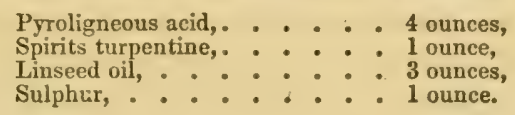

Mix. To be well shaken when used.

Medicine. - Take sulphur, cream of tartar, sassafras, and powdered mandrake, of each two ounces; rub them together in a mortar. Divide the mass into twelve parts, and give one night and morning in the fodder. It is necessary also to make some change in the diet, and by all means avoid musty grain and ground meal, while treating the disease.

\section{CRACKED HEELS.}

This is a very common affection among horses in this country, and is often attended with considerable lamenes. It may be considered in the light of local plethora, or congestion of the capillaries. If they have existed any length of time, an offensive discharge sets up, and the surrounding skin becomes tender, and the limb tumefied; sympathetic fever then sets in; the animal lcsiss hic appetite, and falls off in flesh. Cracked heels may be treated on the same general principles as recommended ander article Grease or Scratches; which see. It is necessary at tines, in order to keep the edges of the crack in contact, to apply a soft pad wetted with Turlington's balsam, and encircle the parts with a narrow roller. To relieve pain, apply a tent moistened with sulphuric ether: 


\section{ACUTE IRRTTATION OF THE SFIN, BY ClIPPINף.}

In the Elements of Teterinary Homoopathy, written by Su. geon Haysock, we find an article on acute irritation of the skin. The author takes to himself the credit of being the first to call attention to the subject: be that as it may, he has earned for himself the thanks of all those who have "a heart to feel another's woe," by giving pr.blicity to his views on this subject.

When we come to take into consideration the irritation and pain some men suffer, who, after allowing their bearks to grow ling, cut the hair off close to the skin, we can then realize thist horses must also suffer from the practice of clipping. This can be explained on the principle, that the hair at its base, or insertion, is much more unyiehling than at its remote point, (if the hair be long,) and therefore, if the hand or blanket be rapidly passed over the short hair, considerable resistance is met with, and a greater degree of motion is felt in the sensitive tiscues that enclose the bulb and radicles of the hair; consequently, a repe. tition of the practice, or from the act of grooming, acute irritation is often the result.

Another reason for the irritation may be assigned. The hair is described as small, cylindrical, transparent, insensible, and elastic filaments, which arise from the skin, and are fastened in it by means of small roots. Being cylindrical, therefore, it is very reasonable to suppose that by cutting off the natural coat of hair at its base, where its calibre is of considerable magnitude, we exposo un immense surface of highly sensitive tissue, which, in reality, may be compared to stripping off so many, minute particles of akin. The stimulating effects of an impure, or even a pure, atmosphere on the interior surface of the hair bulb is injurious. We often hear men complain of taking cold, and experiencingr a feeling of slight pain or irritation at the same time they take cold, probably partly from this cause, and partly from the removal of the pilous covering of the head. The symptoms, as described by Surceon Haycock, are: "Acute irritation of the skin is characwrized by a general soreness of the entire surface. If the obsinver attempts to place his hand upon the body of the animal, 
It shrinks away with great fear. Sometimes the soreness is so very excessive that it is langerous to hastily approtch the poor brute; he will kick and resist handling in every nossible way in which he can. The skin is dry, and the hair feets very dry and harsh to the touch; in some cases, a great number of elevations will be found upon the skin in the region of the neck, the breast, upon the inner surfaces of the fore limbs; upon the haunches under the abdomen; and around the hind limbs, from the stifle joints to the houfs. The appetite is sometimes very much impaired, and the pulse becomes increased in the number of its beats; but, generally speaking, neither the appetite nor the pulse is much affected. Sometimes, again, it is associated with swelling of the limbs and chapped heels, and also swelling of the sheath in horses.

"I will here select a case which will furnish the realer a good example of the form and conditions under which it is generally presented :-

"November 11, 1850. I was requested to attend upon a pony, the property of J. Battles, Esq., solicitor, in this town.

" History, \&c. - The animal in question is about twelve hands two inches in height, of a black color, and well bred. About a week ago it was clipped, and in the course of four or five days after the operation, it was observed to shrink very much if the groom or any one attempted to handle it; and this morning it was found so much worse in the above respect, that I was requested to attend it.

"1. The pulse and respirations are normal.

" 2 . The appetite is by no means good. It eats a little now and then; neither does it partake of much water.

"3. The dung is dry-looking and scanty, and the urine seanty and thick.

64 . It is very much afraid of being handled. If I attempt to loy my hands upon it, it retreats to the far end of the stall, and gathers itself together.

"5. Upon the skin in the region of the neck, also be tween the inner surfaces of the fore limbs, upon the sides of the abdomen, under the abdomen, upon the haunches, and around the hind limbs, are a great number of hard elevations about the size of a sinull nea. 
"6. The fore limbs are swollen from the knecs downwards, and the hind limbs from the lock downwards, and within the bollow of the heel of the right fore limb is a deep crack or fissure which stretches across the shin, and discharges an offensive mat. Łer; the left heel is also slightly chapped.

"It is difficult to accurately determine the cause of the attack in the present case, unless it arose from the sudden exposure of the skin. Previous to its being clipped, it was perfectly healthy; and since then it has been regularly used and fed as before, while the weather has remained, upon the whole, very fine, (considering the period of the year) during the last six or eight days."

The treatment in this case was homcopathic.

Treatment. - We might with truth say " no clipping, no treatInent;" for, if acute irritation is the result of clipping, we have only to discontinue the practice, and that is the end of the matter. But Dame Fashion is such an arbitrary slut that it is no sort of use to oppose her mandates, especially when they receive the sanction of her millions of votaries; therefore we must prescribe something to mitigate the sufferings of the poor victim that has been thus deprived of his natural clothing, and made the subject of unnecessary torture. A simple alkaline wash may possibly answer every purpose. One ounce of saleratus to half a bucket of water will be sufficiently strong: indeed, we do not know but sponging the body twice a day with cold water instead of the former - which should be so used - might have a good effect. If, however, the patient is uneasy, irritable, and feverish, in short, has the usual symptoms of sympathetic derangement of some ono or more of the functions, then give the following:-

$$
\begin{aligned}
& \text { Ca tor oil, } \\
& \text { Tincture of aloes, : : : : : } 8 \text { ounces, } \\
& \text { Essence of peppermint, : } 2 \text { ounces, }
\end{aligned}
$$

The groom should be careful to use a soft brush, and dispense with the currycomb; and, as it is customary, and perhaps judicious, tc clothe the animal, whether exposed or otherwise, the blanket should be lined with soft linen, and when not in use must be spread out to dry.*

" "If the owner," says Haycock, "cannot suffer a long coat of hair, an" will have it shortened, ho must never allow the ho: se to be motionless hile b 


\section{SWEATING.}

"My horse sweats easy," is a common complant anorg hurst swners; and as such view it in the light of a peculiar disease, the practitioner must be prepared to prescribe for such cases. 'The, suceating secms to be the feature most regarded, and if that can only be made to disappear, our employers are generally satisfied ulthough they are not always solicitous to learn the real cause of it.

Let us; therefore, in as brief a manner as possible, inquire into the causes of increased transpiration of the fluids of the body.

A large quantity of watery vapor is continually passing off from the body of horses, and it may be very considerable, although not sensible. If the atmosphere be warm and dry, it readily abforbs the cutaneous exhalation, so as to pass off unolserved; but on a dimp day, when the atmosphere is highly charged with vapor, - almost to saturation, or completely so, - then the exhalation from the surface is there condensed so as, occasionally, to give the horse an appearance of being in a profuse sweat. Under these circumstances, the amount of condensed perspiration depends on the warmth, dryness, and motion of the surrounding air.

The motion of the atmosphere has considerable to do with carrying off the insensible fluid. Many of our readers must have observed that a horse will dry off quicker, and of course sweat

is wet or exposed to a cold blast. He must have a good groom and a gond stable. Those who have both seldom have a horse that requires clipping; but when clipped, he must not want either. A long coat takes up a deal of moistue, and is dificult to dry; but whether wet or dry, it affords some refence tr. the skin, which is laid bare to every breath of air when deprived of its natural covering. Every one must know from himself whether wet clotning ai:d a wet skin, or no clothing and a wet skir, is the most disagreeable and dainger ons. It is true that elipping saves the groom a grent deal of labor He $\quad:$ in dry the horse in half the time, and with less than half the exertion which a long coat requires; but it makes his attention and activity more necessary, fur the horse is almost sure to take cold if not dressed immediately. When we.ll llothed with hair, he is in less dnnger, and not so much dependent on the care of the groom. These observations contain the whole rationale of clipping, and show it, is inapplicable to farm horses; and as country grooms are usually qualified, clipping would prove but problematically beneficial to the saddle of $\mathrm{h}$.ruess hol se of the farmer." 
less, in a draught of air than in a damp stable, where there is no current.

As no evaporation from the skin can, thereture, take place while the atmosphere is loaded with vapur, and as the perspiratory glands still continue to pour it out on the surface, it: must ineritably produce an appearance of profuse sweating. In sueb cases, the reader will perceive the absurdity of dosing a horse; for Ilse conditions under which the fluid is poured forth are peculiar ic all animals whose skins are not covered with scales or plates. Physiologists teach us that the purpose of this watery exhalation, a'url of its increase under a high temperature, (for it does increase under the scorching rays of a noonday sun, whether the horse be drawing a load or not, ) is evidently to keep the lieat of the body as near as possible to a uniform standard. By the evaporation of fluid from the surface of the skin, a considerable quantity of heat is withdrawn from it, becoming latent in the change from fluid to vapor, and this evaporating process lessens the temperature of the whole body. Were it not for this all-wise provision, neither man nor horse could ever endure the rays of a tropical sun; neither could they sustain any high degree of heat for any great length of time without injury to the vital tissues. Carpenter informs us that the perspiration contains a small quantity of solid animal matter, most of which accumulates on the surface: this is - at least should be-removed by the brush and currycomb. Besiles, there are other secretions of the skin which are mingled with it; and there is good reason to think that this excretion is of much importance in carrying off certain substances which would be injurious if allowed to remain in the blood. 'This re. aves confirmation from the fact known to all grooms, that huritur horses, as they are termed, have an abundance of scurf on their hides, and require constant grooming to keep them any ining like decent. We here see the circumstances under which eraporation and condensation take place, and have learned something as regards the object of cutaneous exhalation in its normal or healthy aspect.

We are now prepared to investigate the causes of abnornal exhalation. And this takes place at various times, subject to the preenaing provisions, under several forms of disease; yet of itsclf 
it cannot be considered as such. It is sometimes indicative of pain irritation, Scc. A horse, for example, has an acute attack of gasiro-enteritis, -- inflammation of the stomach and Lawels; - he seems to sweat so profusely that the water runs from his boly in large Irops; the pain, together with the muscular efforts of the wamal, angment this secretion; and thus augmented, it helps to cool our patient and lessen inflammatory symptom\%. Iu such sase, and in many others of an acute character, occurring in a plethoric subject, sweating is decidedly beneficial: it is prostrat. ing, no doulst; but as the object of every practitioner in the treatinent of acute disease is to prostrate by some means or other, sweating is a valuable process, in view of cure. Ilere again we need not prescribe for sweating.

We, however, ofien find horses of a weak, washy constitution laboring under some chronic form of disease, that cannot perform mere ordinary work without getting into a perfect luther. Such are proper subjects for veterinary skill, not in view of prescribing anti-sweating medicine - although it prove so, by restoring the animal to health, - but for the purpose of treating the real malaly. If successful, the sweating will disappear.

A horse must be expected to sweat on a sultry day, especially if he shall have imbibed large quantities of water. The sweating, however, is beneficial, and often wards off an attack of founder or rheumatísm.

Profuse perspiration in the last stages of dissolution is a feature only regarded as a symptom, and therefore it is useless to prescribe with a view of putting a stop to it. For these and other reasons which might be presented, sweating cannot be considererl as a disease.

Sweating often relieves the system from disease, by liberuting, though the suritum, morbid matter; so that if we were to suppress the cutantous exhalation by proviling for its exit thrugh some other depuratory surface, disease of some sort is very liable to succeed.

There are four depuratory surfaces - the skin, lungs, digestive burface, and kidneys: each is continually eliminating materials, many of which, if retained, would prove injurious to hoth man and anirnals. 
But exposed as domestic animals are to such varie'ies of atmospheric changes, it seems natural that some provision should be made, for change or diminution of function. And thus we find that, if a horse in a profuse sweat is suddenly exposed to a current of cool air, the mouths of the exhalants close, putting a surdden stop to transpiration: the result would be disease, and probably death, (which now and then does happen,) were it not that the fluids recede to some other surface. When the kidneys are itg receptacle, it palsses off by the urinary organs ; when it recedes to the digestive surface, a diarrhœa is the result. Shculd the lungs be called upon to perform the extra labor, copious expectoration is the result. In each of these cases disease is very apt to follow, and therefore under no circumstances whatever should the cutaneous exhalation be checked. If an animal is laboring under any form of disease, prescribe for that, and let him sweat.

\section{WARTS.}

These excrescences, arising from the cuticular covering of the skin, are sometimes very annoying to horses, especially when occurring about the eye, sheath, penis, or on parts which come in contact with the harness.

Warts are so familiar to every one, that it appears umnecessary to enter into any description of them, other than to remark, that they are at first composed of fibrin, which ultimately becomes cartilaginous.

Trertment. - A wart having a broad base should be treated in tl e following manner: Take a common suture needle, and arm it with a double licature; each ligature is to be composed of bhree threads of sadller's twine, well waxed; pass the needlo right throngh the centre of the wart, close down to the skin; tie pecil half separately, with a surgeon's lnot, as tight as possible; cut the ends off pretty close to the knot, and in the course of a short time the whole will drop off. A wart having a small circum. scribed pedicle may be removed in the same way, by tying a single ligature round its base. If the exposed surfaces should not heal rearlily, moisten them occasionally with tincture of aloes und myrrh; and if they show a disposition to ulcerate, spricklo 
then with powdered charcoal and bloodroot. equal parts. Warts ubout the sheath or penis should be removed by excision: to de this, we often have to cast the animal, the consequent hemor. rhage to be arrested with tincture of muriate of iron or styptic. See Styptic.

\section{CONSIDERATIONS AND EXPERIMENTS RELATING TO CONTAGIOUS DISEASES.}

"Prevention is cheaper than cure."

In these remarks M. Magendie's object has been to examine into the channels through which deleterious substances find admission into the animal economy.

"Respiration is the principal one. Through it we are continually exposed to the action of gases, vapors, emanations, virulent and caustic poisons, germs and seeds, the ulterior development of which may entail mortal results. The majority of stibstances thus introduced are of a nature to alter the composition of the blood, and disturb its vital operations.

"The vapors have diver's chemical compositions. Some there are which have the power of quickly extinguishing the nervous energy ; and although not many of them possess this fatal property, it no less becomes our duty to inquire into their mode of action. At the head of these we must place prussic acid, a substance so volatile that it condenses while evaporating. Magundie illustrated this by experiment. He mixed, in a conical ressel, a portion of medicinal prussic acid in combination with three fourths of alcohol, and one fourth of the acid. He then took a rabbit, and held its nose to the mouth of the glass ressel. so that it was fully exposed to the vapor rising fro $m$ the mixture. The animal became conrulsed, and in a few secunds died. In this case, the blood of the rabbit became impregnated with the gas of the acid, without the pulmonary vessels being involved. The lungs are constituted of a myriad of tubes, whose mem. branous walls, being extremely thin and porous, have the property of being permeable to vapor. The vapors arising rom the hlood in the same manner pass out, constituting the pulnonary 
trauspiration. This may be plainly seen by introducing 1 os ihorus into the blood. As soon as the blood containing if arrives at the luugs, it escapes by respiration, the animal breathing opaque white vapors, consisting of phosphoric acid, which inflames in contact with air. This contiuual evaporation is nc hinderance to the air coming in contact with the blood circulating through the pulmonary capillary vesseis. What is without may pass into the blood, and vice versa.

"These phenomena command the utmost attention from mediral men. It is of the greatest importance to know the composition of the air we respire, since so many diseases are in this manner produced; and though we with difficulty arrive at any certain knowledge of the miasms rising in marshy grounds, from the decomposition of putrid vegetable and animal matters, there can be no doubt whatever of their entering into the blood, through the inedium of the air, and so producing grave disease. In some countries especially, such affections rage with extreme intensity; in hot, humid climates, and particularly on the sea coast and borders of certain rivers, as, tor instance, the Gulf of Mexico. Vera Cruz, New Orleans, \&c. Such causes of disease admit of demonstration; since, by introduction of them into the blood, experimentally, may be produced, though not exactly the yellow fever, symptoms bearing the greatest resemblance to it, with black vomit and speedy death. Lower Egypt, where the plague formerly prevailed so alarmingly, owing to such causes, has been rendered comparatively healthy by the improved condition of the country.

- What we observe in such insalubrious countries and situationg abroad as these, is apt but too often to present itself in our disEecting rooms at home. In spite of every precaution to disinfect such places, and retard the putrefiction of the bodies in them, every year we have a certain number of dissecting pupils seized with the low fever calied at the present day typhoid.

"A very curious experiment has served to show the facility with which miasms enter the blood through the respiratory passages. For a long time it has been the opinion of M. Magendie, lhat the pulmonary mucous membrane did not extend through the extreme ranitications of die bronchi, - an assertion rebutted 
by several anatomists, on the score of the murous liniags of canals extending throughout these cavities, - and that, if t.re pul. monary membrane could not anatomically be proved to do so, it was on account of its extieme tenuity. In proof, howerer, that bij opinion was well founded, M. Magendie experimented witk a virulent poison called woorara, which was known to tal.e no effect on mucous surfaces, but to pass through the stomach and i:testines unaltered in its properties, although, when placed in rontact with a vascular surface, the snitlest particle of it ucca. sions instant death. With this he sneared the interior of the bronchial tubes without producing any effect; though when he reduced the poison to very fine powder, and contrived the gradual introduction of it into the air cells, where it underwent solution, then its poisonous effects became manifest, furnishing confirmatory evidence of M. Magendie's theory of their anatomy. A proof, as has appeared all along, that respiration is the principal and the most common channel through which miasms enter the blood, is, that animal matters, in a state of putrefaction, iutruduced into the stomach, do not prove destructive. Some carnivora - the dog and the wolf - are fond of putrid tlesh Certain men have the same craving. There are some who live on human flesh; and we know, by many, game that is called high is preferred to that which is fresh.

"If human industry has for a long time made us aequainted with the means of neutralizing the effects of putrefaction, the stomach has ever possessed this property in an eminent degree; and this, doubtless, is the explanation of our being able to eat viands in a putrid condition. M. Magrendie has made this the subject of some very curious experiments. Fiften griais of bluod in a state of putrefaction, giving off ammonia and sulphu. reted hydrogen, was injected into the jugular vein of a dog. 'The effect was, great disturbance of all the functions of the brain, the virculation, and locomotion; and the animal died in twelve hours. Ifere death conld not be owing either to the ammonia or the sul. phuretted hydrogen contained in so small a quantity of blood. A second experiment is, introducing underneath the skin of a dogr a comple: of drachms of putrid water, in which stale fish had been. The simg e absurption of this proved suliticitu: to bring 
on rapil death. In both these cases, after death the lungs proved greatly injected; the blood within the large vessels was deep black and hardly coagulated, and much resembled currant jelly. Frequent repetition of these experiments led the learned professor to the conclusion that, whenever putrid matter in any quantity is introduced into the system, the blood losing its characteristic properties, and becoming unfit for circulation through the lungs, death ensues.

"With a view of ascertaining if the gastric juice possesses ary influence in counteracting the deleterious effects of putrefuction, M. Bernard, after having contrived to obtain some of this juice through means of a stomach fistula, mixed it with an equal quan tity of putrid blood, leaving them together for eighteen hours, and then injecting the mixture into the jugular vein of a dog. The animal giving no signs of having felt any thing amiss, the conclusion was come to, that gastric juice was endowed with the power of neutralizing the deleterious action of the putrid ferment. Spallanzani had already shown that gastric juice was an antiseptic: this observation shows more - that the same juice has the power of robbing putrid matters of their hurtful qualities.

"Under certain conditions putrid miasms prove highly active These conditions are, a sufficient quantity of the miasm, an elevated temperature, and, we must add, individual susceptibility.

"We readily understand that, for the production of the diseaseit is necessary that the miasm should exist in sufficient quantity. spread about in the air, and that the air reach the lungs sufficiently saturated for it to become introduced into the system. The heat \&lso, at the time, ought to be perceptible and continuous. Yellow fev $r$ does not prevail in cold seasons. It is in countries where the air is warm and humid that putid fermentation actively proceeds and acquires all its baneful properties M. Magendie, in his experiments, found that more putrid matter was required to take effect in cold than in hot weather; in addition to which, every individual has his peculiar insusceptibility, (resistance propre.)

"So that the cause of discase called, not without reason, putrid, is to be sought in the introduction into the cir :ulation of putrio. 
matters, le they in the liquid form, or in that of gas or vapor." Lectures delivered to the College of France, by M. Magendie.

\section{MELANOSIS.}

Melanosis exists in the form of tumor or tubercle of ar irıęu. lar shape; and when cut into, presents a sort of black cclor There seem to be two kinds - one located in visceral orgaus and in the eye; the other generally locates about the tail and under the common integument. Gray horses are more subject to it than those of any other color. The only treatment known to the author is, extirpation with the knife.

Extirpation of two Melanotic Tumors from the Body of a Horse, while uncler the Influence of Chloroform.

History of the Case, \&c. - The subject, a gray stallion, aged nine years, the property of D. Iamlin, IIarrison Avenue, was observed, about eighteen months since, to have small tumors, occupying a space known as the humeral region, (below the shoulder blades.) They had gradually increased in size; yet, as the horse was performing his ordinary duties without the least inconvenience, very little notice was taken of the matter, and the owner considered the swelling as nothing more than an "eyesore." Latterly, however, the horse had been used in the shafts; and either in consequence of bruise, or friction from the shafts, the swelling had rapidly increased in size, so as to interfere with the normal action of the shoulder; in consequence of which, our adrice was sought, and after an examination, we proposed an operation, to which the owner consented.

Operation. - Friday, November 4, 1853. The patient was cast, off side up. Dr. Fletcher Oakes, of this city, kindly consented to superintend the administration of chloroform. A sponge, being saturated with two ounces of this article, was enclosed in $n$ suitable breathing apparatus, and thus applied to the patient's nostrils. The quantity used during the operation was three and a half ounces. The pupils of the eyes being dilated, and stertorous breathing having commenced, a straight incision, of eleven inches in length, was made over the regrion occupied ty tho 
tumors ; they were then dissected from their sulo-cellular ar d mus cular attachments. The blood ressels cut during the operation being nerely sub-cutaneous ramifications, it was not thought necessary to employ liratures; and the horse lost but a trifling amount of blood. The wound having been clenused with cold water, its edces were brought together by interrupted sutures, and fincly dressed with compound tincture of myrrh. The horse was shortly afterwards led to his stable.

Description of the Tumors and their Location. - The first was o? an ovoid form, measuring seventeen inches around its short diameter, by seven inches in length, and weighed four pounds. On making a straight incision through its centre, it presented a black, pitchy appearance, and was composed of a somewhat dense, fibrous body, containing within its meshes a thick fluid, resembling coal tar, which left a black stain on the scalpel and fingers, easily removed, however, by water. This tumor was situated on the off side, in the "posterior inferior" region of the shoulder blade.

The second tumor was of a similar form and character, and occupied the sprace inmediately below the former; it weighed a trifle over one pound. The large tumor was firmly imbedded in cellular tissue, and also had a slight attachment to the common integument - its base being united to the intercostal muscles.

Subsequent Treatment. - The wound made by the incision had done well up to the fifth day; when, probably in consequence of an itching sensation, which usually attends the restoration of diseased parts, the animal's attention was directed thitherward, and for the relief of which he commenced rubbing himself against the Btall: this mancuvre was, no doubt, rather pleasant than other Fise; his owner, however, happening to look in about this time, put a stop to it, and rewarded our patient with a dressing He was then secured to the middle of at wide stall, by means of a halter on each sille, and left for the night; during w aich he broke loose, and by means of his teeth tore out every stitch, and laid the wound fairly open. Next morning it presented a frightful looking chasm, from which was issuing a mixture of blood, pus, and serum very profise and somewhat fetid; yet rotwithstandng this intrrmption of the healing process, the hor:e is so far 
recovered as to be able to go to work - just four wieks after the operation.

A twitch having been placed on the horse's nose for the pur. pose of directing his attention from what followed, the edges of the wound were again brought together by stitches, leaving at the base an orifice for the discharge of morbid matter. The parts were then dressed with a compound of aloes and myrrh; a compress of linen, saturated with the same, was applied, which was kept in position by means of a bandage encircling the ches. The dressing was renewed once in twenty-four hours until the third day, when a profuse dicharge of healthy pus having taken place, the pad and bandage were omitted. About this time the off fore limb became infiltrated, - dropsical, — attended with slight sympathetic fever; for which he took

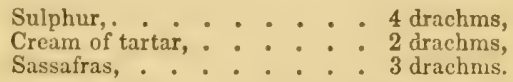

This was given as a drench, in thin gruel, for three successive days, with decided benefit. The cure was completed by the frequent application of equal parts of linseed oil and pyroligneous acid. The dict consisted of hay and scalded shorts, until the patient was able to take exercise; when his regular allowanco was served out.

\section{DISEASES OF THE HOOF AND LAMINE.}

\section{OBSERVATIONS ON THE HORSE'S HOOF.}

Tre external covering of the foot may be divided into four parts, viz., the wall, or crust, the bars, sole, and horny frog. The external portion, named crust, is adapted as a defence to the sensitive parts within. It is composed of small filaments, or hollow subes, consolidated in such a manner as to preserve their canals distinct. These canals constitute the exerementitious outlets of the hoof, through which morbitic or waste matters make their exit: and in them may also be found the ressels by which the 
horn is secreted. The small vessels arising from the vascular and nervous membrane beneath the hoof, which is considered as a continuation of the true skin, enter also into these canals. The small vessels alluded to, technically called papilla, possess the properties of sensibility and conductibility. They are formed frotn cells, and have an allotted function to perform, for which, is their healthy state, they are all-sufficient, and for which no other class has or can perform without derangement to the parta

The bars are a continuation of the external portion just de. scribed. They form an angle at the heels, which terminate towards the toe. They serve to give strength and durability to the hoof, prevent contraction of the heels, and thus aid the hoof in protecting the soft and sensitive parts. The internal portion of the bars presents the same appearances as that of the crust They are held together by vital affinities, and so long as they maintain their normal integrity, the foot will preserve its form.

Next in order is the sole. It is considered to be more elastic than the crust, and is the medium of the sensitive faculty, through which, togrether with its powers of elasticity, the percussion of the foot agrainst the ground is regulated.

The horny frog is still more elastic than either of the parts deEcribed, and any unnecessary "paring," on the part of the smith, is to be deprecated.

On the internal portion of the parts just described we find a beautiful set of lamina, resembling those found on the under part of a mushroom: their number is said to be about five hundred. which articulate with a similar number given off from the coflin bune. Each lamina, having two sides and an edge, forms a series of articulations, numbering about three thousand! The wholo

- The nails of man correspond to the hoof of a horse, for they are formed it a substince analogous. If we examue me nail under the microscope, wo shall fird that it consists of hard, transparent, and somewhat elastic plates, which althere to the vascular and nervous membrine of the papilla. The latter are arranged in lungitudinal and parallel rows. The internal surface of the rinil, like that of a hoof, is soft. pulpy, and marked with longitudinal grooves and prominences, corresponding to the lamina found within the hoof. A sic ilar arrangement, possessing, however, exquisite seusibility, is found on that portion of the finger covered by the nail; and, by this nutual adaptation, the conrefetion between them is sustained. The nails are a continuation of the true skm 
presents a surface of four square feet. Hence the borl; of a horse rests upon sixteen square feet of surface within the hoof.

The hof, we have already observed, serves as a defence to the sensitive parts within. It varies in size and thickness according, to the age and condition of the animal. Its texture may be rendered hard or soft by the judicious application of therapeutiugents Its conformation may be altered, for better or worse, by proper attention to the laws of animal life, stable managcment, and skilful shoeing.

When we see a poor dumb brute driven, hobbling along on three legs, to the nearest blacksmith's shop, with a view of discovering the seat of lameness, and there subjected to the incuisitorial process of pinching, we have almost wished that the poor horse could exchange places with his tormentors. If the cultivators of human medicine had adopted this brutal methorl of diagnosing a disease, it would have been natural to suppose that they were qualifying themselves as butchers.

Some people seem to suppose that a horse's foot is as insensible as a stone; and when we see the smith wrenching off the shoes, often bringing away a portion of the hoof with them, and cutting off large pieces with as little care as a man would trim a log, then applying a red-hot shoe to the part, without any regard to the feelings of the animal, - under these circumstances it would appear to justify the conclusion that the foot is, really, insusceptible to feeling.

Many of our readers have, probably, had occasion to deplore the present barbarous system of shoeing. Dear-bought experience may have taught them a lesson which they are not likely to forget. The Hen. M. P. Wilder, in a letter to the author on this suiject, remarks, "I know of no greater evidence of inhumanity to that noble animal, the horse, than the almost unirersal custom of paring down the foot and burning on the shoe. It has ever, to my mind, been among the barbarisms of the age, and which I trust will no longer be countenanced by civilized society. I sympathize with your efforts to correct this, and other equally'

* Which ccnsists in grasping the foot between the points of a pair of pincers, and applyisg them vigorously to every part of the hoof until a teraler spot is found, (pr:duced!) 
dangermis practices, in the administration of destructive med cines; and I hope your efforts will be crowned with success."

\section{TREADS AND OVERREACHES.}

A tread, or calk, is an injury inflinted on one foot by the "calkin" - or, as often happens, the edge of the shoe-nn another foot, producing a contused wound, which is often troublesome to heal. This sort of injury differs from any incised wound, inasmuch as it is a sort of bruise by which the surrounding parts are lacerated and violently torn from their horny attachments, and the wound, although simple in appearance, is of such a complicat? nature that it often requires several weeks to restore the parts to a healthy state.

The treatment consists in allaying irritation, removing the dead parts, and promoting granulation. We first apply a poultice of carrots; then, with a pair of scissors, remove any partlyseparated portions of skin or hoof. The wound is then dressed with Turlington's balsam. We generally, however, first sprinlile the chasm with a portion of finely-pulverized myrrh: this subftance forms a coating over the newly-formed granulations, and protects them from injury.

In the winter season, a calk, unless attended to early, often becomes a serious affair. During the past two years, a foot disease of a very malignant character has prevailed around Boston. It sometimes appears without any apparent cause, except sligi t febrile symptoms; at others, a calk seems to be the exci ing cause; the disease speedily extends ahove the coronet and within the hoof. It is a species of inflammatory gangrene, and is grnerally attended with sympathetic and occasionally typhoid fevers. The best local remedy is, a mixture of pulverized cliar. coal and fir balsam; the constitutional treatment accorling to the nature of the case.

Whenever a horse is calked, the chasm should be clenased and fi'led up with fir balsam. 


\section{DUARTER CRACK. - (Fissure in the Quarter of the Iloof.}

All horsemen understand what is meant by qua ter crack. It consists of a loss of continuity in the fibres of the hoof, leaving an. opening through its substance. It generally occurs in the fore although often in the hind feet. A fissure of this kind is not con. sidcred of much :mportance; yet, after the cure has been effict ed, there remains a cicatrix, which is, by some horse deal. ro, looked upon as an eyesore; and they often refuse to purchase au otherwise perfect animal solely on this account.

If the crack be only a simple fissure, and does not extend to the sensitive parts of the hoof, there is no perceptible lameness; hence, when such a fissure is first observed, it should be at once attended to, in order to prevent lameness, which, however, is generally slight. For causes and treatment, see next article.

\section{TOE CRACK. - (Fissure in the Longitudinal Fibres of the Fore Part of} the Hoof.)

The hind feet are generally supposed to be the seat of this defect, yet it very frequently occurs in the fore feet. When it occurs in the hind feet, or foot, there is generally considerable lameness present; and the subject has frequently to be laid up for a few days, or else perform his lahor with a lobbling gait, very distressing to himself and mortifying to his driver.

When the crack extends from the coronet down to the toe, and a complete division of the horny fibres takes place, so that the sensitive lamina are exposerl, a discharge of small quantities of blood, and finally of matter, talies place. The subjert is then, of course, too lame for work, and must have immediate attention.

Causes of Quarter and Toe Cracks. - The fact that the parts do crack, would go to show that there must exist some brittleness in the hoof. This may arise from two causes: first, from a want of healthy action in the nutritive and secretory vessels of the foot; secondly, from the common custom of rasping the wall of the hoof, and otherwise mutilating the foot in shoeing.

Still it may arise from contraction of the parts, from a narrow 
heeled shoe, from congestion and deep-seated disease within the livof. In short, any sort of work, management, or system of shoring, that tends to dry up the naturai moisture of the foot, may be considered a direct cause of contraction. Predisposing causes may also exist in breed. It is well known that some animals are foaled marked with the parent's deformity - con tracted quarters, for instance; and such are, more especially than others, liable to quarter crack. This affords a reason why horses, not predisposed, escape the evils alluded to, and others not enumerated; as in, for instance, a dry, sandy country, on shipboard, or in hot stables with dry floors.

Mr. Percivall says, that "greater attention to shoeing and in sreased care about the condition of the hoof itself have, no doubt, liad very beneficial effects in the prevention both of contraction and quarter crack." The same author thus alludes to the causes of toe crack, or toe sand crack, as English surgeons term it. "Toe sand cracks are caused by violence. Shoeing, also, may have something to do in its production. The horses, which are the subjects of it, are those which are employed in laborious or straining draughts. The toe of the hind foot is the grand fulcrum through which the hind limbs, the propellers of the body, exert their power; and it is in some violent and forcible effort that the hind hoof, strained as it is to its uttermost, and particularly at the toe, splits, commonly first at the coronet; the same as in the fore foot, where the horn, but newly formed, is thin and unresisting; the crack subsequently extending gradually down the wall, even as far as the point of the toe.

"Diggring the point of the toe into the ground, or stampling it hard down upon the parement, (and especially when this stress upon the fore part of the wall is at all times promoted by high walkins to the shoe, must certainly, one would think, be the main producer of toe sand crack - an opinion still further favored by the observation which has been made of shaft horses in drays, beingr more subject to the accident than trace horses. Still, however, for all this, it behooves me to say, that with the best judgrs of such matters, the point is one not yet tree from doubt and difference of thinking. Short and upright pasterns, with clubby prominent hoofs, indicate a predisposition to toe 
band crack: the disease being in no instance seen in flat, shelvy, nblique hoofs.

"It is said sand cracks may originate in tread. Undoubtedly, any lesion of the coronary body sufficient to injure or destroy its secretory apparatus, may occasion imperfect or morbid secretion cf ' lorn, or loss of form altogether; but I do not believe this to be a very common cause of sand crack."

Treatment of Toe Crick. - It is generally customary in this lart of the country to call in the aid of the blacksmith to repair at toe crack, which he does in the following manner: if the fissure is only a partial one, that is, commences a short distance helow the coronet, and only extends part of the way down the wall, a red-hot iron, having a sharp edge, is drawn across the upper and lower parts of the crack, and sometimes down the crack itself; with a view of destroying any morbid matter that may exist in the fissure. A crack fixed after this fashion is called cross firing. If the fissure extends from the coronet right down to the toe, two or three pieces of wire are passed through the edges of each half of the hoof, through holes drilled for that purpose, and the fissure is thus riveted together. The operation requires some skill on the part of the blacksmith; for if he should bore the holes too deep, the sensitive lamina might be included, and thus protract the cure. Some physicians recommend encircling the hoof with waxed twine, instead of riveting, with a view of restricting any tendency to expand at the toe, when, by its pressure on the heels, it might favor their contraction, and therefore cannot be of much use. Of the two, we should prefer riveting, if performed by a skilful workman.

But why not close the crack by interrupted sutures, after the following fashion: good substantial waxed threads answer the same purpose as iron rivets, and are far preferable, because they can be sc easily removed after having fulfilled their intention. We have made but one trial of this kind. The case turned out well; still a single experiment is not sufficient to establish its superiority over other methods.

The best practice would be, first, to poultice the toot, (supposing the shoe to have been removed,) with a view of softening the now and removing any extraneous matter that may have insinu- 
ated itself into the erack. When the ho is sufficiently softened it should be cleansed, examined, ard diressed with tincture of myrrh. Select a spot about an inch below the coronet, and with a small gimlet bore a hole through the two edges of the crack, and another one inch above the toe. A straight needle, armed with a strong ligature, is to be passed through the upper loles, brought orer and through a second time; thus closing the two e Iges of the fissure by what the sailors term a "round turn." $\mathrm{Tl}$ \& eame thing is to be repeater at the toe. The assistant, by the aid of pincers or otherwise, shuts the crack as close as possible; the ligatures are each drawn tight, and tied with a surgeon's knot. A small quantity of blister ointment is to be smeared over the crack, and bar shoe applied. A quarter crack may be lreated in a similar numner, omitting, however, the sutures.

The cure is accomplistred in two ways - first, by fusion; secondly, by the growth of new hom from the matrix downwards. After the edges have firmly united, cut the ligatures, and pare the uneven edges of the cicutrix level with the surrounding parts, and the cure is completed.

\section{QUITTOR.}

Quzttor is a fistulous opening running between the sensible and insensible lamince of the foot; the opening, or sinus, runs in Iarious directions downward; at other times, the lateral cartilages are in connection with it, and become diseased. It generally makes its appearance on the insile of the foot, near the matrix of the hoof. In such case, its origin is from bruise or wound. It arises also from pricks in shoeing, gravel, negle ctud 'orns, \&c. Should a nail enter the sensitive laminæ of the fouts und canse suppuration, and the lower outlet become plugged up. the matter moves upward, burrowing through the tissues, until it gains exit above the hoof. This is a true quittor. A disease of this chancter is often rery difficult to heal, unless attended to in its early stage; and a practitioner gains but very littls ercolit in suring such, because he has been so long about it. It frequently happens that we not culy have the quittor to con terd with, but considerable tumefacton and morbid enlargement 
in tile parts above the hoof, against which the horse is apt to strike the other foot, and thus excite persistent inflammation, leaving a denuded, uneven, sanguineous sore, very difficult to heal; for if the animal does not bruise it with the other foot, he lacerates it in lying down or getting up. If we attempt to procect it from this sort of injuries, our only resource is bandage; and we have remarked, in another part of this work, that bandages do not agree with horseflesh, when applied to denuder surfaces; therefore such cases require considerable tact and patience.

Treatment. - We first examine the sinus by means of a smallsized, flexible bougie, such as are used on young persons. Being flexible, we are enabled to trace the cavity, whatever direction it may take. Having discovered that, we make up our mind as to the treatment. Should it descend towards the sole, it is caused either by prick, corn, or gravel, which can be ascertained on careful examination. In order to make such, we remove the shoe pare the foot, and perhaps poultice it, with the double ohject of softening the hoof and removing obstructions to the lower outlet, if any there be. Whether the cause be evident or not, we waste no time in injecting the sinus, (which is practised by inany,) but make a small opening in the sole, as near the base of the sinus as possible, and invite a discharge from it by means of a poultice placed only in contact with the sole. A free discharge once secured from the lower outlet, we have no fears of a cure. So soon as a discharge sets up, inject from below strong tincture of bloodroot, two or three times, and then sprinkle some bloodroot in the cavity; there is no need of any bandage; let the matter have free vent. The upper orifice will now clos: ; it is only necessary to moisten this region with compound linc ture of al, ses, or some other traumatic.

We have tried all manner of ways to cure quittor, and find thire is nothing like making an opening below the sinus. A bad case, however, will generally require time, and some variation in the treatment, according to the nature of the case. We must uot, in our attention to the foot, overlook the horse; his liealth must be attended to; an occusional dose of alterative medicine (sulphur and sassafias) may be given, and the common allowance 
of food shorld be lessened. When the sinuses are superfic:al, and do not extend beyond the coronal region, injections may be tried: among the most efficient are solution of alum, zinc, and sulplate of iron; tincture of muriate of iron, and tincture of bluod. rout. In some cases, however, the knife will be required.

\section{PUMICE FOOT.}

Pumice foot is an aggravated form of convex sole, attended with a morbid condition of the parts and laminal dislocation We now and then see an aged animal, which has long been the subject of chronic disease on the fore feet, presenting actual protrusion of the coffin bone, forwards, between the wall of the hoof and sole; and the bone is of a spongy character, studded with crystallizations, composed of phosphate of lime, \&c. The disease also occurs in animals that have led a sort of fast life; that have been trained for the course ere they had attained maturity; pampered and fed on highly nutritious grain, and driven at times beyond endurance, until a morbid labit is firmly established, which may affect the feet either directly or metastatically. The pathology of pumice sole, says Mr. Percivall, amounts to this: "In sonsequence of inflammation in them, be that inflammation acute or sub-acute, the sensitive laminæ, from causes which have already oven detailed, become detached from their union with the horny laminx, and the coffin bone, losing its ties of suspension, is pressed down by the weight upon the horny sole, which, unable to bear the burden thus unnaturally transmitted to it, bulges, and either immediately or some short time afterwards bursts, and tets the toe of the coffin bone, with its covering of sensitive sole, through its Lreach. This, and this state of foot alone, it is, either actually present or impending, which properly constitutes pumice foot. Flat feet, nay, even convex and fleshy feet, do not of themselves amount to pumice, but, on the contrary, may exist independently of it. They may be, and are, dependent upon altered states of the hoof alone; whereas pumice foot consists in disorganization of the interior economy of the foot; in altered structure and rela. ive situation of the parts within the hoof, and in partial escapo of then. 
"Pumire Sule can have but one Origin. - Its existence is de monstrative proof either of the presence or of the preexistence of laminitis, in the acute or sub-acute form. Those dovetailed and intimate bonds of union between the sensitive and horny laminx which hardly any amount of mechanical force can, in sith rend asunder, gradually lose their hold under the action of inflammation, and let the coffin bone down upon the horny sole. This, as we have seen, may result either from acute or sub-ncuto laminitis, but with these notable differences, - that, whereas, under acute inflammation, pumice foot is rapid, sometimes sudden, always decided in its occurrence; under sub-acute inflammation its approach is tardy and stealthy, and for some time doubtful and indeterminable. Indeed, in the latter it often happens that tho sinking of the sole is the first intimation we obtain of the presence of the disease. The horse may have been observed to step short or gingerly, compared to his usual style of going, and this is succeeded by tenderness of tread to that degree that continuance at work becomes impossible; under which circumstance we are callu to examine his feet, and to the surprise, probably, of the owner, find the soles either actually sunk or showing unmistakable signs of sinking. Pumice sole resulting from acute laminitis is, as we have seen, though at all times a lamentable affiir, a more complicated and serious one still, from its so frequently having suppuration of the foot as an accompaniment; and when this proves to be the case, all prospect of remedy may be said to be at an end. It is not so, however, in the case wherein pumice foot follows a sub-icute or low kind of inflammation. Here there is not the tendency to suppuration, but rather to adhesive action; and this it is that on occasions invites us to take the case under treatment, and now and then we succeed in restoring the integrity of the breach and soundness of the sole. But this, I am reluc tartly forced to add, is but a rare issue, compared with the stateo of pumice sole which defy our art at effecting such restoration of them as will render the feet again useful for work.

"The Treatment of Pumice Sole - when the sase happens to be of such a nature as to inspire us with hope through judicious and careful manargement of it - obviously' presents to us two ab. jects for consideration; the first being the healing of the w'sund 
and closing of the breach in the sole to which it owes its exiot ence; the second, the elevation of the coffin lone, and its adjust. ment, as far as we can, in its natural position. I say 'position,' for as to forcing up the bone into its proper place again, of course that is a matter entirely out of the range of possibility. Whien once complete separation of the lamine has taken place, no power we possess can restore their union; indeed, nc means can be employed to effect so much as we may be able to accomplish to. wards the raising up of the bone before we have completely restored the integrity of the sole, and made the part where the breach existed sound and firm, and able without pain to bear pressure.

"For the Healing of the Wound, the continued application of poultices will be found beneficial so long as any annoying inflammatory action is lurling about the foot, and so long as the wound itself puts on a healthy aspect, and seems disposed to granulate, or actually is granulating. But whenever such is not its character, and particularly when its surface looks pallid, and the circulation through it appears languid, stimulating and detergent dressings ought to be substituted for the poultices.

"Of the various Kinds of Dressings in ordinary use for the purpose of promoting the healing of foot wounds, and their subsequent coating by a suund secretion of horn, none are found to answer well, unless they be, through some suitable contrivance, firmly bound upon the ulcerated surface, so as to give as much pressure to it as the animal can bear. Pressure to the extent of producing pain is injurious; but the utmost degree short of this is uniformly found to be attended with the happiest effects. In short, wi.hout concomitant pressure, the most extolled dressings will sultom prove of much avail. If the hoof be cool, and it is con. cidered that a light shoe can be worn without hurt, providing it be put on with small nails driven through parts of the crust alsle 1c: bear the concussion of the hammer and to hold such nails, great adrantage will be derived from it, inasmuch as it will afford very convenient means for employing such pressure at is fornd so salutary and effectual. This is to be mantaged by obtainingr l:wo or more pieces of iron hooping, cut into lengthe to achnit of being placed diagonatly across the sole, and of beinc confored in that 
Eituation through their ende being driven for stays between the web of the shoe and the sole. 'They should be so placed as to cross each other opposite to the part where the dressing is, that being previously covered with as many thicknesses of tow as become requisite for the necessary pressure. After the hoopiron stays are arranged so as to give firm and steady support to the tow underneath them, they maly be, at the point of crossing, well hammered down upon the foot ; an operation which will sed ves to accommodate them more completely to their situation, at the same time that it operates in giving additional pressure, which will be maintained when the foot comes to be set upon the ground by the standing of the horse upon the compressed dressing.

"In regard to the best medicament to apply, providing the exposed parts of the sensitive sole be - as they commonly arein a healthy condition, stimulating applications agree best, and no one in the class exceeds in efficacy the ol. terebinthinæ. 'This, under the influence of pressure, will generally of itself bring about all we desire; though, should any change of dressing be deemed desirable, we may use either tinct. benzoin cō., or tinct. myrrhæ cō. Should any signs of unhealthiness or malignancy - a rare occurrence - make their appearance, escharotic stimulants, such as solutions of copper and zinc, and even of mercury, might be employed. An astringent, such as solution of alum, or a detergent in the form of chloride of lime, may also occasionally be required.

" Having succeeded in healing the wound and causing the br each to be covered orer with sound though soft horn, a dossil of dry ton well pressed down will be all that will be further needed to keep the dirt and wet from the parts, and to harden and prepare them for being finally stopped and protected from injury when the lorse shall be permitted to take exercise or go to work. The now formed sole being now sound and tolerably firm and hard, should a shoe have not been nailed on the foot befure, now is the time for one to be put on; and the shoe hest for such a descrip. tion of foot is that which will, either of itself or thrcugh additions made to it, enable us to give that amount of pressure upon the sole which is founi to be so requisite for the purposes of support and uplifting of the descended coftin bone, to the extent possible 
into some proximity to its original place. Whether we really possess any such power as will effect this, may very properly be made the subject of doubt; but that we can, by pressure and support to the sole, prevent any further descent of it, should that appear likely to happen, is beyond a question. A broad-web shoe - such a one as Plomley's of Maidstone - is a good one for this purprse; and this should be plugged internally with stopping, intermingled with tow, the two together forming a compressible pillow, upon which reposes with ease and firmness the as yet tender sole of the foot. Over the stopping and tow should be placed, and nailed on with the shoe, a stiff piece of sole leather. Or, which some prefer, after the shoe is nailed on, a piece of gutta percha, cut of smaller size than the circumference of the shoe, may, after being softened in hot water, be kneaded in upon the sole, over the stopping, with the thumb, and pressed around the edge sufficiently underneath the web of the shoe to maintain its hold. With his foot thus shod, and cushioned, and protected, the horse may return gradually to hard work.

"Instead of the broad-web, heavy shoe, it may be advisable, in a case where $t$.e foot is thin of horn and the crust apt to break away, to substitute a shoe as light as it can be made consistent with its purpose. A shoe made narrow but thick in the web will sometimes be found to answer very well when used in conjunction with leather or gutta percha in the manner before directed, such a shoe possessing the advantage of being held on by smaller and fewer nails than the broad shoe requires. And whenever we meet with a foot of such description, with thin and weak or brittle crust, we are not to be particular as to either the num. ber of the nails used to keep the shoe on, or the situations they sccupy through the hoof; for sometimes it becomes necessary to nail the shoe all round in order to fix it firmly for work, and to make use, for the purpose, of double or even of triple the number of (small) nails we ordinarily insert. In fact, if the horse is to go to work in it, the shoe must be secured at any multiplicity and variety of nailing, and clipping in addition, save that of doing positive injury to the foot." 


\section{FUOT ROT.}

A disease is which some have given the above name marle its appearance in the city of Boston in the winter of 1853 , and is at the present time prevailing in different parts of the state. It appears to spread after the manner of sporadic dis. sases, and prevails chiefly among horses of coarse breed, with clumsy feet, brought on in some cases by "hard usage and sore abuse." The disease luxuriates in stables that are filthy, damp, and unventilated, and among horses that are constantly exposed to all sorts of weather; for it is seldom that we hear any thing of the disease prevailing in horses of superior breed, located in comfortable stables, where they are supposed to have that care and attention so necessary for the preservation of health; yet however potent the above causes may be, they are not in all cases direct, but merely approximating. It has been observed that this peculiar disease often follows injuries of the foot by calking - from puncture by nail or otherwise. Here we seem to have a direct cause, which may be termed special; for such engender distinct disease. From the fact, however, that the disease is not prevalent in the summer months, we are led to infer that the combinations of cold, moisture, and bad management are more prolitic of it than any other cause. The term foot rot does not convey any definite idea of the nature of the affection, hut merely implies a state of rottenness, similar to that occurring in sheep and cattle; whereas this disease varies, and often passes through several stagres ere rottenness (gangrene) sets in. Some suijects are attacked suddenly with disease of the plantar $\left.{ }_{0}\right]$. sortunts - deep-seated lymphatitis. In the course of a few din's - sometimes hours - a profuse diccharge of matter, resembling iymph, from the coronet takes place, and inflammatory gangrene supervenes. Or a horse will all at once be seized with lamrness, continually catching up the foot, and in the cours of a few hours pus is seen to ooze from the orifice. Here we have two stages of a disease which may progress to rot or gangrene, vizm inflammatory, characterized by heat, pain, and lameness; sup. purative, of which the discharge of pus is prcot' positive. The 
finole ss a gangrenous state, characterized by transformations aud death of the tissues of the foot. The name of this disease should, therefore, ba conferred in accordance with the notabln changes that occur throughnut its progress: they are inflammation, suppuration, gangrene and it often happens that the abnormal process is arrested in either one or the other of the first etages, although it is prone to run into gangrenes. 'These charnoteristic symptoms furnish a title for the diseuse; and should deat supervene, whether in the inflammatory, suppurative, or putrid stages, the name of the disease will be that of the cause of death; so that foot rot - if it imply a rotten, putrid, or gan. grenous state - should be termed inflammatory gangrene, which is produced by extravasated blood, or rather fluids, they rapidly passing into a state of decomposition, thus destroying the vitality of those tissues - the lamina of the foot - so that the hoof frequently separates from its attachments and falls off.

Case. - A horse, the property of Mr. Doolittle, duing business :n Ivers Street, was punctured by picking up a nail; it entered the sole midway between the point of the frog and the toe of the Jff hind foot: it was dressed in the usual manner by a blacksmith. On the following day the author was requested to se? the animal. He was fuund standing on three legs; the affecter limb drawn up towards the body; the foot very hot and painful; the flank on that side bedewed with perspiration; pulse quick and ju rking; mouth hot and clammy : in shcrt, svmpathetic fever had set in. On removing the shoe and dressings, a small quantity of pus streaked with blood oozed out of the puncture, on dilating which with a drawing knife, a very profuse discharge followerl. Two or three poultices, of an antiseptic and astringent characser, were applied. Chloride of soda, salt and vinegar, fir bal. sam, solution of alum, zinc, and such constitutional remedies as the case seemed to require, were resorted to; but all to no purpose : the horse grew rapidly worse; a thin, aqueous, and acn id discharge from the quarters and coronet took place, which finally separated the hoof from its matrix: the discharge degenerated until it became of a dark reddish color, very offensive. The tissues above the hoof underwent cellular transformations, and hulged out about an inch or more beyond their ordinary limits 
having her: and there deep gangrenous uleerations. Thus did the disease progress (atprarently unchecked by medical treatment, which laad often proved successful) until the eleventh day from the time of the injury, when, on making an effort to get up, a complete separation of hoof from foot took place. Mr. D. inmediately ordered the animal to be put out of hi. nisery, and Le was accordingly destroyed. This disease we have termed influsnmatory gangrene; and although it rarely runs so rapid a tourse, or attains so malignant a type, it is the one commonly known as foot rot.

Ordinarily, and in other than the cold season, puncture of the foot, by nail or otherwise, is followed by healthy suppuration and discharge, and the parts resume very nearly their original condition; but in the case just alluded to, the suppuration was from the first unhealthy, and attended with a positive loss of laminal continuity, ulceration, and gangrene.

Treatment. - It is useless to lay down any particular plan of treatment, for that must depend on the nature, stage, and intensity of the discase. The principal local remedies are, -

1. Antiseptics. - Pyroligneous acid, charcoal, chloride of soda, and lime.

2. Astringents. - Tincture of muriate of iron, sulphate of zinc and of iron, bayberry bark, gum catechu.

3. Remedies to relieve Pain. - Chloroform, sulphuric ether tincture of Indian hemp, infusion of hops or poppy heads.

4. Constitutional Remedies. - Tonics and alteratives. (Se日 Medicinal Preparations.) In cases that indicăte poultices, substitute fir balsam.

\section{CORNS.}

Conns gen rally make their appearance in the inner beel, nitlin the bar and crust, at or near their junction. We find chut a rreat number of horses are aflicted in this way; and it is supposed that an imperfect system of shoeing has more to do with the production of corn than any thing else. The following article from White's Dictionary may possibly furnish the reader a better idea of the nature and treatmeat of corns than the au ihor of this work can give:- 
"In their recent state corns generally cause some degree of tenderness, though not amounting to actual lameness. If not attended to at this period, the horse soon becomes lame; and when the shoe is removed for examination, the horny matter in the part described will be found, upon scraping off the exterior surface, of a dark-red color, to a greater or less extent, according to the length of time it has existed, or rather to the degree of injury the sensible parts have sustained. If the shoe be not romoved at this stage of the disease, which sometimes happens from a supposition that the lameness arises from some other cause, its continued pressure on the tender part, or corn, will at length cause matter to form, which, finding no vent beneath, ascends to the coronet, where it breaks out. Even this is sometimes mistaken for a tread, or blow from the other foot, while the real rause is lost sight of. In the treatment of corns in their recent state, or before suppuration has taken place, the method generally adopted is to pare out the red part, or what is termed the corn, and so contrive the shoe that, when applied to the foot, it may have no bearing on the tender part. 'This, in slight cases, generally affords temporary relief, and enables the horse to go to work again : in a short time, however, the horse's weight causes the shoe again to rest upon the heel, and the inflammation anc lameness of course return. The only effectual mode of taking off pressure from the heel is by means of the bar shoe, and this can only be applied where the frog is sufliciently prominent and firm to receive its pressure. For should the frog be considerably lower than the heels, (that is, supposing the foot to be taken up, and its bottom part held upward,) it must be obvious that the bar shoe cannot bear upon it, and will therefore be useless. The only thing to be done in this case is to pare away he crust of the tender heel, so that the heel of a common shoe may not rest upon it. I am aware that the original cause of corns is often a natural weakness of the inner heel, or a want of sufficient strength in the horn to protect the sensible parts fiom the pressure of the shoe. It is from this consideration, perhitps, that Mr. Budd observes, "We have frequently seen the plan of cutting away the horn (in corns) followed with avidity, on ac. count of the temporary relief it affords; such a plan, however 
is deceitful, and dictated by too shallow an idea of the complaint for though it gives time for the renoval of it when existing, still it leaves what may be termed an increased disposition to it, be. cause it deprives the sensitive parts of the protection of which they already stood too much in need; and we have no hesitation in saying, that it is from this mode of treatment solely that somo horses are so frequently and indeed almost constantly affected. 'The best plan, therefore, which can be followed, is to appiy a bar shre, as this affords more ample means of throving the pressuro o.f the affected parts; no excision of the horr, we repeat, ought to be resorted to, unless there is reason to believe that suppuration has taken place.' If no horn is to be pared away in corns, what, I would ask, is to be done in circumstances where the bar shoe cannot be employed? that is, where the frog is much lower than the heels, or too rotten and tender to bear pressure. Mr. Budd tells us that the shoe is to be 'laid off the part;' that is, the shoe is to be so formed, that when applied to the foot it may not be in contact with the tender heel: this may afford temporary relief, but by one day's work the shoe will be brought to its original form. I am inclined to believe that corns are often rendered inveterate by trusting to such ineffectual means; for the proprietor, finding his horse relieved, sets off perhaps on a journey; the shoe soon bears down upon the heel again, and the bruise or corn is much aggrarated; by dint of spur and whip, however the horse is compelled to go on; and when he arrives at the end of the stage, so high a degree of inflammation will perhaps have taken place that suppuration cannot be prevented. The only mode, I conceive, by which a corn can be either cured or palliated, is to take off all pressure from the diseased parts ; and this not only for a short time, but till the injured sensible part has Lst its tenderness, and formed horn of suticient strength to enathle it to bear pressure. While a horse is worked, the shoe should be frequently examined; and whenever the heel appears to be so near the diseased part as to be in danger of bearing on it, it should be immediately removed, and some more horn pared away, so as to have a considerable vacancy between the heel of the hoof and the heel of the shoe; for even if a bar shoe is upplierl, the horn will in time grow down, so as to be in contack 
with the heel of the shoe. When a horse becomes rery lame from a corn, it will be advisable to leave off the slioe for a short time, and apply a large bran poultice. When tenderncss is perceived about the coronet, and a little matter is seen oozing out from the horn at the heel, it should be pared away, that the matter may escape freely. The exposed part may be dressed at first with a solution of blue or white vitriol; afterwards with tincture of myrrh, or friar's balsam."

\section{BRUISE OF THE SOLE.}

Horses, in travelling over hard, uneven roads, are very apt to cast a shoe. The sole then, being unprotected, becomes bruiserl, and by the time the horse has arrived at home, or at the nearest smith's, he is quite lame. On making an examination of the foot, it will be found hot and painful. The best remedies, in view of inmediate relief, are rest and cold water. The latter may be applied by means of a piece of flannel, tied fringe-like, but loose, around the fetlock, and kept constantly wet. It is probable that, in cold weather, rest alone will perform a cure; if it should not, immerse the foot in tepid water twice a day.

\section{THRUSH.}

Thrush, or, as some call it, frush, is a disease of the horse's hoof very prevalent in the United States; it is a disease so well known among horsemen that any description of it seems superfluous. Its diagnostic symptoms are, fœtid odor, and morbid exudation from the frog, accompanied with softening of the sams. For a common thrush, which does not occusion lameness, the remedy is cleanliness : let the feet be washed night and mosning, and occasionally immersed in salt and water; the trouble will thon disappear. In inreterate cases of this kind, u.r object must be to prevent decomposition - in the use of antiseptics: a charcoal ponltice now and then, and the free use of pyroligneous acid, and salt, are the best means. A few doses of the following composition will also be needed : sassafras, sulpl $\mathrm{ur}$, salt, and charcual, equal parts. Dose, one ounc; daily. A dressing of fir balsam 
may be applied to the frog and sole, which is to be confined there in the usual manner. Thrush is often the result of morbid habit in the system of the horse, giving rise to an excess of morbific products, which naturally gravitate to the feet, and there find an vutlet; therefore we should not be in too much of a hurry to stop suct $L$ issue, for by so doing, the matter may be reabsorbed, and produce sympathetic fev r, swollen legs, Sc. The safest way, therefore, is to treat the disease both locally and constitutionally.

\section{ACUTE INFLAMMATION OF THE FEET.-(Laminitis.)}

Acute inflammation of the feet differs very little in its plyysical phenomena from inflammation in other parts of the system, ex. cept in the former it appears more complete and permanent. Of the agents which produce laminitis, which cause more blood to flow into the vessels of the foot, which regulate their enlargement oz constriction, and finally induce effusion of serum, lymph, or fibrin, and produce alterations in the structure of the foot, much ias been conjectured, yet very little is known. It may be safe for us to argue, however, that the same causes that operate in producing inflammatory action in other parts are all-sufficient in laminitis. In acute laminitis we have an aflux of blood, from which arises that feverish heat known as fever in the foot: the development of heat being directly proportioned to the activity and fulness of the circulation - heat is accompanied with redness and pain; increased pulsation in arteries leading to the foot: this increased pulsation seems due to obstruction in channels through which blood usually circulates with freedom, while the same or even an augmerted force continues to impel it. We next observo cffusion of serum, lymph, and fibrin; though we repeat that laminitis does not differ from inflammation ix some other parts. The varieties of laminitis are acute and subacute; the former follows excessive work: in such cases the system bezomes exhausted; then follows local increase of blood in consequence of weakness in the propelling forces - lungs, heart, and capillaries. When acute laminitis follows a long drive on hard ground or parement, or violence of any sort, including long-continued paw. ing or stampirg, the $b^{1}$ rod is deternined to the feet by a high and 
permanent grade of vital action; which is apt to end in change of structure. The acute form is invariably attended with sympto. matic phenomena, so that the patient exhibits all the symptoms of a ligh fever, attended with intense agony and disturbance of the normal functions. On the other hand subacute laminitis is not so intense nor dangerous, and it differs somewhat in its mode of attack; it has occasionally a metastatic origin - that is, when disease is transferred to a new seat. For example, a horse suffering from pneumonia may be suddenly relieved on the supervention of laminitis; the disease abandons the interior, and assails the extremities. The translation of disease in this way may sometimes be considered salutary. Thus, if such change occur in the system of a horse not enfeebled by age or disease, strong lopes of recovery may be entertained; otherwise the subject is no better off; for it frequently leaves him in that deplorable and utterly ruined condition denominated founder.

Causes of Laminitis. - We have already hinted at some of them, yet the reader must remember that the same agency may at one time only create a predisposition, and at another directly excite the disease. Predisposing causes are those which produce in the system certain changes which prepare it for the development of disease; they are slow and gradual in their operation, not cognizable at all times. 'This is the incubative stage of disease. Exciting causes are those from which diseases seem to have a direct origin, as in metastasis, for example; still it is very difficult, therefore, to decide where the first ends, and the latter commences. The opinion of scientific men must, however, be our guide. Mr. John Field gives the following account of the causes and symptoms of laminitis:-

"This disease may be oceasioned either bysevere work on dry, hard roads, or by inflammation of the lungs, \&c., whereby, in the former instance, it arises from excessive friction between the sensible and horny lamine, while in the latter, from the animal corstantly standing, an undue and continued stress is laid upon that part. The symptoms are, a hard, strong, and frequent pulse; the animal expresses great pain, and blood sometimes oozes from the coronet, attended with a sinking of the coronary ligament. If the fore feet are affected, he extends them forward, and brings 
nis lind legs under his body, to support the weight. If the disease is in the hind legs, he stands on his toes, bringing his fore legs to the cartre of gravity. This complaint is accompanied with great heai mund the feet, acclerated resipiration, and sometimes sweating.

"Should the symptoms continue, there is an effusion of coagu. lated lymph or blond between the sensible and the horny laminæ, in consequence of which the coffin bone descends upon the sensim ble and horny sole, the sole becomes convex, and the front of the hoof is depressed in the centre, or rendered more oblique."

Next to over-exertion and concussion on lard pavements, the drinking of cold water when the animal is heated is the next cause assigned. It is well known to horsemen, that founder often sets in from the latter cause, and also after a hard drive followed by a full meal; and what is founder but an aggravated case of laminitis?

Treatment of Laminitis. - We have tried various kinds of remedies for this affection, but never found any thing equal to packing, after the fashion of hydropathy. The feet are to be enclosed in bandages saturated with a weak mixture of arnicaeight ounces of tincture of arnica to one gallon of water; the bandages are to be about five yards in length and four inches broad. Before applying the bandage, have the shoes carefully removed, cleanse the feet with soft soap and water, and adapt to each a piece of flat sponge just the size of the sole. This answers the purpose of a soft cushion for the horse to stand on, and at the same time keeps the sole moist. Having now applied the bandage, and secured it with tape, nothing further is needed but to keep the parts moist for several days, readjusting the bandage, how. ever, if it should become loose. The constitutional treatment depends upon circumstances: it may be proper in all cases to keep the patient on thin gruel, scalded mashes, and boiled roots, and to give an occasional dose of sulphur and cream of tartar, Should the patient evince signs of much agony, give a few drenches of infusion of hops or poppy heads. High inflammatory symptoms are to met with arnica; dose, twenty drops of the tinclure every six hours, to be given in clear water; this the animal will generally drink. Should thirst prevail, the drink must be ncidulated with cream of tartar, or a few drops of acetir acid. 


\section{CONTRACTION OF THE HOOF.-(Hoof Bonna;}

Sime of the causes of contraction hav : already been alluded to. (See Quarter Crack.) The prevalent custom of (utting away the Lars - which ordinarily support the heels, and prevent their ap. proximation - may be considered, among others, as directly operative in prolucing this deformity, which, in some cases, may bo sonsidered in the light of local atrophy - diminished nutrition. Diminished nutrition generally results from disorder in the digeztive organs, so that contraction of the hoof and indigestion may corxist; although many physicians deny the coexistence of disease. Contraction of this kind is not apt to occaston lameness, hecause there is a very low grade of vital action in the parts. But contraction is now and then the result of deep-seated disease within the hoof - navicularthritis and laminitis, for example; the animal is then dead lame while the inflammatory diathesis ksts.

Treatment. - Contraction associated with inflammatory action of the tissues or cartilages of the foot must be treated in the sams manner as recommended for laminitis: in all cases we must endeavor to give the frog a bearing on the ground; and in order to do this the shoe ought to be removed. Adry, brittle, and con. tracted hoof may be improved by repeated poulticing with sofi arap and rye meal, applied cold. So soon as the hoof softens, let it be dressed, night and morning, with turpentine, linseed oil, and puwdered charcoal, equal parts. Yet, after all, a run at grass in \& soft pasture, the animal having nothing more than tips on lis feet, is the best treatment. A very popular notion exists, that cow manure has a wonderful effect on a contracted hoof; but it is the candid opinion of the author, and no doubt the reader will coincide, that filth and dirt of every kind are unfavorable. to bealthy action. Such remedy, aside from its objection cri the Ecore of decency, savors too much of by-gone days, when live cels were sint on an errand down horse's throats to unrarel their intestires. If any benefit belongs to such an objectionable application, it is due to the property it possesses of retaiting moisture; therefore cold poultices and water are far superior. Clay and tnoist earth, placed in the stall for the horse to stand on, are far 
Iiferior to a stuffing of wet oakum, which can be removed at pleasure. In order to keep it in contact with the sole, we havo only to insinuate two strips of wood between the sole and shoe; one running lengthwise and the other crosswise of the foot. It affords considerable pressure to the foot, is conling and cleanly, and is far superior to the above articles.

\section{CANKER OF THE FOOT.}

This is one of the most intractable diseases with which the reterinary surgeon has to contend. It is a disease somewhat analogous to cancer in the human subject. A true cancer, however, is supposed to have its origin in remote parts; hence the great difficulty in curing it. Dr. Carpenter teaches that "cancerous growths possess a remarkable analogy with the parasitic fungi, which develop themselves in the interior of vegetable and eren animal structures; and the supposition long ago entertained, that cancer might be regarded as an independent growth of corresponding nature, does not now appear so extravagant as it was at one time considered. There can be little doubt that a carcerous tumor of any size may be developed from a single cell; and it is probable that the origin of such growths in parts distant from their primary centre is to be traced to the conveyance of cancer cells, or of their germs by the circulating current; so that it seems very difficult to draw a line which shall separate such independent growths on the one hand from the ordinary tissues of the body, and on the other from structures really parasitic. It is interesting to remark, that blood vessels cannot be traced in these froductions at an early period of their formation, but that they make their appearance, as in the normal development of the tis. sues, at a later date." We consider canker in the horse to be an abnormal development of the ordinary tissues of the foot ; for were it otherwise, we should never be able to cure it. If, however, if alpear in other parts of the body, which is a rare occsrrence, and assume a malignant aspect, it may be defined as true cancer. A common antecedent of canker is thrush; its seat is the hind feet, occurring in horses of coarse breed, with ill-shaped hoofs. and diseased frogs, that always emit a fetill odor. In snch animals 
there seems to exist a peculiar diathesis favorable to the prorluc. tion of canker, which, on the occurrence of a simple injury to the foot by the accidental introduction of a nail, or from any other exciting cause, is immediately followed by an extraordinary morbid growth.

Treatment. - Our first business is to reinove the shoe, : cleanse the foot with a weak solution of chloride of soda; principal part of the morbid growth is then to be dissected ot if any hemorrhage follows, it can be arrested with pledgets of lint saturated with tincture of muriate of iron, or any other styptic; we next sprinkle the whole surface with powdered bloodroot, sanguinaria canadensis, - then apply a dressing of strong pyroligneous acid, and by means of pledgets and bandages, keep a continued pressure on the parts. The foot must be dressed in this manner for several days, occasionally washing it with a solution of alum, sulphate of zinc, or some vegetable astringent - infusior. of oak or bayberry bark. Should these remedies fail, we recom. mend the following: Take a saturated solution of common potass, into which stir a sufficient quantity of finely-pulverized oatmeal, to form a stiff paste; apply this to any fungous growth, and it will disappear in a very short time. This dressing should be followed by one composed of linseed oil and lime water, equal parts

- M. Fischer recommends unslaked lime in preference to slaked; his reasons are, "The latter becomes with water more unctuous, it adheres better, and causes thicker crusts or sloughs, which mere readily become detached. I procure lime as pure as I can, and make it into a paste with water, inmediately before application, in order that it may, in that form, reach the sinises of the fort, after haring sprinkled over the cankerous surfaces pure chlorile of lime, or else that mixed with pulverized tan, according to circumstances. In cases where the calcined calcareous stone refuses readily to absorb the water, or doe not slake, I obriate, in some measure, this inconvenience by making use of boiling water.

"First of all, I confine the paste upon the foot with a piece of linen, tefore I enclose the foot in a boot; otherwise the latter would speedily become destroyed by the caustic. At every fresh dressing, i. e. daily, the linen is calcined, as it were, by the lime, so that at each dressing fresh linen is called Cor." -- Translations from the French, by Percivall. 


\section{CUTTING. - (Interfering.)}

Horses are said to cut, or interfere, when they strike the innes side of the fetlock joint with the hoof or shoe of the opposite foot. It generally arises either from an unnatural curvature in. wards of the limbs, twisting in of the toe, from shelving of the boof, and from prrors in sloeing. It may also arise in zonsequence of weakness and fatigue, during a long juurney orer Leavy and sneven roads; the subject is apt, also, at such times, especially when the toe has a faulty position inwards, - to atrike on the inside of the knee, and produce an inflammatory swelling, termed speedy cut, which sometimes takes a long time to reduce. It is evident, therefore, that, in order to remedy the evil, we must ascertain its causes; yet, in the majority of cases, we have to depend on the blacksmith and a careful driver for a cure: the physician has nothing to offer but advice and palliatives.

\section{GENERALITIES.}

\section{CRIBBING. - (Crib Biting.)*}

THE act of cribbing consists in grasping the crib, ${ }_{0} 1$ a given point, with one or both jaws, at the same time uttering a laryn. geal sound, resembling a grunt. A cribbing horse has generally

* "Although the abnormal action with horses known under the appellation of srib biting is so frequently observed, it is still one far from being sufficiently understood. Many of our best veterinary authors have furnished dissertations or the subjoct; but these present great variety of opinion touching the causes, seat, nature, and consequences of crib biting. Whilst one contends that, in the act, the horse swallows atmospheric air, another cor.tends that the animal rjects air which act is accompanied with a particular noise, created by gas generated in the stomach. Some say that the habit is injurious to the horses tiat practise it, and that it frequently renders them valueless; while others maintain that it nowise materially hurts them. The Court (of Appeal) has pronounced in favor of its innocuousness.

"By this we are led to distinguish crib biting into that which is acquired by babit, habitual, and that which is properly so called, and which is spontaneous

- The opinion which regards crib biting as discharging air fr om the stomash 
bee 1 considered unsound, but we know not on what gruunds; for we look upon a horse as sound so long as he can perform tho dutics of an ordinary horse without inconvenience or lameness: be may have defects, both as regards form and action: but such are not to be construed into unsoundness. It is a remarkable fact that very few cribbers fail to perform the duties required of them. They may, once in a while, have an attack of colic; he

aim: $13 \mathrm{r}$ to belching in ourselves, is evidently an erroneous one, sirce it implics that the act is one of absolute necessity. Now, it is well known that by va. rious means we have it in our power to prevent crib biting in some horses for a icrger or shorter time; but in doing this we never hear of any evil consequences arising from its suppression. Indeed, if such were true, horses ought to blow themselves out with the gas, which, instead of eructating, they are now compelled to retain. And, moreover, did crib biting consist in eructation, gas might make its escape through the nose, and then the animal would havo no occasion for that violent movenent which characterizes crib biting.

"To those who pretend that crib biting consists in swallowing atmospheric air, in order to aid the digestion of horses addicted to the vice, I reply, without entering into any physiological considerations, that if, by any means, the crib biting be put a stop to for several months together, the horse digests quite as well without as with the vice: of this I have often had occasion to convince myself.

"The explication given by Professor Gurlt, of crib biting with eructation,* supplies the reason of the difference of upinion we have adverted to, and is quite conformable to what one daily observes. M. Gurlt asserts that the crib biter swallows air, which he the same instant rejects; but that, neverthe. less, in particular cases, a portion of the air, having descended in to the oesupha. gus, does not reascend into the pharynx, but penetrates into the stomach, into which it is forced by the contraction of the wall of the esuphagus. M. Strant, who has written an admirable memoir t on crib biting in horses, admits of the view of the matter taken by Gurlt, which he explains in this way: "The animal, when he incurvates his head upon his breast, does so to gain a poind d'ampui, in order to force a certain quantity of atmospheric air into the phar. $y n x$, and thus overcome, in this act, the natural impediment offered by the ielum palati and fauces; the larynx is elevated, while coincident muscular conIraction draws up the fauces to receive the swallowed air. At this monent the hurse relaxes in his effurt, (crib biters in the air effect the movement in sight elevation of the head,) and then the air swallowed flows back, and escajes witi the characteristic sound. With old crib biters we may convince ourselveg, by anscultation, that the sound attendant on the act is in truth produced at the menent of the evacuation of the air; and with horses in which the ais reaches the stomach, a second faint, supplementary sound may be heard aloag

- Nachtrage zur Pathologischen Anatomie, von Gurlt, p. 69.

† Bepertur un des T'hierhoilkunde, herausgegeben von IInring 1850. p. 180 
that is not due to aribbing, but to indigestion: still the populan belief is, that cribbing is either the result or canse of colic. The author's opinion is, that cribling is a habit either ac. quired or hereditary ; that the sound or grunt originates in the vocal orcans, from air admitted within them and expelled without entering the trachea, and in consequence of air supplieal tis $t^{1} \mathrm{k} m$ from the lungs during expiration. The grunt is evidenlly

the nsophagus, coming from the air entering the stomachic cavity. Thig lest round has sume analogy to the borborymi (rumblings) of the bowele.

"In this manner we maly explain very readily how it happens that some sit biters blow their bellies out very much in the act, while in others nuthing of the kind happens; so that in some horses the vice really proves prejudicial. while others seem hardly at all decreased in real worth by it.

"Hurtzel d'Arboval, and numerous veterinary authors with him, have soughts the cause of crib biting in the digestive organs; Imt, in perusing this anthur's article on the subject, it is ensy to perceive that he has collected exceptions to establish a general rule, and has mistaken the effect for the eause. Indeed. the medical opinions of this writer savor ton much of the gastro-intestinal organs being the seat of diseases obscure in their niture.

"I know many crib biting hurses, but I am not at"quainted with one instanen in which the rice has proved decidedly (sensiblement) prejucticial, providnng, as is done in my part of the country, measures be taken to hinder horses having it biting the erib any great deal. Muny farmers, indeed, possessing buch horses, regard them, though perhaps through prejudice, as their most hardy workers. I often find a single crib biter in a farmer's stable, where, perhaps, he has been for many years among the other horses, where he has aeçuired this evil habit, without the farmer's being at all able to divine the cause. And I have possessed a harness colt, which no sooner was separated from his dam to be tied up in a stall, than he commenced crib biting, without ever before having shown the slightest tendenry that way. He is at present six or seven rears of age, and still bites the crib. If crib biting, as some pretend, consists in swallowing air to serve the purposes of digestion, certainly this cult ought to have ill digested his food during the time he was kept from practising it; ans if there results from the act the generating of gas in the stomach, the animal $0 \mathrm{~cm}$ this cause wou'd have found himself disordered during his alestirenes from crib biting.

"In general, crib biting ought rather to ive regarded as a vicions halit tha? as a disease : as the latter I hare never been able to regard it. Iforses that are old crib biters present the inconvenience of heing slow fecders; ther refjuire a good deal to satisfy them; and those which gencrate air in their stomachs are rery subject to attacks of meteorization. To obviate such inconveniences, the f llowing means have been recommended : either the ordinary crib-biting strap or an iron T, whose branches so embrace the throttle as to prevent the hor se' arching his neck after the peculiar manzer in which he prepares for the af and accomplishes it." 
an expiratory murmur, and the air necessary for pruducing such is dericed from one of these sources. Some contend that the ammal swallows wind, and thus creates flatulency, colir, \&c.; but the irlea is perfectly ridiculous. It is our firm belief, based upon a knowledge of the structure of the parts involved in the vechanism of respiration, that neither man nor horse, by rolun. tury act, ever has power to swallow atmospheric air. The organs of respiration and deglutition differ so materially in their aniatomical and physiological relations - have each special fun tims to perform - that it is imposible for one to perform the function of the other, which would be the case if a horse actually suallouea wind, - atmospheric air, - and then, as some others contend, regurgitated it.* On these grounds, we question, therefore, the correctness of either theory. If horses possessed the power of aructating wind or gas from the stomach, we might expect, in violent cases of flatulency, to notice its escape in this way, which the author has never yet been able to do. Crib biting, therefore, being nothing but a hahit or vice, can only be corrected by means and appliances which prevent the subject from indulging in it. In this view, all sorts of contrivances have been resorted to, and among them was one which was inrented by Sir Peter Laurie. The space between the bottom of the haty rack and the outer edge of the manger is boarded over, forming a steep inclined plane, leaving, in this way, no edge or point on which the horse can fix his jaw. Attached is a flap or slide, opened only at meal time. The author uses common bur soap as a preventive, which is to be rubbed on the edge and ontside of the crib, and renewed as often as necessary.

- The saliva has the property of enclosing rithin its g-lobules, durng the prucess of mastication, a small quantity of atmospheric air ; but we nerer knew ${ }^{\prime \prime}$ its doing any harm: it may, possibly, answer some useful purpose ir. figesliun, and we strongly suspect that in that wonderiul laboratory, the storcarh t te decontored: 


\section{POLL EVIL.}

\section{"Poll evil resulta either from neglect or abuse."}

Poll evil generally makes its appearance about the nape of the acck, in the form of an inflammatory swelling, which, if not arrosted, ends in abscess and fistula. It generally proceeds from blows or bruises. Horses that are located in low-roofed stables .re apt to strike the poll against the beams or ceiling; and a frequent repetition of the act always ends in induration or poll aril. Some horses are very restless in the stall, and are conitautly jerking their heads upward, especially if tethered too sliort; in consequence, the parts which come in contact with the upper part of the head-stall are bruised; the injury is not often perceived until considerable tumefaction and unhealthy suppuration have set in; the case then becomes exceedingly difficult to cure, and may wear out the patience of all concerned. Excessive friction on the nape of the neck, from bridle or halter, or the pressure of either on the parts, from their being fastened on the head too tightly, are most fertile in producing this malady. Other causes are operative in producing poll evil that we shall just barely allude to, (merely in view of prevention.) It is well known that the poll is a part which very seldom makes the acquaintance of either brush or currycomb; yet it is the recep tacle for considerable dust and filth : owing to the accumulation of either, a cutaneous eruption arises, the itching sensation of which causes the horse to rub whenever he can get a chance; the evil goes on, until what was at first superficial now becomes deep-seated, by mere contiguity of tissue. The bungling and oftentimes cruel manner of forcing a small collar on a large lorse - pulling first this way and then that, now a tug, then a jerk, and perhaps a blow with the whip stick - is not inoperative, to say the least, in producing this malady. Some men are in the constant habit of bracing the horse's head downward with the martingale, so as to bring the mouth and chest in close proximity; and they sildom consider that the strain comes on the horse's poll the pressure of the bridle from without, and the unyielding natuse of the Lon's of the neck, bruise the interme. 
diate soft tissues, and poll evil is the result. Notwithstanding all this, poll evil is of rather rare occurrence.

Poll evil is first noticed in the form of an oval tumor, hot and tender, situated directly in the region of the nape, mostly inclining to one side; in the suppurative stage, and wlien the matter is deep-seated, scarcely any fluctuation can be felt; when, however, the matter lies directly beneath the skin, or in the cellular tis. sues, the reverse is the case. The suppurative finally runs into the alcerative stage; we then observe chasms and sinuses, simi. iar to those observed in fistula of the withers, and finally the bones become involved in the disease.

Treatment. - In the early stage, a sort of antiphlogistic treatment is the best. The patient should be kept on a light diet; have a dose of cooling medicine, and the parts should be kept constantly wet by means of cold water bandages; for an indo lent sort of tumor we substitute a solution of vinegar and salt. Continue this treatment for a few days. Should the tumor increase in size, and have a soft, fluctuating feel, apply a poultice of linseed. We must not wait for the tumor to break of itself; but as soon as matter can be distinctly felt, let it be opened at the lower margin, instead of its summit; by this means the matter can pass off as fast as it forms. It will be prudent to make a pretty large opening, so that no obstruction shall exist to the free and full discharge of matter, which must be pressed out. It is customary in such cases to apply poultices in view of pro. moting the discharge; instead of poultice, the author uses a paste composed of sugar, soap, and powdered bloodruot, equal parts; these are to be rubbed together in a mortar, and spread on cotton cloth, about the thickness of a dollar, and thus applied to the tumor, to be secured by bandage. In the majurity of cases, however, the author endeavors, after having opened the abscess, to put a stop to the suppurative process in the following manner: Having punctured the tumor, and pressed out as much as possible of morbid accumulation, take a six or eight ounce syringe, and inject the cavity several times with tincture of iodine; after doing so, cram into the chasm a portion of salt and bloodroot, equal parts; put a cold water pad on the eminence, and eacircle it with a roller, passed around the head and neck in 
the asual manner, as tight as circumstances permit. On the following day the bandage is to be removed, the part washed and dressed, and a small quantity of tincture of iodine injected, and bandaged as before. This treatment must be followed up for several days, at the end of which, should the discharge havt decreased, and other symptoms appear favorable, the chances are in favor of a cure. Our object in this treatment is to excite adLesire inflammation, by means of which, accompanied by prea. sure, the surfaces of the interiur are glued together.

Cases, however, occur which set at defiance all our skill. In such the ligamentary, teudinous, fleshy, and bony structures are involved, perhaps accompanied with fistulas, ruming in various directions, like so many pipes or drains; and the difficulty of closing the latter is, that they acquire a mucous lining; and all mucous canals are very ditlicult to unite. The only remedy in such cases is the knife : the part must be laid open and all fistu lous pipes dissected out. Should a portion of bone be diseasec, that must also be removed. The chasm is then to be cleansed with a solution of chloride of lime, or pyroligneous acid; its edges brought together by suture, leaving an orifice at the lower part for the discharge of matter. Our object must still be to heal by adhesion, as already described. Should we fail in this, and the part assume a morbid type, inject and dress it with

$$
\left.\begin{array}{l}
\text { Spirits of turpentine, } \\
\text { Pyroligneous acid, } \\
\text { Linseed oil, }
\end{array}\right\} . . \text { equal parts. }
$$

Fir balsam has also a very good effect on indolent and mor'sid parts. So soon, however, as the parts show a disposition to hoal, dress with tincture of aloes and myrrh.

Our treatment must not be altogether of a local character; we must attend to the general health, and keep the bowels soluble Sulphur, sassafras, and cream of tartar are the best remedics.

\section{FISTULA OF THE WITHERS.}

This disease does not differ from the preceding one, except in location : fistula of the withers, however, is more common than poll evil; and this arises in consequence of the withers being 
more expused to injury than the poll. Of the two diseases, tis. tula is the more formidable; for the sinuses often burrow deep between the shoulder blade and spinous processes, in various directions, so that it becomes both difficult and dangerous to search for them. For the treatment of fistula the reader is referred to Poll Evil.

\section{DOCKING.}

Fashion and convenience seem to require that horses murt submit to have their caudal appendages shortened. Yet that fashion which condemns a poor uncomplaining brute to torture merely for the caprice of his owner is to be deplored, especially when performed after the horrid fashion of some who seem to pay no regard to the feelings of the subject, while mangling and searing sensitive tissues that are as susceptible to pain as those in our race. It is useless, however, for the author to offer any arguments against a practice so long established; he, therefore, proposes to point out the best means of ducking.

The animal should be cast, and brought under the influence of chloroform; an assistant then depresses the tail into its natural position; the point of amputation having been selected, the operator feels for a joint or articulation, just posterior to which he commences a circular incision, carrying the knife right round the tail to the point of commencement, cutting down to the fascia. The integuments are then to be forcibly drawn upwards, while the operator disarticulates the joint by making an incision right through it. The coccygeal arteries are to be drawn out with a pair of forceps, and secured by ligature. The integuments, instead of being retracted above the lower end of the bone, are now below it, and thus can be made to protect it from injuries. Two or three stitches are now needed to approximate the edges of the wound, and the operation is finished, without much loss of blood, and with little if any pain to our subject. Here the red-hot iron and guillotine, - a docking machine always puts us in mind of one, - are dispensed with, to the honor of our calling and benefit of our noble patient. The after treatment is very simple; cold water, or some tincture of aloes, will complete the cure. If they ghould not, owing to profuse suppuration, use pyroligneous acid and give a dose of medicine. 
The sommon methods of performing this operation is by means of a docking machine, or other sharp instrument, which takes off the tail at one stroke; but the operator, unless he understands his business, often finds he has severed one of the bones of the tail and left behind some projecting spiculæ, which afterwards have to be removed. To stanch hemorrhage a red-hot iron is applied to the stump; and this is the most barbarous proceeding of the whole, for it is only necessary to seal the arteries with a pointed budding-iron, brought to a white heat, and merely tourh them with the same. For if the iron be not sufficientiy hot, or should it be kept in contact with the part too long, it will bring away an eschar, and thus the process has to be repeated. The common iron, with a hole in the centre, used for closing the arteries, is objectionable, because it is calculated to come in contact with the muscles of the tail, and must necessarily contract them, and leave the bone more exposed. But there is, actually, no necessity for cauterization, for the artery can be secured by ligature in less time than it requires to sear it.

\section{WOUNDS.}

The treatment of wounds depends altogether upon their nature and cause. It is very difficult in the horse - although not so in man - to heal a wound by what is called "first intention," which means union by medium of coagulable lymph without suppuration. The definition of wound, technically, is, a solution of continuity in the soft parts, produced by some mechanical agent. Wounds are divided into incised, contused, lacerated, punctured, and penetrating.

\section{INCISED WOUNDS.}

Incised wounds are those inflicted by sharp instruments. On the human body they often heal without any subsequent inflammation beyond what nature sets up in the restorative process; but the difficulty in the horse is, that we cannot always keep the parts in contact, and therefore it is not so easy to unite them. In many cases, after having been at the trouble to adjust by 
nutures the edges of divided parts, and when all seems going or favorably, the animal gots his head round, and tears the wound open afresh, so that our labor is all in vain. This puts a damper on healing by first intention. There are several other difficulties in the way of healing by this method, well known to anatomists. We shall just merely refer to the principal or e, because it may satisfy the reader that some wounds had better not be sut ared, for they put the subject to a great deal of pain for no purpose. Horses, as well as some other animals, have, in lieu of hands, a peculiar muscular arrangement under the skin, b? means of which they can shake off flies and other foreign bodies; and it is owing to the facility with which they can jerk or move the skin that we often fail in uniting flesh wounds. Other obstacles are to be met with, both in relation to the size of the wound and as regards its anatomical direction. If the wound is seen immediately after infliction, and there seems to be the least probability of healing by first intention, we place a twitch on the horse's nose, and examine the part. If there be found neither dirt nor foreign body of any kind, the blood had better not be washed off; for this is the best healing material in the world. The edges are then to be brought together by interrupted sutures, taking care not to inchule the hair between the edges of the wound, for that would effectually prevent union. Nothing more is needed but to secure the animal so that he cannot get at it. If he is to be kept in the stalle, without exercise, for any length of time, he had better be put on half diet. Pure air will not hurt him!

\section{Contused Wounds.}

These are generally occasioned by hooks, or some blunt body comnected with the harness or vehicle. They generally leave a gaping wound with bruised edges. We have only to remember that nature possesses the power of repairing injuries of this kind - of filling up the parts and corering them with new skin, all we have to do is, to attend to the general health of the animal, ar d keep the wound in a healthy condition. Our usual applica ton is the compond tincture of myrrh. It the part assume ac unheaithy aspect, a sharcoal poultics will rectily that. If suec 
ennnot be applied, owing to the situation of the wo'dnd, dress it with pyroligneous acid.

\section{Lacerated Wounds.}

Lacerated wounds are generally in the form of a rent rather than cut, inflicted (as we have seen cases) by the calking of a shoe tearing off the integuments and-subcellulitr tissue, leaving a sort of triangular flap. In these cures we generally employ sutures and treat them the same as incised wounds.

\section{Punctured Wounds.}

Punctured wounds are those inflicted by a pointed body, as a nail in the foot, point of a fork, or splinter of wood. These are the most dangerous kinds of wounds, for they are frequently the cause of fistula and locked-jaw.

We make it an invariable rule, in the treatment of punctured wounds, to first examine by probe or othervise, and remove any foreign body that may be present, and then poultice with flaxseed, into which we stir a small quantity of fir balsam. In puncture of the foot by nail, instead of plastering it with tar, and forcing a tent into the orifice, and then covering the sole with leather, as most blacksmiths are wont to do, we have the shoe taken off, the foot washed clean, and a moderately warm poultice applied, and renewed daily, until the suppurative stage commences. 'That once established, we consider our patient safe; for many men, as well as animals, have lost their lives from the absorption of pus forned in the wound after the external breach had healed When a bone is injured by the point of a nail, or fork, the curo is rather tedious; the primary means, however, are the same. The poultices may be followed by astringent injections, as alux. water \&c. In case of injury to the bone, we use pyroligneous acid; to be thrown into the wound by means of a small syringe. If extensive disease of the bone sets in, the services of a veterinary surgeon will be required. A very profinse or whealthy $d_{1 s}=$ harge from a punctured wound must be met by constitutionw remedies. Sulphur and sassafras, to the amount of half as 
ounce each, every other day, to the amount of three or fous doses, will arrest the morbid phenomeron. The local remedy in ull cases of this kind is diluted acetic or pyroligneous acid. For the treatment of a fistulous opening, see Fistula. For puncture of joints, see Open Joint.

\section{Penetrating Wounds}

Are in:ficted by the horns of cattle, stakes, shafts, \&c., an 1 bave to be treated according to the nature of the case. A penetrating wound of the walls of the abdomen is generally followed by protrusion of the intestine; this has to be returned; the wound is then closed by strong sutures, and the belly must be encircled with a long bandage. In such cases we generally keep the bowels soluble with scalded shorts, well seasoned with salt, and empty the rectum occasionally by enema.

\section{Penetrating Wound of Intestine.}

To illustrate the mode of procedure when the intestine is wounded, the following case is introduced: We were called to see a three-year-old colt that had been gored by a cow. The animal had a wound on the off side, about four inches in length, in the iliac region, through which a portion of the small intestine protruded. On exploring the breach, it was found to run in a slanting direction, and as it approached the peritoneum, was found quite small, scarcely admitting the little finger; here the bowel was both strangulated and lacerated, the intestinal opening being external to the stricture. Before proceeding to cast the horse, a twitch was placed on the nose, and the edges of the wounded intestine were neatly sewed together with a very fine muture needle. Our reason for doing this before casting wits, lust in the animal's struggles the bowel might $r$ zcede, and give us some trouble in getting hold of it again. There was not much Janger of it, however; still we wanted to be on the safe side. The intestinal wound was not produced by the cow's horn, but tock place some three hours afterwards, and two before we saw the case. in the following manner: the protruded bowel had 
become disten led with gas, and accorling to the owner's accuunt was about the size of his two fists. The animal, probably being in pain, got down and rolled on the injured side, and thus burst the gut. After sewing $\mathrm{p}$ the wounded intestine, it was cleaneod with warm water, and attempts were made to return it within the abdomen, but to no purpose. We then cast the patient, and, ly means of a bundle of straw on each sile, propped him on his back ; the bowel did not return so easily as we had expected, fo: it was found necessary to dilate the stricture by means of a but. ton-pointed histoury. The several layers of abdominal muscles were then sutured with as much nicety as the nature of the wound admitted; and lastly the integuments were brought together by interrupted suture. This case terminated unfarorably, for the animal died on the sixth day from peritc nitis. It may be well to observe that the accident happened on a very cold day, in the depth of winter; and the bowel being so long exposed to the depressing influence of cold, probably led to the fatal result; for it is well known that operations of this kind often prove successful. It may be interesting to the reader to know that wounds of the intestines heal as readily as those of other parts, as the following cases will show:-

- An incision one inch and a half in length was made in tiet bowels of a dog; the wound of the integuments was closed by suture; the animal was scarcely affected by the operation, took food as usual, and had natural evacuations. At the end of a fortnight, when perfectly recovered, he was killed for the purpose of examining the bowel, when the wound appeared to be completely healed.

"In the eighteenth volume of the Philosinplical Transactions a similar experiment is related by Mr. W. Cooper: 'An openino 5as made in the abdomen of a dog; a large wound was made in the intestines, and the wound in the abdomen was stitcher ap, Scc; the dog recovered without any bad symptoms, and became perfectly well in a few days after.' It should be observed that the bowel does not appear to have been stitched up when returned into the belly. 'The following experiment by Mr. Travers is still more remarkable: 'A ligature of thin packthrearl was firmly tied round the first intestine - dusdenum - of a dog, so 
13s completely tc obstruct it ; the ends of the strings were cut off, thd the parts returned; the wound in the abdomen was closed, and the animal expressed no sign of suffering when the opera. cion was concluded. On the following day he was frequently sick, and romited some milk that was given him; his respiration was hurried. Third day his sickness continued, and he vomited some bilious fluid. Fifth day he passed a copious stool of the came appearance as the fluid discharged by romiting; his sick. ness from this time ceased, and his breathing was natural; be took ' read and milk, and drank abundantly of water. Seventh day he had three similar evacuations, and appeared well, eating animal food freely. On the tifteenth day, his cure being estab. lished, he was killed for the purpose of examination. The ligature which was fastened around the intestine divided the interior coats of the gut, in this respect resembling the operation of a ligature upon an artery; the peritoneal or outer coat alone maintained its integrity. The inflammation which the ligature induces on either side of it is terminated by the deposition of a coat of lymph, exterior to the ligature; this quickly becomes organized; and the ligature, thus enclosed, is liberated by the wlcerative process, falls of necessity into the canal, and passes off by stool." " - Travers on Injuries.

\section{Penetrating Wounds of the Caest.}

Wounds of this character are not fatal, provided the lungs or heart are not perforated. All that can be done is to suture the wound, pass several turns of a roller round the chest, and adopt such constitutional means as the case seems to require.

\section{wORMS.}

Animal parasites are sometimes found in the intestinal cranal of a Lorse in very large numbers; they often exist witlout producing any perceptible disturbance in the economy; yet in aome cases they unquestionably produce irritation, suffering, and ill health. The usual disense with which worms are connected in indigestion, known by fetid breath, turked up belly, starmg 
coat, loss of flesh, voracious appetite, and slimy stools. Worms - rxcepting bots - are supposed by some to be of spontaneous origin; but our opinion is, that they are the result of a perrerted state of the parts in which they appear. The long, round worm is an inhabitant of the small intestines; and the pin or flread worm is generally found in the large intestines and 1 fetum.

Trextment. - Various are the remedies used for the expulsion of worms: the chief are, wood ashes, poplar bark, sulphur, salt; castor oil, turpentine, calomel, tartar emetic, and aloes; either of which will sometimes bring away a quantity of worms. 13ut the difficulty does not end here; the worms will generate so long as that morbid habit which gives rise to them exists. Hence tho conrse invariably pursued by the author is to change the morbid labit by alteratives and vermifuges * combined. The following is a good example of the same :-

* "Ir this inquiry the principal experiments were performed by immersing the worms of dogs, cats, and other of the lower animals, in milk or fluid albumen, at a temperature of about $77^{\circ}$ Fahrenheit, and then adding the vermifuge of the thuid. Electricity was empluyed to test the actual death of the worm.

"Tajue Worms. - The decoction of kousso and milk proved fatal in half an hour ; turpentine and albumen from one hour to one hour and a quarter; de. coction of pomegranate bark and milk or albumen, in from three hours to three hours and is half; ethereal extract of male fern with albumeu in from three hours and a half to four hours; and castor oil with albumen in eight nours. Therefore kousso appears to be by far the most potent of the virmifuges.

"Tape worms placed in a salad containing onions and garlic, and dressed with vinegar and oil, died in about eight hours.

"Dolichos pruriens appeared to exert no poisonous infuence, nor did brown ixide of copper; though the latter excited violent mischief in the intestines If a cat, to which it was administered.

- Round YYorms. - Suntonine dissolved in castor oil caused death in ubout ton misutes; bat santonine in milk or in albumen had no appreciable influinse; creosote caused death within two hours; common salt in from two to six hours; and the rne of the herring, or flour of mustard, in four hours. Turpentine and albumen, or petruleum, or oil of cajeput and albumen, were upon a par with common salt. A salad containing garlic and onions caused death in from ten to fifteen hours; garlic acid, pomegranate root, and vinegar operated fatally in about eleren hours; but kousso and the other astringents required from twenty-four to thirty hours befure they produced this result. Ordinary oisters acted rery slowly and unsatisfactorily.

"Froir these experiments Dr. K. recommends that, to the cure of rond 


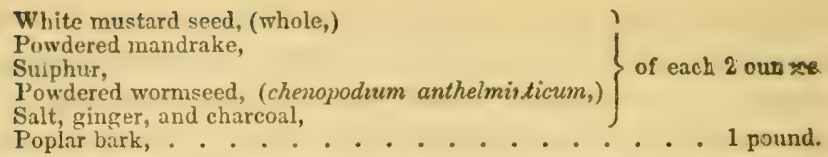

Mix. Dose, one ounce, night and morning, in the food. Undes the exhibition of this medicine, aided by proper dietary regula. tions, the animal will gradually improve in condition, and in the course of a short time the worms will disappear. Should the rectum abound in pin worms, an injection of salt will be indicated.

The following vermifuge is occasionally prescribed by tho author, and it has, in some cases, brought away large quantitieg of worms:-

$$
\begin{aligned}
& \text { Castor oil, . . . . . . . . } 12 \text { ounces, } \\
& \text { Oil of wormseed, . . . . . I ounce, } \\
& \text { Oil of tansy, . . . . . . . } 3 \text { drachms. }
\end{aligned}
$$

To be given on an empty stomach, followed by mashes of fine feed or shorts, well seasoned with salt. To be repeated, if no. cessary, until the bowels respond.

\section{NICKING.}

Nicking is another fashionable barbarism that very few horses escape. The world of horsemen have decided, no tail no horse; and if an animal does not describe an angle of forty-five with his tail, he is said to carry wone. In order, therefore, to find a ready purchaser, an owner is often compelled to have his horse nicked, in order to make him appear more graceful. The operation, as performed in England, is thus described by Surgron: White:-

"The operation consists in making three incisions in the uriler part of the tail, extending quite across, or as far as there is no hair produced. The first cut should be about two or three inches

Forms, a mixture of santonine and castor oil should be made, in proportion 0 from two to five grains of the furmer to one ounce of the latter, and a teaapoonful of this given until the desired effect is produced; and a'ong with this he resommends salt and mustard, with onions and garlic, to be added to thr diet of the patient." - Report on Practical Medicine, by Dr. Küchenmeister. 
from the hase of the tail, and a simbar space should $b$ : left betwren the first and second, and serond and third incisions. On making the second incision, if the first has been sufficiently deep part of the muscle will protrude, which must be drawn out ard cut off. The blereding is to be stopped by pledgets of tow firmly hound on. The tail is now to be kept in an elevated pusition by means of a cord tied to the end of it, and passed over a pulley with a weight attached to the other end of the cord. It is need Less to give a particular description of this part of the procesg, as the apparatus may be seen in any horse dealer's stable, whero it is alwilys kept ready. It will be necessary to keep the horso in the pulleys from three weeks to a month. The morning after the operation, the bandarge must be loosened or cut through on the back part of the tail, or severe inflammation may be the consequence. The weight applied to raise the tail must at first be moderate, not exceeding two or three pounds; but about the sixth day it may be increased to four or five pounds. No kind of dressing is necessary during the process; the loosened bandages will fall off about the third or fourth day, and leave large gaping wounds, which will gradually fill up, and be completely healed in three weeks. When the horse has been in the pulleyg about a week, he should be taken out for a short time, and led up and lown, in order to see in what manner he carries his tail. If it is not sufficiently raised, it may be necessary to put the transrerse line, upon which the double pulley runs, a little farther forward towards the head of the stall, that the tail may be brought more over the horse's back; and slould he carry it on one side, the pulley must be so confined as to keep it on the opposite side for a sufficient time to make him carry it straight. A similar $3 x$ amination should be made daily, and he should have a little exercise."

Th a '1sual mode of operating in the United States, is to make a sub-cutaneous section of the muscles, known as depressores cuccygis, the use of which are to depress the tail. The knifs is introduced as near to the anus as possible on one side of the tail, tetween the bone and muscle; then, with a sort of sawing moticn, - the back of the knife being towards the bones, - the muscle is divided, which may be known by the edge of the knife 
coming in contact with the integuments. This is repeated on the other side, and the operation is finished. The horse is genernlly fettered by a rope from the neck, sirured to each hind leg; he has also a twitch on the nose. This operation, when performet in a skilful manner, is, probably, superior to that recommended by White, which leaves a large cicatrix, very objectionable to Americar. horsemen. It not unfrequently happens that horses lose an enormous quantity of blood after the operation; but that resulis from want of anatomical knowledge. The coccygeal arteries are severed, which the surgeon knows how to avoid. Amateur operators often find that the subject of their experiment is seized witk locked-jaw; and in other cases the tail curves laterally towards the body. In the former, some unnecessary mangling has been performed, and in the latter case, one of the curvatores coccygis has been partly or wholly severed, which allows the associate muscle on the other side to draw the tail that way. Hence the necessity for skilful operators.

\section{METEORIZATION. - (Tympanic Siate of the Abdomen.)}

Meteorization is a tympanitic state of the abdomen, that takes place in acute diseases suddenly and unexpectedly, as does the appearance of a meteor in the heavens. - Hooper.

The following article is translated by Mr. Percivall from the Rec. de Med. Vet.

Puncture of the Cacum. - (Cure.) - A light harness gelding, seven years old, after having eaten a good allowance of oats and bran, was employed to draw a load of dung from Paris to Creteil. He had no sooner arrived when he was attacked witb riolent colics; his belly became rapidly blown out, when, in corsequence of suffocation being threatened, the carter imnediately brought him to the veterinary school.

On his arrival his respiration was highly accelerated; nostrils dilated; countenance anxious; flank so blown out that the process of the ileum is almost effaced; pulse very small, quick, and wiry, \&c. Rectal exploration discovered that the large intes. tines contained but little solid matter, but were mostly distendpu with gas. From time to time the animal made violent 
expt lsive efforts, and when left to himself he lies down ard rolls, \&c.

Diagrostic. - Meterization consecutive on indigestion.

Prescription. - V. S. ; continual walking exercise; simple Clysters; drink of assafuetida 15 grammes, (about $\ni$ ir..) witl a like quantity of camphor. No relief being afforded in an hour afterwards, a drink of aloetic oil, composed of a pint and a lualf of oil with 10 grammes (about $5 \mathrm{j}$ ) of Barbadoes aloes.

Two hours after the administration of this drink. there had been no evacuation of either solid or gaseous matter from the anus. The pulse bad become small and depressed; the skin cold; the respiration anxious, sighing, and short. Asphyxia threatening, the indication is, if we would prevent it, and so save the animal, we must do something instantly. Puncture of the cæcum was determined on.

The skin was penetrated with a sharp, straight bistoury at the most salient part in the flank, about the middle of an imaginary straight line extended horizontally from the angle of the ileum to the last rib, and, for want of a larger trocar, we made use of one of Guerin's, which is used for injections into the joints. This instrument was plunged perpendicularly, with one thrust, through the muscular parietes of the abdomen, so as to penetrate the arch of the cocum, which it did with facility, the resistance of the skin having been previously surmounted by the incision made by the bistoury. The stillette was no sooner withdrawn from the wound than the gas made an impetuous eruption to escape, followed by frothy matters, and spreading around an em. pyreumatic regetable odor.

At length, this current was on a sudden interrupted, on account of the canula being so short that it slipped out of the gut as soon as the latter came to subside and retire from proximity with the prriates. This first result obtained by puncture proving ins?tlicient, we were compelled to renew the operation. A first incision was made through the skin in a part of the flank nearer to the lunbar vetebre, and again the trocar was plunged through the sbdominal muscles in a direction nearly parallel with the transrerse lumbar processes. In this way the instrument penetrated the most prominent part of the cecal arch, and at a point where 
the retraction of the gut was not to be feared so much, tc alter the parallelism between the aperture through the gut and that through the skin. This gave issue to a prolonged flow of gaseous fluids having a repulsive odor; and with the eflux the parietes gradually lost their distention, and the respiration became fuller and freer. The canula was retained in the a perture until the current of gas ceased, and then was withdrawn. The belly had now recovered its former dimensious and suppleness.

The horse was relieved. His countenance had changed for the better; but his pulse was depressed and his skin cold. In order to produce reaction, his body was ordered to be enveloped in two cloths dipped in cold water, and over that to be placed six dry cloths, and he was to be left to himself in a stable made hot. In twenty minutes a very strong reaction had become established in the skin; the hands introduced underneath the cloths experienced great heat; the pulse had recovered its fulness, and with it the peristaltic action of the intestines had become restored; for the animal now continually passed gas and excrementitious solid matters. From this moment all colicky symptoms disappeared.

Now, however, that all apprehension from gaseous indigestion was over, there remained behind such as might arise as consequences of the operation, among which the chief was peri. tonitis. To meet this, bloodletting was practised, and a large sinapism put upon his belly. The next morning the horse ap). peared in full spirits, drawing his provender out of his rack; and the quantity of accumulated facal matters he had evacuated showed the canal to be perfictly free. On the eleventh day after his admission, he returned to his master quite recovered.

\section{PROTRUSION OF THE PENIS. - (Paraphymosis.)}

Paraphymosis consists of a contraction of the prepuce arcund and posterior to, the glans penis. It is generally considered as an inflammatory tumefaction of the glans, accompanied or not with cellular effusion. The remedies are, aperient medicine 
ecld water applications by means of suspensory bandages, and light diet. In cases that resist the ordinary remedies, the stricture must be dirided.

\section{URETHRAL GLEET. - (Blenorrhagia.)}

Blenorrhagia is a simple augmented secretion of mucous matter from the urethra, not communicable by contact. It is supposed to be identical with nasal glect. The worst case the author his ever seen occurred in a stallion which had covered one liundred and twenty mares during a single season. He had a copious discharge of white mucus from the urethra, unattended by symp. toms of pain in volling urine. This is the diagnostic symptom; for if there be any symptoms of pain or inflammatory action, attended with tumefaction of the glans penis, and variations in the color and consistence of the discharge, the case is then one of gonorrhœa, capable of being communicated by contact. Such a disease has never yet come under the author's observation. Still, if gonorrhoa owes its origin to inflammation, - as some contend, - we canuot see how horses can enjoy immunity from it ; therefore veterinarians must be prepared to treat it. In the case just alluded to, blenomhagia arose from excessive action of the generative organs. For this complaint the animal was drerched daily with a portion of the following mixture :-

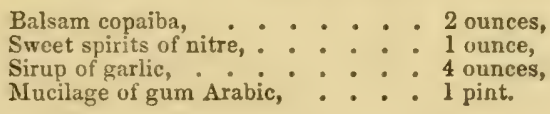

Dose, half a gill.

The penis and sheath were sponged three times a day witt cnld water, and the patient was kept from mares. I'nder tho treatment he recovered. The same remedies are efficient for the treatment of leucorrhcea, occurring in mares, in which cool ing applications $\mathrm{cr}$ astringents are applied to the vagina. 


\section{GLANDERS AND FARCY.}

\section{GLaNDERs.}

It is a notorious fact, that many valuable horses, in this coun try, are yearly sacrificed at the shrine of ignorance; having been pronounced by their owners as grmalered, simply because they have a discharge from the nostrils, accompanied by enlargted maxillary glands.* Aud we do not hesitate to say that many such horses might, by proper medical treatment, be restored to bealth.

Mr. R. Vines, V. S., says, "All the symptoms of disense which constitute glanders and farcy invariably depend on the unhealthy state of the system into which it is reduced or brought, and not, as is supposed, from a specific poison contained in the blood; and these symptoms of disease are found to depend on, and arise from, a variety of causes; whether they occur at the latter states or stages of common inflammatory diseases, such as strangles, common cold, distemper, disease of the lungs, dropsy, dce, or whether they arise independently of such causes; for when the system is brought into an unhealthy state, and is more or less debilitated from neglect, or by the improper treatment of any of these diseases, farcy or glanders is the result. The diseases of every animal will, therefore, assume a character according to the state of the system."

Mr. Percivall, V. S., says, "The state of the body, or constittition, will always have considerable influence on the character und tendency of disease. In horses whose bodies are and hive Inng been in an unthriving and unhealthy condition, a common swollen leg will occasionally run into farcy, and a common cofth or strangles, or an attack of influenza, be followed by glanders. In other cases, such unfortunate sequels will supervent without any ostensible or discoverable cause."

We have no doubt that a case of glanders may be induced under the following circumstances: Suppose we select a horseand many such may be found in this city - whose general health shall be impaired; let such animal be exposed to the merciless

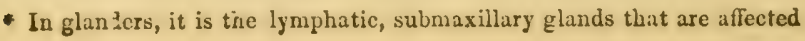


storm for several hours, and he will take what is tesmed, in popular language, a "cold." Let him now be treated accorling to the principles of the "kill or cure system" - bleeding and purging. "The secretions then become impaired; loss of appetit? suts in ; the "coat stares;" there is a dull, sleery appearance about the animal, and a discharge from the nostrils, at first thin Bud opaque, but which soon acquires a tenacious and acrimonious cliaracter ; it finally assumes a putrid type, and decorpeses parts of the mucous surfaces; ulcerations of the cartilage of the nose follow, and we have a pure case of glanders. Then, as another illustration, let us suppose that the function of the skin be impaired, and the animal be confined in a hot and crowded stable. Under these circumstances, the lungs have an extra amount of labor to perform, and soon become incapacitated. We then have deposits of morbific matter on the mucous membrane, which corrode, accumulate, and timally result in tubercle of the lungs.

When horses take cold, there is a loss of equilibrium between the internal and external relations. The reader must bear in mind that the mucous membrane, which lines the internal cavities, is a duplicature of the external surface; but not being exposed, like the skin, to the action of external agents, it is not so strong nor so dense as the latter; yet it performs nearly the same office. If the action of one is suppressed, the other immediately commences to perform the extra work; hence a common cold, which contracts the excrementitious vessels of the external surface, also checks insensible perspiration. Morbitic mater:als now recede to the mucous membrane, producing a discharge either from the nose or eyes; in some cases, however, pro. ducing diarrhœa.

Whenever a horse has taken cold, the prudent owner will en dearor to force a crisis, that is, to relax the external surlare:or, in other words, promote insensible perspiration, - which cun easily be accomplished through the aid of warmth, moisture, and irritants externally, and by giving sudorific and antispasmodic medicines internally. The stricture, if we may so term it, oi the surface, being thus relaxed, permits the egress of morbific mat. ter, which vould otherwise be thrown on the lungs or kirheys. If there is not sufficient power in the system to determine 
Retion to the surface, then diffusible stimulants may be ro sorted to.

Improper stable management is a more frequent cause of catarrh. grlanders, and farcy than any other. The air which is necessery for the purposes of respiration must be pure, or it will irritate the lining membrane of the bronchia and their ramifications. Profusor Coleman relates a case which proves to demonslation the fatal agency of impure atmosphere in generating this class of diseases. "In the expedition to Quiberon, the horses had not been long on board the transports before it became necessary to shut down the hatchways; the consequence of this was, that some of them were sutfocated, and all the rest were disembarked either glandered or farcied."

In a close stable the air is not only vitiated by successive res. piration, but there are other and more powerful sources of mischief. We allude to the injurious gases emanating from the dung and urine.

In this disease, as well as in every other, "while there is life there is hope." A horse should not be condemned until he has had the benefit of veterinary skill. We see no good reason why - provided the disease be of a tuberculous form - the animal may not be so far restored, if treated before the finger of death be placed on him, as to perform ordinary work. We know that in the human subject, sooner or later, softening of tubercle usually takes place, and the portions of tissue imbedded in the deposit are at the same time destroyed; the mingled morbid materials are then throwu out of the body by expectoration, leaving behind a ravity, which Dame Nuture, - a very good doctor, if permitted (1) have her own way - soon fills up with a semi-cartilaginous bouly, leaving only a simple cicatrix behind. At times, however, the contents of the cavity are only in part evacuated, and the retnains form a calcareous mass, which soon becomes enclosed in a sac, and is thus prevented from doing harm. Why, then, may not the same thing take place in the lungs of a tuberculous horse? They are organized after the fashion of ours; they introduce os sgen into the system, and liberate carbonic acid, in the same manner and under the same circumstances as do the lungs of man. The difference in the treatment of each may solve tho 
I roblem. Tlie human patient has the advantag' of nedical skill in the early stacre of his malidly, under the directions of his uwn knowledge, the experience of kind friends, Sc.; aml, lis tirections from the family physician, he so regulates his moit of life that he is placed in the most favorable circumstances for cooperating with nature and with the physiolorical laws of hig b:ing; and bis discase, although of a tuberculons chitrater, nacy be motified in the manner just referred to, so ats not only to rendi:s him a useful member of society, hut to lengthen his days But low striking is the difference in regard to the poor horse! IIe nill work and toil to death without uttering a groan. He labors from day to day, while the disease, in an insidious form, is permanently locating itself in the vital tissues. A slight cough, or other premonitory symptoms, may be present; but generally they are not considered of any consequence. If the poor brute lags in his pace, the whip is brought into requisition to urge him on under his heavy load; and after a day of toil he is often placed under circumstances very unfavorable for the healthy action of the vital forces. So soon as the disease has approached to that intensity as not to be mistaken, he then becomes an olject of terror, neglect, and cruelty. Whereas, had the animal been attended to in the incipient stage, the disease might have terminated as farorably as it oftimes does in the human subject. It is a well-known fact-perhaps confined within the halo of the profession - that thousumds of our most valuable horses annually perish in consequence of neglect and ignorance on the part of their owners. For wherever we find the conditions which the physiologist asserts to be most favorable to the preservation of health most completely fulfilled, there do we find glanders luast grevail. A few facts will place this subject in a striking light: A great majority of the cases of glanders occur ameng horied used under railroad contractions, where the work is of the most laborious sind, and the owners are too poor to furnish their animals with good quarters and wholesome food. So directly, however, is the health of the horse promoted by comfortable quarters, good management, and nutritious diet, that our wealthy citizens seldom, if ever, have a glandered horse, considering. bowever, that the disease is of spontaneous origin. The mortality 
from glanders in that densely populated city, Lorid.n, is not chargeable to any other cause than criminal neglect, indifference, and cruelty.

We shall now introduce a case tending to support our proposition, namely, that glanders may be palliated in the same ratio with its sister disease in the human family - phthisis pulmonolis.

The subject, a dark-bay gelding of the sanguine bilious temper. ament, aged eight years, was placed under our care for treatment. The following symptoms were recorded: A discharge from the left nostril of a purulent grumnus mucus, which adhered to the edges of the part, and formed crusts of a yellow-green color. 'The breath was extremely fetid; the nasal membranes were of a deep-blue and reddish color, and ulcerations were apparent on the nasal membranes; the submaxillary lymphatic glands on the left side slightly enlarged; coat staring; flanks tucked up, and appetite poor; respiration gurgling.

Treatment. - The nasal passages were daily injected with pyroligneous acid. The diet consisted of equal parts of wheaten flour and oatmeal; the drink, Cochituate water, acidulated with elixir of vitriol, eighty drops to the bucket. The medicinal agents used were the same as recommended for farcy, (see Farcy ;) in adlition to which, the patient was occasionally drenched with brandy and salt - - three ounces of the former to one of the latter.

The treatment occupied a period of about three weeks; during which time the horse was kept in a yard having a shed wh: could retire in stormy weather. The ulcerations of the nasal membrants disappeared; he improved in condition, and had sc far jegained his former healthy appearance that he was sold for one hundred and seventy-five dollars. A period of two yeara Las now elapsed, and our former patient enjoys good healtb, with the exception, as the owner informs is, of an occasional cough.

Reryarding the causes of glanders, M. II Bouley considers, -

"I. That glander: is a spontaneous disease only with the horse species, it being in other animals always the result of contagion that in the horse species it may be the result of contagion, but generally it is a product of disordered or perverted nutritice 
action in the system, and, consequently, is in its orignin perulia to the horse species.

"II. That this exclusive generative faculty is coincident with the exclusive uses to which horses are put; the horse being that vital machin which is employed for moving great weights or vvereeming great resistance.

"III. Oxen, in some localities, are likewise so employed; bu then they do their work always at a tardy pace, so slow, indeed, that it does not interfere with rumination; while horses, on the contrary, almost always work with more rapidity, and oftentimes aie compelled to carry great weights at the same rapid pace. And, moreover the horse, nervous and excitable by nature, freely gives himself up to such rapid movements, expending therely so nuch more strength in any given time than the bullock in his sluw movement.

"IV. Excess of such kind of labor appears to be one of the causes of the horse's deterioration and wearing out. And so glanders, viewed as the result of excessive action in the living urgan, is nothing more, in a great number of cases, than the effect of exhaustion induced by labor to which the powers of the animal were inadequate.

"V. But how does this excessive work produce exhaustion and premature wearing out of the machine? Modern science furnishes us with an answer to this question of a more precise and satisfactory description than formerly could have been given.

"VI. Animal life is sustained through veritable combustion. Pulmonary exhalation proves this. The air expired from the lungs contains the products of combustion - carbonic acid and water. The combustible matter entering into the constitution of the organism is therein incessantly separated and eliminated throush the agency of the affinity of the oxygen absorbed upon the pulmonary surface. It is the same with the incombustible mattcr azote; that being separated from its various combinations whenever the oxygen exerted its affinity, and becoming eliminated through the urinary passages.

"The effect of the air, then, introduced into the system through the respiratory passages, is incessantly to destroy organic com. hinations. and eliminute their products in a state of combustion. 
(carbonic acid and water, through the lungs and skin. Those incombustible, azotic matters, separated from the blood in the form of urea, pass through the urinary channels. The oxygen of the air is continually producing combustion and deconposition of the living animal fibre.

"VII. This action of combustion and decomposition is the more potent the more the acts of respiration and circulation are accelerated, and the contact of the air with the blood becomes, in ronsequence, the oftener repeated.

"Work cannot be performed without the acts of respiration and the pulsutions of the heart becoming more energetic, and proportionably so with the speed and intensity of the work; the consequence of which is, to bring the organic fibre oftener into the presence of oxygen, and so to hasten combustion and decomposition.

"Chemical analysis shows that the products of combustion, exhaled through the skin and lungs, after a rapid course are considerably augmented; consequently, decomposition becomes augmented under such circumstances. I pass over, in this estimate of the causes of wear and tear in the animal machine, the nervous exhaustion consequent on muscular contraction, because, although I attach great importance to them, in this discussion they are not necessary for my demonstration.

"VIII. The orgasm is opposed to this oxidation, -

"?. By virtue of the innate force of cohesion existing between its component particles - a force which for a certain time is able to counteract the affinity resulting from the action of oxygen.

" 2. And especially throtigh the continually renewed influence of the aliments introduced in sufficient quantity into the digestive apparatus for furnishing the living tissue with the elemerits proper for its reparation, and the oxygen of the air with combustible matters fit for the development and completion of its affinities, and through combination with it, for the production of the required animal heat.

"IX. But if, while we are exacting continually from the animal machine a large demand of strength, - which, as I said before, entails the introduction of a considerable quantity of at. mospheric air into the air passages, - we do not afford a suf. 
ficient supply of alimentary substance, - that is to say, of azotic and combustible matters, - the oxygen may exert its affinities $\mathbf{c n}$ the matter actually composing the organs themselves, determining a rapid decomposition, and finally producing with the azotic matter a new principle, endowed with powerful novel affinities, ixpediting by its presence the decomposition of the orgasm, and discovering itself during life by that cohort of symptoms and derangements which characterize glanders.

"This active principle, the result of the extreme oxidation of the system, analogous in its origin and progress to ferments, is glardered virus. I am, indeed, struck with the analogy existing between the mode of generation of glandered ferment in the living body, under the influence of the oxygen of the air, and ferments which are concocted without vitality through the atninities of the same gas.

"* * * Now, may we not admit that, in the vital orgasm, azotic matter, continually coming into contact with the oxygen of the air, may become converted into a peculiar ferment, the same as we behold in the dead body, the organic substance turning into putrid ferment through the combined action of air and water and moderate heat? There is an approximation here which has something specious about it.

" Once produced, in whatever way it may be generated, glanlered ferment is certainly accompanied by ulterior phenomena in the system which bear the closest analogy to those of recognized fermentation. Placed in contact with matter capable of feeding it, the glandered principle assimilates it, and greatly hastens the organic decompositions. In fact, chemical analysis seems to demonstrate that the exhalation of carbonic acid is much more considerable in an animal under the influence of glandered ftrmentation, than, if I may be allowed the expressicn, in an animal in health. Such is the theory; let us now consider the facts.

"X. Experience has shown, and every day still shows, that incessant work, without rest, such as is exacted of borses in certain undertakings, is one of the most frequent causes of glanders. ucute and chronic, but principally of acute. No discussion, 1 should imagine, will arise on this point, it being an acknowledged 
fact \& et forth every year in the comptes rendus of the Alfor School.

"It is no less certain that, in the greatest number of rases, whenever a horse becomes g'andered from over work, it falls greatly off in condition before the disease makes its appesranre - a fact which accords with the great exhulation of carbnnic acid and water, the fatal consequences of the activity of the ro. spirutory and circulatory functions.

"On the other hand, whenever glanders has declared itself, the horse rapidly falls off - he becomes a dog-horse - and thio disappearaner of his fat coincides with the augmented exhalation of carbonic acid, which becomes remarkable at the perird of eruptive and acute glanders.

"Another fact is, that the influence of excessive work may be cosnteracted, and even rendered harmless, by a large reparative plimentation. Demonstrative experience of this passed under our eyes, on a very extensive scale too, on the occasion of the construction of the fortifications of Paris. The horses worked hard in draught became glandered or not, according as they belonged to masters who could atford to (and did) keep them well or not. Most of the glandered horses were the property of unfortunate piece-workers, (tácherons,) knowing little of the manugement of horses, and too parsimonious of their feed; while, on the other hand, the disease spared such as were well fed by wealthy contractors, undertaking the work on their own account.

“XI. The laboring ox is not subject, on account of being w orked up, to any disease having the least analogy with glanders. Not to notice his difference of organization, which is a principal consideration in this question, I contend that the difference of results from the same cause in the bullock and the horse is owing to the modes of using them, to the constant slowness of pace of the one, and the oceasional and frequent rapidity of that of the other. This difference may cease to exist whenever the ox is forced into quick work, and especially should he be fat at the time. In such condition, under the influence of hurried respiratiou, oxidation of the combustible elements takes place with 86 great rapidity that the exhalation of the carbonic acid product paunot get "ent with sufficient celerity, and the consequence is 
the animal dies asphyxiated or clearbonneux. In this case, a new principle, a ferment, becomes generated in the blood under the influence of extreme oxidation.

"XII. I am not to be supposed to admit that in every case gianders is the result of extreme oxidation. I reserve this inter pretation for one cause alone of the disease, viz., over-work." London Veterinarian.

\section{FARCY.}

Authorities define farcy to be a disease of the lymphatic vessels, making its appearance in the form of circular swellings, termed farcy buds, which terminate in a discharge and ulceration.

Symptoms. - The horse usually exhibits some symptoms of a deranged condition; sometimes, however, scarcely noticeable, at others very apparent. The horse is not in his usual spirits, appears dull, and does not partake of foor with his accustomed relish. Some horses will have febrile symptoms, puise quicker than natural, mouth hot, urine high-colored, \&c.; others are suddenly attacked with a swollen leg. Horses often become sud. denly lame in one of the hind extremities. Mr. Percivall re. marks, "I have known horses so lame from farcy, before the disease had in any local or characteristic form declared itself, that shoes have been removed, and feet searched, \&c., to discover the cause and seat of lameness, no suspicion having existed, at tre time, that farcy was present in the animal's system. It may so happen, however, that none of these preliminary symptoms are observed or observable; that, on the contrary, farcy at once develops in an attack on some locality - most probably one hind limb. Indeed, so sudden, sharp, and severe are attacks of farcy in some instances, that in the course of one night the horse's limb will be swollen to a frightful size, so as to incapacitate him almost from turning in his stall and walking out of the stable.

"Ordinarily the development of farcy plainly accounts for the halting or lameness; now and then, however, the lameness ap. pesss without any ostensible cause.

"Viewing the afected limb from behind, we perceive a fulnest os soe unside of the thigh. along the course of the femoral vein; 
and the application of our finger to this will imınerliately deter a corded, nodous swelling, which has been happily enough, in the sensation it conveys to our feel, compared to a "cord with so many knots tied in it.' This is at once deslarative of disease in the lymphatic vessels - of the presence of farcy.

"Tracing the cord upward from its place of origin, which com. monly is above the hock, the hand is carried into the groin, and there discovers a lobulated tumor, a swelling of the ingtimal glands, which may, without impropriety, be called a bubo; some. times. however, the bubo does not make its appearance until after the full development of the cord.

"Farcy does not at all times commence its attack in this open and unambiguous form; on occasions it presents itself in a shape so insidious, that at first we hardly suspect it to be farcy, unless there happen to be present circumstances to induce suspicions of its existence. Sometimes one of the limbs, most likely the hind, will swell below instead of above the hock, and the swelling will increase around the fetlock, and an aloscess will form there. In other cases, blotches or isolated pustules will break out upon the limbs, more likely upon the inner than the outer sides of them, or upon the body, or upon the shoulders, neck, breast, or quarters; and these will break and discharge among the hair, clothing those parts with an ichorous or dirty-looking thin puriform matter."

These are the general symptoms of farcy: if any doubt, however, exists as to the nature of the disease, it will in a few days, cometimes in a few hours, be dispelled by observing corded lymphatics issuing from these patches, which soon become running sores.

A case of farcy came under our observation a short time ago. The subject had for some time been suffering under constitutional derangement, gradually losing his appetite and flesh. An influenza was now prevailing in the stable, which attacked all the inmates. The one alluded to had a fetid discharge from the nose, liffering from that of the other horses; and soon farcy buds made their appearance, accompanied by swelling of the legs. The fetid breath, together with the constitutional symptoms, would seem to faror the hypothesis that the patient was a subject of deep-seated farcy, and, probably, had been such for a length of time. It was thonght advisalule to destrov this animal 
The others all recovered; four of the number, however, having swollen legs, were peruitted to run a few days at grass before they could be put to work. Veterinary writers speak of several forms of farcy ; but these are only vorieties of the same disease, differing culy in their symptoms and duration, assuming a mild or malignant form, as the rase may be, in exact ratio to the general health of the subject.

The first stage of farcy is tumefaction of the lymphatics "derelopment of the farcy bud."

The second stage is commonly a suppurative one, terminating in a farcy ulcer. After passing through these two stages, the disease may, and frequently does, terminate in glanders. Hence the prognosis of farcy, in most cases, is considered unfavorable; yet, when it attacks horses in good condition, some hopes may be entertained of a cure. In the diaynosis of farcy we are not apt to be mistaken, provided we keep in mind the language of a distinguished veterinary writer, who says, "No swelling of a hind limb (or any other part) constitutes a case of farcy apart fiom the unequivocal signs of lymphatic disease; there must be present corded, nodulated swellings, - buds in some form or other, together with actual or approaching tumefaction of the lymphatic glands, or the case is not farcy."

"I cannot help thinking," says the same author, "from accounts I have perused in some veterinary works, that both glanders and farcy have been mistaken; or, rather, that diseases of another kind have been mistaken for them, and for farcy oftener than for glanders. One disease in particular, and one that is by no means so very rare in its occurrence, I feel quite certain has been called by the name of farcy, and under this aypellation appears to have bəen ' cured,' and to have been recorded as such. The diseas. I allude to is that which is now known by the name of diffioso inflammation of the cellular membrane - a disease consisting iv the generally sudden appearance of lumps or patches of sub. cutaneous effusion of a solid and even firm description, attended by odematous, swollen states of the limbs, belly, sheath, \&c. ; and thus having, so far, the character of water farcy. ${ }^{*}$ But in

* What was in former times known as anter farcy is ow understood as supet ficial drop $8 y$ - an effusion in to the cellular tisue. 
thcse cases, let it be well ubserved that there is n s lymphatic dis ease, nothing like furcy buds and cords; in which circumstance it is (connected with the course and termination these respective diseares are seen to have) that we are to seek for a correct diag. nasis. But how are we to distinguish farcy buds from some eutane,us eruptions - from surfeits * - which appear so much like them? There is but one species of farcy for which there eruptions can be mistaken; and that is the diffuse or oroadcat variety - the button farcy. Now, should the attack be farcy, the probability is, from its being a general one, that the animal will show signs of ill health at the time; whereas a horse that has 'broken out in a surfeit all over his body, is commonly in unusually good, what is termed fine condition. Then, again, surfeit lumps are often large and irregular in form, and frequently appear in patches; whereas the buds of button farey are small, and regularly spheroid in shape, and spread pretty uniformly over the body. Again, surfeit eruptions are often but of an hour or two continuance - rarely are they visible on the following day ; any doubt, therefore, that may impend over the case is not likely to be of lengthened duration."

The causes of farcy exist in any thing that deranges the lymphatic system; and probably the same causes that operate, either by contagion or otherwise, to produce glanders, will produce farcy. "By inoculation, farcy has been produced by the matter of glanders, and glanders by the matter of farcy; and, consequently, there is every reason to infer a similarity, or rather an identity, in the viruses of the two diseases; and in further proof of this, as we said before, one disease, or form of disease. almost invariably terminates in the other prior to dissolution. 'There can be no question but that the same contaminated or miasmatic atmosphere of the stable or elsewhere, which produces glacders, may occasion farcy, and vice versa."

Treatment of Farcy. - The patient should be placed in a well-ventilated stable; if, however, the season permits, a run at grass, in the daytime, will be preferable. Pure air and green

- Surfeit. A disease of the skin, consisting in an eruption of small pustule it sjpears to arise from a diseased state of the stomach aud bowels. - White 
foud winbined, are almost certain to produce a favomable effect for pure air decarbonizes the blood, deprives it of those impurities which abound in farcy subjects, and at the same time distemds the lungs to their normal capacity; by which means the bluod is eirculated with more force to the extreme vessels. The gr..en food, while its action is alterative, provides for the laxity of tho bowels, keeps them free and unobstructed, and entirely dispenses with cathartic medicine; the latter being generally considered necessary to clcar out the bowels; but in our opinion, the " brisk dose of cathartic medicine," so highly extolled by some, is calcusated to produce unfavorable results, especially if the fatient shall be in a state of debility. Any man who has ever been fuolish enough to practise the common error of periodical dosing with salts and semna, castor oil, dec., can testify as to their prostrating effects; but this is only an item in the catalogue of evils; great pain, griping, loss of appetite, subsequent constipation and dyspepsia, are the consequences of cathartics and purgation. Therefore, if the fecal accumulations can be got rid of under the exhibition of so safe and desirable an agent as grass, it is certainly to be preferred to the tripe-scouring compounds of the day.

The grass may perhaps act as a cathartic, especially if the sub. ject has been accustomed to corn and oats: if this should be the case, a sufficient quantity of $d r y$ food should be allowed to supply the waste of the body and promote the living integrity; for without oil the light will go out, and food is to the system what oil is to the light; therefore, in such case, a liberal allowance of nutritious food will be indicated.

When green food cannot be obtained, a sort of substitute can be cornpounded, consisting of boiled carrots, beets, and turnips, thickened with shorts or fine feed, and the whole pounded up together, to which a tablespoonful of salt may be added.

As regards the drink, we need only observe that pure water in small quantities, is perhaps the best; yet if the patient be in exceedingly poor condition, he may then be allowed two quarts of hay tea and a pint of fresh cow's milk twice a day.

Anima's suffering from zither glanders or farcy should have 
a liberal supply of common salt.* A quantity shculd be placed in a situation were the animal can help himself; in addition to which the food should be salted.

Medicines. - These must possess the following properties :1. Antiseptic. - To preserve the system from putrescence. The principal one is pyroligneous acid; dose, one ounce, twice a tay, in a pint of sage tea.

2. Alterative - Tc shange morbid action, the following is an rxample :-

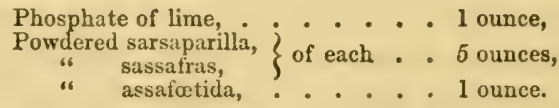

- Saline matters are essential constituents of the blood, of the organized tissues, and of the secretions. They are, therefore, necessary components of our food; for without them health and vitality cannot be maintained.

The alimentary salts, which, on account of their occurring more frequently and largely in the system, may be regarded as of the most importance in a dietetical point of view, are common salt and the earthy phosphates. Ferruginous compounds (salts ?) and probably salts of potash, are also indispensable ingrodients of our food.

1. Common Salt, (Chloride of Sodium.) - Though salt is a constituent of most of our foods and drinks, we do not, in this way, obtain a sufficient supply If it to satisfy the wants of the system; and nature has accordingly furnished us with an appetite for it. The salt, therefore, which we consume at our tatle as a condiment, in reality serves other and far more important purposes in the animal economy than that of merely gratifying the palate. It is a necessary article of food, being essential for the preservation of health and the maintenance of life.

It forms an essential constituent of blood, which fluid doubtless owes many of its important qualicies to it. Thus it probably contributes to keep the blood corpuscles unchanged; for when these are put into water, a powerful and rapid endusmose takes place, in consequence of which they swell up and assume a globula: form; whereas in a weak solution of salt they remain unchanged. Ir malignant cholera, and some wther diseases in which there is a deficiency of shif saline ingredients of the blood, this fluid has a very dark, or even bla:k appearance; whence it has been assumed by some writers that the red color of th: blnod is dependent on the presence of its saline ingredients. From the salt of the blood, aided by water, the gastric juice derives its hydrochloric acid, and the blood and the bile their soda. The soda which exists in the blood, in com bination with albumen, passes out of the system in union with organic matter,

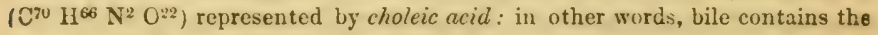
tlements of choleate of soda, though not necessarily arranged as such. Last. ly, "the soda, which has been used in the rital processes, and any excess of soda, must be expelled in the forn of salt, after being separated from the blood by the kidney." - Liebig. 
Mix; and divide into twenty-four powders; one to be given night and morning, in thin gruel.

3. Stimulant. - To arouse vital action, the chief are capsicus nad ginger. 'The author has used the following preparation with considerable success :-

$$
\begin{aligned}
& \text { Iudine, (reduced to powder,) - : : } 4 \text { scruf les, } \\
& \text { Proof spirit, : - } 4 \text { ounces, } \\
& \text { Tincture of caps sum or ginger, : : } 6 \text { ounces. }
\end{aligned}
$$

Dose, one ounce, twice a day, in thin gruel.

Another.

Hydriodate of pot issium, . . . 20 grains.

Dissolve in a pint of water; then add one ounce of tincture of ginger. To be repeated daily.

Such are the remedies on which our hopes of cure are to be founded; they are not to be given conjointly, but separately, as the various stages of the disease indicate.

Should the horse's hind limbs be enormously swollen, so that he cannot move about without inconvenience and pain, then the ollowing drench must be administered :-

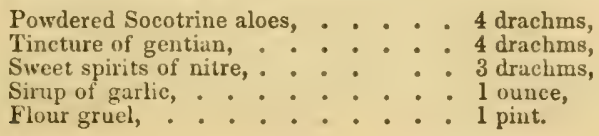

Mix.

It will probably not be necessary to repeat this dose; in fact, we should not recommend the aloes, were it not that the horse is now unable to seek an equivalent in the pasture, and the grave nature of the case calls for some arrent cavable of producing a change in the syotem diverting the fluid (which is now accumu. lating in the cellular tissues of the limbs) from the parts to tho central membranes. Lest we may not be ulderstuod by Li: reader, (non-professional,) we remark, that aloes act as a ma chanical irritant on the alimentary surfaces, and a copious secre. tion of fluid from those surfaces always follows the exhibition of drastic medicine.

The swollen, hot, and tense state of the limb calls for some local application. We therefore first wash he parts with a weak ley of saleratus, and afterwirds apply astringents, com. posed of a strong infusion of one $u^{\prime}$ the following articles bay. 
berry, white oak, nutgalls, gum catechu. Bandages moistened with equal parts of vinegar and water form a good eraporating, cooling lotion, when pain and inflammation are evident; yet, after all, voluntary exercise, such as the animal will take while procuring fwod in the pasture, will generally have a better effect on a tumefied limb than all the local applications we can make.

'The local treatment of furcy buds is a matter of importance; for the discharge from them is sometimes so corrosive, irribating, that it destroys the surrounding skin and subcellular parts. White and some other writers recommend the most destructive poisons as topncal applications, such as corrosive sub limate, muriatic acid, lunar caustic, red precipitate - in effect, no doubt, setting up a worse disease than the one alrearly present. In such articles we have no faith: on the contrary, we consider them first-rate poisons, capable of altering, and in a great majority of cases destroying, one or more of the functions necessary to the support of life. The following will form the best local application we know of :-

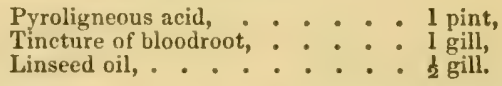

Mix, and wet the furcy buds with it morning and evening.

\section{WET PACKING.}

The method of local treatment, after the fashion of hydropathy, is thus described by Surgeon Haycock:-

"In the first place, procure the following articles, of the best quality of their kind; namely, two pieces of strong, coarse linen. or larding wrappers, one piece of which must be seven yards in leiggth, the other three yards in length, and both of them four feet in width; also, four linen bandayes of the usual wilth, and each of them six yards in length; or, what would be better, eight linen bandages, each bandage three yards in length; also, two pieces of coarse woollen cloth, very firm, but soft and per. fectly pliable in its nature, of the same length and width as the two pieces of harding wrapper; also, eight wool en bandayes, of the same length as the linen ones; also, tleree or four large woul. 
len rugs, such as horses are usually cluthed with in cold weather also, a number of strong iron sliewers, a strong packing needle and several yarts of thick string. Having procured the above articles, (for recollect it is worse than useless not to have them of a sufficient number, size, width, and length,) the second step is to use them properly ; and upon this depends entirely the success of the operation. 'Take the linen sheets and the linen bund. ages, and immerse them in a large quantity of clean cold warra, (iho colder the water the better,) and stir them about in the water so that the whole may become thoroughly saturated. Thirdly take the large sheet out of the water, roll it up the short way, and give it a turn or two for the purpose of forcing out the loose water which it may contain, and giving this into the hans. of an assistant, (of which the operation will require two or three,) he must then strip the patient of all clothing, and freely sponge its body with cold water from the chine to the loins, embracing the sides, and under the abdomen; then take the wet sheet, rolled as it is, - lay it upon the patient's back parallel to the spine, and, holding firm the loose end, let an assistant roll it firmly round and round the body as tight as possible; then take the longer of the woollen wrappers, (not the woollen horse rugs, ) and roll it also firmly round the body, and upon the top of the wet sheet, and secure its loose end with two or three of the iron skewers; and upon the top of this again fold a large woollen rug, which make secure where the ends meet with the needle and thick string. In precisely the same manner apply the smaller of the wet sheets to the neck, (but here a little difficulty may arise, which will require careful attention - the necks of well-bred horses are frequently very thin and spare, and they re. quire in this process to be packed: the best packing is made with a roll of wool, one roll of which is fixed on each side of the nak in the hollow, running parallel with the windpipe,) which foll witl the lesser woollen sheet, and above it again with a woollen rug, made secure as above described. Then repeat the process upon every one of the limbs, and fold above the wet bandages the dry woollen ones. To complete the operation, all that is now required is to spread over the patient the diy woollen rugs the one placed over the body make secure with a sroad surcingle. 
while the one upon the neck may hang loose, after which close the box, and leave the animal alone for three or four hours, or eren more: it may always be known, however when the cloths have been on long enough, by simply passing the hand under them and feeling the state of the skin; and if the skin be wet and liot, do not disturb them; but if the skin be dry, or nearly so, and the linen cloths are also dry, or in a dryish state, remove the whole at once, and put upon the patient fresh, dry, comfortBh)! clothing; the quantity of such clothing necessary will, of course, depend upon the season of the year, and the temperature of the weather. After the cloths are removed, I sometimes hare the skin rapidly and lightly sponged over with cold water, and then three or four men are set vigorously to work with their hare hands to rub it perfectly dry ere I apply the clean clothing. It is seldom that I find it necessary to apply the wet sheets above once or twice before an improvement becomes rapidly visible; and when once such improvement has set in, then assist it with such remedies as may answer best to the phenomena, for it must be borne in mind that the wet sheet is a very weakening agent if applied too frequently."

\section{DISINFECTION OF STABLES.}

The cheapest and perhaps the best stable disinfectants ar quicklime, chloride of lime and of soda, and pulverized charcoal Many of our horsemen have yet to learn that the health of their herses depends, in a great measure, on a proper supply of pure, uncontaminated atmospheric air: when they are convinced of this fact, we may expect a reform. It is a universal custom, in this sity, to collect all stable sweepings denominated manure, and to Jepcsit thrm in a reservoir beneath the stable floor this is carted off from the city about once a week. In the summer months, the stench arising from this semi-putrid mass is almost intolerable. It is no: however, in all cases a matter of choice, but one of necessity; for in a crowderl city, like Boston, the evi] is not easy to remedy. Yet something can be done to conduct the impure emanations from the stable into the surro:mding at mosphere, wh re it would be comparatively harmless. In this 
rien we recommend each stable-kepper to have a ventilatur con. siructed; and it may be grot up on a cheap scale from pine board, which should be dovetailed together. Its form will be a matter of choice; the circular will be most preferable; yet, whire economy is the order of the day, a hollow, square spont will answer. The lower end of this ventilator must be inserted into the stable floor, and only inserted, for if it be suffered to rarh a few inches below the under surface of the floor, it wiil te but an imperfect ventilator. Its length will correspond ti the height of the stable, always allowing a few additional feet, to rise above the roof. It may be protecter from rain by a tri. angular cap.

We cannot close this subject without making what we conceive to be a valuable suggestion, which, if fully carried out, will be for the mutual advantage of stablemen and farmers. Our plan is, that each stable-keeper shall supply himself with a quantity of powdered charcoal, a limited portion of which is to be sprinkled every morning orer the dung heap. For a stable areraging twenty horses, half a barrel of charcoal daily would nct be too much; the more there is of it the better for the farmer, and, indeed, for the whole human race. For then many of the diseases which have of late attacked our fruits and verretables might be arrested, and, perhaps, wholly prevented. Much of the fruit now brought to market is a direct cause of diarrhoea and dysentery.

By this arrangement the farmer will be the one most benefited, and we venture to say that any sensible man would be willing to furnish the requisite quantity of charcoal, provided he has the privilege of purchasing the manure. He certainly would nut object, when purchasing manure, to pay the additional cost of the charcoal, for it surpasses all other substances in the power which it possesses of absorbing ammonia, ard the ralue of mavure is increased in proportion to the amount of amimo nireal salts which it contains. 


\section{ON THE USE OF THE CAUTERY.*}

"The us? of the cautery, to the credit of our art be it sasd, is on the decline. The farriers of former days had ever in their hands their cautery or firing irons; with them they opened abscesses anil penetrated tumors, introduced setons, stanched hemorrhage, cleansad sores, and scored the skin over enlargements and lamenessis of almost all descriptions; indeed, even nowadays, we occasionally meet with some luckless wight of a horse that has gone through this ordeal, hearing marks of having been scored over almost every joint in his body. This barbarous and un. necessary practice is, however, much diminished; the improve. ments of modern times have shown us that we can, in very many of these cases, afford the same relief in a much simpler and more humane manner. Not that I am one of those squeamish or chicken-hearted mortals, who would hesitate, as its medical attendant, to put an animal to any pain, short of actual torture, which I was thoroughly convinced was necessary for its cure or reliet; at the same time, if I thought I could effect by mild means that for which were commonly employed harsh and painful measures, I should fiel it my duty to adopt the former in preference to the latter, eren tho dgh the process required a somewhat longer interval of time. In fact. I hold it up as one of the proudest boasts of molern veterinary surgery, that redbot iron - that terrific though potent remedy - is in many cases superseded by comparatively painless but equally efficacious measures: and let us hope the day is not far distant when we shall require its aid even less than we do at present." - Per siral' on the disorders and lamenesses of hor ses.

- Cautery is of two kinds, actual and potential. By th 2 first is meset the od hot irua ; by the second, any caustic application 


\section{OPERATION OF LITHOTOMY, (FOR STUNE, IN THW} BLADDER OF A HORSE.

The following case occurred in the practice of a vcteri:nry surgeon in England, and may serve to illustrate the manner of procedure :-

" Having drawn out the penis from the sheath or prepuce, the cre:ator passed a rod of whalebone up the urethra, until the end of it could be felt in the perineum. He then cut down upon the end of the rod, and through the opening thus made in the urethra he introduced a director, and with a probe-pointed biotnury continued the opening as far as the left side of the anus. He then introduced his right hand into the rectum, and the two fore fingers of his left hand into the bladder, and, without any difliculty, pushed the stone against the middle finger, by which he guided it to the neck of the bladder, and then easily forced it out through the opening in the urethra. The stone weighed rather more than four and a half ounces. Some parts of the stone appeared to have been broken off, and left in the bladder; these were easily removed by means of a bit of soft sponge tied to a whalebone probe, and some warm water. The wound quickly healed, except a small orifice, through which a part of the urine still passes; but the horse has wrrked hard since, and suffered no inconvenience from it. Mr. M. has no doubt that a stone of seven or eight ounces might be thus extracted." Med. and Phys. Journal.

\section{SCALDED SHORTS.}

Shorts, as they are tamiliarly termed, when scalderl, malse an es vellent diet for sick animals. The usual method of prepara lion is, to turn two or three quarts of shorts into a buckrt, to which add boiling water, so that the mixture, when stirred, chall be about the consistence of a soft poultice: it is then to be cov. ered with a cloth, and not given to the horse until sufficiently cool. When a horse has taken cold, and labors under a discharge from the nostrils, the mash may be put into the manger while bct. with a view of steaming the nasal passages, and faroring 
the discluarge of morbid accumulations. It is our general piao tice, when treating horses for acute diseases, to prescribe an occasional mess of the above; and we invariably observe some Lenefit derived. In acute diseases of the alimentary canal, - infimmation of the bowels for example, - the practice is open to some objection, on account of the irritation which the article might produce on the mucous surfaces. During the active stage of such disease, food of this description is inadmissible, and suct: articles as are mi-ilaginous, lubricating, are indicated. The best we know of are flaxseed, marshmallows, and slippery elm. It is customary in England, in large stables, to set a boiler in which hot water is continually kept for the purposes of the stable, and more particularly for making bran mashes, and at night, if any of the horses look dumpish, (fatigued,) a bran mash and a good warm bed of straw generally resture them. Let a man, who has performed a hard day's work, arriving at home late at night, his clothes drenched with rain, his feet icy cold, and his frame shaking like an aspen leaf, - now partake of a bowl of warm gruel, and tumble into a good feather bed, he can afterwards understand how a poor horse, under similar circumstances, miglı be benefited. White recommends bran mashes " in fever and all infiammatory complaints; they are useful, also, as a preparative to physic, serving to remove any indurated foees there may be in the bowels, whereby the operation of the medicine is rendered more safe and effectual. When a horse has been fed high for some time, a change to a diet of mashes for two or three days will often do a great deal of good."

\section{METHOD OF ADMINISTERING MEDICINES TO HORSES.}

The author almost invariably administers medicine in the form of drench, using a common champagne bottle. Some persone, however, assert that "there is great danger in drenching horseg from a bottle; also, that it is very difficult to make them swallow Huid." We never knew of any accident following the use of the nottle, where ordinary caution was observed. Thr re is a space between the canine teeth and grinders where the bottle can bo introduced, and if kept in that position while "drenching the 
horse," it cannot do any harm. Our usual plan is, to stand on the right side of the horse, our back turned towards his body ; wo then take a firm hold of the lower jaw with the left hand, at the same time moderately elevating the head, (not too high,) while with the right we gradually pour down the contents of the bottle. Time should be taken in the process, and if it is poured down in small ruautities at a time, so much the better; the horse will be more likely to swallow it, especially if it shall be made palatalule by the addition of a few earaway seeds or a little honey. IIorses, like children, must be handled in the most gentle manner. They will generally refuse to drink even a little gruel, when any unnecessary severity is resorted to in its administration. They may be coaxed, but not forced.

In answer to the second objection, we observe, that there is no more difficulty (not half so much) in administering a drench to a horse, under ordinary circumstances, than there is in giving a ball. To the latter we have great objections. First, in reference to its bulk; secondly, the length of time it takes for the gastric fluids to dissolve it; and lastly, its action is uncertain. Whereas medicine given in the fluid form is readily taken up by the lacteals, and operates, for good or evil, in much less time. It has also been urged that, when a horse is suffering from disease of the respiratory organs, the additional excitement following the act of drenching is unfavorable to the cure. Unfortunately, we are in a worse predicament when a ball is given, for then the tongue is forcibly drawn out of the mouth, while the hand is passed up to its root, where the ball is deposited. Our own ex. perience in the matter leads us to decide in favor of the bottle. If any further proofs of its utility are wanting, we may mtntion the fact that one half of our city horsemen are in the habit of administering drink from the bottle without accident.

\section{SOUNINESS, AS OPPOSED TO LAMENESS.}

"Reluctantly as we enter on this difficult and much-debated question, we feel it our duty, in a work on lameness, to make some observations on the subject, though these observations will be rather of a general than of a particular nature, and have 
especial reference to soundne s regarded as the conserse of $\mathrm{gr}$ opposite state o lameness. No person buys or sells a liorse with. out feeling some concern as to the soundness of the animal: the purchaser is apprehensive lest his new horse should from any cause turn out unserviceable or unequal to that for the performance of which he has bought him; the vender is apprehensive, either lest the animal, in other hands, should not prove that sound and effective servant he conceived or represented him to be, or lest some unrepresented or concealed fault or defect he is aware the animal possesses may now, in his new master's hands, be brought to light. Scundness, as opposed to actual or deciled lameness, (or as synonymous with good health,) is a state too well understood to need any definition or description: when we come, however, to draw a line between soundness and lameness in their less distinguishable forms, - to mark the point at which one ends and the other begins, - we meet a difficulty; and this difficulty increases when we nind ourselves called on to include under our denomination of unsoundness that which is likely or has a tendency to bring forth lameness.

"'The number of 'horse cases,' as they are commonly called, that have engaged the attention of our courts of law, have brought eminent persons of the legal profession to our aid in the solution of this intricate question. Lord Mansfield, years aga made an attempt to settle the point according to an ad valarem scale; setting every horse down as sound in the eye of the law, whose cost or value amounted to a certain sum. This, of course, was law that never could hold in horse transactions. Lord Ellenhorough legislated with a great deal more knowledge of horseAesh. The law he laid down was, that 'any infirmity which rendered a horse less fit for present use or convenience consti. tuted unsoundness' - a law which, though it admitted of grea! latitude of construction, and to some especial cases did not prove applicable at all, was still a wholesome and practicable one in a majority of cases of dispute. Lord Tenterden made but little improvement on it when he pronounced every horse unsound thnt 'could not go through the same labor as before the existence of the defect or blemish in dispute, and with the sarre degrses of facility.' 
* Professor Coleman's notion was, that 'every horse oi ght to be considered sound that could perform the ordinary duties of an ordinary horse.' This definition is open to the same objections as the judicial laws of Lords Mansfield and Tenterden: mange. diseases of the eye, (so long as they are confined to one pyc,) nay, glanders* and farcy even, in certain stages, and some other diseases, do not incapacitate a horse, and yet they all amount to palpable unsoundness. On the other hand, many a horse, from age or want of condition, or from possessing a constitution naturally weak or washy, is unfitted for what might he considered 'the ordinary duties of an ordinary horse, and yet caunot be called unsound. Then, again, comes for explanation, what are to be regarded as the orainary duties, and what we are to look upon as an ordinary horse; both presumptions equally indefinable with Lord Ellenborongh's standard of finess, and with Lord Tenterden's statu quo 'before the existence of the defect or blemish.'

"The late Mr. Castley, reterinary surgeon to the 12th Lancers, - whose opinions on this subject, as well as on every other, hie habits of acute and accurate observation rendered of peculiar value to us, - felt inclined, to use his own words, "to steer a middle course;' in accordance with which he 'ventured on the following propositions :' - '1st. That all recognized disease constitutes unsoundness for the time being.' ' 2 dly. That changes of structure or an altered condition of parts, and derangement or impairment of function, are allowed by all to be our two great 'sndmarks in conducting examinations for soundness.' The first of these 'propositions' is fairly inclusible in the second ; all disease consisting either in change of structure or change of function, and most disease involving both these changes. And in regard to the second rule for our guidance, obvious and decisive as are changes of structure combined with deranged or impaired function of parts in general, there are still some of that trifling

- A large carrying firm on the mestern road had, many years since, a great number of glandered horses working in entire teams: these horses were bot.ght in young, at high prices, but from neglect and mismanagement soon becans in. sected with the diseasr, and in this state worked on, in some instunces, for many years 
or uniufluential nature that can hardly, when they do exist, lo looked upon as unsoundness: such are chronic or partial disease of certain parts or organs, the obliteration of a vein * or artery, for example, the conversion of fibro-cartilage into bone, as in splent, chronic or partial disease of such an organ as the lirer \&c., \&c.

"Our present inquiry into the nature of so'.ndness being restricted to its relation to limeness, and it being our intention here to deal with broad principles, leaving the nicer shades of distinction for consideration until such time as we come to treat of particular lamenesses, we may safely say that, -

"1. Every horse showing lameness must be pronounced unEound; although the converse of this, as a fundamental principle, will by no means hold good, every horse not showing larneness not necessarily being (considered as) a sound horse. For instance, a horse shall have a spavin, or a curb, or a swollen back sinew, and still evince no lameness, even though he may show marks of having been fired or blistered for the same, and so give us every reason to believe that formerly he has experienced actual lameness from one or other of these defects. Would, however, any veterinary surgeon, under such circumstances, give a certificate of soundness? If he did, it must be qualified in a manner that would little induce any person to purchase such a horse, unless at a price consonant with the evident reduction of his value. It will be requisite, therefore, for us to say, not simply that every lame horse is unsound, but to add the words, or that lus that about lim which is likely on work to render him lame. This will, it is true, open the door to difference of opinion and equivocaion. There may, as we have seen, spring up two opinions concerning the preserce even of lameness. There will in morc cases be two opinions concerning that which is accounted to be the precursor of lameness, or have a tendency at some period, proximate or remote, to produce lameness; all which differences Itre best got $r^{\cdot} d$ of by reference to the ablest veterinary advice. i here will be less diversity of opinion among professional men

- "It has happencd, however, that a horse has been returoed after purchase to "usscund' in consequence of a lost (jugular) vein." 
thun among others, and the more skilful and respectable the pro fessional persons are, the greater will be the probability of a happy unison in their riews of the case. To lay down any statute law which shall meet such cases as these, is, from the very naturo of vital structures and functions, totally an impossible natter.

"We ought to be able to establish it as an axiom, athough it may prove one not unassailable by argument, that a lame horse is an snsound horse. It might be objected, for example, that a horse having a stone in his foot - than which nothing, for the time, renders a horse more lame - should be regarded as unsisund; and yet by this rule he must be so considered so long as he continues to go lame, though as so: nd from the moment thas the stone is removed. The shoe 'nailet on too tight' furnishes another similar example. A horse, quite sound, enters a forge to be shod, and comes out going, as grooms call it, 'scrambling, i. e., lame; he is, in fact, no longer a sound horse : take him back, however, into the forge, and remove his shoes, nail them on 'easy, and, if not completely restored to soundness, he is thereby evidently so much relieved as to give pretty fair earnest of his becoming well or as sound as ever by the next or the following day. It may be said, and we quite agree in the reply, that such trivial points as these are not likely to come before us for decision, or to cause us any trouble if they do: still it is right we should be armed on all sides to defend that law which we, as professional men, deem it wholesome and just to lay down ; viz., that every horse going lame - no matter from what cause - ought to be pronounced unsound.

"If any real objection can be urged to the institution of such a law, one presents itself in the case of a horse that is lame at one time and sound at another. For instance, a horse shall have a frush, of which he shall flinch or go palpably lame every time e happens to tread upon a stone, or whenever he goes upou Lurd, uneven surfaces; though at other times, upon soft gr jund or upon turf, he shall appear quite sound. This horse, we think, stands, in respect to the question of soundness, altogether in a different pcsition from either the stone-in-the-foot or the tightshoe case: here is disease - demonstrable divease; and although it gites rise but occasionally to lameness, still, as lameness is at 
times the result, we hold that the horse ought to be accounted unsound. The spavin - in certain forms - affords another ex. ample of temporary or transitory lamenes. A spavined horse shall come excessively lame out of his stable in the morning, but after having gone a while and waxed warm, shall no longer exhibit lameness, or even stiffness of his hock. In accordance with the laws of the judges, and with that of our late professor, (Coleman,) such a horse being not 'less fit for present use or conrenience,' being 'able to go through the same labor as befors the defect or blemish,' able to perform the 'ordinary duties of an ordinary horse,' - such a horse, we repeat, must be pronounced. so long as he continues in this aptitude, to be sound; whereas, however much we may differ concerning other points, we believe all veterinarians will concur with us in opinion in declaring the occasionally lame spavined - if not the lame frushed - horse to be unsound, notwithstanding his redeeming quality of becoming sound on work, and of continuing so to the end of that work.

"However strong we may feel ourselves in our axiom - that a lame horse must be accounted unsound - the moment, as we observed before, we attempt the converse of it, viz., that every horse free from lameness is (as respects the question of lameness) to be held as sound, we change into a position most infirm and untenable. All sorts of diseases and defects stare us in the face, which, though not the immediate producers of lameness, too surely, in our minds, betoken its approach, waiting only for work or other exciting cause for its development; and with such betokenınent before us, it is quite impossible we can, with any show of reason or equity, pronounce the horse having them, notwithstanding he at the time goes free from lameness, to be virtually : eound horse. For how can we in conscience call that horse gound that we know has that about him which will probably nay, certainly - cause him to become lame the first long or heary day's work he is put to perform? As well might we call an apple or a pear sound which we know to be rotten at the core. And yet, strictly and literally speaking, the animal goes sound is as sound in action to appearance as is the rotten apple or pesr. In zases where so much difficulty, nay, impossibility, presents it. eelf to the drawing of a distinction between the two opposite and 
(as we say call them) abhorrent states of soundness and un. soundness, it has struck us some good might arise from a di. vision of unsoundness into actual and prospective; the latter de. nomination indicating a state of trunsient or trustless soundus: Notwithstanding a horse may be free from lameness, may go sound, yet, so long as he has that ahout him which will probaily or surcly render hin lame the first time he is put to hard wonk Le is rirtually an unsound horse, in honesty unwarrantuble and ti:e best denomination we are able to find for such a failable ron. dition - a sort of intermediate state between soundness and un. zoundness - is prospective unsoundress. So far as astract action is concerned, the horse, it is true, must be regarded as sound; although that which he has upon him, making him liable or certain to become lame whenever he is put to excess of action or work, certainly stands in the way of any warranty of sound. ness being given.

"Prospective unsoundness, however, although it relieves us frorr the necessity of doing that which no protessional man conscientiously can do in very many of the subjects brought before him, viz., of pronouncing the horse either actually sound or unsound, yet unfortunately it opens a door through which crowds of cases, really doubtful in their character or rendered so by the variety of opinions given on them, are ready to be forced in, and made to perplex us in coming to any proper or judicious selection of them. One horse has manifest diseuse, in some form or another, as the cause of his being pronounced likely or certain to go lamo at no very remote period: his case admits of no question. But another horse has - no disease - only a malformatirn, a defor. mity, or misshapenness, the result of which is weaknoss of linb, and consequent liability to failure - to lameness, in lact. I third horse has neither disease nor deformity, nothing but a ' lad Labit,' and that is said to amount to unsoundness. And it is the cases that come under one or other of these latter denominations - which are the offspring either of natural defect, of use or wear, or of habit - that, for the most part, puzzle veterinury practitioners in coming to judiuious decisions on soundness.

"To elucidate these observations by example: A horse shall have a spavin or a curb, or a swollen or fired lack sinew, any 
disease, in short, from which or exertion he is likely, as our ex. perience tells us, to become lame: such a horse is prospectively unsound. But suppose he have a club foot, a parrot mouth, bent limbs, curved or curby-looking hocks, weak joints, narrow or flat feet, a lip down, \&c. - all natural deformities or malformations, none of them coming fairly or popularly under the category of discase - what is to be done in passing judgment upon them? The equitable adjudication appears to be, as in the case of disease, to declare that such of them constitute unsoundness as are probable or certain to give rise on work to lameness; but, then, we shall experience difficulty, in some of the cases, in drawing the line between actual lameness and nitural failing or weakness. A horse foaled with evident deficiency of physical power, partial or general, can hardly be called unsound; though should he have that about him which renders it likely he will, when put to work, recome actually lame, he ought, assuredly, to be pronounced prospectively so. 'Cutting,' as the striking of one foot against its fellow leg is called, arise from whatever cause it may, is apt to produce orcasional lameness, and, when it does so, is fairly regarded as a species of prospective unsoundness. Springhalt is iction so unnatural that some do not hesitate to affirm it to be a pecies of unsoundness, though it is a well-known fact that many norses so affected will do the same amount of work as it is reasonable to suppose they would or could do were they free from it. After all, as the foregoing observations will abundantly tes. tify, a good deal, in the decisions between soundness and unsoundnees, must be left to the skill and judgment of the professional man: he alone can unriddle the true nature of the case, and form a just estimate of the probabilities of lameness; and, if he be but trustworthy and honest in his opinions, he is, beycnd question, the preferable authority in such cases of appeal for ad vice.

"When we, as men acquainted with the animal economy, consider the multiplicity of evils even quadruped 'flesh is heir to,' and reflect in how many ways its health and action may become impaired, and how graduated down those impairments may be into states of indisputable soundness, we have no right to feel surprised at the intricacy in which we find the subject before us 
incolred, no more than we have, in a strictly patholognal oint of view, at the comparative paucity of sound horses coming unler our olservation. The separation of monomania in man from odility or eccentricity is hardly more diflieult than resolving the question of soundness in its dubious or transitory form is in horses; a great deal, after all, must be matter of opinicn, and those opinions will ever prove best worthy our rdiance which are founded on the widest experience, coupled with the bost char. acter for honesty. No more responsible duty attaches to a profissional man than that of giving a certificate of soundiness : by it the warranty of the dealer or vender is either confirmed or falsified, the purchase completed or set on one side, the value of the animal either estahlished or destroyed; on all which accounts is the veterinarian pledged, not only to use his 'hundred eyes' in making the examination, but also his maturest judgment in diving into the nature of any unsoundness he may discover, as well as into its positive or probable effect on the action or capabilities of the animal, both present and to come. This leads us, before we close the subject, to say a few words on warranty; by which is meant an indemnity against any unsoundness, or a pledge given - commonly in writing - by the vender to the furchaser, that the horse is sound and quiet, and possesses such and such qualifications. Without such indemnitication or pledge, the law says Careat emptor - let the purchaser take the consequences; the rule at law being, that every body who purchases a horse takes him at his own judgment, and has no remedy against the seller, supposing the horse to turn out, upon a future trial, or a more considerate inspection after the purchase, to be wort: less hin the sum given; unless he (the purchaser) can prove he was incuced to purchase by representations false withir the kncwl. edge of the seller; to fasten a fraud of which nature upou an experienced dealer in horses is, however, a diffi'ult matter." VTarranties are of different kinds - express or implied, general or special. An express warranty speaks for itself. And as for an implied warranty, such a thing is hardly known, or, at least, rarely taken advantage of in horse dealing, the price paid, huw 
ever high, not being legally held to be any gruaranty of the 6oundness of the animal; and any thing that might transpire be. tween seller and buyer, implying warrany, being worth nothing without proof, which, being procured, would render the transac. tion, in law, tantamuunt to an express warranty. A general war. ranty extends to all defects and fiults known and unknown to the Beller; but a special waranty is contined in its operation to the parts or particulars specifically pointed out. A lac:s 0 may l:s Narranted of such an age; or, having some defect visible up:s his limbs, such as a spavin, or a curb, or a fired leg, of which be dos not go lame at the time, that defect may be specitied, and the horse warranted not (within any reasonable or prescribed period) to become lame in consequence of it. A general warranty, however, affords $n o$ protection against sucl defects as are "plain and obvious' to every body, and, consequently, to the purchaser; no more than a special warranty does against any which are not included or named in the specification. 'But if, on the sale of a horse, the seller agree to deliver it sound and free firom blemish at the expiration of a specified period, the warranty is Lroken by a fault in the horse when delivered, althongh such defect was obvious at the time of sale; and as some splints cause lameness and others do not, a splint is not one of those plain defects against which a warranty will not indemnify; and when a seller warranta a horse sound at the time of sale, and the horse afterwards becomes lame from the effects of a splint, visible when the lcrse was bought, it is certain that the warranty is bruken.' 'This rule will apply to spavin, or to curb, or to windgall, or, in fact, to any cther defect 'visible at the time of sale.' For all warranties can only undertake for the animal's qualifications at the time of salo: rone can extend to any subsequent period unless there be a zpecial clause 'to deliver the horse free from blemish; and that lelivery be by mutual agreement delayed.*

"The form in which a receipt including warranty is geners.lly mritten :-

" Received, the 16th of July, 1845, of A. 13., Esquire, the sum of ninety pounds, for a gray gelding (stallion or mare) warranted sound, and quict to ride and drive.' 
"Or, W Warranted free from vice and blemish, except

"Or, ' Warranted in every respect, except - _ _ .

"Or, "Warranted to have been constantly driven both in singl, and double harness, to have carried a lady, to have been regularly hunted, to be a good hunter or hackney, \&c., \&c.'

"Following the word 'except' there being every opportunity efforded the (honest) vender of stating what he may know inval. idating the warranty, and thereby saving his reputation as well as seseening himself from the probability of litigation afterwards.

"With respect to what (oral) declarations of the seller will amount to a warranty, the primary rule for the interpretation of contracts in general is applicable. It depends upon the intentiun of the parties. A simple affirmation of the goodness of an article is a warranty, provided it (a warranty) appear to have been intended; whereas the sublimest epithets that seller ever employed to recommend his goods to a credulous buyer will be regarded as the idle phraseology of the market, unless an intention to warrant actually appear.' In fine, 'it is from the intention of the parties, as collected from the whole transaction, and from the meaning they appear to have attached to particular expressions, that the existence or non-existence of a warranty is to be inferred.'*

" Let us now consider how the rights of the parties are affected by the horse being unsound at the time of the warranty. The contract being thus broken on the part of the seller, it is at the buyer's option either to treat it as a nullity, and return the horse, or to retain him, notwithstanding, and bring an action on the warranty. In the former case, the price paid is the measure of the damages he will be entitled to recover in an action; in the latter, the difference between that price and his real value. If he offer to rescind the contract and return the horse, he may also recover the expenses of his keep; but in order to do this, a positive tender is said to be necessary. No notice of the unsoundness need be given to the verder to entitle the rendee to maintiin the action; nor is it necessary to bring the action immediately on discovering the unsoundness.' - 'But although such a notice be not essential, yet it is always advisable to give it, is 
the omitting to du so will furnish at the trial strong presumption that the horse, at the time of sale, was free from the defect com. plained of ; thus rendering the proof of a breach of warranty more difficult. Common justice and honesty require that the commodity should be returned at the earliest period, and before it has been so changed by lapse of time as to make it impos. sible to ascertain, by proper tests, what were its original properties." - Hippopathology.

\section{LYMPHATITIS.}

"Lymphatitis is a disease which, although withcut place in any of our systematic books by our professtd writers, is yet, upon the whole, well known, and is designated by a variety of names. In Scotland, for example, it is called weed; while in various parts of England it is known as felltick, thick leg, farcy, water farcy, shot-o'-grease, and a number of others which it is unnecessary to detail, and which, if detailed, would be perfectly impossible to understand. Fifteen years ago, a Mr. J. Henderson wrote a paper upon this affection, which the reader will tind in the ninth volume of The Veterinariun; and from that time to the present it does not appear that our knowledge of its pathology is very greatly increased.

"Symptoms. - The disease, for the most part, commences with a shivering fit, though, in many cases, its existence may be so slight, and its duration so short, as not to be noticed by any save a careful observer. Generally the attack is very sudden; the owner, or the servant in care, may go now, as it were, out of the Etable, and leave his horse to all appearance perfectly well, and upon returning in an hour hence he will find him standing upon three legs, while the fourth will be flexed and beld bigh from the ground; the pulse will vary in its beats according to the intensity of the attack, rarely, however, beating less than fifty, or more than one hundred per minute; while the respirations muy be fifteen or twenty, or even forty, in the same interval of tume. If the affected limb be examined it will be found hot and swollen, and tender if pressed apon, which symptoms for many bours will gradually increase in intensity. Soon after ec mmence- 
ment, a number of vessels may be seen running arross thr. limb in various directions, of about the thickness of a quill; they are the most numerous, however, upon the inner surface of the leg, where they appear to terminate in round or irregular formed masses, which masses are acutely tender if squetzed within the hand; these prominent rassels are the inflamed lymphation, and the prominent masses alluded ro are the inflamed lymphatir glands. Sometimes the swelling extends from the junction of the linb with the body down to the very foot; at uther tines it only renches down to the huck, and when very severe a sort of dew exades from the skin and lies upon the hair.

"The coirser the breed and the older the animal, the greatcr the liability to lymphatitis. Young coarse-bred horses are also very prone to it, particularly if highly fed and under worked; but in the young horse, the disease, in the majority of cases, if not in all, quickly runs its course, and the affected limb beconnes in time perfectly restored to its pristine condition, and if due precaution be taken the malady may not again manifest itself, at least for years to come; while in old horses the diseased limb is seldom or never reduced - it remains permanently thickened, and the animal is extremely liable to have acute or sub-acute attacks of the same disease periodically. In the majority of cases, agrain, Its action is usually contined to a hind leg, and that on the left side; sometimes both limbs are affected, but never, that I have seen, very acutely so at the same time; the lett limb might be attacked, and some time atterwards the right one, but never both limbs simultaneously. I have also found that if the discase be treated according to the old mode, nimely, by bleeding and purging, that horses so treated are prone to be attacked fir more frequently than when treated homoeopathically.

"Causes. - The predisposing causes are simple, the chief of which are peculiarity of breed, and the regular giving of very nutritious food in too great abundance; also previous attacks of the same disease, old age, and the sudden changing of the animal from a poor to a rich diet. The immediate or exciting causes are - heavy blows upon the limbs; severe scratches and cuts; sudden over-exertion; working of the animal in water, or very wet ground: the sudden checking of old discharges from disedsed 
limbs, such as grease, bad thrushes, \&c. ; allowing the antmal to stand in cold draughts when perspiring treely, or checking the perspiration suddenly by riding him into a stream of cold water." - Veterinary Homœopathy, by Surgeon Haycock.

Treatment. - The best treatment the author knows of is, to apply diluted tincture of arnica externally, and give twenty grair: of hydriodate of potassa twice daily.

\section{ON THE GADFLY GRU'B FOUND BENEATH THE SKIN OF THE HORSE.}

"We know that the horse harbors several species of œ. trides, or gadflies, in his body, of which those hest known are the oestrus equi, the ostrus veterinus, and the oestrus hamorrhoidalis, whose habitations are the stomach and intestines. But what we do not seem to be generally aware of is, that under the skin, even, larve, or grubs, of the diptera family breed and give rise to the formation of tumors analogous to such as strike our notice, at certain times of the year, upon the bodies of our large ruminants: and particularly of those who appear, in all other respects, to enjoy the best health. Redi and Huzard (the father) have spokin of these inhabitants of the skin of the horse. Bracy Clark, likewise, has mentioned them in his Essay on Bots; but he regards them as identical with those of the 3ypoderma species which exist underneath the thick skin of the ox.

"Dr. Roulin, of the Institute, in his Researches on certain Changes observed in domestic Animals transported from the Old to the New Continent, expresses himself as follows: 'In the zatos of Llanos, the horses are almost entirely left to themselves. They are driven up only from time to time to keep them from becoming quite wild, to take off them the larve of the œstri, and to mark the foals with a red-hot iron. To what species do these American larve belong? As yet we remain in ignorance of this.' Last of all, M. Loiset, a celebrated veterinary surgeon of the Department of the North, puhlished, some years ago, a short Notice on the Estrus Cuticolens of the horse, and has given a description of the larex of this cestrus, of which we have, ac cording to the text, made a full copy. 
"At the present day, with nature herself before our eyes, we feel satisfied that this description, confessed to be imperfect even oy the author himself, viewed as a branch of natural history, is wanting in exactitule. And this induced him to introduce a portrait of the insect in question, with a fresh description of it more in accordance with the rigorous precision prescribed liy science.

"Its character once well established, we shall be able readily to resolve the question, whether the nestrus in point be identical with the hypoderme of the ox, or whether it constitutes another species to be added to the genus hypoderma.

" The larra cuticolens (skin-habitant grub) of the horse has a cylindrical form, measuring more round in its fore than its hinder part. It is without brain or feet. Its body is constituted of eleven segments, including the one in which is found the buccal orifice, (or mouth,) which consists of a very small hole, edged with a black borler, with some bristles around so fine as to be with difliculty perceptible by the naked eye. The foremost segment is of all the smallest. From this the segments, as far back as the fifth, grow gradually larger; while, on the contrary, the five posterior continue to diminish as they approach the hinder part. These segments, examined upon their ventral surface, with the exception of the two last, are divided transversely, by slight grooves, into two unequal halves, each furnished with a great number of spinous tubercles, whose points, upon the anterior half of the segment, are directed backwards, but forwards upon the posterior half. Two cribriform plates, the sole organ of respiranou with which the grub is furnished, are seated upon a ecrt of flattened termination of the anal segment.

"Alike in this respect to the hypoderma bovis, the skin-habi. tant grub of the horse has, contrary to what is observed in the majority of cases, the inferior surface of the body convex, while the dorsal side of the segments is slightly concave. Such form is in this manner exactly fitted to the spherical cavity which serves as a habitation for the parasite. It is worthy of remark, that che dorsal surface of the body is without bristles, save upon the two or three foremost segments. The general color of the kin s white; the bristly tubercles alone being brown, more or leso 
sharled. The skin itsalf is translueid and vesiculons, as it were In size, the larva is much below the hypoderma boris, since if does nct exceed an inch in length, while the larva of the ox ostrus, at full growth, attains to from three to four inches.

"This difference, in itself considerable, is not the only ong wo have to remark. Upon the subject of our inquiry we do not obeerve the six longitudinal lines which, upon the hypoderme nf the $o x$, form so many series of tuberculous eminences, ranged at nfrtain intervals from the first to the last segment. Neither are to be scen the five or six etninences surrounding the mouth of the latter; thongh, to make up for it, we find at the posterior and inferior side of the second segment a kind of transverse prominence shooting beyond the surrounding skin, and furnished with very small tuhercles, which have no existence in the grub found in the skin of the ox.

"Thrse differences, united to those of size, suffice, in our mind, to authorize the conclusion, that the larva in question, though it belong to the genus hypoderma, constitutes a distiuct speries, up to the present time undescribed, to which we shall gire the name of hypoderma equi.

"No doubt we shall be asked, That are the habits of this insect in its different states? Noborly, as yet, that we know of has inrestigated them. The larva alone being recognized, it is to that the few observations apply of which science is in possession We know that this larva is found principally upon horses that have been living at pasture in the months of July and August, and that throngh its presence are caused large indurated knots or buttons upon the skin, which are found in the greatest numbers along the spine, from the withers to the croup inclusive. These buttons, whose volume raries from a lentil to a small nut, have, according to M. Loiset, a shape inclining to conical; and, by carefully separating the hairs clothing them, may be seen on their summit a narrow aperture, resembling such as a large needle would make. Compressing the tumor causes to issue from this opening a minute quantity of purulent serosity, which, after being removed, is followed, in the last months of the growth of the tumor, by a vesicular point, which is neither more nor less than the posterior extremity of the larra. The efforts made to 
expel this are ordinarily ineffectual up to the period at which its growth fits it for metamorphosis; when, by squeezing the pus. iule forcibly between the nails, a vermicular body springs livelily out, as though impelled by elasticity, and rolls upon the ground. This body is no other than the larva.

"There can be no doubt but that these larre feed upon the pus which forms in the tumors that serve them as habitations if to the moment of their transformation; neither is there any that the bristles clothing their body serve to augment the secretion of the pus through irritation of the skin, no more than there is doubt that the animal makes use of them, like the hypoderma of the $0 x$, for the execution of the motions required for his escape from his foul abode. Once at liberty, he sets out in search of shelter either in the earth or the dung, and therein, after having remained for ten or eleven months underneath the horse's skin, it changes into $\mathrm{fly}$.

"The larva that has been engaging our notice is comparatively rare in the south, but frequently found in the northern parts of France; it is likewise common in Belgium and Holland, along the entire shore of the Baltic and the North Sea.

"Save the phenomena already detailed, the cuticular larva of the horse occasions, according to M. Loiset, no appreciable morbid derangement. Nevertheless, about the period of its full growth, it appears to occasion some troublesome itchings, which give way to lotions of cold water, at times slightly vinegared, or else to some of the means employed for the destruction of the larva of the hypoderma bovis.

"How long does the state of fly continue? What are the habits of the insect after it has arrived at its final transforna. tion? These two yuestions, as yet, wait for answers; but it is to be hoped they will not wait much longer. We have for guar. snty of this the renowned seal of MII. the professors of 0 if Veterinary School, touching all that concerns the interest of science of which those gentlemen are the worthy representa lives." - Translated by Mr. Percivall, from the Juurnal des Vet prinairs du Midi. 


\section{YEDICINAL PREPARATIONS USED IN THE VETERINARY PRACTICE.}

Compound for Wounds, Saddlegalls, \&c.

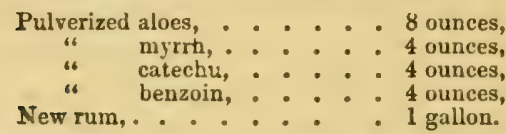

Let the mixture stand for two or three weeks, frequently shaking it, and filter through fine linen.

Styptic. - (To arrest Hemorrhage.)

Powdered gum benzoin,

" sulphate of potassa, $\}$ each $\frac{1}{2}$ pound,
Water, . . . . . . . 5 pints.

Mix, and boil in a glazed vessel, for five hours, stirring constantly, and add fresh quantities of boiling water to supply the loss which is constantly taking place by evaporation. This mixture possesses the property of coagulating blood.

\section{Another.}

Tincture of mastic.

Another.

Tincture of muriate of iron.

Physic Ball.

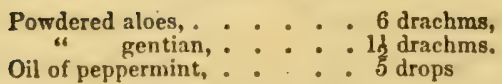

- ft soap, sufficient to form a bolus. A little honey, or mucilage will also render the mass tenacious enough to administer.

Physic Drench. - (Cathartic medicine.)

Pulverize: aloes, . . . . 6 drachms,

Sirup of buckthorn, . . . 1 ounce,

rincture of ginger, . : . 1 ounce.

Laxative Ball.

Puderel aloes, . . . . . 3 drachms,

". sulphur, . . . I drachm.

Mandrake, . . : : . 2 drachms.

To he formed inte a bolus, with honey or mucilage. 


\section{Another.}

Powdered aloes, . : : : 3 drachms,
Soap, . - . : : : 4 drachms,

\section{Croton Purge.}

Pulverized croton seed and farina are frequently used as pur gatives by the profession; the former in doses varying from ffteen to thirty grains, and the latter from twenty-five to forty. fire grains.

\section{Alterative Drench. - (To change morbid action.) \\ Sulphur, . . . . . 1 ounce, \\ Powdered mandrake, . . . 2 drachms, \\ Thin gruel, ....... 1 pint.}

Antispasmodic Drench. - (For spasmodic action, either nervous or muscular.)

$\left.\begin{array}{l}\text { Tincture of assafoetida, } \\ \text { valerian, }\end{array}\right\}$. each 1 ounce,

Sirup of garlic, . . . . 3 ounces,

Gruel, . . . . . 1 pint.

\section{Another. - (For spasmodic cough.)}

Balsam copaiba. . . . . . t ounce,

Sweet spirits of nitre, : : 3 drachms,

Sulphuric ether, . . . d drachm,

Tincture of musk, $\quad: \quad \frac{1}{2}$ ounce.

Half of the above quantity to be given, night and $\mathrm{x}$ orning, in gruel.

\section{Tonic Drench. - (For weakness and debility.) \\ Part wine, . . . . . 3 ounces, \\ Tincture of cinnamon,. . : $\frac{1}{2}$ ounce, \\ Powdered goldenseal, . : . 4 drachms.}

To be giren in thin gruel. Should the bowels be torpid, cmit the port wine, and substitute one and a half ounce of pale brandy.

\section{Astringent Drench. - (See Diarrhœa.) \\ Diuretic Drench.}

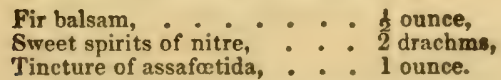

To be given in a thin mucilage of slippery elm. 
Nauseant and Diaphoretic Drench. - ( To increrse the function of cutaneous exhalants in febrile diseases.)

Powdered lobelia, . . . . . . 2 trachms, bloodroot, ...... 1 drachm.

To be given in warm water, and repeated at given intervals.

\section{Stimulating Drench.}

$\left.\begin{array}{cc}\text { T'incture of capsicum, } \\ \text { "“ } \\ \text { ginger, } \\ \text { cinnamon, }\end{array}\right\} \ldots . .$. each $f$ an ounce.

To be given in gruel.

Narcotic Drench. - (To relieve pain and induce sleep.)

Tincture of Indian hemp, . . . 3 dracnms,

Chloroform, ........ $\frac{1}{2} \mathrm{drachm}$.

To be given in warm water. An infusion of poppies, or hops, is a good anodyne.

\section{Sedative Drench. - (To lessen arterial action.) \\ Tincture of arnica, . . . . 4 drachms, \\ water, ......... 1 pint.}

To be repeated, gradually lessening the dose.

Cooling and Refrigerating Drench. - (For fevers or thirst.)

Cream of tartar, ....... t ounce

To be given in an infusion of lemon balm.

Phthisical Drench. - (For Phthisis Pulmonalis.)

Powdered iodine, ..... 10 grains, hydriodate of potassa, . .. 20 grains.

To be given daily, in a decoction of comfrey, (symphitium offici nalis.)

Vermifuge Drench.

Aloes, . . . . . . . . 4 dracnmn

Oil of wormseed,

Powdered male fern, (aspidium felix mas,) 1 ounce.

To be given in one pint of weak soap suds an hour before feeding.

Parturient Drench. - (Given to arouse the uterus in protracted labor.)

Spurred rye, (secale cornutum, - . . 3t drachms.

To be given in a decoction of bethroot, (trillium purpureum.) 


\section{Antacid Drench. - (To correct flatulency.)}

Lime water, . . . . . . 2 ounces,

$\left.\begin{array}{c}\text { Tincture of gentian, } \\ \text { ginger, }\end{array}\right\}$. each $\frac{1}{2}$ an ounce.

To be given in an infusion of horsemint, (monarda punstata.)

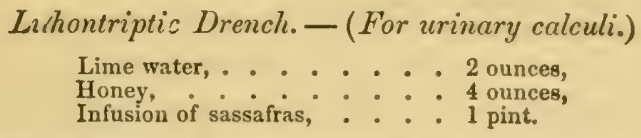

Fo be given daily, for a fortnight or more.

$$
\text { Saline Aperients. }
$$

(Either of the following is a dose.)

Epsom salts, . . . . . 12 ounces.

Glauber salts, . . . . . 12 ounces.

Rochelle salts, . . . . 8 ounces.

Sulphur, . . . . . I to 2 ounces.

Demulcents. - (Intended to lubricate and sheathe mucous surfaces.)

Mucilage of slippery elm.

" gum acacia, (Arabic.)
" Ium tragacanth.
" beland moss.
liquorice root.

The mucilage is made by pouring boiling water on a certain quantity of either of the above articles, and stirring until the required consistence is obtained. The dose is ad libitum. -

Discutients. - (Medicines that are supposed to possess the pover of repelling or resolving tumors.)

Ointment of iodine and hydriodate of potassa. made thus : -

$$
\begin{aligned}
& \text { Bayberry wax, } \\
& \text { Mutton tallow, }\} . . \quad \text { of each } 6 \text { ounces. } \\
& \text { Iodine, } \\
& \text { Hydriodate of potassa, }\} \text { - of each } 1 \text { ounce. }
\end{aligned}
$$

Melt the wax and tallow; and when partly cool, rub the whoin together in a mortar. This is an excellent preparation for enlarged glands, before they suppurate. The next best discutiente are, cold water, diluted acetic acid, soft soap, brine, and new rum. In fact, all refrigerants act as discutients.

\section{Rubefacients.}

Rubefacients are substances which, when applied to the skin of a horse, produce increased action in the part without bliste: 
ing: such are alcohol, tincture of capsicum, stimulating linimenta of various kinds, strong vinegar, and turpentine, mixed with linseed oil. They are indicated in all cases of internal congestion in view of counter irritation : for chronic lameness, and to soften indurated and indolent tumors.

\section{Vesicants, or Blisters.}

The principal one used by the author, and several times alluded to in this work, is reptate of cantharides, made as fol. lows :-

Strong acetic acid, $: \therefore:: 8$ ounces,
Water,
Powdered Spanish flies, $: \therefore \frac{1}{3}$ ounces.

Mix; let it stand for fourteen or more days, and then filter through blotting paper. Used in cases of spavin, splent, ringbone, and callous swellings. The usual vesicant is the common horse blister, thus prepared : -

Take lard, free from salt, twelve ounces; melt it in an earthen vessel with two ounces of rosin, - taking care not to raise the temperature above that of a man's blood, - then add powdered Spanish flies, two ounces; oil of origanum, one ounce : stir until oool.

The part to be blistered should be shaved, and then rubbed for a few minutes with strong vinegar; after wiping the part dry, spread on the blister to about the thickness of a dollar. If it be necessary to keep up the vesicatory action, let it be dressed daily with savin ointment.

\section{Antiseptics.}

Antiseptics are remedies which arrest decomposition and ex. cite the healing process in wounds; among them we name pyro ligneous acid, salt, charcoal, chloride of lime and of soda.

\section{Emollients.}

The best emollient for softening and lubricating a part is puultice of slippery elm; the next best is tepid water.

\section{Digestrves.}

Digestives are used for the purpose of hastening suppuration I we have used a great many, but find none eyual to. - 


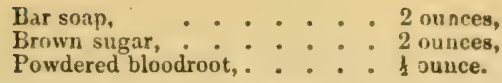

Mix ; and apply by means of bandage.

\section{Fomentations.}

Fomentations are indicated in all inflammatory swellings, straiss, and bruises, and are occasionally applied over the regicn of deep-seated inflanmatory disease - located in the intestimes kidneys, throat, \&c The usual fomentations are composed of warn water, infusion of poppies, hops, and lobelia. They must be perseveringly applied, or they are of little use.

\section{Common Horse Liniment.}

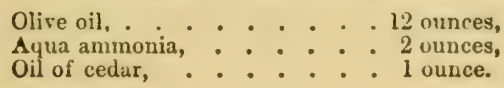

Mix.

\section{Sirup of Garlic.}

Take of bruised garlic, four ounces; acetic acid and water, of each six ounces. Let the garlic macerate for five days; express the liquor and strain it; then add two pounds of white Havana sugar; boil over a slow fire until it is of the consistence of sirup. Duse, two to four ounces. It is an excellent antispasmodic.

\section{Tincture of Assafoetida.}

Take gum assafœtida, six ounces; pale brandy, one quart. Macerate for two weeks, and filter through fine linen. This is also an efficient antispasmodic. Duse, three to eight drachms, so be given in thin mucilage or gruel.

\section{Tincture of Capsicum.}

Take of powdered red peppers, two ounces; new mim, one quaurt. Macerate for fourteen days, and filter through blotting paper.

\section{Tincture of Arnica.}

Take of arnica flowers, (imported from Germany,) four ounces ; new rum, one pint. Macerate for fourteen days; express the iqquor, and filter through blotting paper. This remedy, in the proportion of one ounce to a pint of water, forms a good application for wounds, bruises, sardlle galls, \&Ec. The authur has used 
it with great success in umaurosis and other diseases of the eye of a paralytic character. Given to a horse laboring under in. flammatory affections, in the proportion of twenty drops, diluted with water, it acts as a sedative, and lessens the heart's action; in view of producing effect, however, the dose must be repeated at intervals of four hours. It is useful also in ophthalmia.

\section{Tincture of Ginger.}

Take powdered Jamaica ginger, five ounces ; pale brandy, one quart. Macerate for fourteen days, and filter. Properties, stimulant and carminative. Dose, one to two ounces, in zruel.

\section{Tincture of Cinnamon.}

Take bruised cinnamon, four ounces; new rußn, one pint. Macerate for fourteen days, and filter. Dose, one ounce.

\section{Compound Tincture of Gentian.}

Take gentian root, two ounces; orange peel, dried, one ounce; cardamom seeds, bruised, half an ounce; proof spirit, two pints. Macerate for fourteen days, and filter. Professor Morton recom. mends this as a grateful bitter. Dose, from one to two ounces

\section{Composition for Colic.}

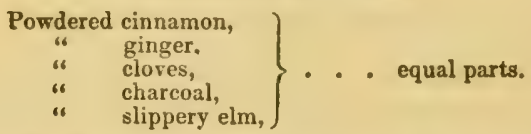

Dose, a table-spoonful, to which add one quart of boiling water. Let it stand for a short time, then pour off the clear liquor ; sweeten with honey, and drench the subject. .

\section{Basilicon Ointment.}

This is a very good digestive, and is prepared as follows: Take lard, free from salt, beeswax, Canada balsam, and resin equal parts. Melt over a slow fire, and, while cooling, stir constantly.

\section{Liniment of Turpentine.}

Take oil of turpentine, olive oil, of each equal parts. Mix This is recommended by Professor Morton as a $u$ ieful digestiva or rubefacient. 


\section{Ćciraway Seeds.}

The most valuable remedy, and one which we invariably re sort to for the correction of flatulency, or for the expulsion of wind frum the stomach and bowels, is the above. As a carrainative, caraways stand unrivalled; they also possess antispas. modi? properties, to which, in the treatment of spasmodic colic, their efficiency has justly been ascribed. If they were brought into general use, to the exclusion of turpentine, gin and molasses, saleratus, \&c., \&c., so extensively used in this city, we should not hear of so many cases terminating fatally. Scarcely a week passes but we hear of valuable horses dying from diseases supervening on maltreated colic. In a recent case of spasmodic colic that came under our observation, the subject, a stud, valued at $\$ 175$, was drenched with half a pint of vinegar and two ounces of saleratus! The death of so valuable an animal has probably taught its owner a lesson not to be forgotten. If a man should be suddenly attacked with colic, would he be so in. sane as to swill down medicines which his own common sense would seem to teach are opposed to the cure? Would he not rather try a little peppermint water, ginger tea, or caraway ? And if so, why not give the same to his horse, when similarly aftlicted? The diseases of the latter require the same sanative treatment for their cure.

There is not a more effectual or innocent agent in the whole materia medica, for the treatment of colic, than caraways. And this our opinion is confirmed by that of varioas eminent veteri. nary practitioners The only objection to their use is, that they are innocent-simple. "The horse wants something power. ful;" he often gets it too; the remerly lessens not the disease, for that is only aggravated - augmented; the vital flame, the living principle, goes out, and the animal dies a vicrin to ous misguided notions.

Caraways should be powdered and given in warm water, in doses of half a table-spoonful, and repeated as occasion may rejuire. Horses which, in consequence of deranged digestive .rcans, are the frequent subjects of colic, may be benefited by a weekly dose of the article in their food. 


\section{Hydrastus Canadensis, (Goldenseal.)}

This article has lately been introduced into our mute ia medica It is a valuable tonic and alterative, and as all bitter medicines are supposed to be laxative, that property may with propriety also be added. This agent may be used with safety whenever the nature of the case requires that these indications are to be fulfilled. Dr. McCaur. has contributed an article to the New Jersey Medical Reporter, (November number,) in faror of this valuable article. He "was led to the use of goldenseal by noticing its well-known sanative properties over inflammations of the mucous surfaces, such as aphtha of the mouth, dxc. I hope that some of the profession will give the article a fair trial."

Goldenseal possesses all the tonic properties attributed to genlian; it is superior to that article, however, inasmuch as its therapeutic action is susceptible of wider range. It may be used in cases of local inflammation, when the latter article, in consequence of its stimulating effect, would be positively injurious. There is no agent in the materia medica that admits of a wider range of application than the one under consideration. As an alterative it ranks higher, in our estimation, than any single medicine ever used, and we feel confident that the veterinary pro ession will, in subsequent years, give this article a decided preference to the mineral alteratives. It acts very gradually on the system of a horse, improving the depraved secretions and excretions, especially in those broken-down states of constitution supervening on hard work, had management, and in that prostrated state of the system which sometimes follows the imprudent use of the fleam, antimony, arsenic, nitre, \&c., \&c. Its mode of action is less evident than its ultimate effects : it changes exis:ing morbid actions, without any apparent influence over any pasticular function. Its manifest general effect is, to invigorate the system as a whole, and thus aid in removing disease wherev. er it may be located. The complaints for which we have generally prescribed it are acute and chronic diseases of the liver, and diseases of the mucous surfaces, in doses of from one to three drachms every twelve hours. In ophthalmia it may be used with decided advantage as a local application, in the proporti:n of half a drachm of the powder to half a fint of boiling waice 
When cool, the clear liquor is to be poured off; it is then fit for ase. Let it be undirstood that we merely refer to the agnnt as a local remedy. There are other conditions which require fulfilment well known to the profession, and without attention to which no case of ophthalmia could ever be brought to a favorable termination. The conditions alluded $t r$, may be thus expressed: Keep the bowels regular; confine the animal to a light diet; keep the head cool, and feet warm; ventilate the stabie, and confine the horse to a dark corner.

Goldenseal, combined with an equal quantity of charcoal, in the proportion of two drachms night and morning, is of great value in dysentery, flux, and scouring, especially when there is a tendency to putrescence. The powdered root has been used with decided advantage, as an injection, in diarrhœa, and in falling of the fundament and womb. It has long been employed in human practice, in ardor urinæ, gleet, gonorrhœea, leucorrhœe, \&c. Dr. McCann states, that "the ardor urinæ, and discharges of mucus, have been entirely suspended, in every case, in from twenty-four to seventy-two hours. It is a perfect and permanent eradicator of the disorder."

In fetid discharges from the vagina or anus, we have employed it with decided advantage. The dry powder has been fcund highly useful alone, (although we prefer to add to it a small quantity of charcoal,) in obstinate ulcers and old sores.

Goldenseal belongs to the class Polyandria, order Polygynia, natural order Ranunculacex. It is an indigenous plant, growing in different parts of the United States, but most abundantly beyond the Alleghanies. It has a perennial root, and an herhaconus stem, from five to twelve inches in height, :wo unequa] leaves, and a single flesh-colored flower. The root is tcrtucus, and from which arise numerous long tibres, of a brigh:-yellon solor. 


\section{A POSOLOGICAL TABI,E}

\section{FOR THE HORSE;}

WITH THE

\section{ACTION OF THE MEDICINAL SUBSTANCES."}

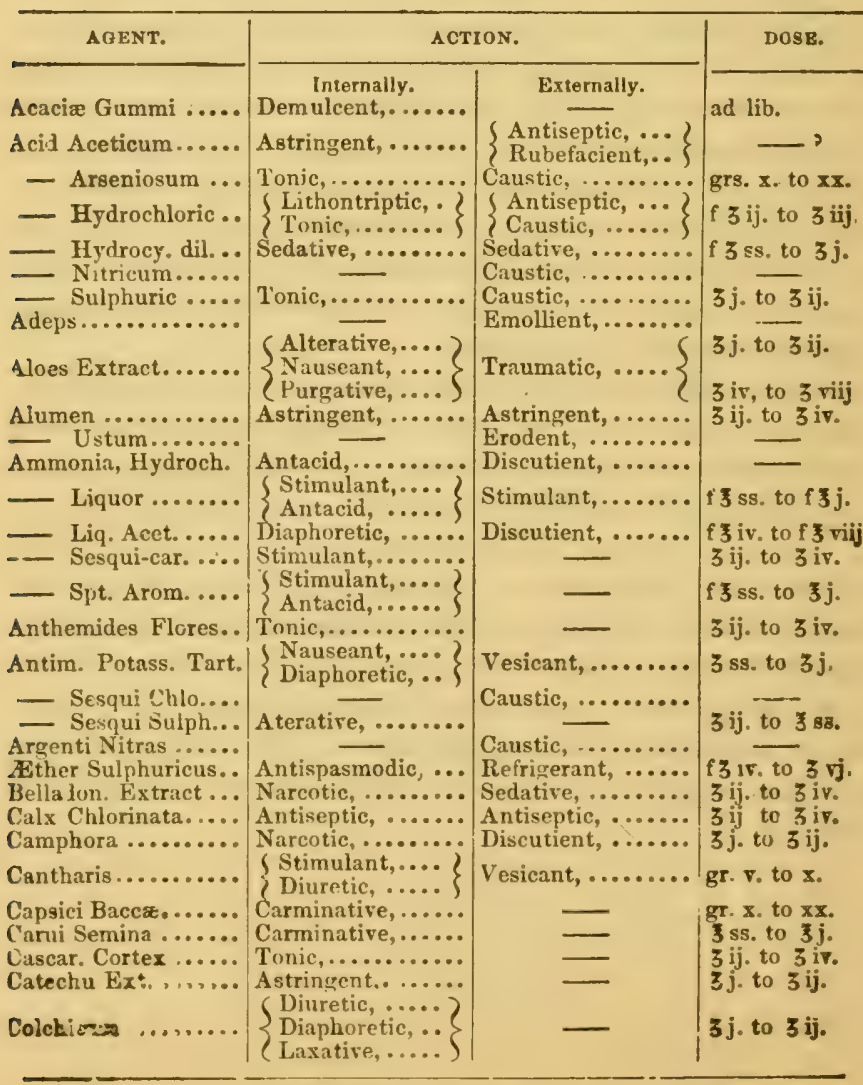




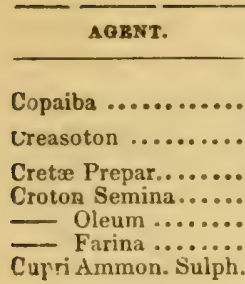

._Diacetas ......

. Diniodidum ...

-_ Sulphas.......

J)igitalis...........

Ferri Iodidum.......

Sulphas.

İallie

Gentiana Rad........

- Tincture .......

Helleboris Nig.......

Hydrarg. Bichlorid...

- Chlorid........

- Biniodid.......

- Nitratis.......

Oxydum ......

Hyosciami Ext......

Iodinium ...........

Lini Semina.........

- Oleum ........

Magnesia Sulph.....

Myrrha

Oleum Olivæ.

- Palma........

Opium Rapi..........

Tinciura.......

Petroleum .........

Pimenta Bacce.....

Pix Abietina.........

_- Liquida ........

- Nigra

Flumbi Acetas

- Diacetas ......

Potussa ............

Potassa Carbonas...

- Chloras .......

- Nitras

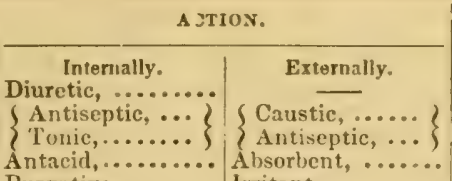

Purgative........ A I

Purgative,........

P'urgatire,.........

Tonic,...........

Tonic,...........

$\{$ Alterative, ....

$\{$ I onic,........

Astringent, ... \{ Erodent, .....

Tonic,....... $\{$ Excitant,....

$\{$ Narcotic, .....

$\{$ Diuretic, .....

Alterative,....

$\{$ Tonic,........

Astringent,...

$\{$ Tonic,........ $\}$

Astringent, ........

Tonic,.............

Tonic,...........

Alterative,........

\{ Alterative,...?

$\{$ Cathartic,.... $\}$

Alteratire,........

Narcot.\& Anodyne,

\{Glandular ex-

Demulcent,.......

Laxative, .........

\{ Laxative......

$\{$ Diuretic, .....

\{ Antiseptic, ...

$\{$ Tonic,........

Demulcent, .......

$\{$ Nareotic and \{ Antispasmodic, Stimulant,........ $\{$ Stimulant,....

$\{$ Tonic,........

Traumatic,....... $3 \mathrm{ij}$. to $3 \mathrm{iv}$

\{ Sedative, .....

$\{$ Astringent, ....

S Antacid,.....?

Sanstic, ..........

$\{$ Diuretic, ...... $\}$

Stimulant?......

$\left\{\begin{array}{l}\text { Febrifuge, .... } \\ \text { Diuretic,.... }\end{array}\right\}$
Astringent, .......

Excitant, .........

Caustic, ...........

$\left\{\begin{array}{l}\text { Stimulant }, \ldots \ldots \\ \text { Detergent,.... } \\ \text { Detergent,...... }\end{array}\right.$

Sedatire.........

\{ Glandular ex-

$\left\{\begin{array}{c}\text { citint,...... } \\ \text { citas }\end{array}\right.$

Emollient, ........

Emolient,.........

Emollient,........ Oj. to Oij.

Emollient,.........

Emollient,........

Anodyne,........

$3 \mathrm{j}$. to $3 \mathrm{ij}$.

3 ss. to 3 ij

3 ij. to 3 ir

Rubefacient,......

Rubefacient, ......

Rubefacient, ......

Sedatire, .........

Sedative, ..........

$208 \mathrm{~B}$.

3 ss to $\bar{j}$.

f 3 s. to $3 j$ ?

$3 \mathrm{ij}$. to 3 ir.

r. $x i j$. to xxiv

tt. $x x$, to $x=x$

3j. to $\equiv \mathrm{ii}$.

$5 \mathrm{j}$. to $3 \mathrm{ij}$.

5j. tu $5 \mathrm{ij}$.

$3 \mathrm{j}$. to $3 \mathrm{j}$.

gr. $\mathrm{xx}$. to $1 \mathrm{x}$

$3 \mathrm{j}$. to $3 \mathrm{ij}$.

3 ss. to $3 \mathrm{j}$.

$3 \mathrm{ij}$. to $3 \mathrm{iv.}$

$3 \mathrm{ij}$. to $3 \mathrm{iv}$.

3 ij. to 3 iv.

zss. to $\mathbf{j}$.

gr. v. to $x$.

3 ss. to $3 \mathrm{ij}$.

$3 \mathrm{j}$. to $3 \mathrm{ij}$.

r. 5 . to $x$.

ad lib.

Oj. to Oij.

ibss. to $\mathrm{ib}$.

3 ss. to $3 \mathrm{j}$.

\section{$3 \mathrm{ij.}$ to 3 iv}

$3 \mathrm{j}$. to $3 \mathrm{ij}$.

\{ Refrigerant, ..

ij. to $5 \mathrm{iv}$
3 j. to 3 iss. 


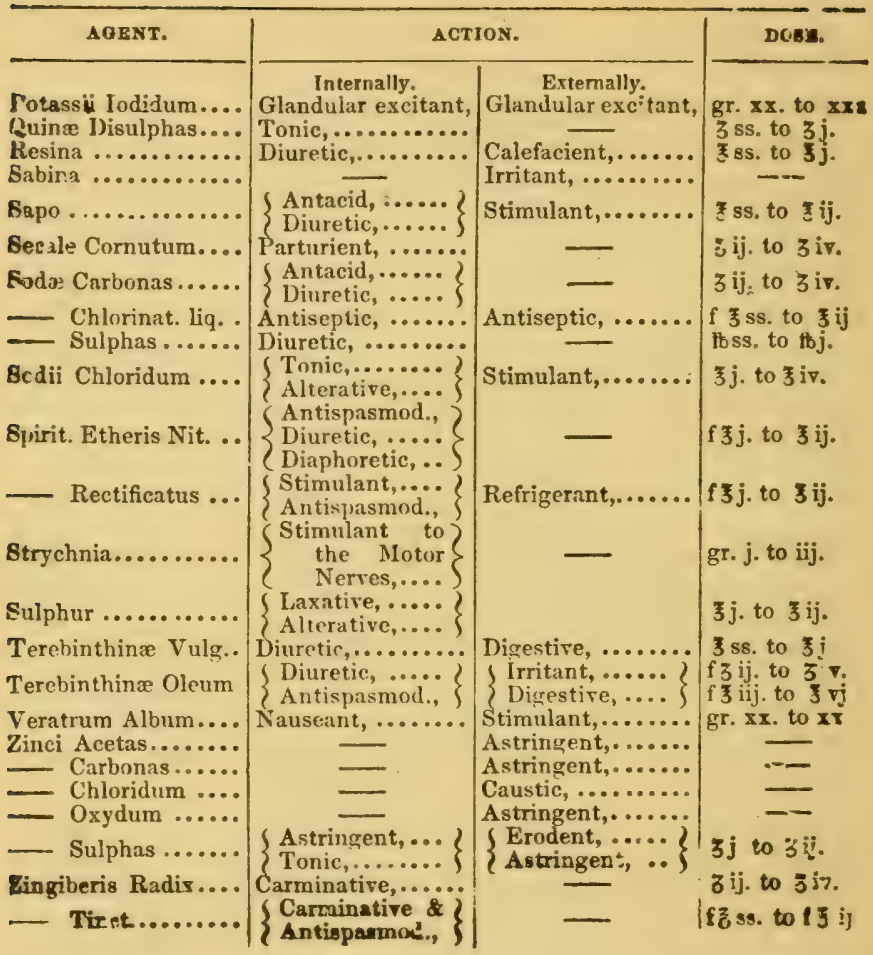




\section{ABSTRACT FROU THE SEVENTH CENSUS.}

\section{A Table of the Number and Value of Live Stock on the United States.}

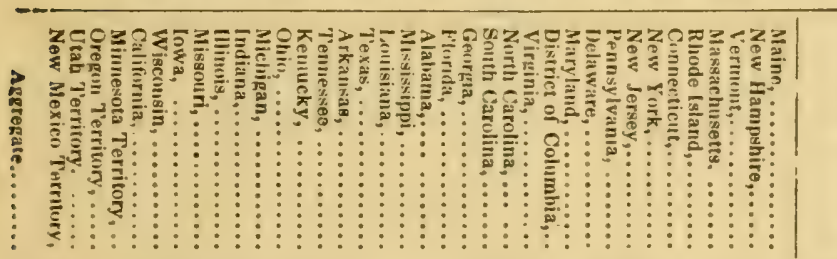

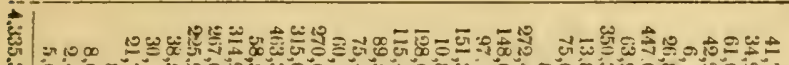
出

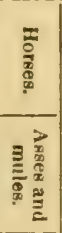

造) D

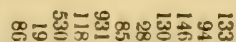

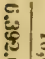
$\stackrel{\circ}{\Sigma}$ $x+70$ $-181820$

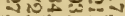

$$
\text { is }
$$

ज़en 4 10

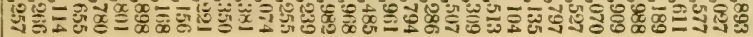

1

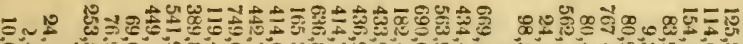

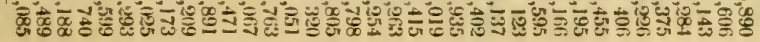

(⿻)

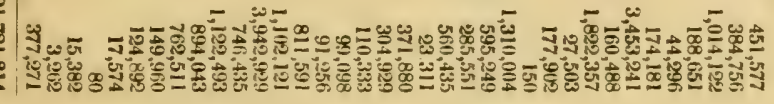
$\sim 20$ ⿻

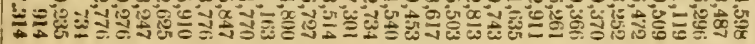$$
\overline{1}
$$ 


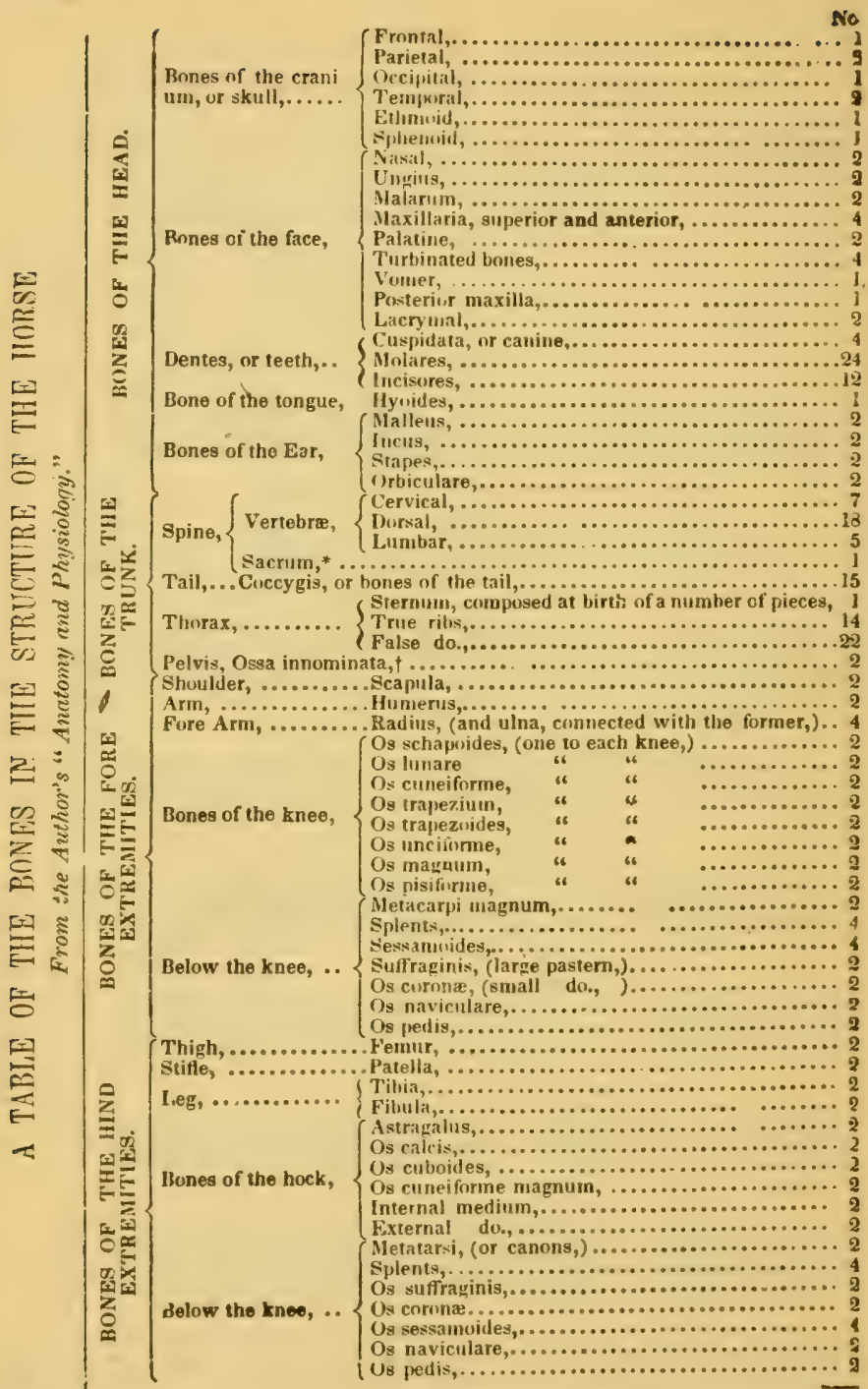

Total,....................... 242

Dr. Hooper reckons the number of bones in the human subject at 248 .

- The bones in the sacrum of the colt consist of five pieces.

† The pelvis of the young animal is made up of the two ossa innominata, each of which is formed of two nieces; the larger is ralled os ileun, the small.r. in allusion to the humaw

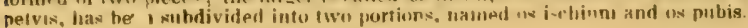








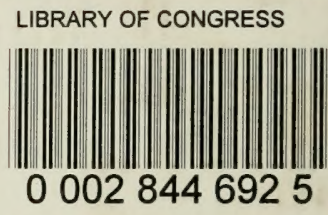

